\title{
Approaches to Writing Instruction in Aotearoa: The Influences of Teachers' Beliefs and Practices on Progress
}

\author{
By Helen Margaret Walls \\ Submitted to the Victoria University of Wellington \\ In fulfilment of the \\ Requirements for the degree of \\ Doctor of Philosophy \\ In Education
}

Victoria University of Wellington

2019 

For the children I have worked with in schools, and for my own children, David and Michael.

Nā tō rourou, nā taku rourou, ka ora ai te iwi With your food basket and my food basket the people will thrive 



\begin{abstract}
In the educational context, social constructivists are those who view knowledge as constructed through social experiences. In the class-room, these theorists favour student-led and cooperative group work over teacher-directed and individual work and de-emphasize the explicit teaching of technical skills. Literacy teaching in New Zealand has been influenced by constructivism since the 1980s. Whether this influence has been positive is, however, open to doubt. According to current achievement data many students are under-achieving. A very different perspective is offered by social cognitivism, according to which experimental and quantitative methodologies are used to assess the effectiveness of various teaching approaches. While more widespread use of these methods could bring about much-needed change, advocates of constructivism have discouraged their uptake by (i) associating their own approaches with social values and (ii) representing scientific methods as unsuited to the contexts at stake. International research has shown that teachers take a more pragmatic view: Studies have demonstrated that the majority of teachers are comfortable with a range of approaches, and thus that seemingly disparate approaches may co-exist. There has been very little research on the beliefs of New Zealand teachers, although Ministry of Education publications for teachers are essentially constructivist.
\end{abstract}

Study One investigated the ideological context of the New Zealand primary school. A total of 626 teachers completed a survey on their beliefs and practices for teaching writing. Principal components analysis of beliefs isolated three dimensions, which appear to reflect valuation of (i) explicit, (ii) socio-cultural and (iii) process-writing approaches respectively. Principal components analysis of practices isolated six dimensions: (i) explicit and structured approaches; (ii) socio-cultural and process writing approaches; (iii) attention to surface features; (iv) advanced writing practices; (v) basic writing practices, and (vi) teacher goal selection. In the second phase of this study, a sub-sample of 19 survey respondents supplied writing samples from the students in their classes, at two time points, allowing for the 
measurement of progress over time. Teachers' scale locations for reported beliefs and practices were compared with their students' rates of progress. Explicit teaching beliefs and practices emerged as being strongly - although only marginally significantly - correlated with progress and socio-cultural practices were negatively - and significantly - correlated with achievement. In addition, a number of individual survey items were positively, and significantly, correlated with achievement, all belonging to the explicit teaching dimensions. Two items were negatively and significantly correlated with achievement, and these belonged to the process-writing and socio-cultural practices dimension.

A sub-sample of eight teachers were interviewed in order to gain a deeper understanding of their beliefs and practices. In general, teachers' comments reflected their scale locations in the survey data. While those who focused on the explicit teaching of technical skills achieved the greatest gains for student achievement, others used socio-cultural and process approaches thoughtfully to address students' social and emotional needs.

The pedagogical method that is the subject of Study Two, "Fast Feedback", was developed in line with social cognitivist findings and is thus at odds with the quasi-official view. Fast Feedback centres on individualized goals and regular, focused assessment in order to accelerate student progress. In 2015 nine teachers were engaged to trial this method - in seven classrooms, across three Wellington schools. Achievement data were collected for 136 student participants, and were compared with the equivalent data from students at a control school. Data analysis revealed that the treatment group made significantly more progress than the control group (ES 0.5). It also revealed variability across classrooms. Interestingly, the highest rates of progress were achieved (in all classrooms) during the first half of the intervention. Clearly worded, process-oriented goals were the most effective. The addressing of technical skills - sentence writing, spelling and handwriting - proved to be essential. In interviews, teachers observed that the predictable structure of Fast Feedback lessons was motivating for students, and led to a greater sense of self-responsibility on their (the students') part. 
In conclusion, these two empirical studies together indicate that explicit approaches informed by scientific research - are most likely to raise student achievement. The Ministry should therefore work with urgency to ensure teachers have information about these methods, so that more New Zealand students will experience success in learning to write. 



\section{Table of Contents}

LIST OF FIGURES

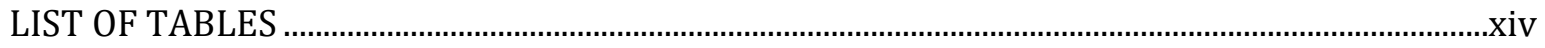

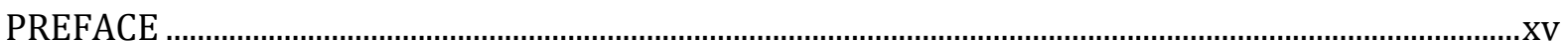

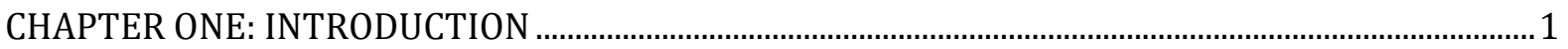

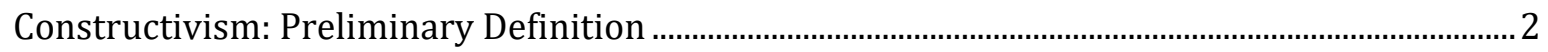

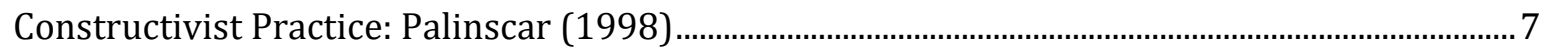

Constructivism in New Zealand: Gilbert (2018) ..................................................................................

Constructivist Approaches to Literacy Teaching.............................................................................. 10

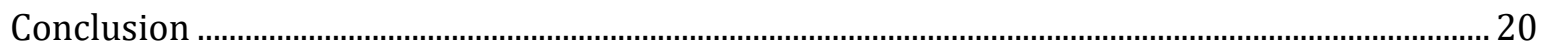

CHAPTER TWO: EFFECTIVE WRITING PROGRAMMES …................................................................. 21

Social Cognitivism and Writing Research ........................................................................................... 21

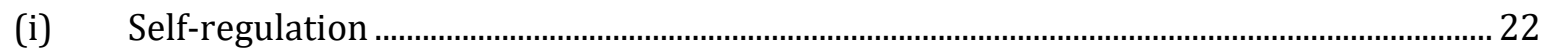

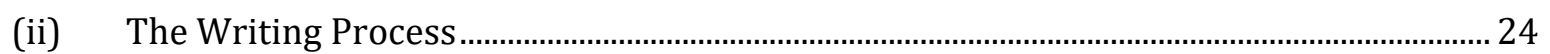

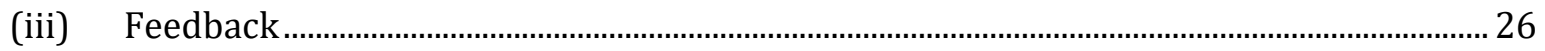

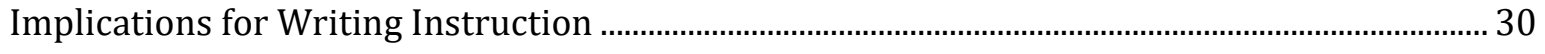

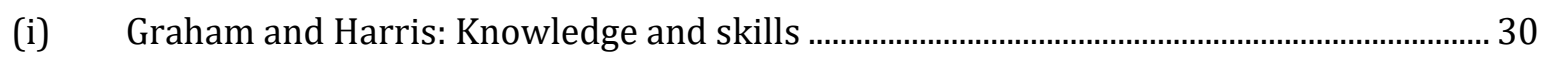

(ii) Zimmerman: self-regulation, the "multilevel" model............................................................... 32

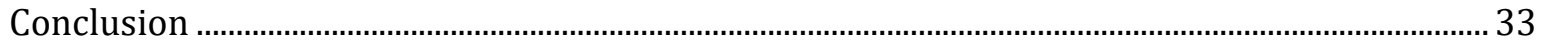

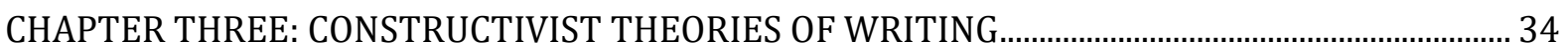

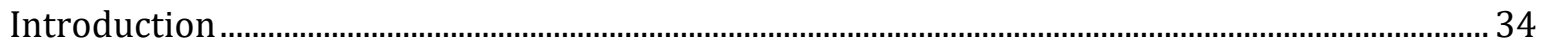

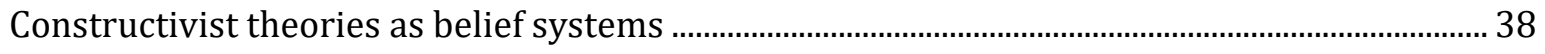

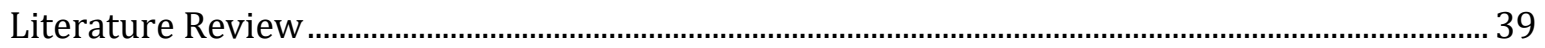


Process Writing: The Precursors

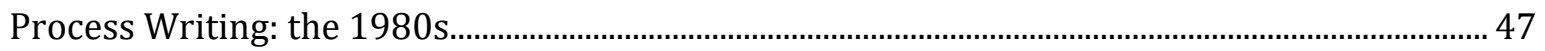

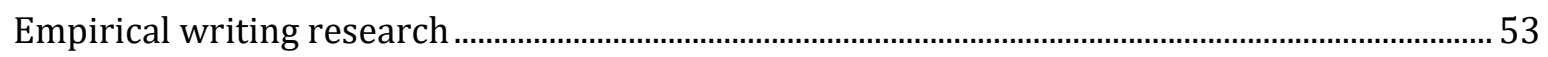

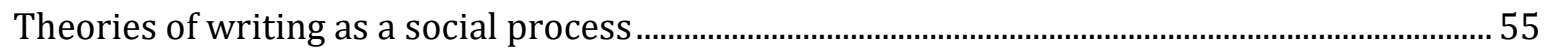

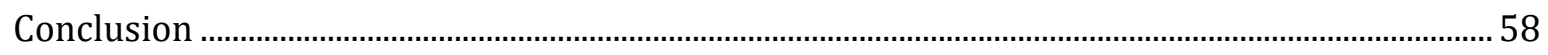

CHAPTER FOUR: WRITING IN NEW ZEALAND PEDAGOGY: THE CURRENT CONSENSUS ............ 59

Introduction: The Ministry's Commitment to Constructivism ......................................................... 59

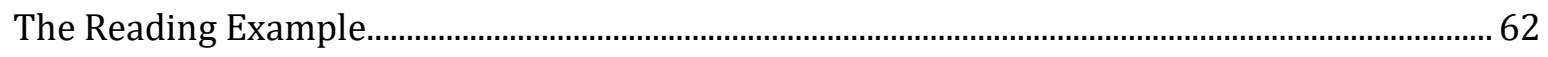

Ministry Recommendations for the Teaching of Writing: Effective Literacy Practice; The

Literacy Learning Progressions; Sound Sense; Teaching Handwriting .......................................... 64

The Literacy Learning Progressions ................................................................................................. 69

Documents to support the development of transcription skills: 'Sound Sense' and 'Teaching

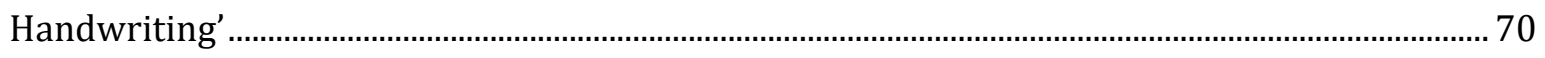

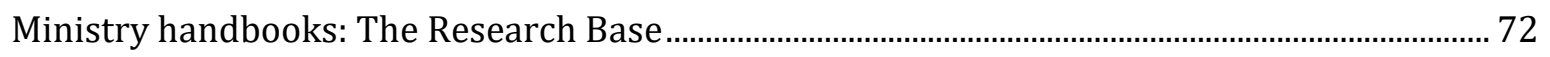

Quality teaching for Diverse Students in Schooling: Best Evidence Synthensis (Alton-Lee,

2003)

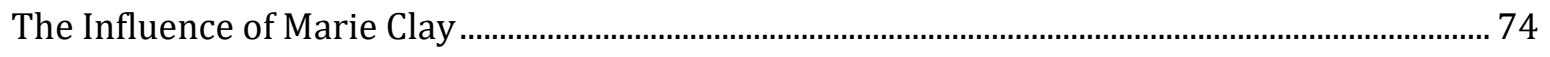

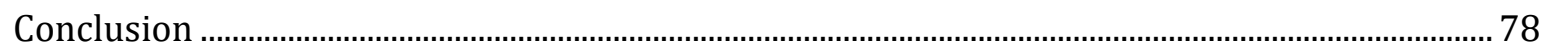

CHAPTER FIVE: PREVIOUS RESEARCH ON TEACHERS' BELIEFS ……............................................... 79

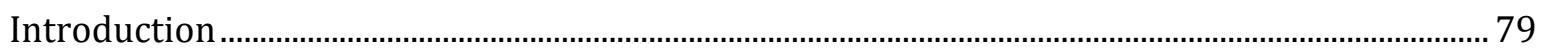

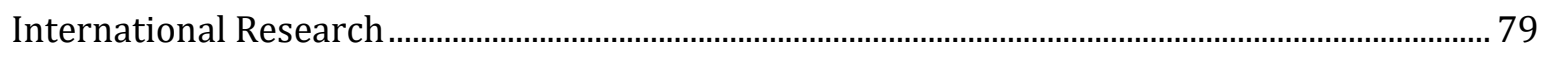

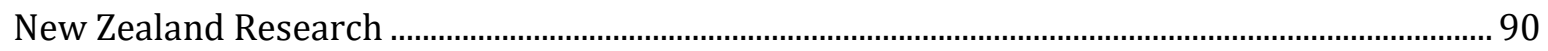

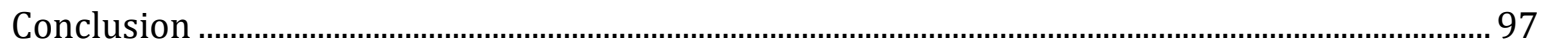




\section{CHAPTER SEVEN, STUDY ONE: ASSOCIATIONS BETWEEN TEACHERS' BELIEFS AND}

PRACTICES AND STUDENTS' PROGRESS IN WRITING.

Introduction

METHODS..

Participants.

Instruments.

(i) Beliefs and Practices survey .

(ii) Fast Feedback Marking Rubric

Procedure.

Analysis

Ethical Considerations

RESULTS

Beliefs Survey: Principal Components Analysis.

Explicit teaching beliefs

Socio-cultural beliefs.

Process writing

Practices Survey: Principal Components Analysis.

Practices Survey: Distribution of teachers' responses to individual items

(i) Explicit and structured approaches.

(ii) Process-writing and sociocultural practices...

(iii) Attention to surface features.

(iv) Advanced writing 
(v) Basic writing

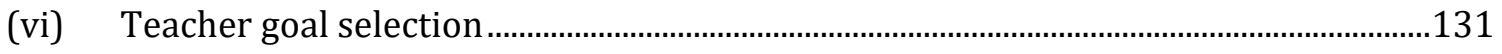

Correlations between teachers' beliefs and practices..................................................................132

Correlations between teachers' beliefs and practices and year levels taught..............................133

Correlations: Beliefs and Practices Dimensions and Student Progress .........................................134

Correlations: Individual Survey Items and Student Progress ........................................................135

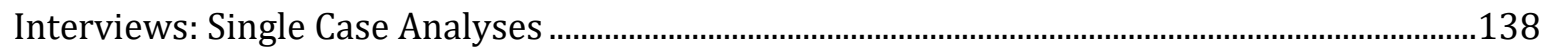

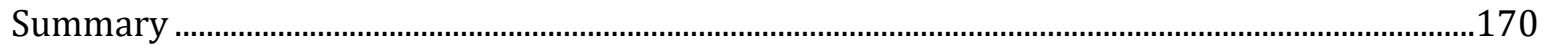

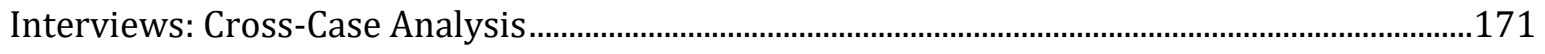

(i) Uses of technology for the teaching of writing..................................................................172

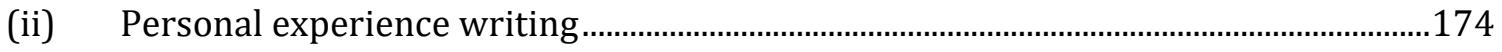

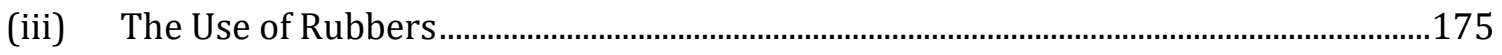

DISCUSSION

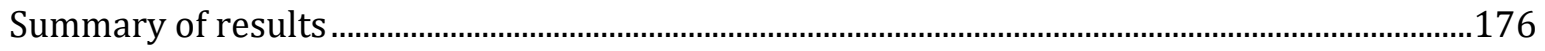

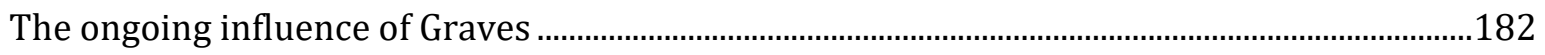

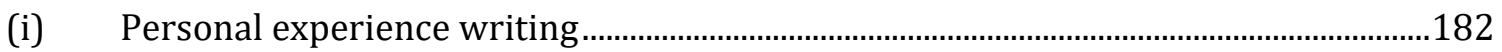

(ii) The prohibition of rubbers in favour of crossing out .........................................................183

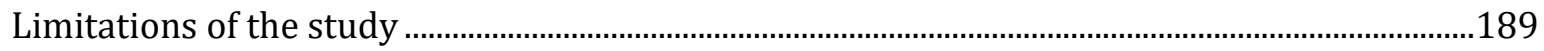

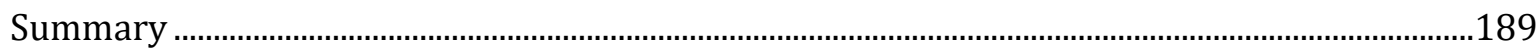

CHAPTER EIGHT, STUDY TWO: A QUASI-EXPERIMENTAL TEST OF FAST FEEDBACK PEDAGOGY

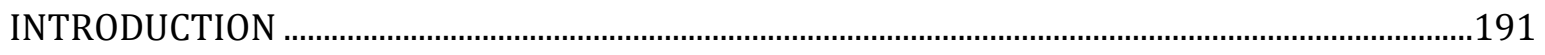

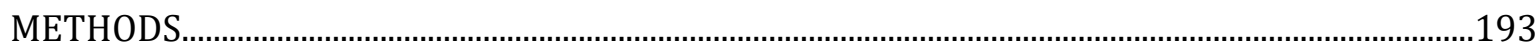




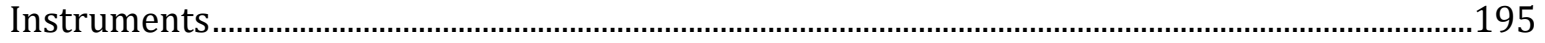

Procedure

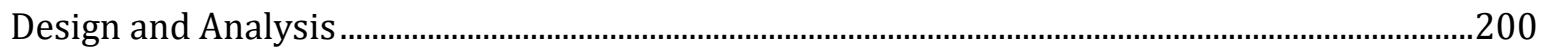

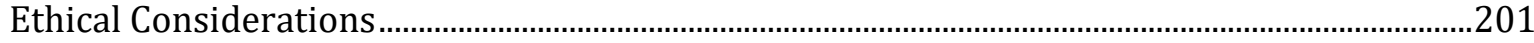

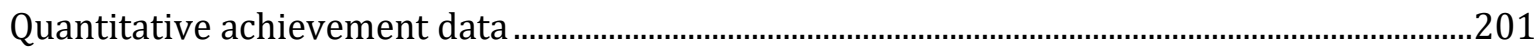

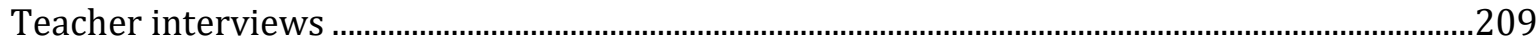

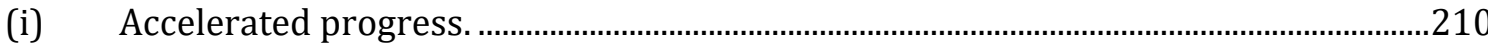

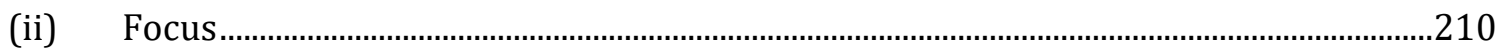

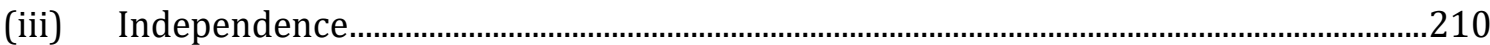

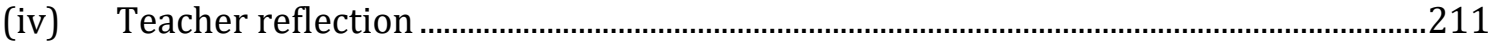

(v) The relevance of the goal: "To write in perfect sentences" ............................................211

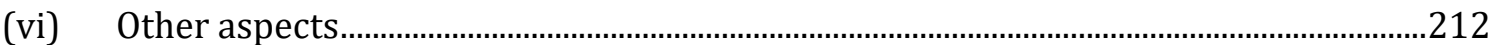

(vii) Difficulties with using Fast Feedback ………....................................................................212

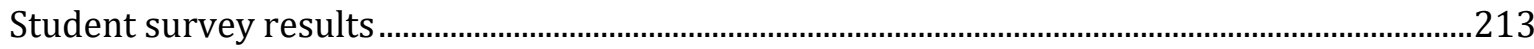

Writing samples from three special needs students......................................................................22

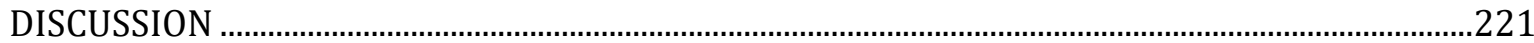

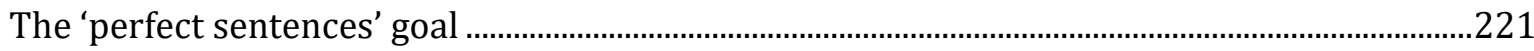

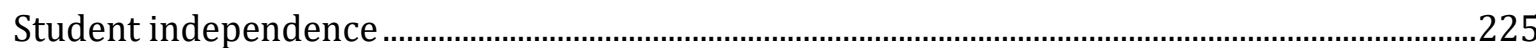

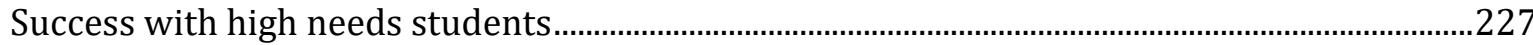

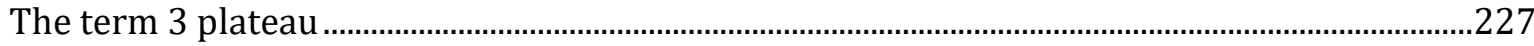

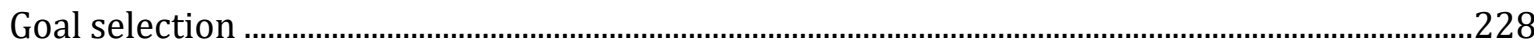

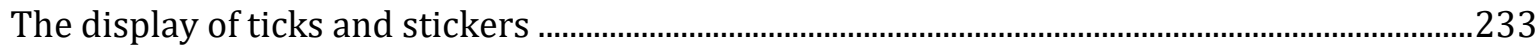


Writing instruction

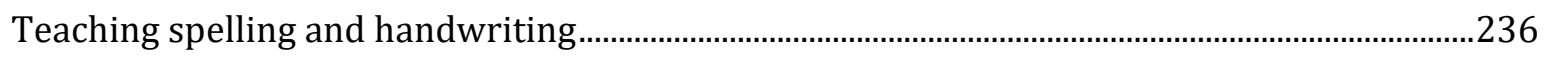

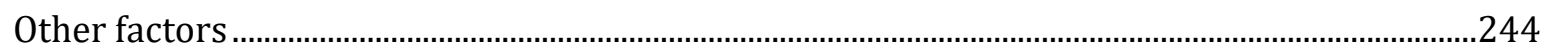

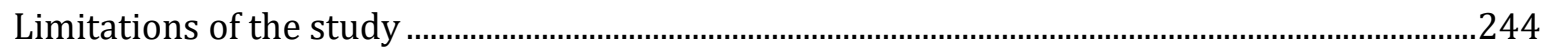

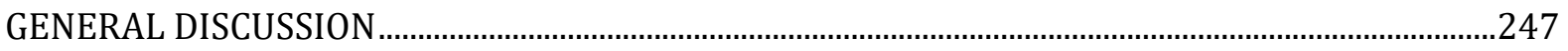

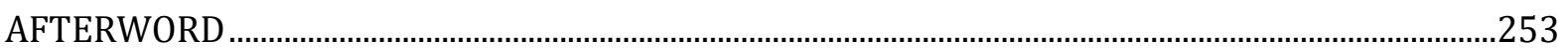

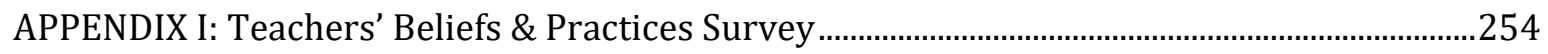

APPENDIX II: Assessment Rubric for Draft Writing Book Samples...............................................260

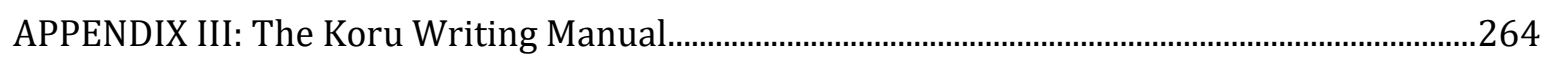

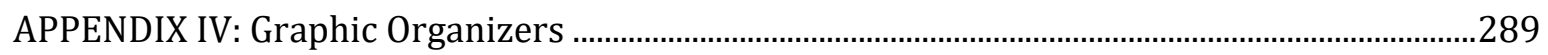

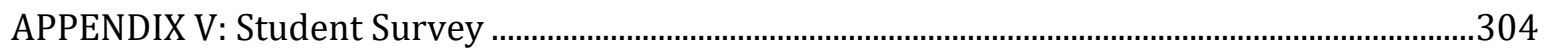

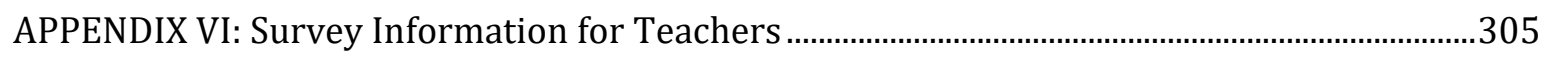

APPENDIX VII: Interview Information for Participants ...................................................................307

APPENDIX VIII: Teachers' Beliefs Information for Principals..............................................................309

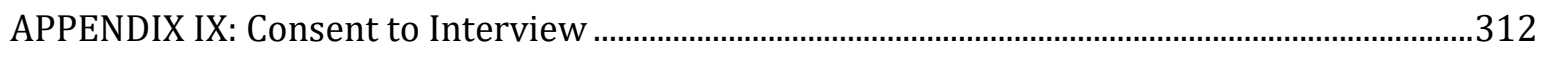

APPENDIX X: Teachers' Beliefs Information for Participants ...........................................................314

APPENDIX XI: Fast Feedback Consent for Parents .............................................................................316

APPENDIX XII: Fast Feedback Information for Students ……....................................................317

APPENDIX XIII: Fast Feedback Information for Parents ....................................................................318

APPENDIX XIV: Fast Feedback Information Control School .............................................................320

APPENDIX XV: Fast Feedback Consent Form for Principals ............................................................322

APPENDIX XVI: Fast Feedback Information for Teachers and Principals......................................323

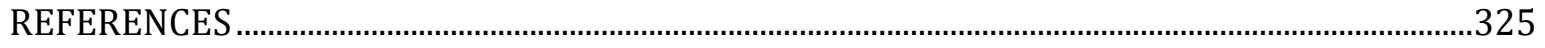




\section{LIST OF FIGURES}

Figure 1: Distribution of teachers' responses to the individual items associated with the belief in explicit teaching dimension

Figure 2: Distribution of teachers' responses to the individual items associated with the belief in socio-cultural approaches dimension 120

Figure 3: Distribution of teachers' responses to the individual items associated with the belief in process writing approaches dimension 121

Figure 4: Distribution of response to the items that did not load in any of the beliefs dimensions

Figure 5: Distribution of teachers' responses to the individual items associated with the explicit and structured practices dimension

Figure 6: Distribution of teachers' responses to the individual items associated with the processwriting and socio-cultural practices dimension 128

Figure 7: Distribution of teachers' responses to the individual items associated with the attention to surface features practices dimension

Figure 8: Distribution of teachers' responses to the individual items associated with the advanced writing practices dimension.

Figure 9: Distribution of teachers' responses to the individual items associated with the basic writing practices dimension

Figure 10: Distribution of teachers' responses to the individual items associated with the teacher goal selection dimension 
Figure 11: Distribution of teachers' responses to the item, when planning writing programmes I consider research evidence about what will work.

Figure 12: Student A at Time Point One.

Figure 13: Student A at Time Point Two

Figure 14: Student B at Time Point One.

Figure 15: Student B at Time Point Two

Figure 16: Student $C$ at Time Point One

Figure 17: Student $C$ at Time Point Two 150

Figure 18: Student D at Time Point One 153

Figure 19: Student D at Time Point Two 153

Figure 20: Student E at Time Point One. 156

Figure 21: Student E at Time Point Two 157

Figure 22: Student $\mathrm{F}$ at Time Point One.

Figure 23: Student F at Time Point Two 162

Figure 24: Student G at Time Point One. 165

Figure 25: Student G at Time Point Two. 166

Figure 26: Student $\mathrm{H}$ at Time Point One 169

Figure 27: Student I at Time Point Two. 170

Figure 28: Junior-level writing with crossing out 185

Figure 29: Senior-level writing with crossing out. 186

Figure 30: D/d corrections dominate 187 
Figure 31: Teacher corrections may represent a missed opportunity for student learning...... 188

Figure 32: Comparison of progress on the rubric measurement scale made by the treatment and control groups, between Time Point One and Time Point Four

Figure 33: Progress made by the treatment group between the four time points

Figure 34: Progress of six treatment group classes over the four time points.

Figure 35:The overall progress of students in each of the six treatment group classes

Figure 36: A comparison of the effects of commonly used goals.. 206

Figure 37: Dot plot showing the levels of achievement in the aspects assessed and how these relate to each other in terms of a typical profile of treatment group students.

Figure 38: Abe's writing sample at Time Point Three

Figure 39: Abe's writing sample at Time Point Four

Figure 40: Si's writing sample at Time Point One

Figure 41: Si's writing sample at Time Point Four

Figure 42: Mark at Time Point One

Figure 43: Mark at Time Point Four

Figure 44: PJ's writing at Time Point One 223

Figure 45: PJ's writing at Time Point Three 223

Figure 46: Jen's writing at Time Point One 224

Figure 47: Jen's writing at Time Point Four 224

Figure 48: Tom's writing at Time Point One 224

Figure 49: Tom's writing at Time Point Four.. 225 
Figure 50: Ana's writing at Time Point One

Figure 51: Ana's writing at Time Point Four

Figure 52: Siu's writing at Time Point One.

Figure 53: Siu's writing at Time Point Four.

Figure 54: Ben's writing at Time Point One

Figure 55: Ben's writing at Time Point Four

Figure 56: Mele uses the tracking page to provide qualitative positive feedback in the form of written comments .234

Figure 57: A student has written his own positive self-evaluations alongside Julie's tracking with ticks and stickers 235

Figure 58: Progress is tracked horizontally on Jeremy's tracking sheet. 236

Figure 59: JJ's writing at Time Point One. 238

Figure 60: JJ's writing at Time Point Four. 238

Figure 61: Lex's writing at Time Point One.

Figure 62: Lex's writing at Time Point Four. 239

Figure 63: The use of pen (i) 240

Figure 64: The use of pen (ii 241

Figure 65: Every incorrectly spelt word is corrected by Julie 242

Figure 66: Natalie chooses to make one positive written comment and to reinforce the positive message with a colourful stamp

Figure 67: Kiri corrects every spelling error and re-arranges the structure of two sentences. She also uses ticks throughout the piece 


\section{LIST OF TABLES}

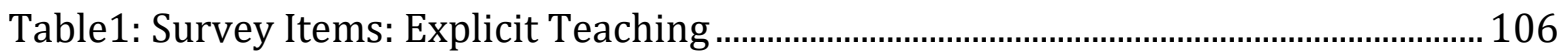

Table 2: Survey Items: Valuation of Correctness in Writing................................................. 106

able 3: Survey Items: Whole Language/Process Writing Approaches............................... 107

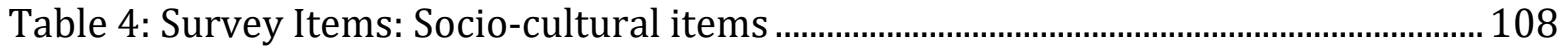

Table 5: Items associated with each of the three dimensions of the beliefs survey, with association strengths

Table 6: Items associated with each of the six practices dimensions, with association strengths

Table 7: Correlations between beliefs and practices dimensions

Table 8: Correlations between the average year level taught by teachers and their locations on dimensions of beliefs and practices.

Table 9: Correlations between the average progress of students aggregated by class and the locations on dimensions of beliefs and practices of their teachers.

Table 10: Correlations between individual items and student progress in writing with $\mathrm{p}<.10$

Table 11: Teachers' percentile locations for each beliefs factor. Teachers are listed in order of the progress their students made.

Table 12: Teachers' percentile locations for each practices factor. Teachers are listed in order of the amount of progress their students made

Table 13: Student responses to the question "How helpful is Fast Feedback for your learning?" ( $\mathrm{n}=119)$ 



\section{PREFACE}

A number of early experiences led to my interest in the teaching of writing and the use of feedback. These include my years as a primary school student in the 1980s - the hey day of process writing. I first encountered 'feedback' when studying performance violin as an undergraduate. Following the advice of friends, I began to tape myself practicing and was impressed with the speed with which my playing improved. The power of feedback was reinforced for me as a trainee teacher at the New Zealand Graduate School of Education - whose directors encouraged self-reflection (in consultation with tutors) both at the end of every observed lesson, and at the end of every term.

I graduated from the NZGSE in 2003, and began three years of teaching in Wairoa. Wairoa is a high poverty town, and most of the locals identify as Māori. As a privileged person, with very little experience of country life or Māori culture I had a lot to learn, but the children I taught forgave my ignorance and made me feel welcome. From a professional perspective, my years in Wairoa were inspirational. My students continually impressed me with their intelligence and energy. It was clear that they had enormous academic potential, and I discovered that most learning difficulties could be overcome, so long as I equipped myself with the best information about key learning progressions and effective teaching methods.

Two exceptional professional development experiences came my way during those years. The first was a course offered by Barbara Brann, an Australian expert on writing difficulties and the creator of the "Casey Caterpillar" Handwriting Programme (2000). Barbara led us through a range of writing activities - such as writing with our non-dominant hands, and pseudo-word dictations - to illustrate the complexity of the beginning writer's process, and I understood for the first time the profound importance of transcription skills. Furthermore, Barbara modeled meticulous care with formative assessment of student writing. I returned to my class with much greater confidence and a sense of urgency. I now understood the reasons for many of my (highly intelligent) students' difficulties and knew that they could be overcome. 
A second professional breakthrough occurred when I was loaned a video for the teaching of writing, The Management of an Independent Writing Programme (Hood, 1992) and watched a teacher modeling the system I have come to refer to as Fast Feedback - described and trialled in the second of the empirical studies presented in this thesis. I have used Fast Feedback ever since, with excellent results. Fast Feedback conferencing means constant reflection on student progress, which has led me to refine others aspect of my teaching (assessment, lesson content and structure, and methods for explaining and modeling certain skills). ${ }^{1}$

Since leaving Wairoa I have worked as a teacher in Central Wellington, East London, and (for the past eight years) at a Decile One school in Porirua East. I admire the maturity of my students - particularly in the empathy they show for one another. Unfortunately, over my fifteen years in these schools I have also observed that many are under-served by the current system. It is not unusual to meet senior level students who still struggle with the basics of the alphabetic code, or have an unaddressed handwriting difficulty - and hate writing as a result. These fundamental skills need to be taught well - especially to children who have had limited experience with written language before coming to school.

Such anecdotal observations are supported by hard data. According to the 'Progress in International Reading Literacy Study' (2011), which administered reading assessments in 45 countries, New Zealand students achieved a lower mean score than students in most other countries, including students in all but one of the English-speaking comparison countries. Inequitable outcomes also emerged as a major issue: The range of our reading scores from the highest to the lowest achievers was greater than that of most other countries (including the Anglophones). Additionally, for New Zealand students, the literacy knowledge they possess when first starting school is associated with larger differences in school achievement than it is

\footnotetext{
${ }^{1}$ I am immensely grateful to the teacher who is the original creator of Fast Feedback, but have (unfortunately) been unable to acquire a copy of the video in recent years. I spoke to Harry Hood about my wish to get in contact with her, and though he was not able to recall her name, he believes she must have been working at Abbotsford School in Dunedin in the early 1990s.
} 
in most other countries. Significant differences were found between the outcomes of Pakeha students, and those of Māori and Pasifika students.

In sum, this research is grounded in my successes and frustrations as a classroom teacher. My goal has been to examine the "current consensus" of writing teaching in New Zealand primary schools, and to investigate the impacts of a range of approaches - in order to determine which are the most likely to raise student achievement.

In what follows, I investigate two areas of interest - with two empirical studies. In the first, I consider the theoretical beliefs and practices of New Zealand teachers, through the use of a survey and interviews. The impact of various approaches on student achievement is also examined, by comparing rates of student progress over two terms, from students in the classes of teachers who hold a range of beliefs, and who report using a range of practices.

In the second study, the Fast Feedback system is trialed in seven classrooms. Student achievement data are compared with data from students at a control school. As Fast feedback encapsulates social cognitivist methods for writing teaching and feedback, it is interesting to consider the impacts these methods have on student achievement in the New Zealand school system - known for its adherence to quite different, constructivist-oriented approaches.

Results of the two studies converge. Together, they indicate that explicit and structured approaches (currently undervalued by the Ministry) are more effective than constructivistoriented ones. I therefore conclude by arguing that the Ministry's constructivist orientation should be re-evaluated, and that a much more directive approach to teacher education should be adopted - one which is founded in empirical research, and which equips teachers with practical methods for targeting the key skills their student need to acquire on their journey to becoming literate. This is particularly important in the junior year levels, where teaching methods should be implemented with a view to developing independent readers and writers so that students may engage successfully in a range of contexts, including political contexts, and may help to bring about the changes needed for New Zealand to become a fairer society. 
I owe enormous thanks to the principals, teachers and student participants who were involved in the empirical work. Without their openness and effort none of this would have been possible.

I am very grateful to my supervisors, Dr Vivien Van Rij and Dr Michael Johnston, who gave their time generously throughout the project. Vivien I thank especially for always keeping me alert to the creativity of children, and Michael for his considerable expertise in research design and the analysis and representation of data.

Thanks also to Dr Bronwyn Wood, for her guidance with qualitative analysis; fellow post-graduate students Radha Hendrikx and Essie Russell, who helped with the development of the marking rubric; Denise Cornford, the Leaders organiser at the NZEI, who generously agreed to let me distribute my survey at union meetings; and Rob Holmes, for IT support.

The years working on this project were made much easier by support from colleagues at Windley School, in particular the school principal, Rhys McKinley.

Finally, I wish to thank my parents Peter and Kathryn Walls, for their ongoing interest and support. 


\section{CHAPTER ONE: INTRODUCTION}

While New Zealand educators have taken some pride in an international reputation for progressive literacy teaching, a wide disparity between New Zealand's highest and lowestachieving students has been evident for some time. In 1999, the Ministry of Education developed a National Literacy Strategy to address this problem. Tunmer and Chapman (2015) evaluated this strategy, examining nationwide achievement data and concluding that it has failed to achieve its aim. To evince this failure, the authors summarise results from the Progress in International Reading Literacy Study (PIRLS) reading assessments. PIRLS is a reading test created by the International Association for the Evaluation of Educational Achievement, which was administered to children in 45 countries in 2001, 2005/2006, 2011 and 2013. In the 2011 assessments, New Zealand was in the bottom half of the mean-score country ranking. Of the six English speaking comparison countries (including Northern Ireland, the United States, Ireland, England, Canada and Australia), all but the US achieved a higher mean score than New Zealand. Inequitable outcomes also emerged as a major issue. In 2011, the range of New Zealand's reading scores - the difference between the highest to the lowest achievers - was greater than that of most other countries, including all of the six - readily comparable - English speaking countries. Additionally, for New Zealand students, the literacy knowledge they possess when first starting school is associated with larger differences in school achievement than it is in most other countries. Significant differences were also found between the outcomes of Pakeha students, and those of Māori and Pasifika students and this pattern has not changed over the three PIRLS assessment cycles (Prochnow, Tunmer, \& Greaney, in Tunmer \& Chapman, 2015). National Standards data also expose inequitable outcomes: In 2014, 84.3\% of Pakeha students achieved at or above the standard for reading, compared with just $68.6 \%$ of Māori, and $65.1 \%$ of Pasifika students. For writing, $76.8 \%$ of Pakeha students achieved at or above the standard, compared with just $61.2 \%$ of Māori, and 59.6\% of Pasifika students (MOE, 2014). 
Tunmer, Prochnow, and Greaney (2015) attribute these negative trends to an ongoing commitment of the Ministry of Education to constructivism, an orientation which, they argue, encompasses an "anti-science attitude" (p. 214). They express serious concern about the way in which some constructivist authors have actively discouraged teachers from applying the results of generalisable educational research, and cite a 1996 article by Smith and Elley as an example of such discouragement. International researchers have also commented on the constructivist rejection of empirical findings (see for example, Needels \& Knapp, 1994; McKenna, Robinson, \& Miller, 1990), with Mckenna et al. declaring that (constructivist) whole-language proponents are "unmoved by neutral or negative results for their methodologies" (p. 3).

\section{Constructivism: Preliminary Definition}

In the current educational context, constructivism is used to refer to a perspective which places emphasis on the active role of learners, who are viewed as constructing knowledge in their own idiosyncratic ways, often through social interaction. Constructivists describe language as both a product and a tool of culture, which shapes our understandings and thought processes.

If, as Tunmer and Chapman argue, constructivist pedagogy is not grounded in science, what then, is the basis of this most influential educational movement? In what follows, the development of constructivism is traced, and two key tenets emerge: (i) the political ideal of a democratic classroom, and (ii) a relativist theory of knowledge. Both of these reflect anxiety about power. Constructivism could therefore be described as an ideological (rather than a scientific) approach - largely concerned with social goals, rather than with the efficacy of teaching methods.

(i)The democratic classroom Bruner (1990) described constructivism as a "profound expression of democratic culture" (p. 30). This ideal grew out of an interest in and respect for the inner life of the child, and associated hopes for a society which respects its individual members as such. In the introduction to his novel Emile, Rousseau expresses a vision for education which works in harmony with children's "natural" capabilities, an idea which, according to Dewey (1922), 
"sounded the key note of all modern efforts for educational progress" (p. 1). According to Rousseau:

The wisest [he applies this adjective ironically] writers devote themselves to what a man ought to know, without asking what a child is capable of learning. They are always looking for the man in the child, without considering what he is before he becomes a man. (p. 1)

Montessori (1912) likewise encouraged teachers to take care to understand their students, so that "from that child itself he will learn to perfect himself as an educator" (p. 13), and that school may "permit the free, natural manifestations of the child" (p. 15). Montessori describes a powerful "inner force" (p. 24) which must be nurtured. She warns against, "the loss of consciousness of that individual power and greatness which are the sources of [the child's] inner life" (p. 26).

In the 1930s the psychologist Piaget worked to understand the unique qualities of children by applying scientific methodology. He identified stages of child development that he believed were biologically determined, and described physical and social experiences as occurring gradually, and varying according to the mental level of a child, so that acquisitions and changes in maturity occur as a step-by-step process and succeed one another "according to definite laws" (Piaget, 1950, p. 157). It is worth noting that Piaget's scientific approach is not typical of constructivist methodology, though his findings validate the constructivist 'childcentred' pedagogy. In the writings of Rousseau, Dewey, Piaget, and Vygotsky (to whom we shall return), the unique qualities of children are invoked to justify educational approaches which allow freedom, discovery, and self-expression. The teaching of habits and routine action was regarded as much less valuable. Rousseau asserts that "the only habit the child should be allowed to contract is that of having no habits" (p. 30).

In conjunction with a goal of nurturing the individual, we find a larger goal at the heart of the progressive vision - the reshaping and regeneration of society. The issue is explored, once again dramatically, by Rousseau, who describes traditional teaching approaches using the 
imagery of imprisonment: "Our wisdom is slavish prejudice, our customs consist in control, constraint, compulsion" (p. 10). He insists on the power of nature, and describes a tension between the natural, inner life of the child and the pressures of society, writing, "[f]orced to combat either nature or society, you must make your choice between the man and the citizen, you cannot train both" (p. 7). Montessori, at the end of her Chapter "Critical Consideration", quotes the Italian physician Giuseppe Sergi, writing, "To-day [sic] an urgent need imposes itself upon society: the reconstruction of methods in education and instruction, and he who fights for this cause, fights for human regeneration" (p. 27). In Dewey's book Democracy and Education (1916), again we find progressive education defined as "reconstruction" (p. 76). Dewey envisaged a system whereby progressive educators, rather than teaching old habits and "cultural products of the past" (p. 75), would instead provide relevant experiences through which children would grasp new concepts and form new, better habits, so that the future adult society would be "an improvement on their own" (p. 79).

In the 1950s, the ideals of innateness and freedom became practically integrated in a learner-centred curricula. This may have originated in Carl Rogers' method of person-centred psychotherapy, in which the therapist's primary role is to provide an environment of support, so that a client feels free to develop a sense of self. Rogers (1956) argued that "[i]t is possible for us to choose to value man as a self-actualizing process of becoming; to value creativity, and the process by which knowledge becomes self-transcending" (p. 1063).

Similar themes were quickly adopted in the area of literacy research. At the Dartmouth seminar of 1966, which has been described as a "watershed" in the movement of writing reform (Strickland, Bodino, Buchan, Jones, Nelson, \& Rosen, 2001, p. 388), American and British researchers debated definitions of literacy, eventually accepting the somewhat counter-intuitive definition "personal growth" (Sublette, 1973, p. 351). Donald Graves, founder of the (constructivist) process writing approach to writing teaching, urged teachers to allow children to write from their first day of school and to fully control the process, describing the writer's voice as an essential element of all writing (Graves, 2003). Graves describes the writer as an 
inventive craftsperson, who works "on the edge of consciousness" (p. 234), looking for, "differences in the material, the surprise, the explosion that will set him aback" (p. 6).

(ii) Relativism

The challenging philosophical assumption that absolute truths do not exist, and that knowledge and meaning are constructed emerged out of the investigations of the development of language and thought, of Piaget, Vygotsky, and Bruner (Palinscar, 1998).

Piaget (1950) argued that social interaction is crucial to the development of logical thought, since logic depends upon words having constant and shared meanings (thus allowing concepts to be considered from any viewpoint). He described the development of language and thought as following a sequential progression from sensory perceptions, to egocentric and intuitive thought and speech, to logical, directed thought and speech. According to this staged model, it is around age eight that children become capable of following common rules or norms, and are therefore capable of cooperation and logical discussion.

Piaget's contemporary, Vygotsky, praised Piaget for his systematic investigation of children's thought and speech, though his own description of language acquisition is fundamentally different. He asserted that the "true direction of the development of thinking is not from the individual to the social, but from the social to the individual" (trans. 1986, p. 36). Social speech is a starting point, from which egocentric and inner speech develop. This inner speech, observed in young children during problem solving tasks, comes to serve both intuitive and logical thinking. Vygotsky famously coined the phrase 'Zone of Proximal Development' to characterize the interface between, on the one hand, an individual's unconscious, or spontaneous understandings and (on the other) those which are verbally introduced by someone more expert, in a conscious and deliberate way. According to Vygotsky, spontaneous concepts developing "upwards", meeting with scientific concepts developing "downwards", are "two aspects of one and the same process of the development of verbal thought" (p. 196). Most profoundly, Vygotsky argued that the role of intuition and imagination be reconsidered, on the grounds that words are "generalized concepts" and a "symbolic inventory of all experiences and 
things" (p. 8). Imagination and logical thought are thus unified "in the very first generalization, in the very first concept formed by man" (p. 39).

The same thinking is followed in Bruner, Goodnow, and Austin's (1956) discussion of categorization: “Do such categories as 'tomatoes, lions, snobs, atoms, and mamalia exist?" they ask, going on to assert that "In so far as they have been invented and found applicable to instances of nature, they do". They qualify their answers, however, by adding (importantly): "They exist as inventions, not as discoveries" (p. 7). And so, according to Vygotsky and Bruner, language reflects its own reality. This reality is different from that perceived by the senses, and meaning "belongs in the realm of language as much as in the realm of thought" (Vygotsky, p. 6). As a construction, language reflects individual and cultural differences and also reinforces them. Psychology, if it is concerned with meaning, becomes a "cultural psychology" (Bruner, 1990, p. xii), and all truths depend on one's point of view.

Skinner, also speculating philosophically, presents an opposite but equally fascinating possibility:

Privacy[...]causes trouble first of all for the verbal community. The individual suffers in turn. Because the community cannot reinforce self-descriptive responses consistently, a person cannot describe or otherwise 'know' events occurring within his own skin as subtly and precisely as he knows events in the world at large. (1963, p. 953)

Thus a clear dichotomy emerges. The constructivists emphasise the subjectivity of knowledge and deny the authority of more expert others, while scientists such as Skinner express the need for objectivity. ${ }^{1}$

\footnotetext{
${ }^{1}$ It is important to note that a relativist view of knowledge may apply to either (i) an individual's learning process - in which our understandings emerge from cognitive processes, or (ii) the process by which knowledge itself is socially constructed, with reality "fundamentally unknowable" (Gilbert, 2018, p. 20). While Piaget may have endorsed the notion of an individual's 'constructive' learning processes, he may have rejected the latter, more radical view.
} 
It is clear that one could consider these philosophical questions in a number of ways, though absolute answers are unlikely to emerge. We may, however, examine the practical implications of constructivism for our schools and classrooms.

\section{Constructivist Practice: Palinscar (1998)}

Palinscar - a constructivist theorist - exemplifies the practical implications of constructivism for pedagogy and learning. ${ }^{2}$ Palinscar's applications of constructivist principles are logical and transparent. By the same token, however, they are simplistic: they fail to acknowledge the limitations of constructivist methods insofar as their application to young children and their acquisition of basic skills is concerned.

We may infer Palinscar's fundamental position from her representation of the challenge to educators as, "the development, among learners, of an intersubjective attitude about the joint construction of meaning; a commitment to find a common ground on which to build shared understanding" (p. 355). From this statement we see that the constructivist value of democracy (a social value), and the relativist view of meaning (a philosophical position), have been integrated quite problematically. If we understand language and meaning as always being constructed through discourse, they would not need to be learned formally. The same values are mirrored in Palinscar's discussion of teacher professional development, in which she advocates an inquiry approach, whereby teachers examine their own practice, experiment with new methods and then share their "accumulated wisdom with one another" (p. 370).

The "critical role of the teacher", according to Palinscar, is to create an environment in which children learn to validate one another's ideas (p. 357), and to "follow and engage" in the student's discussions (Lampert, 1990, p. 41, cited by Palinscar, p. 363). In her discussion of a study of peer work undertaken by Taylor and Cox (1997), she expresses a preference for "interaction" over "modelling", and defines success as "a function of the extent to which there was shared ownership of the learning" (p. 358). Citing research comparing the time spent on

\footnotetext{
${ }^{2}$ As of today, an internet search for Palinscar produces over 1000 citations.
} 
various activities in a constructivist and a traditional classroom, Palinscar clearly approves of the fact that, in the constructivist class, $71 \%$ of time was spent in student-centred presentations and peer work, while only 29\% was "teacher-centred" (p. 357). ${ }^{3}$ In the traditional classroom, by comparison, $40 \%$ of the lesson was used for independent desk work, $29 \%$ was used for "teacher-directed" discussion, and 1\% was used for group work. The terms "student-centred" and "teacher-centred" are somewhat problematic. Though full definitions have not been included in the review, these terms appear to describe who it is that is directing the course of a lesson. Unfortunately, “centred”, implies actions which may work around, or for, someone, so that "teacher-centred" implies selfishness on the teacher's part, while "student-centred" is suggestive of the noble ideals of individual freedom and democratic classroom relationships. When it comes to the important area of assessment, Palinscar advocates a "dynamic" approach, in which an assessor interacts with a student with some flexibility and openness in order to judge, not only their current skills but also their future potential. For Palinscar, this approach stands, commendably "in striking contrast with assessment procedures informed by the psychological theory that prevailed in the 1960s, in which testing contexts [...] were designed to reduce social influences" (p. 366). Palinscar advocates the "Learning Potential Assessment Device" according to which an assessor interacts with a student in a flexible manner, in order to focus on their strategy use at points of difficulty. He or she then creates a "cognitive map", which charts a student's familiarity with a content area, as well as their methods and (supposed) "modifiability” (p. 367). Such assessment depends on a high level of interpretation by the examiner. As such it is potentially unreliable, and also quite possibly more intrusive than a quantitative measure of discrete skills. Although they are clearly inspired by democratic values, such methods may in fact elevate the authoritative role of the teacher.

On the important question of effectiveness, Palinscar is frustratingly anecdotal. For example, she writes that, on a peer editing intervention "students who had experienced group work came to think of revision as reconceptualization, whereas those who worked alone

\footnotetext{
${ }^{3}$ Even these teacher-directed interactions are described as "facilitative rather than directive".
} 
continued to think of revision as principally editing" (p. 364). On a scientific inquiry study, she observes: "participants became comfortable identifying with scientific activity and not simply attributing scientific activity to others" (p. 366).

\section{Constructivism in New Zealand: Gilbert (2018)}

Gilbert (2018) defines four different forms of constructivism that have been influential in New Zealand since the 1980s. These include (i) personal constructivism, a psychological theory of individual learning, according to which children develop their own intellectual structures through experience; (ii) "constructivist pedagogy", an approach to teaching which attempts to extend the spontaneous processes of personal constructivism into formal learning environments; (iii) "social constructivism in the educational context", in which the social - and cultural - aspects of learning are emphasized; and (iv) "social constructivism [as] a theory of how knowledge is constructed in the disciplines" (p.20). This final form, according to Gilbert, has origins in sociology. It is a research area, investigating how knowledge is constructed by experts in a field, following particular disciplinary processes.

Gilbert argues that the different conceptions of knowledge inherent in these theories have led to confusion and the misapplication of certain methods to "areas beyond its [constructivism's] original remit" (p.18). For example, with personal constructivism, the term knowledge refers to personal constructs, whereas with constructivist pedagogy, knowledge refers to both personal understandings, and to specific curriculum concepts. In educationallyoriented social constructivism, personal knowledge is built through social interaction, and is therefore co-constructed. Finally, when one considers Gilbert's fourth form of constructivism (that which examines disciplinary knowledge), it appears that personal knowledge is rather irrelevant. Gilbert describes these differences in meanings as having had "significant" impacts on educators, "for what they tell us about our implicit understandings of education's purpose" (p. 21). 


\section{Constructivist Approaches to Literacy Teaching}

For the constructivist approach to literacy, we must turn to a range of sources. What emerges is a focus on personally-meaningful contexts, including (for reading) the use of real literature and, for writing, authentic and interesting purposes. Reading and writing processes are regarded as "natural", with their development compared to that of speech, and understood as the effortless result of active engagement in language and print. The role of the teacher is de-emphasised and the explicit teaching of skills is downplayed (Graham \& Harris, 1994; Needels \& Knapp, 1994). These methods are often described as a Whole Language approach.

Defining Whole Language more explicitly can be problematic. Bergeron (1990), in an often-cited and comprehensive review of Whole Language literature, found many inconsistencies of definition. One third of the reviewed articles failed to define the term at all, while another third failed to cite its theoretical origins. More to the point, she found descriptions of instructional strategies equally variable, though references to constructing meaning, using literature, teaching the writing process, cooperation, and consideration of students' emotional needs were most common. Bergeron's own definition reads:

Whole language is a concept that embodies both a philosophy of language development as well as the instructional approaches embedded within, and supportive of, that philosophy. This concept includes the use of real literature and writing in the context of meaningful, functional, and cooperative experiences in order to develop in students' motivation and interest in the process of learning. (p. 319)

If teaching methods are not, themselves, clearly defined, constructivist ideals of freedom and democracy are repetitively cited in the Whole Language literature (see Moorman, Blanton, \& McLaughlin, 1994). Yetta Goodman describes the Whole Language classroom:

The teacher is viewed as a co-learner with the students. The environment is a democratic one in which the teacher and the learners collaboratively set agreedupon goals. Teachers are knowledgeable about students as well as content, but 
their major commitment is to plan learning experiences that build on the background and experience of the learners. Teachers strive to understand the needs and expectations of students, their cultures, and the communities in which they live. (1989, p. 114)

Process Writing, as first advocated by Graves in the 1980s, applies the Whole Language approach to the teaching of (obviously enough) writing. Immersion in meaningful tasks is seen as key, with the explicit teaching of transcription skills (spelling and handwriting) regarded as relatively unimportant. Students are invited to choose their own topics. They are encouraged to draw on their own 'authentic' experiences. The processes of planning and revision are taught, and are often practised through sharing and peer collaboration. The teacher takes on a facilitative role, addressing individual needs through private conferencing in "teachable moments" (Graham \& Harris, 1994). Its effectiveness, however, remains uncertain. Graham and Harris (1994) commented on the scarcity of quantitative evidence in this area, referring to just one major study, that of Hillocks (1984). Hillocks, using meta-analysis of treatment studies from 1963 to 1982 , found that while process writing had a positive effect size of .19, this was only about a third of the effect size of an "environmental approach" (p. 114), characterized by clear objectives and structured problem-solving tasks. Hillocks noted that Graves depended on qualitative case studies, which have limited value when it comes to the discovery of generalisable principles for effective teaching. Indeed, a lack of quantitative data is a general and significant issue with regard to research investigating the efficacy of constructivist pedagogy. This is a problem inherent in the constructivist relativist philosophy, with Bruner (1956) using the concept of educational quality to demonstrate the relativist position asserting that such concepts are defined by culture and depend on one's point of view. A yardstick by which constructivist pedagogies might be measured is thus removed.

A third, more radical approach New Literacy Studies, emerged during the mid 1990s. This has drawn on the work of the New London Group (their manifesto was published in 1996), whose members sought to redefine the "why, what and how" of literacy pedagogy in response to 
the impacts of multilingualism and information technology. New London Group theorists, Cope and Kalantzis (2009) described multilingualism ("the burgeoning variety of social languages [...] in affinity groups contexts", p. 166) as having altered everyday communication, so that this experience is "increasingly one of negotiating discourse differences". Information technology has introduced "audio, gestural and spatial modes" so that literacy must now be considered a "multimodal" practice (p. 166). These developments imply that (i) meaning making should be conceived of as an "active and dynamic transformation of the social world", and (ii) "the traditional emphasis on alphabetical literacy [needs] to be supplemented in a pedagogy of multiliteracies by learning how to read and write multimodal texts which integrated the other modes with language" (p. 166). According to these authors, this new, "transformative" pedagogy should build on progressive approaches through a greater emphasis on anlysis and application. Cognition must be regarded as "situated" (in other words, individuals' understandings reflect their prior cultural experiences). Learners' own interpretations of material should be respected, and learners should be encouraged to analyse relationships of power.

Like Whole Language theorists, the advocates of a New Literacies approach deemphasized the importance of the explicit teaching of skills, and downplayed the importance of controlled studies for educational research. The teaching of phonics was equated with 'skills and drills', and with a simplictic view of learning:

There is some merit in sound-to-letter correspondances but not enough to merit its fetishication by the back-to-basics people [...] The horizons of phonics are set so low and the results so easy to measure that it is not hard to show improved results, even amongst children who come from communities and cultures that historically have not achieved at school. (Cope, \& Kalantzis, p. 183)

This statement requires interrogation, particularly when considered alongside the authors' description of learning to write:

Some kinds of learners seem to "get it", others do not. The more academic modes of written language make intuitive sense to some but not to others [...] learning to write is 
about forming an identity; some learners can comfortably work their way into that identity and others cannot, and the difference has to do with social class and community background. (p. 183)

Thus, methods of teaching which have been demonstrated to raise achievement for at-risk groups are discounted as "simplistic", while the otherwise low results of these students are attributed to their backgrounds. These assertions, used to justify the constructivist, relativist view of curriculum, effectively absolve teachers of any responsibility to equip students with readily observable skills.

In New Zealand, the theories of the New London Group have informed "socio-cultural", or "culturally-responsive" approaches to teaching, promoted in Ministry documents such as $\mathrm{Ka}$ Hikitia (the Māori education strategy, 2013-2018), and in the academic work of researchers such as Bishop, Berryman, Cavanagh, and Teddy (2009) and Jesson and Cockle (2016). A central theme in this literature is that education must reflect cultural identity, allowing "previously marginalized students to more successfully participate [...] on their own culturally constituted terms" (Bishop et al., p. 736), or (as stated in the introduction to Ka Hikitia) ensuring that "Māori students are enjoying and achieving success as Māori" (MOE, p. 5). The importance of "product-learning" is de-emphasised, in favour of co-constructed, process-oriented experiences (Bishop et al., p. 740). Reflection by teachers and students on power relationships is seen as key, leading to "interactive" and "discursive" classroom environments.

\section{Underachievement and socio-economic status}

Socio-cultural theory assumes that inequitable outcomes in New Zealand are due to cultural differences and the failure of our school system to accommodate these. The economic impacts of colonisation are understated, with any discussion of the relationship between low socio-economic status and educational underachievement dismissed as "deficit theorizing" (Bishop et al., p. 736) or as perpetuating "socially constructed impoverishment" (p. 740). These claims ignore the findings of empirical research which demonstrate a strong relationship 
between economic, and educational, disadvantage. Two studies are pertinent here, that of Marks (2007) and that of Marie, Fergusson, and Boden (2008).

The large scale study by Marks (2007) used multiple regression analysis to ascertain the effect of socio-economic backgrounds on student achievement in the 2000 PISA results. Marks established that data from New Zealand students demonstrated relatively low intra-class correlations (i.e., much greater variability of results). Controlling for socio-economic factors produced a decline in intra-class correlations of $44 \%$, proportionally larger than that found for most other OECD countries, suggesting that these factors have a significant impact on New Zealand students' achievement.

Marie, Fergusson, and Boden (2008) gathered data from 934 participants in the longitudinal Christchurch Health and Development Study. The researchers interviewed young adult participants about their history of educational attainment, and their ancestry and cultural identification. These were compared with the participants' socio-economic status (calculated at the time of their birth), and assessments of their families' material living standards - obtained every year from birth to age ten. Analysis revealed statistically significant associations between ethnicity and educational outcomes, with Māori having generally lower levels of educational achievement. Māori were also exposed to significantly greater levels of socio-economic disadvantage in childhood. Notably, control for socio-economic factors reduced associations between cultural identity and educational outcomes to non-significance, a finding that suggests that disparities in socio-economic status during childhood are a major factor in educational achievement, whereas ethnic and cultural factors are only associated through correlation with socioeconomic measures.

Consideration of studies such as these is vital. An appreciation of the impacts of poverty enables us to think in practical terms, and to focus on ways in which these might be ameliorated. In low decile schools, where levels of transience are high, we might (for example) develop better systems of between school communication so that important information about students' strengths and needs is shared, and learning time is not wasted. Another implication is that we 
must take responsibility for developing in all students the skills necessary to succeed in working life, so as to break the cycle of poverty and underachievement. Literacy skills are essential, and we must work with a sense of urgency to develop highly effective programmes.

\section{An anti-science attitude}

As noted in my introduction to this chapter, Tunmer and colleagues have proposed that the Ministry's comitment to constructivism reflects an "anti-science attitude" (p. 12). Indeed, the literature reviewed thus far, testifies to the fact that constructivists favour descriptive - rather than empirical - approaches to research. What is more, they have ignored the findings of scientifically-based studies which suggest a need for the re-evaluation of some of their methods. In the field of reading, such work includes cognitivist studies by Gough \& Tunmer (1986), Stanovich (1986), Snowling, Hulme, and Nation (1997), and Rose (2006) - all of which indicate that much greater emphasis should be placed on the explicit teaching of phonological knowledge and decoding skills than proponents of Whole Language would recommend. In regard to writing, social cognitive research has highlighted the significance of transcription skills (spelling and handwriting), and the need for these skills to be automatised - in order to reduce constraints on a child's working memory (Berninger, 1999; McCutcheon, 1996). In addition, cognitivist writing researchers have isolated the complexity of the writing process, and argued that skills such as planning and revision must be taught explicitly in order for students to make progress (Graham \& Harris, 1997). ${ }^{4}$ These findings call into question Graves' assumption that immersion in meaningful writing tasks - in the absence of explicit teaching of technical skills - will be enough to develop students' abilities.

\section{False oppositions}

It would be a mistake to disregard all constructivist methods in their entirety. Social cognitivist writing researchers Graham and Harris (1997) recommend the use of authentic and

\footnotetext{
${ }^{4}$ Social cognitivist writing research, which is of clear relevance to the two empirical studies presented later in this thesis, will be examined in some detail in the following chapter. A closer examination of constructivist recommendations for the teaching of writing is presented in Chapter Three.
} 
meaningful tasks for the practice of newly taught skills, and peer evalution as a way to encourage students' critical, self-regulatory processes. Furthermore, cognitivist models support the constructivist view of learning as a process which involves active engagement by students who feel personally connected to the material (see, for example, Flower \& Hayes, 1981; Bereiter \& Scardamalia, 1987; and Zimmerman 2013). Finally, most educationalists - of whatever theoretical position - would be sympathetic to the social goals of constructivism, and would regard the socio-cultural priorities of inclusiveness and respect as essential - for purposes that go well beyond the goal of measurable educational outcomes. Unfortunately, there is a tendency in the constructivist literature to present what should be a reasoned discussion as a dichotomous "struggle" (to use a favoured term of Goodman, 1993). In this way, proponents of the movement have constructed unecessary and counter-productive oppositions between their own, and other, approaches.

Moorman, Blanton, and McLaughlin (1994) used deconstructive rhetorical analysis (based on the work of Derrida) to examine false oppositions implicit in the Whole Language literature. Their analysis of figurative language revealed two binary oppositions: "natural versus artificial", and "personal versus external control". In the first of these, Whole Language methods are presented as natural (and good) through reference to "authenticity" and what is "natural". In contrast, alternative techniques are associated with the unnatural (and thus unhealthy) through terms like "inauthentic writing", "industrial product", and "synthetic texts". (The latter applied by Goodman to leveled readers, cited in Moorman et al., p. 322). The second opposition is that of "personal versus external control", with Whole Language theorists defining students' "ownership" of literacy as "the overarching goal in the framework" (Au, Scheu, \& Herman, 1990, cited in Moorman et al., p. 324). Ownership, in turn, is associated with empowerment of both students and teachers, who are described as engaged together in the struggle against the "imperatives" and "hegemony" of pre-planned programmes (Goodman, cited by Moorman et al., p. 324). Altweger and Flores (1989) go so far as to describe the effects of levelled reading 
programmes as "subordination [...] one might describe students in a basal reading programme as 'objects' rather than 'active subjects' of the learning process" (cited in Moorman et al., p. 324).

The consequences of these false oppostions may be significant. As Moorman and colleagues argue, although evocations of the natural and personal have wide appeal, the associated view of literacy learning may - contrary to the political aims of constructivism - in fact serve to perpetuate inequitable economic relations and social outcomes, in two key ways. First, the failure to acknowledge that the alphabet is an invented code - and that literacy is governed by certain rules - obscures the hard work needed for students to become literate (and therefore empowered) members of society. Second, a high valuation of that which is personal may discourage political activism. Moorman et al. write:

Paradoxically, the radical educational change advocated in the whole language literature requires action precisely in the public sphere that whole language portrays as unreal and inauthentic. The message that the private should prevail over the public and political [...] keeps the movement safely within the system of thinking it claims to be revolting against. (p. 326)

False oppositions are also evident in the socio-cultural literature. For example, Bishop, Berryman, Cavanagh, and Teddy (2009) describe the Te Kotahitanga research and professional development programme, a large-scale, Ministry funded project delivered in secondary schools. The Te Kotahitanga project sought to raise achievement of Māori. '[S]tudent 'voices' were used to identify "discursive positions related to Māori student learning" (p. 734). This information was then used in professional development teachers - with the goal of increasing teachers' awareness of the experiences of Māori students at school and to reflect on their attitudes to, and relationships with, marginalized students. An effective teaching profile was developed, which identifies a set of six practices to demonstrate care, and high expectations, enabling teachers to "engage in effective teaching interactions with Māori students as Māori” (p. 737). 
The authors construct an opposition between "traditional" and Te Kotangitanga approaches. Their use of figurative language is emotive. Traditional methods are associated with infection, described as "pathologizing classroom practice" which involves "transmission teaching" (p. 737). They are also associated with religious fervor, and power: "the [...] imposition of the teacher displaying cultural iconography of their own choice” (p. 741). Te Kotangitanga approaches, on the other hand, are associated with life, "spirit", and student ownership. Curriculum is "relevant" and is constructed on the students' "own culturally constituted terms". Students are engaged "actively and holistically and in real life" (p. 741); and the "learning forum involves a rich and dynamic sharing of knowledge [...] ideas are given life and spirit through dialogue, debate and careful consideration" (p. 737). Significantly, Bishop et al. also associate these practices with truth: "this new pedagogy recognizes that all people who are involved in the learning and teaching process are participants who have meaningful experiences, valid concerns, and legitimate questions" (p. 741, italics added).

According to Bishop and colleagues, "Pathologizing classroom practices" include "transmission teaching, remedial programs and behavior modification programs" (p. 736). While these are described in distasteful terms, the alternative methods - when considered objectively - do not seem to be radically different. The authors recommend "a wider range of interactions" including, "some instruction (a mixture of process and transmission), the monitoring of processes and uptake" and "the recognition of appropriate student behavior" (p. 740). While they position themselves as activists, proposing that the means of addressing educational disparities "lies elsewhere than in mainstream education" (p. 741), it could be argued that they have few substantively different methods to offer. Meanwhile, by casting the educational debate in moral terms, these researchers discourage any objective appraisal of $T e$ Kotahitanga methods. 


\section{Power}

If we do in fact accept the need for a different approach in order to raise achievement, how then do we tackle the problems of power in a teacher-directed classroom? In a series of articles written in the 1980s, Lisa Delpit discusses the issue of power as it had arisen in the American context. Delpit (1988) observed that imbalances of power exist in all classrooms. A "culture of power" develops inevitably, reflecting the mainstream (usually the majority) which constitutes "those who have power" (p. 282). At the same time however, this group tends to be unconscious of the system within which they are privileged. The codes that determine self-presentation and ways of interacting remain unstated and implicit. Such codes are not easily transmitted across cultures. Delpit found that minority students participate more successfully in the classroom and school if these codes are, in fact, made explicit. Additionally, she acknowledged the importance of basic literacy skills for successful participation in society. Delpit (1986) described her own experience implementing a process writing approach in a Philadelphia school in the 1980s. In this context, she observed the privileged white students as they "zoomed ahead" (p. 381), while poor black students continued to struggle. Additionally, she described a faculty among which the progressive white teachers favoured the process writing approaches, and black teachers continued to focus on skills. Delpit argued that the process writing focus on "fluency", was not targeting the actual needs of the black students:

[M]aybe the black teachers are so adamant against what they understand to be the writing-process approach because they hear their students' voices and see their fluency clearly. They are anxious to move to the next step, the step vital to success in America - the appropriation of the oral and written forms demanded by the mainstream. (p. 383)

Commenting on the political impact of the constructivist view,

[W]riting process advocates often give the impression that they view the direct teaching of skills to be restrictive, at best, and at worst, politically repressive to students already oppressed by a racist educational system. Black teachers on the 
other hand, see the teaching of skills to be essential to their students' survival". (p. 383)

\section{Conclusion}

Any discussion of constructivist methods is caught between subjective values and objective science. On this point, I defer to Skinner (1956):

By admiring the student for knowledge and blaming him for ignorance, we escape some of the responsibility of teaching him. We resist any analysis of the educational process which threatens the notion of inner wisdom or questions the contention that the fault of ignorance lies with the student [...] We are quite unprepared to judge effective educational measures. As long as only a few pupils learn much of what is taught, we do not worry much about uniformity or regimentation. We do not fear the feeble technique; but we should view with dismay a system under which every student learned everything listed in a syllabus - although such a system is far from unthinkable. (p. 1059) 


\section{CHAPTER TWO: EFFECTIVE WRITING PROGRAMMES}

\section{Social Cognitivism and Writing Research}

In the previous chapter constructivism, the philosophy that currently dominates New Zealand (school) curriculum was examined. This philosophy prioritises the social values of personal freedom and democracy. However there is evidence that constructivist teaching approaches are failing to meet the needs of students: PIRLS and National Standards data both indicate that significant numbers - especially those from on-average disadvantaged demographic groups are achieving below typical levels for their age groups. ${ }^{5}$ It seems therefore, that there is an urgent need for the Ministry of Education to re-evaluate its constructivist position, and to equip teachers with a range of effective, evidence-based teaching methods. This is not to say that we must disregard the values on which constructivism is based. However, more effective literacy programmes are a necessity if we are to achieve a fair and equal society in which all New Zealand students leave school with positive options for future study and work.

Three interconnected research areas, all of which typically use quantitative, experimental or quasi-experiemental designs would be relevant to such a re-evaluation. These areas are respectively concerned with self-regulation, with feedback, and with the writing process itself. The self-regulation literature offers insights into thinking processes, and the connection between thinking and writing. Feedback research concerns the elements of effective feedback, including those that activate learners' self-regulation strategies and enhance their self-efficacy. Although the three research areas are interconnected, for the sake of clarity I introduce them as three separate strands (in as much as this is possible), before describing the mutual influence of these strands on one another.

\footnotetext{
${ }^{5}$ See Chapter One for a more in-depth discussion of these data.
} 


\section{(i) Self-regulation}

According to social cognitivism and research on learning dispositions, self-regulation is a key aspect of all learning. Bandura (1991) claimed that "[s]elf-regulatory systems lie at the very heart of causal processes. They not only mediate the effects of most external influences, but provide the very basis for purposeful action" (p. 248). Self-regulation may be described as being a product of purposeful self-awareness. It encompasses a range of cognitive processes, from planning to evaluation. Closely related are self-efficacy beliefs, defined as "people's beliefs about their capabilities to exercise control over their own level of functioning and over events that affect their lives" (Bandura, 1991, p. 257). Self-efficacy naturally impacts on self-regulation and consequently on achievement, and achievement reinforces self-efficacy in turn.

Self-regulation theory grew out of work on cognitive modelling, in which problem solving strategies are modelled and explained to students, and students' acquisition of new concepts is assessed. Using this approach in a number of studies conducted in the 1970s, Zimmerman and his colleagues observed rapid progress in students' acquisition of new abstract concepts, in their ability to transfer this knowledge to different tasks, and in their retention of this knowledge over time. They also found that cognitive modelling was an effective technique for teaching problem-solving strategies to young children, leading them to critique stage descriptions of development (for example, Piaget's) as being "unduly pessimistic" (Zimmerman, 2015, p. 136). One such study taught children the physics concept of conservation of volume. An adult model answered conservation questions, for example, whether a flattened ball of clay had more or less clay than an un-flattened ball, or whether a glass of water had more or less water when it was poured into a narrow cylinder. The adult models were sometimes asked to justify their answers. This method was found to have a positive impact on learning, with participants able to answer similar questions correctly with reference to different objects. The modelling that included explanation and justification had the most significant positive impact (2015, p. 136). 
Zimmerman observed students' abilities to transfer conceptual knowledge to new problems and interpreted it as a transition from social to self-regulated learning. In this transition, students identify shortcomings in their first attempts, and then apply new (taught) strategies, with perseverance. In order to test the significance of self-regulation, he developed a structured interview, the Self-Regulated Learning Interview Scale (used for students to assess their own use of self-regulation strategies), as well as the Scale Rating Student Self-Regulated Learning (for teachers to assess their students' use of self-regulation strategies). Using multiple regression analyses, Zimmerman found that achievement was predicted with a high level of accuracy by the SRLI (more than 90\% accuracy), and that teachers' ratings were highly correlated with their students' self-assessments.

Zimmerman's experimental work is extensive, and he has emphasised the particular importance of self-regulation to writing (see, for example, Zimmerman and Bandura, 1994). Zimmerman's cyclical phase model (2015) includes a forethought phase, in which learners analyse a task and set goals related to it, a performance phase, during which learners exercise self-control and self-monitoring, and self-evaluation, which may lead to a second phase of goal setting. Zimmerman identifies two kinds of students. Proactive learners put thought and effort into selecting useful goals and creating a plan for the task ahead. This helps to guide their performance, and allows for an informative evaluation process because their outcomes may be assessed according to the selected criteria. In contrast, reactive learners do not plan effectively. This means that they lack strategies to guide their performance, and that they have no clear measures for self-evaluation. Self-evaluation with reference to planned goals and strategies leads learners to attribute results to controllable factors (for example problem solving strategies), rather than (discouragingly) to uncontrollable factors, like lack of ability. As might be expected, attributing results to factors within one's personal control sustains motivation. Proactive students (with their high levels of self-satisfaction) modify strategies, while reactive students resort to defensive behaviours "to protect themselves from future dissatisfaction and 
aversive affect, such as helplessness, procrastination, task avoidance, cognitive disengagement, and apathy" (p. 144).

\section{(ii) The Writing Process}

Social cognition research since the 1980s has greatly increased our understanding of the writing process. A starting point was the cognitive process theory of writing postulated by Flower and Hayes (1981). Flower and Hayes used a think aloud protocol to study the mental habits of adult writers, asking them to verbalise every thought while they wrote. While this method is reliant on the subjective self-descriptions of participants and may therefore be problematic from an empirical point of view, ${ }^{6}$ Flower and Hayes' model has had seminal influence and continues to shape research in the field.

Flower and Hayes defined writing as a "goal directed thinking process" (Flower \& Hayes, 1981, p. 366), involving a writer's long term memory, the task, and processes of planning, transcribing, evaluating and revising. They found, importantly, that all of these interact recursively throughout composition, coordinated by the monitor, or writing strategist (in cognitive terms, a 'central executive'). Bereiter and Scardamalia (1987) built on the work of Flower and Hayes to describe the different processes of skilled and unskilled writers. ${ }^{7}$ They found that unskilled writers typically employ a relatively simple process, described as "knowledge telling", which involves recalling relevant information, checking, and transcribing. For more skilled writers, the demands of a task and their knowledge of a topic interact, resulting in new or altered understandings. This is described as a "knowledge-transforming" process (1987, p. 6).

Extensive studies have investigated the impact of transcription skills - spelling and handwriting - on the process of beginning writers. Research employing sound and reliable research methodologies (including the use of experimental designs, adequate sample sizes, and

\footnotetext{
${ }^{6}$ See Skinner, 1963 for an in-depth discussion of this issue.

${ }^{7}$ Bereiter and Scardamalia, like Flower and Hayes, used think aloud protocols for this research.
} 
random selection to control or treatment groups), has shown that these skills are significant in two key ways. ${ }^{8}$ First, until these skills become automatized, they require conscious attention and effort, and therefore occupy limited cognitive resources. This often prevents a writer from attending fully to other, more creative, aspects of the process (Berninger, 1999; McCutcheon, 1996). Second, spelling and handwriting impact on the whole of the writing process, not just on transcribing. Handwriting is a factor in written planning, and spelling skills are required to identify and correct errors during reviewing (Berninger, 1999). Indeed, there is evidence that spelling and handwriting skills in the early year levels are predictive of compositional fluency (the speed of writing) throughout primary school (Graham, Berninger, Abott, Abott, \& Whitaker, 1997, cited by Berninger, Graham, Vaughan, Abbott, Begay, Byrd Coleman, Curtin, \& Minich Hawkins, 2002). Furthermore, fluency is correlated with writing quality (Berninger, Yates, Cartwright, Rutberg, Remy, \& Abbott, 1992, cited by Berninger et al., 2002). The Simple View of Writing (Berninger, 2002; Berninger \& Graham, 1998; cited by Berninger et al., 2002), describes the developing writer's process, emphasising transcription skills and self-regulation processes as two elements key to text generation.

It emerges, therefore, that self-regulation (or self-aware, purposeful thinking) is indispensable in the cycles of planning, monitoring and evaluating that are essential to the writing process. Connections between writing and thinking have been quite thoroughly explored in the writing process literature, with reference to both philosophical and psychological theories. ${ }^{9}$ As we have already seen, Bereiter and Scardamalia (1987) emphasise differences between speech and writing, and the greater challenge of the solitary writing process, as well as the opportunities this process provides for intellectual growth. It is interesting in this regard that the social cognitivist emphasis on the unique challenges of writing

\footnotetext{
${ }^{8}$ See Graham, S., McKeown, D., Kiuhara, S., \& Harris, K.R. (2012) for a meta-analysis of studies of writing instruction in elementary (primary) grades. Studies included in this meta-analysis were all experimental or quasi-experimental, included a measure of writing quality at post-test (with interrater reliability of quality established), and obtained the statistics necessary for computing an ES. See Berninger, V. (1999) for a study that specifically investigates the impact of transcription skills on working memory processes. ${ }^{9}$ See Applebee (1984) for a review of the literature.
} 
as a solitary process contrast with whole-language descriptions which emphasise similarities between writing and speech. Olson (1977, cited in Applebee, 1984) also emphasises the solitary nature of writing, as well as its logical (rather than its interpersonal) function. Emig (1977) describes correspondences between the writing process and more general learning strategies. He emphasises a need for writers to integrate sources of information, the permanence of text and thus its availability for review, and the active and "self-rhythmed" nature of writing (Emig, cited in Applebee, p. 577).

The processes identified above are essentially cognitive, but self-regulation also has an instrumental aspect. Zimmerman and Risemberg (1997) distinguish between "behavioural" and "environmental" strategies - both of which are self-regulatory and practical (pp. 76-77). The former include tracking the number of pages written in a day and celebrating a completed assignment, while the latter might involve organising resources and the writing space. Significantly, all processes interact via a 'feedback loop', through which writers monitor the effectiveness of their strategies and modify them accordingly.

\section{(iii) Feedback}

As asserted by Bangert-Drowns, Kulik, Kulik, and Morgan (1991): “[A]ny theory that depicts learning as a process of mutual influence between learners and their environments must involve feedback implicitly or explicitly because, without feedback, mutual influence is by definition impossible" (p. 214). Feedback interventions have produced inconsistent results, however, leading Locke and Latham to make a contrasting statement: "[F]eedback is only information, that is, data, and as such has no necessary results" (1991, p. 224, cited in Kluger \& DeNisi, 1996, p. 254). Clearly, if we are to use feedback we need to identify those characteristics which make it effective.

What kind of information is most helpful to learners? The goal setting and feedback theories of Locke and Latham (2002), Kluger and De Nisi (1996) and Hattie and Timperley (2007) are very useful here. They show that feedback which targets learning processes 
(explicitly self-regulatory processes in Hattie and Timperley's model) is vastly more helpful than that which focuses on outcomes.

The prominent Goal-Setting Theory of Locke and Latham (2002) "was formulated inductively largely on the basis of [the authors'] empirical research conducted over nearly four decades" (p. 705). This work focused on performance goals and their relationship to performance outcomes. The theory describes different types of goals, their functions and moderating factors, and the way in which these elements interact.

Four key findings are highly relevant to the present research. First, Locke and Latham show that learners' commitment to goals is crucial to success. Interestingly, they found no significant difference in performance outcomes between self-set and teacher-assigned goals (as long as the rationale was made clear). Second, they found that self-efficacy is extremely important to success. They showed that this develops (i) as learners experience success, (ii) through role-modelling, and (iii) by teachers communicating confidence in the learner's potential. Third, they found that feedback accelerated progress by indicating when a learner might need to change his or her strategies, and motivating them to work harder. Finally, they identified core properties of the most successful goals - clarity, specificity and difficulty among them. As noted above, goals relating to learning processes are more effective than those relating to performance outcomes.

Kluger and De Nisi (1996) conducted a meta-analysis of feedback interventions, reviewing approximately 3, 000 studies. The authors selected just 131 of these for inclusion in the analysis. Criteria for selection were that studies were experimental or quasi-experimental, with a treatment group receiving a feedback intervention not confounded by other variables. A measure of performance needed to be included, and the sample size had to be greater than 10 , with sufficient statistical information provided for calculating an effect size.

Kluger and De Nisi described four possible responses of a learner to feedback describing the difference between a current level of achievement and a set goal, which they term the 
"feedback standard comparison" (p. 259). These are (i) working harder towards the goal, (ii) giving up on the goal, (iii) changing the goal, or (iv), rejecting the feedback. They observed that feedback focuses a learner's attention on one of three possible kinds of processing: general selfevaluation, evaluation of effort and persistence, or evaluation of task-specific strategies. They conclude that feedback loses its effectiveness when it takes attention away from the task towards the self.

Hattie and Timperley (2007) analysed effect sizes from 12 meta-analyses assessing feedback (including that of Kluger and De Nisi's, on which they drew heavily) to provide their own conceptual analysis of feedback. The major contribution of this work is the volume of research reviewed - 196 studies in total, with 6, 972 effect sizes. The authors articulate their theory in terms which are probably accessible to most classroom teachers, irrespective of their academic background or prior knowledge of feedback interventions.

Hattie and Timperley (2007) calculated an average effect size of .79 across all the studies they reviewed, which is about twice the average effect of schooling, though they noted that there was wide variability in the effect sizes across the different studies. They argued that the type of feedback influences whether its impact is positive or negative, and proposed that quality feedback should answer three questions: "Where am I going?”, “How am I going?” and, “Where to next?" (pp. 81-86). Like Kluger and De Nisi, they identified different processing levels at which feedback might be aimed. They concluded that task level feedback (on simple tasks) can be effective and may increase confidence - though it needs to be specific and delivered as comments not marks. Process level feedback (i.e. feedback which addresses the strategies used to complete a task) can lead to deeper learning and learning which can be generalized. Selfregulation feedback may be of value, due to the importance of self-efficacy for learning in general, but the way in which this feedback is received depends on a learner's self-assessment capabilities, commitment and confidence. Personal feedback (i.e., comments relating to an individual's personal qualities) is the least effective of the four levels. 
The question now arises as to how feedback information is best presented. Some quite specific findings have emerged. Individual, private feedback is often most effective, possibly because feedback in a group situation tends to be perceived as irrelevant by individuals (Nadler, 1979, cited by Hattie et al., 2007). According to Kluger and De Nisi (1996), feedback in group situations is likely to encourage comparison and direct attention to the self-level, the least effective processing level. Feedback that indicates improved performance over time is effective; self-confidence naturally grows as students observe their progress (Bandura, 1989; Locke and Latham, 1990, cited by Schunk \& Swartz, 1993). Kluger and De Nisi describe velocity feedback information, which shows improvement over a number of trials, and which may motivate students to task level processes, the most effective processing level (1996, p. 268). Goalprogress feedback which shows students that goals are attainable (Locke and Latham, 1990, cited by Schunk et al., 1993), and that their newly acquired learning is useful, is also effective (Paris, Lipton and Wixson, 1983, cited by Schunk et al., 1993). Data displays using graphs for students to view can be a clear way to show this progress over time, and may work to accelerate progress. According to the meta-analysis by Fuchs and Fuchs of studies of formative evaluation, studies using graphs of student progress had a weighted mean of .70, compared to .26 for written recording (Fuchs \& Fuchs, 1986). ${ }^{10}$ One final matter is the timing of feedback. It is interesting that the impact of immediate versus delayed feedback seems to be somewhat dependent on context and the level to which feedback is directed. For example, immediate feedback may be more effective when students are learning something new, and less effective during a practice and fluency-building stage (Hattie et al., 2007). It may be more effective for inclass activities than for tests (Kulik \& Kulik, 1988, cited by Hattie et al., 2007).

\footnotetext{
${ }^{10}$ Precision Teaching, a behaviourist-developed student self-evaluation system, tracks student progress using graphs. It has been shown to be highly effective through empirical research (Lindsley, 1992). I have used this system in my own classrooms and have observed positive impacts on both motivation and achievement.
} 
Feedback cannot happen as an isolated event, but is inextricably linked to (formative) assessment. Research indicates that ongoing formative assessment has great potential in itself to impact positively on learning (Fuchs et al., 1986; Hattie, 1999). For teachers, it encourages an inductive approach to goal setting, and constant monitoring of progress, in real and familiar classroom settings. When assessment information is analysed carefully, it may support in-depth and realistic teacher judgements, and lead to more appropriate goal selection and learning experiences (Fuchs et al., 1986). Additionally, close monitoring of student progress may become a catalyst for teacher innovation and improved practice (Black \& Wiliam, 1998). ${ }^{11}$

In summary, feedback should focus on processes (not outcomes or the self, i.e., the student as such), and it should be part of continuing assessment which tracks progress over time.

\section{Implications for Writing Instruction}

\section{(i) Graham and Harris: Knowledge and skills}

In a useful synthesis of their own and others' experimental research, ${ }^{12}$ Graham and Harris (1997) identified "knowledge, skill, will and self-regulation" (p. 415) as crucial to success. Their contingent recommendations could be regarded as guiding principles for successful writing lessons. ${ }^{13}$

One such principle is that time should be devoted to teaching critical transcription skills quite explicitly, with a focus on "those skills that yield the highest rate of return" (p. 418). For handwriting, it is necessary to teach correct letter formation and pen grip, and for spelling, instruction should address common spelling patterns and the application of these patterns to

\footnotetext{
${ }^{11}$ Formative assessment must be implemented expertly to achieve these gains. Significantly, a number of prominent researchers suggest that teacher practice in this area is currently weak (Black et al., 1998; Hattie et al., 2007, Parr \& Limbrick, 2010).

12 In what could be described as a social cognitivist approach to methodology, Graham and Harris favour experimental research designs, and studies that provide enough statistical information from which to calculate effect sizes. For examples see: Graham, S., MacArthur, C., Swartz, S., \& Page-Voth. (1992), and Graham, S., McKeown, D., Kiuhara, S., \& Harris, K. R. (2012).

${ }^{13}$ Graham and Harris's recommendations helped to inform the practices described in my own writing manual (See Appendix ii).
} 
new words (using analogy), as well as the correct spelling of high frequency words, strategies for memorisation, and strategies for proof reading. Students should also be encouraged to use external references such as dictionaries and to ask for help from other people. Once a new knowledge item has been introduced, briefly practised and evaluated, it is best practised in the context of real and meaningful writing. This is particularly the case for grammar and word usage skills. ${ }^{14}$ The authors point out that "explicit and synonymous instruction is not necessarily synonymous with mindless rule following" (p. 419), suggesting, for example, that teachers may introduce new spelling patterns by encouraging students to sort words and, in this way, discover the patterns for themselves. This point merits considerable emphasis. Clearly, it is possible to provide meaningful and interesting learning experiences - as constructivists would wish - even while teaching the basics of the alphabetic code.

Graham and Harris recommend explicit instruction, and classroom routines whereby the planning, monitoring and evaluating processes are "expected and reinforced" (p. 419). Practice time should occupy at least 45 minutes every day, along with frequent opportunities for peer discussions about how the processes work. Writing tasks must be meaningful if selfregulation is to be applied. Allowing students to select their own topics and purposes does not necessarily ensure this, however. For example, Graham and Harris note that the process of writing about personal experience may, because the content is readily available in memory, be counter-productively undemanding. Alternative possibilities for increasing interest include legitimate tasks for real audiences (for example letters to local politicians about a problem affecting the children), or allowing students to develop their own interpretations of tasks initially selected by the teacher. Peer collaboration tends to encourage reflection on processes and introduce students to new techniques. Finally, Graham and Harris highlighted the importance of encouragement; they warn teachers against emphasizing children's writing difficulties.

\footnotetext{
${ }^{14}$ See Wyse \& Torgerson (2017) for more detailed discussion of empirical research relating to the teaching of grammar.
} 


\section{(ii) Zimmerman: self-regulation, the "multilevel" model}

Schunk and Zimmerman (1997) cited in Zimmerman (2013), describe the all-important transition from social to self-regulated learning in terms of four levels. The first is observational - a student carefully watches a skill being performed and described by the teacher. The second level is that of emulation; learners copy the model, using the skill in a similar task. (As learners work to copy models closely, their accuracy and motivation are greatly increased if the teacher gives further, individualised modelling, guidance, feedback and social reinforcement.) The third level is self-controlled; learners practice the skill independently (on new tasks, often structured by the teacher to enhance performance and self-observational skills). At this self-controlled level learners rely on their memories of the model to form an internal standard, as opposed to "an overt social referent" (p. 140). The final level is that of full self-regulation, achieved when learners adapt their use of the skill to new environments, outside of the classroom setting. Learners are now able to vary strategies based on outcomes. They are able to select a strategy and adapt it to suit the task, with no dependence on a model or teacher. Applied to writing, Zimmerman's model serves to underline the importance of modelling and guidance, along with the power of feedback. Formative assessment plays a critical role, allowing the teacher to tailor instruction to meet students' needs. ${ }^{15}$

Zimmerman and Risemberg (1997) reviewed research regarding the ways in which feedback may be used to develop student self-regulation skills in writing. The results cited provide a useful summary of guiding principles for best practice. For example, goals improve writing fluency, and goal-setting combined with self-monitoring and self-evaluation improve writing fluency and quality. Additionally, goals which address the writing process produce

\footnotetext{
15 Graham and Harris have applied these principles in the self-regulated strategy development (SRSD) model, a model which currently "permeate[s] the literature, and which yields "the strongest writing performance outcomes for students with intellectual or developmental disabilities" (Joseph \& Konrad, 2009, p. 15). The SRSD procedure involves teaching self-regulation strategies such as goal setting and self-monitoring, within a routine of self-instructions. Strategies are explicitly discussed and modelled, and their significance is made clear. Scaffolding, discussion and individualised feedback are used to support the child from guided to independent practice.
} 
better results than goals which address writing outcomes, and process goals combined with feedback produce the best results of all (Hull, 1981; Graham, MacArthur, Schwartz, \& Voth, 1992; Schunk and Schwartz, 1993b, cited in Zimmerman et al., 1997). Finally, it is clear that using specific criteria to evaluate writing leads to improved writing and rewriting (Hillocks, 1986, cited in Zimmerman et al., 1997).

\section{Conclusion}

Social cognitive research offers a great deal of practically-useful principles for the teaching of writing. It has specified what needs to be taught, and how best to teach it. It has identified feedback as crucial, and provided guidance for its effective use. Study Two in the present work describes an intervention based on application of this research evidence, in and for New Zealand classrooms. The goal was to discover an approach which is effective, and which can be taken up easily by any New Zealand teacher to accelerate the progress of students in challenging classroom settings. 


\section{CHAPTER THREE: CONSTRUCTIVIST THEORIES OF WRITING}

\section{Introduction}

As explained in Chapter One, the Ministry of Education promotes constructivist approaches to literacy teaching, despite a lack of evidence to support them. Tunmer and Chapman (2015) were the first to raise this issue, questioning the effectiveness of these methods, and observing that they were not research-based. In their recently published book, Excellence and Equity in Literacy Education - The Case of New Zealand (2015), they cite recent PIRLS results that indicate high levels of variability between good and poor readers, and "Matthew effects", whereby children who enter school with lower levels of literacy knowledge are likely to continue to be disadvantaged throughout their school years. They argue that these outcomes are a result of the Ministry's commitment to constructivism, an orientation which embodies what they characterize as an "anti-science attitude" (p.12). ${ }^{16}$ Noting that the National Literacy Strategy of the late 1990s was driven by practitioners (while advice from a panel of tertiary and NZCER researchers was largely ignored), ${ }^{17}$ they go on to express serious concern at the extent to which teachers have been discouraged from applying the results of educational research.

While Tunmer and Chapman focus on reading, writing may be an area of even greater concern. New Zealand Ministry of Education National Standards data indicate that fewer students are achieving the expectations for their year level for writing than for reading or mathematics. In 2015, 78.1\% of children achieved at or above the expected level for reading, while just $71.5 \%$ achieved at or above the standard for writing. Inequitable outcomes are another worrying issue. In 2015, 77.3\% of Pakeha students achieved at or above the standards for writing, compared with just $61.6 \%$ of Māori, and $60.6 \%$ of Pacific students. Significantly, just $54.5 \%$ of students in decile one schools achieved at or above the standard (compared to $82.5 \%$

\footnotetext{
16 Tunmer and Chapman quote a 1996 article by commited constructivists, Smith and Elley, to illustrate this point.

17 NZCER, or the New Zealand Centre for Educational Research is an independent, statutory research organization.
} 
in decile ten schools), with Māori and Pasifika students making up 49\% and $42 \%$ of the proportion of students at decile one schools, respectively (retrieved from: educationcounts.govt.nz, January, 2019). ${ }^{18}$ Finally, 79.4\% of girls achieved at or above the standard, compared with just $63.9 \%$ of boys (retrieved from educationcounts.govt.nz, June 2017).

Given the role of constructivism in the pedagogical environment - a role Tunmer and Chapman associate with resistance to empirical research as the proper foundation of any teaching method - a prefatory definition for the purpose of the current work is in order. ${ }^{19}$ With regard to reading instruction, Tunmer and Chapman use the term to refer to a view of literacy learning (and reading in particular) as a "by-product of active mental engagement with little or no need for explicit, systematic teaching of letter-sound patterns". According to the proponents of this view, "children are naturally predisposed to learn written language essentially like they learn spoken language, so long as the emphasis is on the communication of meaning" (Tunmer, Greaney, \& Prochnow, in Tunmer \& Chapman, 2015, p. 122). One could also refer to this view as it relates specifically to literacy learning - as a Whole Language philosophy. Ken Goodman (widely regarded as the founder of Whole-Language) describes the movement, and its roots in constructivism are clear:

[A] holistic reading and writing curriculum which uses real, authentic literature and real books. It puts learners in control of what they read and write about [...] It revalues the classroom as a democratic learning community where teachers and pupils learn together and learn to live peacefully together. (1992, p. 65)

What is more, Goodman rejects the use of controlled studies, describing empirically supported teaching practices as "narrow", "unscientific" and "misconceived" (1992, p. 197). His own

\footnotetext{
${ }^{18}$ These statistics suggest that socio-economic status may be a more significant factor in underachievement than student ethnicity is.

${ }^{19}$ As we have seen in chapter one, the term "constructivist" describes a broad, multi-disciplinary philosophical movement.
} 
research involved the analysis of reading errors, leading to the development of his "multiple cues model" (first presented publicly in 1967), which - Goodman himself describes - drew on the work of constructivist theorists from a range of disciplines, including Rosenblatt - whose reader-response theory supported Goodman's view of "reading as a process of construction" (1992, p. 193), as well as Chomsky, Piaget and Vygotsky. According to the "multiple-cues" model, minimal word level information is used in decoding text, and (by the same token) meaning and language-structure cues take precedence (see Tunmer et al., p. 122, for further discussion). This is a process which Goodman himself has referred to as a "psychological guessing game" (1992, p. 192).

Tunmer et al. reject the multiple-cues model, arguing instead that fully analytic processing of letter-sound combinations is essential in order to read complex words and to establish orthographic patterns in memory - from which additional letter-sound patterns can be induced. They cite a number of findings from empirical research: (i) Words are not predictable based on the meaning of the text. There are, on average, ten possible words that could be inserted into any sentence grammatically, with meaning retained (Pinker, 1994, cited in Tunmer et. al, p. 127); (ii) More predictable words tend to be function words (often already known), rather than less frequently occurring (and more meaningful) content words (Gough, 1983, cited in Tumner et al., p. 128); (iii) Studies comparing children's abilities to recognize words in context versus those in isolation suggest that context aids weaker readers only (Nicholson, 1991, cited in Tumner et al., p. 128); (iv) Finally, in one of Tunmer and Chapman's own studies, Year 1 children were asked to describe the strategies they used for decoding. The majority reported using word-based strategies (as opposed to text-based ones), and those children who reported using word-based strategies outperformed the others on a range of reading and writing measures (Tunmer \& Chapman, 2002, cited in Tunmer et al., p. 129).

While Whole Language pedagogy (and the multiple cues model on which it is based) is of greatest relevance to reading instruction, Process Writing is a constructivist approach to 
writing instruction that Goodman describes as "compatible" with his own (1992, p. 196). Popularized for teachers during in the 1980s, this method is based on the assumption that learning to write is a natural process, and pedagogically, it prioritises student meaning-making over the explicit teaching of technical skills. More recent theories of writing and writing instruction are also constructivist-oriented (for example social-interactive and socio-cultural theories - currently prominent in the academic literature), but it is Process Writing that continues to have the greatest impact on actual classroom practice. ${ }^{20}$ American researchers, Pritchart and Honeycutt (2006) describe it as "the primary paradigm" (p. 276). Although in New Zealand, few teachers would use the term Process Writing to describe their writing programmes, recent surveys of teacher practice indicate that key aspects of Process Writing continue to be widely used (such as writing tasks based on students' personal experiences, and a relatively low proportion of time spent on teaching spelling patterns and rules - see Parr \& Jesson, 2015). ${ }^{21}$

This brings me to the problem of terminology: Process Writing methods are many and varied - definitions have evolved considerably in the academic literature and recommended methods have been interpreted and applied in a variety of ways by classroom teachers. The early approaches of the 1980s were founded in descriptive, non-experimental research. They prioritized student choice and a 'natural' process, which they conceived of as linear and expressed by the formula - draft, write, revise, edit. Student motivation and personal engagement were seen as key pedagogical aims, and students' personal experiences were regularly used as inspiration for writing. Peer and teacher conferences were integral and used to provide writers with authentic audience reactions. Finally, the importance of structured lessons and pre-planned explicit teaching was de-emphasized, even for the teaching of technical skills. In recent years, mostly in the U.S., researchers have applied the findings of empirical

\footnotetext{
${ }^{20}$ Social-interactive and socio-cultural theories dominate the academic literature but offer few practical suggestions for teachers. Process writing, on the other hand, is an approach to research and teaching, which was developed in classrooms and marketed to teachers.
} 
studies to refine and improve these early Process Writing approaches. In the current literature, the writing process is depicted as recursive and complex (reflecting cognitive process models such as that of Flower and Hayes, 1981). Teachers are encouraged to explicitly teach procedural knowledge and strategies, in the context of authentic and meaningful writing tasks, as part of a broader writing program that includes other aspects - such as the explicit teaching of technical skills (see Graham, Harris, \& Santelego, 2015, for a review of empirical writing research which recommends these approaches). While the term Process Writing continues to be used in the U.S. to describe this revised approach, in New Zealand the term still typically refers to the movement of the 1980s.

\section{Constructivist theories as belief systems}

In what follows, constructivism is considered as a belief system, founded in the idealistic goals of its proponents. This is not to imply a lack of sympathy for the goals in question, but to examine the impact of ideology on recommendations for classroom practice.

Pajares (1992), in a review of research on teachers' beliefs, distinguished between beliefs and knowledge: According to Pajares, beliefs are characterized by "existential presumption", "affective and evaluative loading", and "episodic structure” (p. 309).

Existential presumptions are those incontrovertible, personal beliefs people hold about life, including (of particular importance for teachers) beliefs about other people, for example, "girls are nurturing". Affective and evaluative loading is self-explanatory, for example, "adolescents are struggling with hormones and I feel sorry for them". Beliefs have an episodic structure in that they are influenced by personal memories. (Pajares cites research by Goodman [1988] and Calderhead and Robson [1991], which indicate that pre-service teachers hold vivid images from their own time at school, and use these to interpret new information and to guide their teaching practice.) Pajares raises two other important points. First, beliefs do not require consensus and are less open to critical examination than knowledge is. As a result, they are relatively inflexible. Second, belief systems tend to be broadly and poorly defined. This (Pajares 
argues) is because their relevance to factual information may be limited. In contrast, knowledge - which is arrived at through processes of logical reasoning - tends to be narrowly and clearly defined.

Evidently, boundaries between beliefs and knowledge are not straightforward - it is difficult to imagine cognitive knowledge in the absence of affective and evaluative components. Pajares himself acknowledges that his analysis may be an oversimplification. The difference between beliefs and knowledge is in degree and not kind.

\section{Literature Review}

In the following review the development of constructivist theories of writing is described, particularly Process Writing, and also social-interactive and socio-cultural theories. The work of key theorists is examined, in its relevant historical and political contexts, and so the account is presented as a chronology. ${ }^{22}$ The essential beliefs and recommended practices of theorists are described, and are considered for the extent to which they are based on empirical knowledge of writing instruction.

\section{Process Writing: The Precursors}

In a review of the historical contexts for writing research, Nystrand (2006) described the reconceptualization of writing instruction that occurred during the 1960s and 1970s, when approaches emphasizing the study of genre, model texts, rules of usage and principles of style were displaced by process-oriented methods. Two historical factors were key. First, the Vietnam War and resulting student protests, which had a direct and significant impact on US colleges and in particular on the writing programmes at City University New York (CUNY). As Hawkes (2008) documents, Vietnam highlighted racial and educational inequality, as a greater proportion of white students were granted college deferments from the military draft compared to their black counterparts. City University New York became a centre for open

\footnotetext{
${ }^{22}$ Cognitive, empirical research has already been presented in some detail in Chapter Two. In the present chapter it is discussed in only in terms of its influence on other theories.
} 
admissions protests, and in 1970 the college brought in an open admissions policy - five years ahead of schedule. ${ }^{23}$ Student numbers grew rapidly (from 14, 000 to 34, 000 in three years), with many new students lacking the writing skills needed for college. Two CUNY English faculty members - Kenneth Bruffee and Mina Shaughnessey - trialed new methods of instruction for these students, methods that became integral aspects of the process writing approach (Hawkes, 2008).

Bruffee is notable, in particular, as the founder of cooperative learning and as a commited social constructivist. At CUNY he established a peer-tutoring centre, staffed entirely by students and located near the subway entrance to campus. This was an attempt to overcome the educational limitations of the traditional lecture structure. Significantly, it was also an attempt to redefine the roles of teacher and student, and was (as Bruffee himself was happy to acknowledge) an overtly political act. "This was a period", wrote Bruffee, "in which young people were experimenting with restructuring American Society and American selves. Restructuring education had to be a part of that" (Bruffee, letter, cited by Hawkes, p. 28).

Shaughnessey was employed at CUNY from 1965 until her death in 1978. Her major contribution to the literature was the monograph Errors and Expectations (1977), in which she analyses errors taken from 4, 000 struggling college writers, offering explanations for their confusions as well as suggestions for further teaching. As Nystrand asserts, “Shaughnessey's was a strong voice". Indeed, Errors and Expectations is a visionary work - idealistic, yet practical. While her work is widely cited in discussions of the development of Process Writing (see Nystrand, 2006; Pritchart \& Honeycutt, 2006) it seems that her more challenging ideas were largely ignored by later advocates.

Shaughnessey acknowledged that her focus on errors was "certain to raise questions both pedagogical and political" (p. 6). She observes:

\footnotetext{
${ }^{23}$ As Hawkes explains, the war and open admissions were related issues, as most of those drafted to serve were black or Puerto Rican - lacking college deferments.
} 
Some [teachers] rebel against the idea of error itself. All linguistic forms, they argue, are finally arbitrary [...] When one considers the damage that has been done to students in the name of correct writing, this effort to redefine error [...] is understandable. Doubtless it is part of a much vaster thrust within this society not only to reduce penalties for being culturally different but to be enriched by that diversity. (p. 9)

In opposition to such trends, Shaughnessey asserted that students want to know the patterns of the written code, so as to be able to "move across the territory of language as if they had a map and not as if they were being forced to make their way across a minefield" (p. 10). She stressed the importance of a writer's relationship to his or her audience, describing errors as "unintentional and unprofitable intrusions upon the consciousness of the reader" (p. 12). She presented a political argument too:

[A] person who does not control the dominant code in a society that generates more writing than any society in history is likely to be pitched against more obstacles than are apparent to those who have mastered that code (p. 14)

In her following chapters, Shaughnessey dealt with handwriting and punctuation, syntax, common errors, spelling, vocabulary, overall organization, and expectations. In each chapter, an analysis of errors is followed by detailed recommendations for teaching, often including an outline of key teaching points and student practice activities. While Shaughnessey herself collected quantitative data on her students' progress (marking before and after writing samples using a analytic rubric), her methodology and results are not a major focus of Errors and Expectations. But her conclusions (and consequent advice) anticipated the findings of much more recent empirical work. In her discussion of handwriting as "fundamental to other writing skills", for example, she makes a point central to the description of Berninger et al. (2002) of the beginning writer's process. Her recommendation of sentence-combining as a way to teach grammatical knowledge is equally prescient, as evinced by more recent reviews of empirical work (see Myhill \& Watson, 2014; Wyse \& Torgerson, 2017). For spelling, Shaugnessey 
describes a needs-based programme, involving an analysis of errors and then the teaching of whatever strategies are required, including phonemic analysis, graphemic and orthographic knowledge, self-awareness and the ability to look and check (see Brann, 2001; or McNeill \& Kirk, 2013 for similar advice). Of particular interest to the present research is her discussion of how to teach syntactically correct sentences, a process which she describes in three steps: "Getting the thought...Getting the thought down...readying the written statement for other eyes" (pp. 81-82). Finally, it is notable that her concluding chapter is entirely dedicated to teachers' expectations, with high expectations now widely acknowledged as a hallmark of the most effective teachers (see, for example, Pressley, Wharton-McDonald, Allington, Collins Block, Morrow, Tracey, Baker, Brooks, Cronin, Nelson, \& Woo, 2009).

While Shaughnessey's interest in error and her structured approaches to teaching skills were largely ignored, some of her other recommendations are certainly recognizable as elements of early Process Writing. These include the use of personal-experience writing for mileage and for handwriting practice; teaching writing as a process, in which "meaning is crafted, stage by stage" (p. 81); teacher-student conferences - which are to be held throughout the composing process (not just at the end); the use of peer conferencing; and writing across the curriculum as a way to provide students with authentic writing tasks. Anticipating even later, social-interactive, theories of writing, Shaughnessey describes writing as "a social act" (being the first person to do this, according to Nystrand, 2006).

Whatever theoretical orientation we wish to ascribe to Shaughnessey, the instructional approach she advocates for is more balanced and firmly grounded in student needs, than the simplified version of Process Writing adopted by later advocates.

A second historical context that had a major impact on approaches to writing instruction (again, identified by Nystrand) was the 'cognitive revolution' of the 1950s and 1960s, during which time Chomsky's ideas about language development informed many new research programmes at Harvard and MIT, and influenced scholars in schools of psychology, linguistics, 
the arts and education. A number of prominent writing scholars worked at Harvard during this period, including Janet Emig, James Moffett and James Britton, all of whom exerted significant influence on writing research and teaching approaches and are regularly cited as major contributors to the development of Process Writing (for example, Nystrand, 2006).

Emig (1971) reports on the composing processes of eight Chicago students. Emig gathered her data using student think-alouds during composing, and student interviews. Emig deduced that there are two possible modes of composing - reflexive and extensive - "processes of different lengths and with different clustering of components" (p. 91). The reflexive mode is described as the more complex of the two. It is generally used in students' self-chosen writing activities, and involves writing in a personal and exploratory manner, with more time spent on "pre-writing" (gathering and formulating ideas), and on revision and reformulation. In contrast, extensive writing generally occurs as a "school-sponsored" activity, with student attitudes to this writing described as "detached and reportorial" (p. 91). Emig is highly critical of traditional rhetoric and composition handbooks, which typically convey the writing process as wholly rational, and which describe components of the process as extrinsic to the writer. She is equally critical of schools - with school writing described as "a limited, and limiting, experience" (p. 97) - and of teachers, who she perceived as lacking knowledge of literature and the writing process. Significantly, she also made her political views clear. Her final paragraph reads:

American high schools and colleges must seriously and immediately consider that the teacher-centred presentation of composition, like the teacher-centred presentation of almost every other segment of curriculum, is pedagogically, developmentally, and politically an anachronism. (p. 100)

Emig's research - with a sample of only eight, all performing in a context established by her, with no control group - is typical of research purporting to support a constructivist position (see also, for example, Dyson, 1999; Goodman, 1992; Graves, 2003). 
Moffett (1981) describes a writing programme that he developed for "experimental purposes" and modified in response to the feedback of other teachers. The programme presents a hierarchy of writing tasks of (apparently) increasing difficulty. It includes three broad types of writing assignment: The most basic of these is described as "revising inner speech" (or "precomposition note-taking"), with suggested tasks including a sensory monologue in which the writer sits in nature and records in a short time all of the sights and sounds they experience. The second, more advanced, kind of writing is described as "dialogues leading to monologues", with tasks including inventing or reproducing a conversation between two people. The third, most advanced, kind of writing involves "narratives of increasing distance between author and subject" in which the student is asked to draw ideas from personal experience and then to abstract these in increasingly sophisticated ways. Moffett emphasized the significance of a writer's awareness of audience in shaping their writing process. He attempted to promote this awareness through teacher conferencing and peer work. He recommended a lesson structure that includes small group work and feedback from peers, and teacher conferencing in which the teacher responds "naturally", as a reader, rather than as a critic.

Moffett's work is entirely based on assumptions about how writing develops - it is not supported by any empirical work - although he presents these ideas with authority and conviction. One can see how less critical readers may be inclined to accept them without question.

Moffett is far from alone amongst writing theorists in eschewing an empirical basis for his work. For example, Britton (1975) was very concerned to distance himself from empirical researchers, describing (disparagingly) their "severely methodological or pedagogical intention" (p.7). Despite his purported lack of interest in empirical research, Britton in fact drew on a large data source, analyzing 2,122 student writing samples, and following the progress of 
students over a four-year period. ${ }^{24} \mathrm{He}$ then created a set of "multidimensional" writing categories - a matrix of possible text types depending on particular audiences and "functions" either "expressive", "poetic" or "transactional". This conception of writing development was informed by early speech research (and in particular the work of Sapir, Vygotsky and Piaget) Britton describes writing as "written down monologues". Expressive writing (the term is taken directly from research on speech) is seen as the base from which other writing develops. It is described as an utterance "that stays close to the speaker" (p. 55), and includes personal diary entries, first drafts and personal letters. Britton recommends that beginning writers start with expressive writing as this allows them to draw on their knowledge of speech. Transactional writing "to get things done"(p. 88) and poetic writing "that uses language as an art medium" (p. 90), are considered more complex:

The more fully an utterance meets the demands of some kind of participation in the world's affairs, the nearer it will approach the transactional end of the scale: the more fully it satisfies the spectator-role demands, the nearer it will move to the poetic end. The move in both cases is from an intimate to a more public audience. (p. 83)

Clearly, the work of Emig, Britton and Moffett was formative in the development of Process Writing. Fundamentally the Process Writing approach derives from a (defining) focus on students' experiences of the writing process, but other tendencies of these early theorists also persisted: First, their models of writing development are based on non-experimental approaches to research, and stress similarities between speech and writing; (ii) they recommended personal experience writing for beginning writers, and de-emphasized genre and correctness; (iii) they identified a writer's awareness of his or her audience as key - for them this is the element which shapes the writing process.

\footnotetext{
${ }^{24}$ This method could be described as 'empirical' in a sense, though it is not the kind of work that can be generalized, as there is no test of his (implicit) theory that expressive writing is closer to speech and allows learners to draw on their knowledge of speech.
} 
Most significantly, the work of these theorists - with an exception, in one important respect, of Shaughnessey, laid the foundations for Process Writing as an idealistic belief-based movement. Their goals were explicitly articulated but emotively expressed, and they quite emphatically rejected empirical methods. It could be argued, moreover, that their emphasis on "expression" and the personal is reflective of a certain naïve (perhaps even mystical) conception of writing - and one that lacks logical support. Why should it be any easier for a child to write about a personal experience than to retell a traditional tale, or even to report the results of a science experiment? In fact, personal experience writing, lacking the supportive structure of genre and involving the description of abstract thoughts and emotions, may present a far greater challenge (See Stotsky, 1995, for a critique of the emphasis on "personal” writing by Process Writing advocates).

It is important to note that the influence of Moffett and Britton, in particular, was not confined to Process Writing. Nystrand identifies both theorists as key participants in the historic Anglo-American Dartmouth seminar of 1966, which marked a turning point in writing curriculum design. Dartmouth seminar participants critiqued the contemporary, which, they argued, led to formulaic school writing. They proposed an alternative conception of writing and writing instruction, emphasizing "personal growth" (Dixon, 1967, cited by Nystrand, p. 12). Stotsky describes Moffett and Britton as "[t]he two most influential theorists with respect to the design of developmental writing programs in the past several decades" (1995, p. 762) though, she asserts, "there seems to be no empirical evidence to support the validity of their principles" (p. 763). It is easy to identify the influence of Britton in particular on the New Zealand curricula of 1993 and 2007 (still in use). In the 1993 version, we find types of writing described in terms of their "functions" - either "expressive", "poetic" or "transactional", exactly duplicating Britton's own terminology (and, in fact, his definitions). In the 2007 document, these categories are gone, though Britton's influence is still marked. There is a strong emphasis on the links between spoken and written language, with speaking and writing combined in one "strand", and the first achievement objective at all levels requires students to make connections between 
speech and writing (for example, at level 3, students will use "a developing understanding of the connections between oral, written and visual language when creating texts", NZC, 2007). Additionally, this document prioritizes the development of students' awareness of "purposes and audiences" - this is the second achievement objective at all levels.

The fact that these ideas, so central in the development of Process Writing, have been adopted in the design of the New Zealand curriculum is clearly relevant to my first research question. It lends significant weight to Tunmer and Chapman's (2015) claim that the Ministry of Education is committed to what might be described as constructivist principles. More detailed discussion of this point is provided in the review of Ministry publications - Chapter Five.

\section{Process Writing: the 1980s}

During the 1970s and 1980s, researchers including Don Murray, Donald Graves, Lucy Calkins and Nancy Atwell trialed the (then new) process approaches with teachers in New York and the San Francisco Bay Area. Their findings and recommendations were widely disseminated, largely through handbooks such as Graves' Writing: Teachers and Children at Work, 2003; and Calkins' The Art of Teaching Writing, (1994) ${ }^{25}$ and also as an element of the influential Whole Language movement (see Goodman, 1992). In the following paragraphs the literature from this group of researchers is examined in some detail. Familiar themes re-emerge, including (i) reliance on anecdotal research; (ii) writing and writing development described in simplistic terms, and as 'natural' processes; (iii) recommendations that students choose their own topics - something which became fused (unnecessarily) with the use of personal experiences as inspiration for writing; and (iv) a de-emphasis of explicit teaching of writing skills. The political arguments, emotion and subjective opinion suggestive of Pajares' distinction of belief from knowledge are prominent.

\footnotetext{
${ }^{25}$ For further discussion which links these theorists and examines their combined influence on the Process Writing movement see Pritchart \& Honeycutt, 2006; and Simmerman, Harward, Pierce, Peterson, Morrison, Korth, Billen, \& Shumwey, 2012.
} 
(i) Anecdotal 'evidence'. A number of Process Writing advocates assert

(somewhat condescendingly) that anecdotes are an appropriate basis for educational research because classroom teachers understand them (see, for example, Atwell, 1982). Goodman (1992) takes this point further, actually portraying the use of class-based, descriptive methods as being driven by teachers themselves. He argues for their use in strong terms, describing "the struggle" against empirical work and "the illusion of science" (p. 191). ${ }^{26}$ He writes:

Perhaps the single most important factor in the development of whole language in the United States is the rebellion of professional teachers against the technology which does not permit them to use their knowledge. (p. 191)

For Goodman, a descriptive approach to research is an idealistic decision. He associates the use of what he calls "dehumanizing" standardized tests and the articulation of implicitly antiegalitarian "skills hierarchies" with a right-wing political agenda, "making education a commodity to be sold in a competitive marketplace [and] perpetuating the status quo" (pp. 190192).

(ii) As in the work of Emig, Britton and Moffett, Process Writing literature from the 1980s conceives of writing development as 'natural', born out of a desire to communicate, and similar to the development of speech (see Graves, 1983; Murray, 1973). Calkins invokes research on early speech:

We can invite our children inside the world of written language if we take our cue from how babies learn to talk. As Courtenay Cazden emphasizes, "oral language development takes place on a non-sequenced, whole-task basis'" (Cazden, 1972, p. 138, cited by Calkins, 1986, p. 60).

\footnotetext{
${ }^{26}$ Significantly, in this article Goodman describes Whole Language as an inclusive philosophy of education, and identifies Process Writing as compatible with it. He also describes the New Zealand education system (going back to the 1930s) as "progressive [...] The single national school system was child centred, and they were receptive to a view of reading as holistic and meaning-seeking" (p. 194).
} 
For Calkins, writing too is a "natural, joyful human activity" (p. 64). In a similar spirit, Murray (1973) asserts that we use language "not so much to report [...] as to discover" (p. 1235). He defines writing as an art "and art is profound play"(p. 1235). Interestingly, both Murray and Calkins associate writing with primitive urges - Murray explicitly states “Writing satisfies man’s primitive hunger to communicate" (p. 1235), while Calkins describes classroom "rituals" and the "growth" of ideas (p. 39) - metaphorical language which summons images of a preindustrial world. For Graves, writing is a craft, with the writer working "on the edge of consciousness" looking for "differences in the material, the surprise, the explosion that will set him aback" (2003, p. 234). Reflecting this emphasis on creativity and discovery, he recommends that first drafts should be re-worked using crossing out - no erasing - with conventions considered only in the final stages of writing. While these emotive descriptions certainly capture the depth of thinking and the excitement writing opportunities sometimes bring, they are also inaccurate - failing to acknowledge, for example, the role of thoughtful planning, or any of the constraints of the written code.

(iii) Student choice of topic is emphasized for reasons of student motivation, and as an essential part of a mature writer's process (see Graves, 2003; Murray, 1973). It also reflects a political position - Atwell describes it as a "democratic" act, which represents "a redistribution of power" (1985, p. 36). However valid the reasons for allowing students to choose their topics, this practice became fused (unnecessarily) with encouraging students to use personal experiences as inspiration. This fusion is clearly evident in Murray's 1973 essay Why Teach Writing - And How, in which he dissuades teachers from setting class assignments, as they "deny the individual his search for meaning". ${ }^{27}$ This search, it seems, will be concerned with the real and the personal. Murray defines writing as "an ethical act, because the single most important quality in writing is honesty" and as "a process of self-discovery" (1973, p. 1237).

\footnotetext{
${ }^{27}$ Murray’s conferencing system, devised originally for college-level students, was adapted by Graves as a key part of Process Writing in primary schools (as reported by Stotsky, 1995).
} 
The question of what constitutes appropriate or interesting personal experience writing is not a simple one, and yet we find it largely unexamined in the Process Writing literature. Calkins, in her 1986 handbook The Art of Teaching Writing, asserts, "Youngsters [...] will care about writing when it is personal and interpersonal" (p. 14). She describes some personal and (apparently meaningful) writing experiences - a six-year old girl writing about her little brother; a fifteen-year old boy writing about the class rabbit giving birth, and later about his pregnant cousin. She goes on to recount her own experience developing an idea: "I begin by writing about my son's frayed blanket and end up realizing I'm suffering from empty nest syndrome" (p. 8). Calkins' proclivity for a certain kind of "personal" topic is made more obvious when she comments, disparagingly, on a tendency for some children to write about "Ninjas and Spidermen [...] topics someone else has already invented" (p. 119). Calkins apparently fails to see that her own interests have also, already been anticipated (if not invented) by someone else (the term empty-nest syndrome), or to recognize just how exciting and meaningful super-heroes are to certain children. Her comments highlight the potential pitfalls of subjective personal beliefs when it comes to educational decision-making, perhaps especially when considered in the context of a primary school system predominantly staffed by women, with much lower rates of writing achievement amongst boys.

The Process Writing approach does not encourage pre-determined teaching objectives. As Calkins puts it, Process Writing teachers "teach into [...] students' intentions. First our students are engaged in their own important work. Then we ask ourselves, 'What is the one thing I can suggest or demonstrate that might help the most?"' (p. 194). Graves expresses a similar sentiment: "In each craft, teaching and writing, there is a careful, unhurried approach to working with both text and child. The teacher as craftsperson waits, listens, looks for ways to help the child control the writing" (p. 9). In her twelfth chapter: "Don't be afraid to teach", Calkins discusses how mini-lessons may be used for what she sees as more "formal" teaching. She suggests a range of possible strategies, the provision of opportunities for discussion about the writing process ("writerly conversations"); the teaching of procedures such as peer 
conferencing; to introduce to children the power of print (she describes a lesson in which the teacher labels classroom objects); the teaching of how to listen for sounds in words; and the exploration of literature as inspiration for student writing. Graves includes a chapter: "Help children learn the skills they need", though this is concerned mainly with observations regarding children's writing habits and development. Explicit, practical advice is limited as Graves continually returns to conferencing and questioning as main teaching strategies. For example, for teaching revision, we find a list of questions: "What did you want to show?"; "What part did you like best?"; and “What will interest your readers most?” (p. 158).

(iv) The teaching of technical skills (spelling and handwriting) has been controversial since the beginning of Process Writing (see Matsuda, 2003, p. 69). Graves acknowledges their significance, and the demands they make on beginning writers' conscious attention. However, he makes few suggestions for teaching them. Regarding handwriting, he states: "[I]f children have enough writing time, and are in control of their topics, their handwriting improves [...] When children have a well-chosen topic, their urge to express so dominates the activity that they lose track of the conscious aspect of handwriting to focus more on the message" (p. 178). He recalls including two children in a National Institute of Education Study, specifically because they demonstrated handwriting difficulties, but claims that he stopped studying the handwriting variables early on in the study as these children (now motivated writers) forgot about their difficulties. This positive result would have been more convincing had it been captured in data. It is very unclear what Graves means when he uses the word "forgot". Did these children no longer think about their difficulties or did they overcome them? As we know from scientifically-based research, handwriting can only be used unconsciously after it has been practiced to automaticity. Until such time, it may place significant constraints on the beginning writer's working memory, limiting the cognitive resources available for allocation to 'higher order' processes such as composition (see Berninger 1999, and McCutcheon, 1996 for further discussion). 
Graves' advice for spelling teaching is similar: We should teach children to spell "to communicate" and allow invented spellings, shifting the emphasis from correctness to the construction of meaning. He asserts: "Proficiency in reading, as well as continued practice in writing [...] all aid the child in moving toward regularized spellings" (p. 188). If regularized spelling is not learnt in this way, Graves reassures:

There are many persons in adult education courses who have found that spelling need be no barrier to excellent writing. The difference is they have put spelling in its place in the composing process, and have found ways to get help with difficult words, have learned their blind spots on spelling words, and have found some very good editors or friends to help them. (p. 188)

Calkins ignores the teaching of handwriting completely, except for urging teachers to "separate composition from transcription" (p. 292). She describes her own approach during the writing lesson: "I keep an eye out for the child who writes a letter, scrutinizes it to be certain it is perfectly rounded, then erases it and tries again. 'It is important for you to worry about what you are saying now, 'I tell this youngster, 'let the penmanship go'” (p. 292). For spelling, she asserts: "We can trust that children will pick up sound-symbol correspondences if we allow them to be readers and writers from the first day of school on, immersed in real experiences with sounds and letters" (p. 72). Calkins does include three pages of practical advice on how to run a needs-based spelling programme (see pages 306-309), although, in a 550-page handbook, this aspect of teaching writing is clearly not prioritized.

Aspects of the Process Writing lesson structure, designed to support a process of student topic choice, drafting, feedback and revision, are well defined and could be considered a useful starting point for teachers who want to provide their students with extended opportunities to write, and to practice peer and self-evaluation. Recent empirical research has demonstrated that this structure can be effective when used as part of a balanced program (one that also involves explicit teaching and the development of students' technical skills). As to the 
details of this lesson structure, Graves and Calkins both describe a lesson which begins with some teacher modeling, using thinking aloud to “make explicit what children ordinarily can't see" (Graves, p. 45), including choosing a topic, gathering and organizing ideas, and experiencing surprise and discovery as these ideas are refined and ordered. What follows is student-writing time, with students working on individualized tasks and at varying stages in the writing process (some drafting, some editing or publishing). Writing workshops are recommended, as a way for students to share their work in progress and ask their peers for help. Teacher conferencing and "mini-lessons" are regarded as key, with teachers encouraged to ask questions of the writers, modeling the type of internal processing that they may adopt as mature writers.

The question now arises as to which frameworks other than Process Writing may influence current teachers' beliefs. Two strands of research have been prominent in the academic literature, though their influence in schools may be negligible. The first strand to consider is empirical research, including experimental testing of cognitive process models and experimental writing intervention research; the second is (like Process writing), constructivistoriented. It provides new theories of writing as a social process, including social-interactive and socio-cultural models.

\section{Empirical writing research}

During the 1980s - partly as a consequence of the Process Writing movement and the renewed interest in writing instruction that it provoked, and partly due to increases in US federal research funding - a number of empirical studies into the cognitive processes involved in writing were undertaken. ${ }^{28}$ Since the most influential of these studies have been discussed in Chapter Two, the present survey will be brief. They include the seminal cognitive process model

\footnotetext{
${ }^{28}$ Nystrand (2006) documents how this new strand of cognitive research came about partly due to the renewed interest in writing that the Process Writing movement provoked, and also as a result of increases in federal funding for research in the US during the 1970s and 1980s. An important figure here is Francis Keppel, previously dean of Harvard's Graduate school of education, who became the Commissioner of Education in 1963, serving both the Kennedy and Johnson administrations. He argued for education reform based on rigorous empirical research.
} 
of Flower and Hayes (1981), which was developed using a 'think-aloud' protocol (in which adult writers were asked to speak their thoughts while composing). ${ }^{29}$ This model identifies components of the writing process, including the writer's long-term memory, the writing task, and writing processes (planning, translating and reviewing), all of which are coordinated by the writing strategist, or 'monitor'. Flower and Hayes' two key findings were that (i) writers continually set sub-goals throughout composition; (ii) the writing processes interact recursively (rather than in a linear way). A second important writing process model (also developed using the think-aloud protocol) is that of Bereiter and Scardamalia (1987), which describes the different processes of skilled and unskilled writers. More skilled writers were found to be able to change and clarify their own thinking on a topic during (and as a result of) writing. Other seminal work includes Zimmerman and Risemburg's (1997) cyclical phase model - developed through cognitive modeling experiments as well as structured interviews for students and teachers - which explains the function of self-regulation in the writing process. According to this model, skilled writers employ proactive planning strategies, leading to more effective selfevaluation and increased motivation. A number of other experimental studies have investigated the role of transcription skills on beginning writers' processes, and these have informed Berninger's (2002) "Simple view of Writing" which emphasizes transcription skills along with self-regulation processes as two elements key to text generation.

Experimental work continues to proliferate, providing detailed information about effective teaching strategies. A useful meta-analysis of research-based writing practices is provided in the study of Graham, Harris and Santelego (2015). The authors synthesized the findings of true and quasi-experiments, single-subject designs and qualitative studies of exemplary teachers, to identify practices likely to raise student achievement. This article, reflecting its US context, defines achievement in terms of meeting Common Core State Standards.

${ }^{29}$ There are two obvious flaws to this 'think-aloud' method: (i) only conscious processes can be probed; (ii) the think-aloud process is itself cognitively demanding and may interfere with the writing process. 
Interestingly, Graham, Harris and Santelego suggest that teachers implement a "process approach" as one aspect of a balanced writing programme. They identify benefits such as (i) teachers working to create a supportive and motivating environment for students, and providing extended opportunities to write for real audiences and authentic purposes; (ii) the use of routines in which students are asked to plan, write and revise their work, and in which personal responsibility is encouraged; (iii) high levels of peer collaboration; and (iv) teachers providing regular, individualized assistance and feedback. However six recommendations diverge from the traditional Process Writing model: These are (i) that goal setting be key, with the most useful goals described as "clear, specific and reasonably challenging"(p. 510); (ii) that students should have access to word processors, allowing them to produce writing which is legible, and can easily be deleted, rewritten or moved; (iii) that teachers should teach all foundational writing skills explicitly, including transcription skills (handwriting, spelling and typing) and sentence-construction skills. (The best method for teaching sentence construction, according to Graham et al, is sentence combining, a method in which teachers model combining simple sentences into complex ones, and students then practice); (iv) that teachers aim to increase students' knowledge about writing, focusing on content and genre knowledge (providing models of exemplary writing is suggested), as well as vocabulary knowledge; (v) that writing strategies be taught; ${ }^{30}$ and (vi) to use writing as a tool to support students' learning across the curriculum - meaning that they use content learned in other subject areas as topics for writing.

\section{Theories of writing as a social process}

New conceptions of writing as a social process also began to gain traction during the 1980s (see Matsuda, 2003, for an account of process and "post-process" movements). These represent

\footnotetext{
30 These range from general strategies, such as brainstorming, which can be applied across genres, to genrespecific ones, according to which, for example, when planning a story, students are taught to think about characters, the setting and the story problem, as well as self-regulation processes such as goal setting and selfevaluation. Teachers are encouraged to explain the rationale for the use of any given strategy, model it, and provide opportunities for guided practice.
} 
writing as an activity that is shaped in conformity with societal agendas (see Bazerman, 2006, for further discussion). Thus, they are even more politically oriented than Process Writing: As Berlin (1998) explains, for early "expressionistic" theorists of the 1970s (i.e., early process writing theorists), a political goal was the democratization of society, with writing seen as a means of self-expression and empowerment. Later, social-epistemic theorists went further. For them, ideology needed to be "placed at the centre of teaching and learning" on the grounds that "the liberated consciousness of students is the only educational objective worth considering" (Berlin, 1988, p. 492).

One early example of a social writing theory is the 'transactional' view of Harste, Woodward and Burke (1984). For these theorists, literacy learning is a "socio-psycholinguistic process", and meaning "resides neither in the environment nor totally in the head of the language learner but rather is the result of on-going sign interpretation" (p. 93). This echoes social constructivism in its definition of knowledge as "theory, not fact" (p. 86). ${ }^{31}$ Harste et al. are suspicious of experimental approaches on the grounds that the control of components in a study may "distort the relationships which occur, and in the process alter the event" (p. 88). Learners are described as active, always striving to make meaning. Educators, for their part, are dissuaded from attempting to control the learning environment, or to focus on particular outcomes, because "the same surface experience for two different language users will result in two different events and two different experiences" (p. 104).

The 'transactional' theory was followed in 1989 by Nystrand's Social-Interactive Model of Writing. Nystrand argues that cognitive models (such as that of Flower and Hayes) fail to explain the workings of the (metaphorical) writing monitor - a major omission. He proposes that the workings of this monitor are strongly influenced by a writer's awareness of his or her audience, and describes writing as "an episode of interaction" (p. 70). According to Nystrand's model, writers interact with their readers in three ways. First, they initiate a shared frame of

\footnotetext{
${ }^{31}$ The authors make explicit reference to Kuhn's “theoretical paradigms” (p. 86).
} 
reference. Second, they sustain the discourse, testing the information in terms of their own expressive intentions and the likelihood that a future reader will understand them. Third, they deal with any ambiguities through clarification of genre, topic or localized "discourse comments" (p. 81).

While conceptions of writing as a social process are interesting to contemplate, it is somewhat difficult to imagine how they could impact on instructional practices. Jesson and Cockle (2016) outline their socio-cultural view of writing as "a dialogic act", which "involves negotiation, internalization and possible appropriation or transformation of available social and cultural meanings"(p. 605). They argue that, in order to engage in this process, learners from diverse cultural backgrounds need to perceive the relevance of their existing cultural expertise. The study proper was based in two multicultural Auckland schools seeking to achieve better outcomes for their students in writing, and was guided by the overarching question "What are the opportunities for students to build on existing expertise in Year 4-6 classrooms?" (p. 606). It aimed to identify whether (and how) students' prior social and cultural knowledge was brought into focus "or framed as relevant" (p. 606). Research methods were descriptive (in the constructivist tradition), comprising classroom observations and student interviews, with no achievement measures, although the participating schools had already been identified as having large numbers of students achieving at below average levels. Observations revealed that lessons consistently followed a structure of teacher-led discussion (generally taking up a significant proportion of time - 53\% across all recorded blocks), followed by student practice. Analysis of the whole class discussions, as well as student interview comments, indicated that teachers sought to incorporate prior knowledge in the form of shared experiences, or prior learning, but that there were few opportunities for students to draw on their out-of-school experiences. The authors conclude that the typical lesson pattern "constrains opportunities for a dialogic stance in writing lessons" and suggest that teachers work to frame out of school experiences of texts (such as oral story-telling) as relevant to school writing too. These ideas are challenging and interesting ones - they surely warrant further consideration. But they remain, as yet, untested. 


\section{Conclusion}

Inspired by hope for a fairer society, constructivist theories of writing have taken on many of the characteristics of belief systems. They resonate with strongly felt emotion, and they are selfsustaining. However, their proponents have largely failed to respond to empirical research, and they have concomitantly failed to improve student achievement in writing. 
CHAPTER FOUR: WRITING IN NEW ZEALAND PEDAGOGY: THE CURRENT CONSENSUS

\section{Introduction: The Ministry's Commitment to Constructivism}

Standard approaches to the teaching of writing in New Zealand as described by relevant publications from the Ministry of Education are based on a constructivist philosophy and are driven by what might be described as social values. ${ }^{32} \mathrm{~A}$ key concept is that of "child-centred" learning which arose out of the work of progressive theorists in the early twentieth century (e.g., Dewey, 1916), who envisaged classrooms as model (i.e., ideal) societies. In this model, children engage in learning experiences of relevance to their own lives, and teachers nurture a culture of democracy. This is no doubt an exciting vision, and its wide appeal in the twentieth century - during which two world wars highlighted the dangers of authoritarianism - is not surprising. An article by Romanish, 1995, illustrates this point:

The axis powers in WWII spent enormous sums of money and vast energies developing the minds of their young. Additionally, before the collapse of the Soviet Union, they boasted of 'eradicating illiteracy' as part of their revolution. Surely the tyrants lacked any fear of a literate population. It is clear that literacy for democratic living requires a form and character that differ dramatically from the often popularized notion of basic reading and writing skills of the kind required for employment applications. (p. 17)

Evidently, it is critically important to consider the political implications of education, and childcentred learning may have potential for developing greater agency and independence in students.

Despite its potential, however, certain tensions are implicit in such an approach. ${ }^{33}$ The first of these relates to curriculum. If students are to determine what they learn, how can

\footnotetext{
${ }^{32}$ Chapter One is dedicated to a discussion of constructivism, and Chapter Three describes constructivist approaches for the teaching of writing - including whole language, process writing and socio-cultural approaches.

${ }^{33}$ Significantly, early theorists such as Dewey and Harold Rugg themselves acknowledged these tensions. See Palmer (2001) for a discussion.
} 
educators ensure that fundamental literacy skills will be covered? Literacy involves the learning of a code, which is not necessarily a particularly creative activity in itself, and as such is unlikely to take place in the context of authentic problem-solving tasks. The second tension arises when one considers the role of the teacher. While inclusivity and respect for students should be a priority in all classrooms (for ethical, as well as educational reasons), teachers of young children possess far more advanced literacy skills than their students. In order for these teachers to be effective, they require some knowledge of key learning progressions and how to teach to them. Unfortunately, as constructivists and whole-language advocates have embraced child-centred learning, they have failed to address these challenges. Instead, we find that the issue of skills has been confused by redefinitions of the term literacy, through an emphasis on its creative (rather than technical) functions. Additionally, the key logical progressions that must be addressed (if students are to move from emergent to fluent reading and writing) have been denied, with the idea of "multiple pathways to literacy" prominent. The concept of multi-literacies has been adopted from New Literacy Studies, a school of thought which emerged from the New London Group during the mid 1990s. This group called attention to the impacts that multilingualism and technology have had on communication, and argued for the critical framing of literacy instruction in order to begin to address the issues at stake (see Chapter One for some more detailed discussion of New Literacies).

An example of such a redefinition of literacy is to be found in a Ministry-commissioned report into literacy and e-learning (McDowell, 2010), in which literacy is defined as,

[T] he capacity to learn and transform discourses [...] the ways particular groups of people (for example, certain sorts of lawyers, women, families, cultural groups, and so forth) behave, interact, value, think, believe, speak, (and often) read and write. (p. 6) In this reconceptualization of literacy learning, proponents of broadly constructivist approaches have ignored findings of empirical research that indicate that certain key skills must be mastered early on in order for children to become literate and that explicit teaching of these 
skills is essential. ${ }^{34}$ They attempt to discredit these findings by attacking the validity of the scientific method itself. A notable example of this occurs in the writing of the celebrated educationalist, Marie Clay. Clay, a committed constructivist, writes:

Controlled experimental studies of groups have tended to report that alphabetic, phonological, and orthographic stages in letter learning seem to occur sequentially. Average scores give rise to stage-wise descriptions of progress; the design of the research determines the outcome description. (1998, p. 134)

Clay's own research is concerned with qualitative and descriptive methods rather than experimental work.

The rhetoric of some whole language proponents further complicates the issue: The terms child-centred and whole language connote nurture and holism respectively - the positive values with which they are intended to be associated. Connotations of freedom and democracy in the political sphere are also common. For example, whole language is often referred to as a "grassroots movement" (see Goodman, 1992; Harris, 1993), conjuring images of political courage and authenticity. Even more worrying is when distasteful metaphors of centralized power and silenced populations are invoked to justify whole language methods against the alternatives. Examples of this are to be found in Harris (1993), in which she describes the whole language classroom as follows: “Teachers and students take power [...] whole-language classrooms are not silent [...] the teacher's desk is not the center of the room" (p. 48-49, italics added). These statements defy common sense. Silence is often helpful to learners, such as when they are concentrating on their writing. ${ }^{35}$ What is more, though I have never seen a teacher's desk positioned in the middle of a classroom, a teacher's physical presence in the centre of a room may allow him or her to observe and respond to the needs of many students.

\footnotetext{
${ }^{34}$ See Chapter Two of this thesis for a summary of empirical findings about the teaching of writing. 35 This is not to say that classrooms should always be silent - talk, movement and music are also essential. My objection to Harris's reference to silence is that she uses it to invoke images of political dictatorships and therefore prevents objective consideration of its benefits for certain activities.
} 
A second problem with the vocabulary of much of the constructivist literature is its dependence on jargon, designed to impress and persuade, though it is fundamentally unhelpful to teachers and those other professionals who may be concerned with how the philosophical arguments could be practically applied in schools and classrooms. An excerpt from McNaughton's (1999) chapter in Stirring the Waters: The Influence of Marie Clay, is heavily laden with Latinate abstractions:

For Clay (1991), the explanation [of children's literacy acquisition] is located in children's strategic invention and construction, as channeled by specific forms of teaching. It blends cognitive developmental and constructivist theorizing with a focus on the dynamic properties of instructional conditions. Similarly, contemporary sociocultural or coconstructivist theorizing describes children's development in terms of expertise in activities that contribute to family and community literacy practices. (p. 5)

The Ministry handbooks are a case in point. While one must commend the Ministry's commitment to the values of democracy and diversity, under threat as they are in what seems to be an increasingly intolerant world, these handbooks fail to address the learning process realistically - almost as if adherence to their social values is all that counts.

\section{The Reading Example}

Patel (2010) has investigated the Ministry's commitment to constructivism in relation to reading instruction, as expressed in Effective Literacy Practice in Years 1 to 4 (Ministry of Education, 2003). Her analysis offers a template for my own discussion, as it contrasts the Ministry's ideologically-driven advice with the findings of empirical studies. In her article, Reading at Risk: Why Effective literacy Practice is not Effective (2010), Patel provides a comprehensive survey of recent empirical research which validates the explicit and systematic teaching of phonemic awareness, the alphabetic principal, automatic and fluent word recognition, vocabulary knowledge, and comprehension strategies, and compares the relevant findings with advice in the handbook. She makes three main criticisms, citing over 50 studies, 
all, as she explains, based on scientific research, using "rigorous, systematic and objective methodologies" (Reyna, 2004, p. 47; in Patel p. 55):

(i) that the authors of Effective Literacy Practice do not provide sufficient research evidence for the approaches they recommend;

(ii) that they omit "vast amounts of research" (p. 61) indicating that the explicit teaching of specific skills is critical for effective reading teaching;

(iii) that they encourage whole-language teaching (immersion in reading and writing activities), rather than systematic instruction in key skills;

(iv) that they fail to provide information on the specific skills children should have at different stages of development, (helpful in order for teachers to target particular areas of need for struggling readers).

(v) Referring to a "one-size fits all approach" (p. 62), Patel cites numerous studies which indicate that a focus on these staged skills is vital to the success of students from lower socio-economic backgrounds and "ethnic" minorities. ${ }^{36}$

In sum, Patel objects to the Ministry's promotion of the whole language approach, largely because that approach is not supported by scientifically-rigorous research. A fundamental shift may be needed in the way in which New Zealand educational policy is developed, with a move away from ideologically-based to research-based policy formation. Returning to the more specific question of whole language itself, it would be short-sighted to disregard all of the many varied and probably fruitful methods to which this broad term can refer. If we are to take

\footnotetext{
${ }^{36}$ Patel acknowledges that a second Ministry handbook, The Literacy Learning Progressions: Meeting the Reading and Writing Demands of the Curriculum (Ministry of Education, 2010) places a greater focus on these skills than Effective Literacy Practice, though she points out that this text continues to stress meaningful context as key, and refers teachers back to Effective Literacy Practice, which (as we have already seen) contains limited advice on how teachers might target these skills.
} 
student achievement seriously, however, an objective and empirical appraisal of these methods is needed.

Ministry Recommendations for the Teaching of Writing: Effective Literacy Practice; The Literacy Learning Progressions; Sound Sense; Teaching Handwriting

Before turning to the principal focus of this thesis, the teaching of writing, a review of the relevant Ministry publications for teachers is in order. All are recommended on the Literacy pages of Te Kete Ipurangi, the Ministry's website for schools. ${ }^{37}$ Effective Literacy Practice in Years 1-4 (2003) is the most comprehensive of these, comprising eight chapters covering all aspects of literacy, and described as a "core professional text" by the Ministry (Patel, p. 52). ${ }^{38}$ The Literacy Learning Progressions (2013) identifies expected literacy skills for each year level. Sound Sense (MOE, 2018) and Teaching Handwriting (MOE, 1985) advise teachers on ways to address transcription skills. Clearly, this list is not exhaustive. ${ }^{39}$ However, these publications all provided free to teachers (the first two in hard copy) - represent the Ministry's philosophical position. Together, they address all aspects of a primary writing programme, including composition and transcription. As is the case for reading, these handbooks clearly recommend what might be categorized, broadly, as whole language approaches. And again, one observes a dearth of engagement with empirical research.

(i) Effective literacy Practice in Years 1-4

According to the foreword, Effective Literacy Practice was developed in response to the recommendations of the 1998 government-appointed literacy taskforce, and that it is thus "integral to the ongoing implementation of the government's Literacy Strategy" (p. 6). Rather

\footnotetext{
${ }^{37}$ See, http://literacyonline.tki.org.nz/ (retrieved 9/12/18).

${ }^{38} \mathrm{~A}$ version of ELP FOR years 5-8 is also available. I have chosen to focus on the junior teaching handbook as the theoretical position is the same in both.

${ }^{39} \mathrm{~A}$ search of the literacy online pages of TKI, using the search terms "writing teaching" returned over 400 results.
} 
than being divided into chapters according to specific approaches beneficial for reading, writing, spelling and so on, Effective Literacy Practice is organized under thematic headings:

- A focus on effective practice,

- knowledge of literacy learning,

- knowledge of the learner,

- instructional strategies,

- expectations,

- partnerships,

- effective programmes.

These seem to have been loosely adapted from a Ministry-commissioned research report Best evidence synthesis: Quality teaching for Diverse Students in Schooling (Alton-Lee, 2003).

A whole-language orientation is signaled strongly throughout the text of Effective Literacy Practice. According to its introductory chapter, the handbook shows teachers "the evidence that links practice, learning processes, and student outcomes" (p. 6). But the criteria for the inclusion of research are never made clear, and references to empirical work (especially those relating to writing, rather than to reading, or to literacy-learning generally) are scarce. More common are statements that clearly signal the Ministry's whole language ideals, and (simultaneously) its resistance to current science-based educational research.

Also in the introduction we are told that the handbook "builds on and gives new emphasis to New Zealand's long-held tradition of child-centred learning" (p. 9). The practical implications of this (albeit worthy) vision are complex, as acknowledged by early theorists (see for example, Palmer et al. 2001, for a discussion of the work of Harold Rugg). How, for example, might teachers balance the goal of a democratic classroom with the need to teach fundamental literacy skills? This question is bypassed in $E L P$, via an emphasis on the creative aspects of literacy, and the idea (or, according to ELP, "fact") that "children take different pathways towards becoming literate" (p. 10). 
The "socialization model" is presented as the theoretical basis for the handbook, a model which "is built on the idea that the child constructs meaning within social settings" (p. 20). An implication of this is that literacy practices differ in different settings, so that literacy is redefined as "multiliteracies", a concept introduced early in the book:

It's useful to think in terms of a dynamic, shifting set of literacy practices that shape young learners, and indeed all people, as social beings". (p. 19)

Child-centred learning and the concept of "multiple pathways to literacy" (p. 21) are therefore presented as flip-sides of the same coin, and are also presented as being incongruent with approaches by which teachers set the priorities for new skill learning in accordance with identified key progressions. As the ELP authors declare,

There is [...] no place for programmes with prescriptive methods and materials or for predetermined, recipe-style literacy activities that claim to fit the needs of all learners. There is no evidence of a single sequence of literacy development. (p. 21, italics added) Applying these understandings specifically to the teaching of writing, another ex cathedra declaration is made:

Writing is a creative act, not a set of quantifiable skills to be taught in a predetermined sequence. (p. 136, italics added)

Thus, a whole-language definition of literacy learning as a creative and personally meaningful process is used to dismiss the value of early skills such as phonemic awareness, letter formation and the ability to construct a complete sentence - skills which have been identified as critical to writing fluency. ${ }^{40}$ This is an unnecessary and unfortunate position and, logically, a false dichotomy: Fluency with technical skills enables students to express themselves more easily. In addition, the language used in these excerpts is loaded with connotations. While dynamism and energy are invoked in the authors' definition of multiliteracies, the methodical teaching of skills

\footnotetext{
${ }^{40}$ See Chapter Two of this thesis for a summary of empirical writing research.
} 
is presented as hierarchical and inflexible, as well as ill-informed, through connotations of clinical approaches that merely "claim" to address learning needs.

Somewhat ironically, in emphasizing diversity the authors of Effective Literacy Practice actually demonstrate bias in their assessment of the needs of children from culturally diverse backgrounds. In a discussion of motivation and engagement we are told, "When these learners' cultural values and knowledge are incorporated into their learning activities, they are more motivated to learn" (p. 22). This statement requires interrogation - not least because there is no scientific evidence to support it. ${ }^{41}$ Naturally, we want schools to be inclusive and welcoming places for all, but edicts that certain topics suit some cultural groups better than others may be prejudicial.

Another way in which the Ministry signals its commitment to whole language approaches is in its emphasis on content in the first instance, irrespective of the technical ability of a student. This is evident in a description of the purpose of conferencing, with teachers advised to model content-based questions such as:

Is my writing making sense? Is the idea worthwhile? Is this expressed in an interesting way? What should I explain further? What should I leave out? Is there another way of writing this? Will the readers be able to imagine what I'm thinking? What am I going to do next? (p. 136)

The omission of any questions or comments here relating to the technical aspects of writing is striking. Even for emergent writers, teachers are told, "the talk may focus mainly on establishing the student's intentions, clarifying the topic, or discussing the encoding skills they need to use" (p. 137). The emphasis on meaning before encoding skills is unrealistic and impractical. As an emergent writer is understood to be a child who is just beginning to reproduce a few recognizable letters, focused teaching on hearing sounds and forming letters should be a critical

\footnotetext{
${ }^{41}$ See Sandra Stotsky's (1995) article for a discussion of the over-reliance on personal experience writing by whole language teachers.
} 
priority. Quality content is, quite clearly, of the utmost importance. However, the way in which the ELP authors use the valuation of meaning and content to deny the significance of technical skills is problematic in consideration of the constraints that technical difficulties place on a beginning writer's working memory. (See McCutcheon, 1996, for a description of constraints on working memory; and Brann, 2001, for some discussion of the key progression for learning to write.)

The emphasis in ELP on conferencing echo the process writing approaches recommended by Graves (2003). As discussed in Chapter Three of the present work, proponents of whole language teaching for reading have often promoted process writing as a complementary approach. The influence of Graves emerges elsewhere too, for example, in the recommendation that "students need opportunities to write simply and honestly about their own experiences and things that matter a lot to them and to share their writing" (p. 109), and in statements such as: "students' handwriting develops in the course of their experiences of writing $[\ldots]$. Initially, the teacher needs to accept some irregularities, especially when an undue emphasis on letter forms could interrupt a young writer's flow of thought" (p. 148). ${ }^{42}$ Of course, this may be a fair point in some instances, although it could also be misleading. If letter formation is interrupting writer's flow of thought, this is an indication that the skill has not yet been automatized, so teaching and practice is required.

All this having been said, Effective Literacy Practice does contain some reasonable and practical advice. First, the authors stress self-regulation as a key element of literacy learning. Second, they acknowledge a need for explicit teaching in order for students to become 'strategic' writers. Third, they register the value of phonemic awareness and letter formation, and also of the teaching of spelling. All of these recommendations are supported by the findings of empirical studies (see Chapter Two for a description of this body of research). The problem

\footnotetext{
${ }^{42}$ See my discussion of Graves process writing approach, and a summary of Sandra Stotky's compelling critique of the use of personal experience writing in Chapter Three.
} 
does not consist in the absence of such advice, but in the relative emphasis given to writing as a creative act. 43

\section{The Literacy Learning Progressions}

Intended as a 'reference point' for teachers, describing the skills students need to meet the demands of the New Zealand Curriculum, The $L L P$ was published in 2015. Its constructivism (in relation to whole language and socio-cultural imperatives) is embodied in these introductory statements:

- The pathway to literacy is developmental;

- Social and cultural practices shape literacy learning;

- Students take individual and multiple pathways in their learning. (p. 4)

As in the $E L P$ handbook, complex implications of a socio-cultural perspective are glossed over:

Literacy is a socio-cultural practice [...] students are more likely to achieve when they see themselves and their culture reflected in curriculum subject matter in all learning contexts. (p. 7)

It is assumed that students should study what is already known and of direct relevance to them - and in all curriculum areas. This assumption appears to stem from philosophical arguments for child-centred learning, as well as the whole language preoccupation with personal experiences as the best motivation for writing.

While the $L L P$ provides detailed descriptions of the skills one would hope to see in students at each year of schooling, information on requisite teaching strategies is insufficient and often inaccurate. ${ }^{44}$ For example, in a discussion of encoding, teachers are advised that, "students draw on the same knowledge and skills for both reading and writing" (p. 6). But as the research of Brann (2001), and Berninger et al. (2002) has shown, writing in the first instance is about

\footnotetext{
${ }^{43}$ I return to $E L P$ later in this chapter as I look at research which has informed Ministry advice.

${ }^{44}$ Patel makes this point discussing the example of reading.
} 
listening to hear and record sounds, with the motor skill of letter formation being a fundamental aspect of this. Reading does not require the same listening or motor skills. In this regard, it is notable that, of the 24 references identified for $L L P$, none refer specifically to the teaching of writing (except for those presenting writing assessment results and an asttle writing rubric user-manual). Another problem is a lack of specific and practical suggestions for teaching students who may be struggling. On page 7 we find general suggestions to help students meet the demands of the curriculum, and these point once again to an underlying constructivist theoretical framework:

- Understand the developmental process for the year groups they teach;

- Be aware that learners construct meaning within social and cultural settings (including home and school settings);

- Recognize the importance of making connections to students' individual expertise and interests and building from there.

Documents to support the development of transcription skills: 'Sound Sense' and

\section{'Teaching Handwriting'}

Despite assertions in ELP that writing is primarily a creative process, and its downplaying of "quantifiable skills" for writing, the Ministry does in fact provide teachers with a number of resources for the teaching of grammar, spelling and handwriting, all available on the Literacy Online pages of the TKI website. ${ }^{45}$ I have taken as examples Sound Sense (2018), and Teaching Handwriting (1987).

While Sound Sense addresses the development of phonemic awareness in the junior years, and offers some practical advice to teachers, it also pulls back in this area by declaring:

There is no need to teach students every combination of letters and sounds that they are likely to come across. As students become more aware of the sounds and patterns of

\footnotetext{
${ }^{45}$ See http://literacyonline.tki.org.nz/ (retrieved 9/12/18).
} 
language through many reading and writing experiences, they learn to transfer their understandings to further reading and writing [...] some students will relish exploring the intricacies of English, while others may find its irregularities and intricacies confusing and need very clear and focused teaching in meaningful reading and writing contexts. (p. 4$)^{46}$

Once more, the Ministry's theoretical position emerges in conjunction with apparent resistance to research evidence. As Patel reports, explicit teaching in phonemic awareness is critical in beginning reading instruction, particularly for students from lower-socio-economic backgrounds who have often had limited exposure to the conventions of print in their pre and extra-school lives. Of particular pertinence to the argument that immersion in meaningful reading and writing contexts will be sufficient to develop phonemic awareness skills is a study by Foorman, Francis, Noby and Liberman (1991) in which half of the first grade participants received instruction in letter-sound correspondences, including working with these sounds in isolation, and the other half received instruction in reading whole words through meaningful contexts. From October to May (of the American school year), students who received explicit letter-sound instruction increased their reading accuracy from $30 \%$ to $80 \%$, and those who received instruction in meaningful contexts improved their reading accuracy from $31 \%$ to $60 \%$ (Foorman et al., 1991, cited in Patel, 2010, p. 57).

External references in Sound Sense are confined to the works of Marie Clay, a monograph by Cunningham (2005), and a (political) statement of position on phonics instruction from the International Reading Association. All but three references are to the Ministry's own previouslypublished works.

\footnotetext{
46 This quotation clearly illustrates the influence of Clay (1999), who wrote of her "fear [that certain concepts of literacy learning] might be used to justify teaching children all their letters or single-letter sounds" (p.140).
} 
The much earlier (1987) publication, Teaching Handwriting, is notable in that, unlike the Ministry resources reviewed above, it makes no reference to a theoretical position. In the Foreword, the place of handwriting in the curriculum is made clear in an uncomplicated way:

The teaching of handwriting is not an end in itself. It is a skill which, along with spelling and punctuation, is an essential tool in effective written communication. (p. 3)

The advice that follows is clear - research is regularly cited and the findings align with recent empirical work by experts (e.g., Brann, 2001). Handwriting is described as a physical skill which requires correct pencil grip, and consistency with movement and shape. The handbook recommends that teachers model and describe the elements of letter shapes as they go (citing Markoff, 1976), and provides a recommended sequence for instruction, addressing all elements of the skill (including such things as posture and paper positioning). Interestingly, it also addresses common errors in the teaching of handwriting (citing Hoffmeister, 1973), including inadequate supervision, and a lack of immediate feedback (see Brann, 2001, for more recent work addressing the same points).

\section{Ministry handbooks: The Research Base}

Given the strong constructivist convictions expressed in ELP, the LLP and Sound Sense (Teaching Handwriting is clearly an exception), the question arises as to the kind of research that has informed these documents. Two major influences appear to be significant. The first of these is Alton-Lee's (2003) Best Evidence Synthesis, which is referenced several times in ELP, and is recommended as further reading at the end of four of its eight chapters (it also appears to have inspired the thematic organization of the material). Another key influence is the work of Marie Clay, which is often used to justify the concepts of multiple pathways to literacy, and literacy as a social practice. Clay's work appears in the bibliographies of all three handbooks. It is also cited in many of the other writing-related titles referenced in ELP (see for example, McNaughton, 1999; Dyson, 1999; and Smith and Elley, 1997). 
Lee, 2003)

This report, commissioned by the Ministry of Education, purports to synthesize research findings "to provide a rigorous, transparent, and concise evidence-base for informing policy and practice" (p. 11). However, the research methodology at stake is not transparent. For example, although Alton-Lee discusses the variability of effect sizes, she does not specify whether these were used as criteria for determining which studies would be considered in the review. Significantly, Alton-Lee herself characterizes her approach as a "developing" methodology (p. 13), and goes on to explain:

As the range of best evidence syntheses proceed informed by the processes of critique and feedback, increasing systematic knowledge management capability and formative quality assurance, we aim to develop collaboratively a best evidence synthesis toolkit or protocol that can optimize the value of this approach. (p. 13) $)^{47}$

Rather than identifying specific criteria for the selection of studies to be reviewed, Alton-Lee identifies five "characteristics": the research provides evidence of links between teaching and student outcomes; the research identifies generic, or cross-curricular principles that can be applied to learning for students aged from five to 18; "particular weight was given" to outcomes-linked research presented in leading, peer-reviewed handbooks; when the findings from international research are also demonstrated in a New Zealand context, this work was included; and "where an evaluation of national monitoring outcomes demonstrated a lift in student achievement in New Zealand, information about policy-linked pedagogical strategies that appear to be influencing such a lift is included" (p. 12); ${ }^{48}$ finally, the synthesis includes quantitative, meta-analysis and case studies.

\footnotetext{
${ }^{47}$ The preponderance of polysyllabic abstractions evident here is notable throughout the report. ${ }^{48}$ There is a problematic lack of transparency here. The reference to "policy-linked pedagogical strategies that appear to be influencing such a lift" does not encourage faith in the statistical processes used that
} 
Synthesized findings from studies such as these informed the report, which identifies ten characteristics of quality teaching. Briefly summarized, these are: that teaching is focused on raising student achievement, and this, it is stipulated, includes "social outcomes" (p. 16); practices encourage caring and inclusive communities; links are created between school and other cultural contexts; teaching is responsive to students; sufficient time is given for learning; multiple tasks are used to promote learning; curriculum goals, tasks, resources and teaching practices align; feedback is provided; teaching promotes strategies such as self-regulation and metacognition; goal-oriented assessment is used constructively by students and teachers.

Reflecting on what is explained about the research methodology used here, as well as on the study's findings, it seems the Best Evidence Synthesis rests on an ill-defined process under which such a broad range of research was examined that the set of principles identified thereby, are so generic as to be of limited value. The characteristics of quality teaching seem of course, to be unimpeachable - they cover critically important social and emotional considerations and emphasize the obvious importance of responding to student needs, and aligning goals, tasks and feedback. How these characteristics may be applied practically to teaching in specific curriculum areas, is another matter entirely. It seems likely that the efficacy of these ten principles may lie very much in the precise ways in which they are implemented, and this detail is missing in the $B E S$.

\section{The Influence of Marie Clay}

Marie Clay, born in Wellington in 1926, was - as is generally recognized - an accomplished educational researcher whose work has had a profound influence on the teaching of reading and writing worldwide. A graduate of the University of New Zealand, she completed her Masters thesis in 1946 on the teaching of reading to "Special Class Children" (Gaffney \& Askew, 1999, ix), and in 1950 was awarded a Fullbright scholarship and a Smith-Mundt grant to study

may or may not have demonstrated correlations between specific teaching approaches and improved outcomes. 
developmental psychology at the University of Minnesota's Institute of Child Welfare. On her return to New Zealand Clay took up a teaching position at the University of Auckland, where (in 1975) she became the first female professor. In 1992 Clay also became the first non-American to be elected president of the International Reading Association. Clay's main research interest was in the reading development of lower ability children. She was involved in descriptive work, tracking individuals' progress over time. This work informed the development of the Reading Recovery Programme (which became a national programme in 1983), and the design of the Observation Survey of Early Literacy Achievement (1993) - a comprehensive assessment of reading and writing skills, used nationally to assess the progress of students after one year at school. ${ }^{49}$

In her monograph By Different Paths to Common Outcomes (1998), Clay articulated an adherence to principles of literacy as a constructive process and, what its advocates describe as, child-centred learning. She associated her theory with constructivist ideology through frequent reference to the work of Vygotsky and Bruner (as discussed in Chapter One of the present study), and positioned herself against systematic (and thus sequential) teaching techniques.

Clay conceived of literacy learning as a process that draws on individual learners' prior knowledge, and a range of problem-solving strategies. She emphasizes the reciprocity of reading and writing on the grounds that children "are contemporaneously learning to write the code that they are being taught to read" (p. 136, italics added). She claims, accordingly that, "there is no predictable sequence" for learning; good teaching "arises out of the understanding teachers have of their craft and never out of prescriptive programs" (p. 130, italics added). Clay warns against "teaching children all their letters or single letter sounds" (p. 140), and suggests that "too early and rigid patterning may prevent later modification" (p. 142).

Clay implicitly dismisses the specific and peculiar challenges that writing (and, in particular, handwriting) present. Her list of early writing skills (she emphasizes that this is not a

${ }^{49}$ See Anderson (1999) for further bibliographical information on Marie Clay. 
sequential list $)^{50}$ makes no mention of handwriting at all. Interestingly however, in the course of a discussion of how writing can help with learning to read, Clay observes that writing "fosters slow analysis" partly due to "the motor, muscular, or movement nature of the task" (p. 137). But she apparently ignores the fact that the acquisition of handwriting is a significant hurdle for many children - a hurdle which teachers could help to address. ${ }^{51}$

Clay's apparent lack of interest in the particular challenges of writing, and especially handwriting, may have resulted in barriers to progress for many Reading Recovery students. For example, teachers are advised to give children unlined paper, yet this arguably makes it difficult for the students to judge the relative size of letter shapes, amongst other things. 52

As Tunmer and Chapman (2011) have observed, the Reading Recovery Trust has been unwilling to compare the programme with other methods in controlled experimental conditions. There is no doubt that Clay was a pioneer, and that many children have benefitted from Reading Recovery. It is only reasonable, however, to expect that her methods should continue to be evaluated and her programmes modified as our knowledge of literacy acquisition grows. Unfortunately, later constructivist researchers treat her ideas as unimpeachable, and have failed to test her methods in any rigorous way.

\footnotetext{
${ }^{50}$ The emphasis here is my own. Clay's conviction that writing skills are not learned sequentially needs interrogation. How is it logical to think that a child may learn to write before they know the alphabet, for example?

${ }^{51}$ See Berninger (2002) for research which examines correlations between fluent handwriting and development in other aspects of writing. This research is also summarized in Chapter Two.

${ }^{52}$ From my own experience as a trained Reading Recovery teacher, I have been in a position to observe how Clay's principles work in practice. First, Clay's anti-prescriptivism is belied by the fact that every aspect of the Reading Recovery lesson is specified; and this lesson structure is the same for every student - irrespective of book level or reading strategies. Second, Clay's reluctance to acknowledge predictable patterns of skill and knowledge development, has, in my experience, proved problematic. As I work with a number of children who are already over six and a half years old and cannot name more than a few letters, or write more than two or three words, it is impractical not to target these particular knowledge items in the first instance. The learning of these letters and words cannot be "left to chance" through the reading and writing of texts which have been chosen primarily for their motivational qualities. They need to be taught at the outset, in order for children to have any access to real reading at all.
} 
The work of other New Zealand researchers cited in ELP closely aligns with that of Clay. I take as my examples chapters by McNaughton and Dyson, both published in the (1999) monograph, Stirring the waters: The influence of Marie Clay.

McNaughton (1999) clearly articulates a standard constructivist position, according to which learning "is located in children's strategic invention and instruction" (p. 5). He therefore emphasizes the child's personalized experience of literacy learning, and the significance of their home life in shaping this experience. He argues, accordingly, that culturally diverse learners need a broad curriculum (i.e., a curriculum that recognizes their own cultural context among others), and that teachers need to be sensitive (to "identify and connect" with their cultures).

As we have seen so often, this "social" emphasis carries with it a resistance to the teaching of skills as such. McNaughton induces that whole-language style, text-based literacy instruction, which allows for more implicit learning (guessing on the basis of supportive clues), is preferable to the explicit teaching of phonics. This is an enthymeme: A wide curriculum cannot be accessible to students who do not have the skills that it assumes. Furthermore, research suggests that McNaughton may well be mistaken in his assumption that children from diverse backgrounds would not respond positively to the explicit teaching of the alphabetic code. For example, a study by Foorman, Francis, Fletcher and Mehta (1998) found that children from culturally and linguistically diverse backgrounds who received explicit instruction in letter-sound correspondences made faster progress than peers who were taught through immersion in literature.

Dyson (1999) documents children's uses of media references in a multicultural school in the East San Francisco Bay Area. ${ }^{53} \mathrm{~A}$ theme in this article is recontextualization of children's appropriated media material into school-valued forms of writing. Dyson argues for greater open-mindedness amongst teachers about what constitutes subject matter worthy of school

53 The title of this article, Writing (Dallas) Cowboys: A Dialogic Perspective on the "What did I Write?" Question references an earlier (1975) Clay article. 
writing. She urges them to remain alert to ways in which children's "chosen worlds reverberate in particular situations" (p. 145).

The points raised by McNaughton and Dyson are important. It is essential that educators examine their (possibly false) assumptions about the skills children bring to literacy learning, and also what constitutes a worthwhile literary experience. However, when it comes to their implications for literacy achievement, these researchers' arguments remain hypothetical. Additionally, the pseudo-scientific language they use would be inaccessible to many. While paying homage to Clay - someone who worked steadily on the practical application of research - these theorists appear to be much less concerned with teaching at the "coal face".

Before ending this discussion, it seems important to point out that, of the entire ELP reference list only eleven of 164 titles treat writing (several of these are earlier Ministry publications or reports on national assessment results). Demonstrably then, the Ministry has relied to a disproportionate extent on a small number of (mostly New Zealand) researchers. Little attention has been paid to the many international, science-based studies, which have trialed particular teaching methods in order to establish best practice.

\section{Conclusion}

Constructivist-oriented approaches to the teaching of writing are clearly and repetitively articulated in Ministry handbooks for teachers. This theoretical position is used to deny empirically-supported models of learning to write, under which technical skills are understood to be of critical importance. Much of the most important scientific research in this area has not been considered at all. 


\section{CHAPTER FIVE: PREVIOUS RESEARCH ON TEACHERS' BELIEFS}

\section{Introduction}

Empirical research into writing instruction has identified a number of effective instructional practices (see, for example Graham, Harris, \& Santelego, 2015), though there is evidence that many of these strategies are not used or are used only infrequently by teachers (as discussed by Brindle, Graham, Harris, \& Herbert, 2016). One important reason for this may involve teachers' philosophical beliefs: As observed by Pajares (1992), and discussed in Chapter Three, beliefs are almost, by definition, rigid and strongly felt, so that they tend to over-ride knowledge in situations in which challenging, on-the-go decision-making is required. Brindle et al. provide examples of ways in which beliefs may become a barrier to best practice, including the reluctance of constructivist-oriented teachers to use explicit instruction, even though explicit instruction has been shown to be effective (see Brindle et al., 2016, for further discussion of this point). Investigations of teachers' beliefs and their impacts are rare, and very few studies examine whether teachers' theoretical orientations are differently associated with student achievement and progress (see Brindle et al.; or Fang, 1996 for substantive reviews of the literature). While a number of New Zealand studies have examined teaching practices (for example, Parr \& Jesson's comprehensive review of writing instruction, 2015), or have identified characteristics of highly effective teachers (for example Gadd, 2014), only one New Zealand study found in the literature survey for the present work focuses primarily on teachers' theoretical orientations, and this is restricted to beliefs about spelling.

\section{International Research}

Pajares (1992) considers research on teachers' beliefs, acknowledging both challenges and potential in this field of research. Stressing the importance of teachers' professional convictions, Pajares speculates that these are formed early and tend to persist - more so than for people in other professions, because teachers are already familiar with their working environments when they begin. Furthermore, because people who choose to become teachers tend to be those who 
enjoyed school, they see no need to question the status quo. Finally, the ill-defined and multifaceted nature of teachers' work (which involves many complex and spontaneous decisions) reinforces teachers' dependence on intuition and impulse. Pajares also discusses the difficulty of studying beliefs - problems of definition are primary. Future research in this area will, he suggests, depend upon careful definition of fundamental beliefs (or 'constructs'), and an appreciation of how the (more readily observable) 'sub-constructs' are governed by the former. Pajares recommends that, because we infer belief from what people say and do, research must be in depth. Both quantitative and qualitative methods should be considered, with teachers' responses and explanations, as well as observations of practice, all used to form a meaningful picture. Researchers should continually consider the relationship between teachers' beliefs on one hand, and teachers' practice and students' achievement on the other, so as to identify beliefs that are empirically observable as conducive to effective teaching and student cognitive and affective growth.

Pajares concludes:

Attention to the beliefs of teachers and teacher candidates can inform educational practice in ways that prevailing research agendas have not and can not [...]. When they are clearly conceptualized, when their key assumptions are examined, when precise meanings are consistently understood and adhered to, and when specific belief constructs are properly assessed and investigated, beliefs can be [...] the single most important construct in educational research. (p. 329)

Zhang (1996) also reviewed studies in this area, offering further practical suggestions for future research. He reported that, while teachers' beliefs may influence what and how they teach, research in this area has produced mixed results - the relationship between beliefs and instructional practices varies from very consistent to very inconsistent. Zhang identifies two main reasons for this. The first of these is the complexity of school environments, within which teachers' beliefs and practices are constrained by classroom realities (such as organization and 
management, students' diverse needs, and available teaching resources) and the (often contradictory) advice of teacher-educators, principals and mentor-teachers. Zhang's second reason relates specifically to research methods, in particular to construct validity, which can be difficult to establish for many reasons. Zhang identifies some common problems, such as the use of researcher-determined categories of belief - taxonomies that are always subjective and possibly at odds with those of study participants. Another issue is that, when research participants are required to select one category over another this can present a false picture, as different (or even apparently contradictory) beliefs are often not mutually exclusive (for example, a teacher may believe in the importance of students writing meaningful texts, as well as in the importance of teaching basic skills). Finally, different teachers may have different understandings of theoretical approaches, with terms such as whole language being particularly unhelpful as they have been defined in broad and somewhat elusive terms in the literature.

Graham, Harris, MacArthur, and Fink's (2001) survey of primary grade teachers in the US attempted to address such problems and continues to influence recent research. Their purpose was to develop a survey instrument to measure teachers' theoretical orientations about "skills based" and "natural-learning approaches", and their use of related teaching practices. A nationally-representative sample of 153 teachers participated. Rather than requiring the teachers to select one theoretical orientation or another, Graham et al. presented them with a set of statements with which they could agree or disagree. Factor analysis was used to identify different dimensions of belief as well as dimensions of practice, and these dimensions were compared, to assess the internal consistency of the data obtained (i.e., to assess whether reported beliefs and practices appeared to align in predictable relationships). The authors predicted that teachers would emphasize the importance of both natural learning and skillsbased orientations and that the beliefs and practices within each dimension would be positively correlated. 
Briefly, a skills-based orientation prioritizes the explicit teaching of technical skills, and places relatively less emphasis on the importance of meaningful and authentic writing tasks. Under natural learning approaches, on the other hand, students' engagement in the writing process, and their desire to communicate purposefully, are viewed as key aspects of a successful programme, and technical skills are seen as being less important than content. Evidently, this orientation is consistent with (constructivist-oriented) Whole Language and Process Writing approaches.

Nine items were selected to assess teachers' agreement with each approach, with teachers being asked to select a response ranging from strongly disagree to strongly agree, on a 6-point Likert scale.

Teachers' writing practices were investigated with a further 12 questions, asking how often the teachers or their students engaged in specific writing activities. Four of these items related to specific skills (handwriting, spelling, grammar, strategies for planning and revision); four related to instructional procedures (re-teaching skills or strategies, modeling writing strategies, conferencing, and providing mini-lessons). The final four questions related to student activities (sharing their writing with peers, helping peers with their work, selecting their own topics, and using invented spellings).

Graham and his colleagues expected to uncover two main dimensions of teacher belief (natural learning and skills-based instruction). In fact, they found three: A factor analysis revealed one dimension representing beliefs about natural learning, whereas the other two represented separate aspects of skills-based instruction; beliefs about the importance of explicit instruction, and beliefs about the importance of correctness in writing. This is significant, as skills-based instruction had, in previous literature, been defined in terms that combined explicit instruction and correct performance (as Graham et al. comment, citing research by Dreher, 1990; and McIntyre \& Pressley, 1996). A second key finding (as Graham et al. had predicted) was that natural learning and explicit approaches were not incompatible, with most teachers in 
this study valuing both: $99 \%$ of teachers in this study agreed that explicit instruction was important, and 73\% also believed that the natural learning approach was important. In contrast, only $39 \%$ of teachers believed that correctness was important.

Correlations between factor scores for teachers' beliefs, and associated practice tended to be consistent with the authors' predictions, with $70 \%$ of the hypothesized relationships confirmed. Teachers' beliefs about correctness were positively correlated with the reported frequency of teaching grammar, handwriting and spelling, and negatively correlated with encouraging students to use invented spellings. Teachers' beliefs about natural learning were positively correlated with reported frequency of conferences and mini-lessons, as well as the prevalence of students being allowed to choose their own topics, engage in peer work, and use invented spellings. One unexpected result was that teachers' beliefs about explicit instruction, while positively correlated with the teaching of skills and strategies, were not positively related to the modeling of writing strategies or to the reported teaching of handwriting, spelling, grammar and planning.

These results suggest that the scale developed by Graham et al. may be a reliable tool for capturing teachers' self-reported beliefs and practice with regard to writing, largely because beliefs and practices dimensions correlated in intuitive ways. Even so, as the authors themselves point out, this information is still of limited value - classroom observations and analysis of student work would be required to establish how closely reported practice aligns with actual practice, and the impacts of practice on student achievement.

Two important studies have directly built on the survey of Graham et al. (2002). Troia, Lin, Cohen, and Munroe (2011) investigated six teachers' beliefs and instructional practices in a Seattle school, over the course of one year. The particular context for this study is important; the research was undertaken while the school's teachers were participating in professional development in a "writing-workshop" approach. In other words, teachers were being trained to use a Process Writing approach, employing methods such as mini-lessons on skills, strategies 
and "craft elements" (p. 156), as well as to provide their students with opportunities for personal writing, and to routinely use conferencing and student sharing of work. The authors investigated the specific practices teachers were employing in the context of writing workshop, the nature of teachers' knowledge and beliefs about writing instruction, whether these changed in the context of a year's professional development), and whether teachers' knowledge and beliefs influenced their teaching practices. A mixed methods design was used, with data sources including classroom observations, interviews and rating scales - including the Graham et al. Teachers Writing Orientation Scale (TWOS) and a Teacher Efficacy Scale for writing.

This study has clear limitations: particularly the small sample size, the unusual context of school-wide professional development and the omission of any measure of student achievement. Despite these, the results of the survey are of interest in that they closely replicate the previous findings of Graham et al.: These Seattle teachers held a balanced view toward writing instruction, with high rates of endorsing explicit instruction and natural approaches, and less commitment to correct writing.

In a more comprehensive study, Ritchey, Coker, and Jackson (2015) investigated the relationship between teachers' beliefs and instructional practices, and students' writing performance. Twenty-eight teachers and 328 students from schools in the Northeastern US participated. Teachers were surveyed using the TWOS (Graham et al.). Writing was assessed using two measures (a norm-referenced assessment as well as a researcher-developed task), which were administered several times over a six-month period. Together, these measures assessed a range of aspects of the writing, including transcription skills, number of words written, and the quality of content, description, vocabulary, and grammatical structures. The authors hypothesized that teachers' beliefs would be related to instructional practices - for example, that the natural learning orientation would be associated with conferencing, peer work, and student selection of topics. They also anticipated that teachers' beliefs would be related to different aspects of students' writing performance. They predicted, in specific terms, 
that the correct writing orientation would be negatively correlated with writing quality, that the explicit instruction orientation would be positively correlated with writing achievement, and that the natural learning orientation would be associated with longer student texts.

The results of the teachers' orientation survey were similar to those reported by Graham et al. Explicit instruction was the most supported orientation, followed by natural learning, and then correct writing. The results also supported the conclusions of Graham et al. that teachers take a balanced theoretical stance: most teachers expressed agreement with both explicit instruction and natural learning approaches. Regarding the relationship between teachers' theoretical orientations and reported practice, results diverged from those of Graham et al., with some surprising correlations emerging. For example, there were positive, statistically significant correlations between the correct writing orientation and peer sharing practice, and the explicit instruction orientation and allowing the use of invented spelling (both practices which Graham et al. associate with the natural learning orientation). The natural learning orientation was positively correlated with engaging in mini-lessons and teaching spelling. Results also revealed that the relationship between teachers' theoretical orientations and practices varied according to grade level. For example, only for the older, third-grade students was the natural learning orientation associated with allowing students to select their own topics - possibly (the authors speculate) because this presents too great a challenge for younger students. Given that predicted relationships between theoretical orientations and instructional practices were largely unconfirmed, it is not surprising that relationships between teachers' theoretical orientations and student achievement outcomes were also somewhat unexpected. For example, the correct writing orientation predicted growth in a quality score for one of the writing measures, though (the authors speculate) this may have been due to its association with peer sharing of writing (a practice usually associated with natural learning). Across all student outcomes that were measured, there were limited effects for teachers' orientations, and no single orientation was positively and significantly correlated with student progress. 
McCarthy and Mkhise (2013) investigated teachers' orientations towards writing, and how these differ across high-income and low-income schools. Participants included 29 teachers of third grade children, across four US States, including Illinois, Utah, Vermont and West Virginia. Data were obtained using interviews with teachers and school leaders, classroom observations, and the analysis of student work samples (these were used to gain further insight into teaching approaches, though student achievement was not actually measured). The researchers analyzed teachers' interview responses to develop categories of teacher priorities, including "developing structure" (the sequencing and organization of texts), "rhetorical style" (the creative use of language, for example metaphorical and descriptive language), voice (students' personal expression of ideas and beliefs), "reading-writing connections" (using ideas from literature to inspire writing), "grammar and mechanics" (punctuation and spelling), and "sentence structure" (writing in complete sentences). Though the teachers themselves were not required to complete the TWOS (Graham et al.), the researchers identified ways in which their new set of categories cohered with the empirically-derived constructs of Graham et al., concluding that teachers who focused on grammar and mechanics, and sentence structure had more in common with the correct writing construct; that those who focused more on rhetorical style, voice and reading-writing connections had more in common with natural learning methods; and that those who focused on developing structure had more in common with the explicit instruction construct.

While the combined use of two categories for analysis seems somewhat problematic (with the researchers' own categories used in conjunction with those of Graham et al.), the results of this study are interesting, particularly because of the significant differences found between teachers of high-income and low-income schools. ${ }^{54}$ Rhetorical style, voice and fostering reading-writing connections (all aligned with the natural learning orientation) were prioritized by a majority of teachers in high-income schools (86\%, 60\% and $80 \%$ respectively), compared

\footnotetext{
${ }^{54}$ See Jean Anyon's Social Class and School Knowledge (1981) for a thought-provoking and historically important discussion of the differences in curriculum in high and low-income schools.
} 
with $50 \%$ or less of the teachers in low-income schools (42\%, 14\% and 50\%). In striking contrast, grammar, mechanics and sentence structure (aligned with the correct-writing orientation) were prioritized by a minority of teachers in high-income schools ( $26 \%$ and none respectively), but a majority of teachers in low-income schools (71\% and 79\%). Developing structure (aligned with explicit instruction), was prioritized by $90 \%$ of teachers, and was the only category that cut across both high-income and low-income settings.

In their discussion, the authors offer several possible reasons for these different emphases. They report on various pressures that teachers in low-income schools face, including catering for many students for whom English is a second language, and increased pressure to have their (sometimes unprepared) students pass state tests. They describe these teachers' focus on grammar, mechanics and sentence construction as a response to "perceived needs" but argue that it is misguided and "in striking contrast to effective practices" (p. 28). They suggest that if skills are taught hierarchically (with those most basic skills taught first), low-income children will miss out on authentic and challenging curriculum. This argument seems difficult to substantiate without any measure of student achievement: A measure showing student achievement over the course of several months would be particularly useful as it may indicate how helpful (or not) particular teaching priorities may be to students with diverse needs.

Two further studies which investigated teachers' theoretical beliefs but which did not use the TWOS include that of Simmerman, Harward, Pierce, Peterson, Morrison, Korth, Billen, and Shumway (2012), and Gaitas and Martins (2015).

Simmerman et al. investigated the extent to which teachers value and use various aspects of writing instruction, their perceptions of themselves as writers, and influences on their writing teaching. While the article title refers to perceptions of "process writing", commitment to the (current, or updated) process writing approach was not a criterion for the 
selection of participants. ${ }^{55}$ The researchers surveyed 177 teachers across 74 Utah schools. The survey consisted of 55, five-point Likert-scale items related to different aspects of writing lessons, with room for further written comment. It also included one question that asked teachers to rank themselves as writers, and two open-ended questions that focused on influences on their teaching.

Teachers' responses to the first part of this survey (regarding the value and use of aspects of writing lessons) are the most relevant to the present research. For this section, on every survey item, teachers reported valuing writing instruction more than they reported implementing it. When the age, experience and grade level of teachers was considered, some significant differences were found, with older teachers valuing and teaching spelling more than younger teachers, more experienced teachers valuing and teaching mechanics more than less experienced teachers, and teachers of higher grade levels using writing evaluation and teaching genres more than those teaching in the lower grades. Looking at combined scores across all teachers, it is interesting that natural learning (or process writing) approaches achieved the highest value scores. These included responding to student needs, daily writing, students sharing their writing with peers, and teaching the writing process. The lowest value scores were for commercial writing programs, dictation, worksheets and technology-based genres. Regarding the teachers' written comments, most of these explained why they chose not to use certain methods, with four main themes emerging: lack of time, lack of relevance for particular grade levels, the need for further professional development, and a lack of access to resources.

Gaitaz and Martins (2014) surveyed 255 Portugese primary school teachers to examine the relationships between their theoretical beliefs and classroom practices. A 52 item Likertscale questionnaire was used, including 24 items relating to theoretical beliefs. Responses were analyzed using exploratory factor analysis, and revealed two factors: Meaning-based and codebased beliefs. Examples of meaning-based beliefs included, "Written language conventions will

\footnotetext{
${ }^{55}$ Instead this title indicates how widely accepted process writing is in the US. Also, that the term process writing itself has not lost popularity as it has here in New Zealand.
} 
gradually be learned by practicing written language expression". Examples of code-based beliefs included, "Formal and systematic instruction about writing is essential to ensuring the proper development of all the skills needed in order to write". Results revealed that a majority of teachers take a multi-dimensional view of literacy learning (75\% reported valuing both types of belief), though they expressed a stronger preference for meaning-based beliefs than code-based ones. Correlations between beliefs and practices were reported to be "coherent" (and in-line with the findings of Graham et al.). Meaning-based beliefs were positively correlated with updated process approaches (such as planning and revising), and "autonomous" writing activities (including reports or recounts, stories and personal messages). Code-based beliefs were positively correlated with themed compositions, copying and dictation, and the reported use of spelling and grammar worksheets.

These two studies, which both involved high numbers of participants across many schools, provide some insight into common attitudes and practice in their regions. The surveys also have merits: both include a high number of items - and were capable, therefore, of capturing detailed information. The Simmerman et al. survey has other particular strengths: it allowed for both quantitative and qualitative data collection, and survey items were worded clearly and objectively. For example, in the section headed philosophic emphasis, these emphases are presented in simple terms, requiring teachers to rate, "Increasing writing fluency", "Enhancing composition abilities" and "Enhancing mechanics abilities” (p. 297-298). A limitation of both studies is the omission of any student achievement data.

A study which attempted to determine relationships between teachers' beliefs and their effectiveness is that of Poulson, Avramidis, Fox, Medwell, and Wray (2001). These authors surveyed 225 British teachers identified as particularly successful, comparing their responses with those of 71 teachers "who represented a range of effectiveness" (p. 271). Sampling of these participants was based on recommendations from local educational advisors, as well as on any eternal data available for the teachers in question, though no measure of student progress was 
included in the study itself. The survey instrument was a Likert-scale questionnaire, based on de Ford's (1985) Theoretical Orientation to Reading Profile, with equivalent questions added to evaluate writing beliefs. De Ford's profile identified three clusters of theoretical beliefs in relation to reading, including (i) a bottom-up, phonics-based approach; (ii) a skills approach (which prioritized whole word reading and visual analysis in the context of meaningful texts); and (iii) a top down approach (which prioritized the sense of story and the use of meaningbased cues for decoding new words). The equivalent writing categories devised by Poulson et al. include (i) 'presentation' which prioritized handwriting and spelling skills; (ii) 'process' which emphasizes purpose, and the communicative power of writing; and (iii) 'forms', with a focus on vocabulary choice, form and the structure of texts. Results indicated that the more effective teachers disagreed with the presentation orientation, while the comparison group indicated a neutral attitude overall. For the process and forms orientations, both groups indicated agreement with these approaches, producing similar mean scores. This study is interesting as it explicitly considers theoretical orientations in terms of their relationships to student achievement, though the writing constructs themselves may lack validity (as they have been superimposed onto a measure designed to investigate beliefs about reading). Some investigation into comparisons between the teachers' valuation of these constructs and their actual classroom practice would be interesting.

\section{New Zealand Research}

Parr and Jesson (2015) is highly relevant to the present research. These authors reviewed policy contexts and national resources for writing teaching, as well as other recent (post 2000) writing research, and reported on the findings of their own study - a survey of New Zealand teachers, investigating two key questions: What are the major characteristics of practice of New Zealand primary teachers? Do patterns of practice differ across year levels? While these authors did not specifically inquire into teachers' beliefs, their insights suggest that constructivism continues to exert a significant influence on the teaching of writing in New Zealand. 
To begin with policy contexts, Parr and Jesson make two main observations that are particularly interesting. First, they described the relative autonomy of New Zealand schools (governed by Boards of Trustees, elected by parents), which are required to interpret and apply the national curriculum to their local contexts, and which administer their own professional development funds, so that participation in professional learning is always voluntary. Second, they examined the ways in which the Ministry of Education promotes the notion of teaching as a process of inquiry, in which teachers tailor their own professional development through a process of evaluating student needs, trialing new approaches, and reflecting on impacts. This view of teaching, the authors point out, is inherent in Marie Clay's philosophy and has continued to be supported through nationally-offered professional development programmes (for example, the Literacy Professional Development Project, reported on by Timperley, Parr \& Meissel, 2015). It has been further supported through Ministry-sanctioned resources and tools such as the e-asTTle writing assessment tool which, in its rubric form: "reinforced the idea that development may be patterned differently across students whose writing might reflect the same overall level” (p. 986).

While the authors described the implications of these policies as "significant" (having lead to wide variation in the ways writing is taught), they did not take a critical stance. Nor did they use the term constructivist in relation to them. ${ }^{56}$ It seems clear, however, that policies which emphasize teachers' autonomy and localized (adapted) curriculum value a speculative position more than an empirical one. When teachers and schools are asked to tailor their own programs, it is implied that teachers' own judgments should supersede the findings of rigorous academic research. Additionally, the notion of individualized writing developmental stages is in direct contradiction to an understanding of key progressions, which is supported by intervention research (for example, extensive work into the significance of transcription skills,

\footnotetext{
${ }^{56}$ Parr and Jesson do describe the Ministry publications Effective Literacy Practice Years 1-4, (2006) and Effective Literacy Practice Years 5-8 (2007) as drawing on "socio-cognitive and socio-cultural views of writing but with an emphasis on the latter" (p. 987). They also report that in devising the curriculum and national resources, teachers (rather than researchers) had the greatest input.
} 
which strongly indicates that these need to become automatized quickly in order for students to make progress in all other aspects of their writing). This argument requires further exploration and is the focus of Chapter Two.

The major focus of Parr and Jesson's article is their own survey. This was completed online by a representative sample of 118 New Zealand teachers. Questions investigated teachers' confidence to teach writing, their confidence as writers, the commercial resources they used, purposes for writing in their classrooms, the teaching practices they prioritized, and the time spent on writing in their classrooms.

The findings regarding teaching practices are of the greatest relevance to the present research in that they probably reflect beliefs. Survey items included: deconstructing a text, modeling the writing process, build vocabulary, sentence combining or grammar, punctuation, spelling through rules and patterns, strategies for spelling unknown words, goal setting with students, feedback to students, monitoring students while writing, small group approaches, planning strategies, facilitating content generation, and facilitating language experience. Items were rated using a five-point scale according to the prevalence of each practice. Teachers placed greatest emphasis on providing feedback, modeling writing, and goal setting with students. The least emphasis was placed on teaching spelling through rules and patterns and teaching strategies for spelling unknown words. The greatest difference in year levels was seen in the extent to which teachers emphasized teaching strategies for spelling, with Year 1-2 teachers prioritizing this more than teachers of other year levels. The authors comment on this "relatively minor emphasis on teaching basic skills" (p. 1008) and suggest that this may differ from the findings of studies undertaken in the US, though they do not suggest that it is at all concerning. ${ }^{57}$ Other interesting findings include the low use of commercial resources $(56 \%$

\footnotetext{
${ }^{57}$ Certainly, an investigation into the practices of English teachers (2015) suggests that there may be a greater focus on these basic skills in England than in New Zealand. Most teachers in the study reported teaching spelling on a weekly basis (and junior-level teachers reported teaching phonemic awareness skills daily), and these skills were generally taught more frequently than writing processes (planning, reviewing and revising) and punctuation use (Dockrell, Marshall, \& Wyse; 2015).
} 
named none). Resources that were named included PM Writing, First steps, and (interestingly) a Lucy Calkins publication, identified by two teachers as "Teaching Primary Writing" (although this is not, in fact, a Calkins title). Finally, when asked to rate their preparedness to teach writing, in-service professional development was valued by $62 \%$ of teachers, while $70 \%$ rated the pre-service training as non-existent, or minimally or somewhat helpful.

Parr and Jesson also include a meta-review of other, recent (post 2000) New Zealand writing research. They include articles with a focus on writing in Years 1-8, published in journals or as doctoral theses. The most relevant of these are Parr and Limbrick's (2010) description of the practices of exemplary writing teachers, (which includes some discussion of these teachers' beliefs) and Timperley and Parr's (2009) investigation into teachers' use of learning goals. It is interesting to first consider the overview that Parr and Jesson provide. Significantly, this survey suggests that constructivist beliefs and methodologies predominate in the research community. ${ }^{58}$ For example, of the 13 articles surveyed, seven were classified as "descriptions of practice". These used case study designs and collected only qualitative data. Of the remaining six (all of which were classified as intervention research), just two used quantitative data to report impacts on student achievement. Notably, even for those studies that did include some quantitative measure of student achievement, constructivist beliefs about teaching were clearly articulated.

An example is Parr and Limbrick's (2010) study of exemplary teachers. These researchers used student achievement data to identify six effective teachers of writing, and followed up with observations and interviews to describe these teachers' practices. In their introduction, Parr and Limbrick state:

What effective literacy teachers do can be described but not prescribed (Mazzoni \& Gambrell, 2003). In specifying any such actions there is a risk that, in deconstructing an

\footnotetext{
58 The theoretical basis for studies was not reported. I infer constructivist orientations based on elements of the studies' methods.
} 
activity like teaching, the true complexity of expert activity is oversimplified as well as the importance of context overlooked. Effective practice is not something absolute; it varies with context. (p. 583)

In fact, Parr and Limbrick's findings seem to contradict this statement. They report that the most effective teachers in the group were very systematic and explicit in their teaching, commenting that they demonstrated "a sense of purpose and meaningfulness; of coherence [...] and of being consistent, systematic and specific" (p. 589). These expert teachers also planned carefully, and they clearly articulated learning aims, which they also shared with their students. They made links with students' prior knowledge and supported new learning through explicit teaching, scaffolding, and by providing opportunities for clarification and revision. ${ }^{59}$

Also of interest is Parr and Limbrick's exploration of teachers' beliefs. During interviews, teachers were asked how students best learned to write, and to describe effective practice. Responses were reasonably consistent, with most teachers emphasizing the importance of a supportive environment with regular opportunities for writing, of students having interesting experiences, and of students seeing good writing modeled. They also discussed the importance of sharing learning intentions and giving feedback, and the display of student work and writing supports around the classroom. Interestingly, few of the teachers emphasized their own roles in relation to student learning, and only one referred to judging her teaching effectiveness in terms of the progress her students made. These findings seem to suggest greater support for constructivist approaches to writing instruction since all of the methods mentioned could be considered to be natural learning approaches, and the use of student data was not strongly supported - though the sample size was too small to provide reliable information.

Timperley and Parr (2009) described teachers' selection and use of learning goals, their use of teaching strategies to promote student self-regulation, and the impacts of this on student

\footnotetext{
${ }^{59}$ Evidently, this is a structure that is recommended by cognitive researchers, including Zimmerman, whose research is described in Chapter Two.
} 
understandings. Conceived from a socially-oriented view of self-regulated learning, the study involved classroom observations, student interviews, and a questionnaire assessing teachers' confidence with sharing learning objectives and giving feedback. Fifteen teachers, teaching classes from Year 2 to Year 8, participated.

While this research did not investigate teachers' beliefs directly, it seems probable that teachers' goals (which, of course, reflect their teaching priorities) could offer some insight into their theoretical orientations too. A list of teaching goals is striking in that every one is content or vocabulary-related. For example (in a Year 3-4 class), "Making a piece of writing better by adding or replacing certain words" (p. 50), and (in Year 7-8), "Writing attention-grabbing, descriptive, informative orientations in the context of a recount" (p. 50). These content-related goals may indicate that these teachers' hold constructivist beliefs - for them, meaning making takes priority. It would be interesting to know how many of their students already had control over the basic mechanics of handwriting, spelling, writing in complete sentences, or organizing their writing in paragraphs.

The authors themselves are not critical of the participating teachers' goal selection; their focus was on how these goals were communicated to students. However, they do observe that, even though learning goals focused on content, the teachers' verbal feedback usually focused on mechanics, so that "these features were unwittingly promoted" (p. 58). Another observation was that the students themselves tended to focus on handwriting, spelling or punctuation. The authors' explanation for this was as follows: "It is well known that struggling writers often think of writing as a task that involves correct spelling and grammar, with the product neatly presented" (p. 57). This comment, in my view, fails to consider the difficulty of distinguishing cause and effect. Perhaps these struggling writers focus on the mechanics because they need to, in order to write at all.

McNeil and Kirk's (2013) study was not included in Parr and Jesson's meta-review as it relates only to spelling. Nonetheless, from the point of view of the present research, although 
this study is not concerned with composition, its focus on teacher beliefs makes it highly relevant.

McNeil and Kirk used an electronic survey, which was completed by 405 primary school teachers from a range of regions and socioeconomic contexts. Survey questions examined spelling assessment, instructional methods and grouping, the selection of words for spelling lists, instructional practices, beliefs about spelling, the adequacy of teacher training and professional development, and the teachers' individual perceived strengths and weaknesses. Teachers' beliefs were assessed with statements (for example "teaching letter-sound correspondences is an important component of spelling instruction", p. 552), with which respondents were required to rate their degree of agreement using a five-point Likert scale. Responses regarding teachers' beliefs were compared with those regarding instruction, with some dramatic patterns emerging: All spelling practices were valued more than they were used. For example, while $92-97 \%$ of respondents believed in teaching metalinguistic strategies, only 27-42\% taught these "most of the time" or "always" (p. 544). There was a greater match between the valuation and use of grouping students according to ability, with $67 \%$ of teachers reporting using spelling groups. This is a relatively high number (compared to U.S. studies), which, the authors speculate, may be due to the emphasis on needs based, and individualized assistance characteristic of New Zealand reading programs. A majority of teachers (69\%) felt that they had not had adequate preparation to teach spelling as part of their pre-service training, almost exactly replicating Parr and Jesson's findings regarding the pre-service training for teaching writing in general. ${ }^{60}$ The four most common weaknesses teachers identified in their programs included a lack of time to teach spelling, difficulty catering for individual needs, their own lack of knowledge, and difficulty providing instruction on spelling skills.

The authors suggested that teachers' actual practice may be even "less robust" (p. 549) than their reported practice, and identified inadequate teacher education and an over-crowded

\footnotetext{
${ }^{60}$ These are alarming statistics that should be of great concern to pre-service teacher educators.
} 
curriculum as the two main causes. Their suggestions for improving spelling education in New Zealand are practical: Initial teacher education should build training teachers' knowledge of language structures, and support them to implement evidence-based practices in the classroom. ${ }^{61}$ This article, which presents clear and compelling findings, may be further evidence that constructivist beliefs have had a significant (and problematic) impact on the teaching of basic writing skills.

\section{Conclusion}

Previous research on teachers' beliefs about writing pedagogy has produced inconsistent results, though some progress has been made, particularly in the international research. The TWOS study of Graham et al. could be considered seminal: This survey tool has been utilized a number of times in more recent research (for example, McCarthy et al., 2013; Ritchey et al., 2015; Troia et al., 2011), with quite consistent findings emerging. This body of work together indicates that three belief constructs are prevalent, including the valuation of natural learning, explicit teaching and correct writing, and that the majority of teachers favour both natural learning and explicit approaches.

Investigating the important question of the relationships between teachers' beliefs and student achievement, Ritchey et al. applied the TWOS in combination with student writing assessments. This was a promising study, though inconsistencies between teachers' reported beliefs and practices in the (relatively small) sample of just 28 participants, resulted in correlations which are difficult to interpret meaningfully. Poulson et al. (2001) examined the same question using their own survey to compare the beliefs of successful and less successful teachers. A key finding was that the more effective teachers disagreed with a 'presentation' orientation - which prioritized the teaching of spelling and handwriting skills, though the use of

\footnotetext{
${ }^{61}$ Evidently, providing clear direction for teachers about what and how to teach is at odds with the current inquiry model outlined by Parr and Jesson.
} 
newly theorized - and untested - constructs, and the absence of a rigorous measure for establishing teaching effectiveness are significant limitations of the study.

Teachers' beliefs may exert a profound influence on what they choose to teach and the methods they use. While there is some evidence that New Zealand teachers favor constructivistoriented teaching methods for writing instruction, there has been no research, to date, which focuses primarily on their beliefs. The present study is intended to address this gap, using clear definitions of belief constructs and a robust measure of student achievement, to ensure that the research is relevant and purposeful. This research may be of particular importance to the New Zealand education system, which is currently failing to achieve equitable outcomes for its students. 


\section{CHAPTER SIX: INTRODUCTION TO THE EMPIRICAL STUDIES}

Underachievement in literacy, and socially inequitable achievement, are significant problems in New Zealand. This has been evident over four cycles of PIRLS testing (2001, 2006, 2011 and 2016), in which New Zealand students achieved a lower mean score than students in most other countries, and Pakeha students performed significantly better than Māori (see Prochnow, Tunmer, \& Greaney, 2015, for a full discussion). National standards data further evince these trends. Additionally, these data demonstrate that rates of achievement are far lower in lowerdecile schools - which large proportions of Māori and Pasifika students attend - suggesting that barriers to achievement may be more related to socio-economic than ethnic or cultural factors. While the PIRLS assessments focus on reading, National Standards data indicate that writing may be an area of even greater concern. For example, data for 2014 indicate that just $78.6 \%$ of Pakeha students, $61.2 \%$ of Māori students and 59.6\% of Pasifika students achieved at the expected levels for writing, compared with $84.3 \%, 68.6 \%$ and $65.1 \%$ for reading, respectively. ${ }^{62}$

These poor results may be, at least in part, due to an adherence to constructivist approaches, and to a rejection of scientific research, by the New Zealand Ministry of Education. ${ }^{63}$ This failure to accommodate the findings of empirical research may be counterproductive to the Ministry's commitment to equity, particularly for students who struggle with the acquisition of basic literacy skills. Empirical, social cognitivist research indicates that for these students, immersion in personally meaningful tasks is not enough. Instead, a range of skills must be taught explicitly, including transcription skills (spelling and handwriting), and the

\footnotetext{
${ }^{62}$ Educational inequality is a concept that may require some further discussion. I use it to describe trends in student achievement, whereby students from particular ethnic groups, and from poorer communities, are not achieving at the same levels as other students. Social inequality and educational inequality are obviously distinct from one another, though they also impact on one another. This point makes intuitive sense, and has been explored using quantitative methods in the studies of Marie, Fegusson, and Boden (2008) and Marks (2007) - the results of which are summarized in Chapter One.

${ }^{63}$ The term constructivist is broad, and somewhat problematic. It is used by Tunmer et al. (2015), while Patel (2010) describes the Ministry's orientation with the more specific term whole language. My own review of key Ministry documents for teachers suggests that the constructivist-oriented movement, New Literacy Studies has also had significant influence (as discussed in Chapter Four).
} 
writing processes of planning, revising and self-regulation (see Chapter Two for a review of social cognitivist writing research).

Notwithstanding the Ministry's position, the beliefs and practices of New Zealand teachers, themselves, is a question that still requires investigation. Previous international studies of teachers' beliefs suggest that most teachers value both explicit and 'natural learning' (i.e. constructivist-oriented) approaches, though comprehensive work in this area has not yet been undertaken in the New Zealand setting. Another important area of investigation, not yet comprehensively studied in either the international or local context, is the relationship between teachers' beliefs and their students' progress.

The two empirical studies reported in the present work attempt to re-examine the Ministry's constructivist ideology and its impact on student achievement. The first of these is an exploration of the reported beliefs and practices for the teaching of writing of 626 New Zealand teachers, and the impact of these beliefs and practices on student achievement. In the first stage of the project, a survey was used to determine belief constructs. In the second, the progress of students in classes of teachers with a range of beliefs was compared, in order to investigate whether particular beliefs were associated with greater rates of progress. Finally, eight teachers were interviewed about their beliefs. This provided some more nuanced information about the constructs identified in the survey data.

In the second study, Fast Feedback - a system informed by social cognitivist research, and used, thus far, only in my own classrooms - is trialed to investigate its efficacy more widely, under controlled conditions. Nine teachers were engaged to trial the methods in question, teaching seven classes, in three Wellington schools. Student writing samples were collected at four time points, and were marked using an analytic rubric. Equivalent data were collected from students at a control school, allowing for a comparison of rates of progress by the participating and control groups. A student survey and teacher interviews were used to assess broader impacts of the intervention. 
It is hoped that this empirical work will go some way towards describing the "status quo" of writing teaching in New Zealand, and will provide some evidence about whether or not current approaches are helpful (or counter-productive) in efforts to raise student achievement and to reduce educational inequality. 


\section{CHAPTER SEVEN, STUDY ONE: ASSOCIATIONS BETWEEN TEACHERS' BELIEFS AND PRACTICES AND STUDENTS' PROGRESS IN WRITING}

\section{Introduction}

Previous international research in the area of teachers' beliefs indicates that most teachers value both 'natural learning' (i.e., whole language pedagogy) and explicit teaching approaches, and that a smaller proportion emphasize correctness in the teaching and learning of writing (e.g., McCarthy et al.; Ritchey et al., 2015; Troia et al., 2011 - see Chapter Five for a review). A small number of international studies have attempted to examine relationships between teachers' beliefs and student achievement (for example, Ritchey et al., 2015; Poulson et al., 2001), although results have been inconsistent.

While some New Zealand studies have surveyed teachers' practices, there has been no published research to date, which focuses primarily on their beliefs. This is the focus of the present study, which comprised three phases: In the first phase, 626 teachers were surveyed about their beliefs and practices, asked to indicate their levels of agreement with particular approaches on a four-point Likert scale and the frequency with which they engage in particular pedagogical practices, also on a four-point scale. These data were analysed using factor analysis, from which dimensions of beliefs and practices were identified. In phase two, a sub-sample of 19 teachers (representative of a range of beliefs) supplied writing samples from the students in their classes, from two time points - allowing for an analysis of student progress over time. Correlations between students' rates of progress and their teachers' scale location on each of the beliefs and practices dimensions were examined in order to establish whether any particular beliefs and practices are associated with greater rates of progress than others. In the final phase, eight teachers were interviewed about their beliefs and practices, in order to investigate these constructs in some greater depth. 
This study focused on three key questions:

1. What are the beliefs and practices of New Zealand primary teachers for the teaching of writing?

2. Are teachers' beliefs correlated with teaching practices in predictable ways?

3. Are particular beliefs and practices associated with greater rates of progress for students?

\section{METHODS}

\section{Participants}

Participants included 626 New Zealand primary teachers as survey respondents. A sub-sample (19) of this group also contributed writing samples from students in their classes. From this smaller group, eight volunteered to be case study participants, and were interviewed about their beliefs and practices relating to the teaching and learning of writing.

At the beginning of the 2018 school year, ten principals of schools in the Wellington region were approached via email. Permission was requested to distribute the survey to teachers at their schools, with a free afternoon tea offered as thanks for the teachers' participation. Six principals accepted this offer, and the survey was distributed in these schools in March and April.

In early March 2018 the New Zealand Educational Institute (the New Zealand primary teachers' union) was approached for permission to distribute the survey at some of the paid union meetings that were to be held over the following few months. ${ }^{64}$ The NZEI Leaders Organiser agreed to this, and in March and April the survey was distributed at six of the meetings held in the wider Wellington region. 65

\footnotetext{
${ }^{64}$ These meetings were held throughout New Zealand for all teachers who belong to the union, as a means of consulting with them before beginning the three yearly round of negotiations with the government regarding the terms of our collective contract.

65 These school and union meeting visits all took place in the wider Wellington region, including locations in Central Wellington, Porirua, The Hutt Valley, and the Kapiti Coast.
} 
As well as these face-to-face meetings, a link to the survey was posted on the $\mathrm{New}$ Zealand Teachers (Primary) Facebook page. One hundred and fifty teachers responded online. They were based in schools across New Zealand - in both the North and South Islands, in urban and rural communities.

In communications with teachers it was explained that participation was voluntary. An incentive was offered for completed surveys: All would go into a draw to win a $\$ 100$ gift card for the teacher and a $\$ 100$ gift card for their school.

The next stage of the study involved the collection of student writing samples, and interviews with teachers. Thirty-three teachers were contacted via email. These teachers were selected for two reasons: (i) they had indicated on their surveys that they were happy to be contacted for further research; (ii) scale locations in the factor analysis indicated that the group represented a range of different beliefs - important for the purpose of comparison. ${ }^{66}$ They were provided with information about the research, and were asked to share their class writing. A $\$ 20$ supermarket voucher was offered as thanks for participation. Nineteen of the teachers emailed agreed to share writing samples, and eight agreed to share writing samples and to be interviewed. These teachers' principals gave consent for their schools to be involved in the project.

\section{Instruments}

\section{(i) Beliefs and Practices survey}

A survey of teachers' beliefs and practices for teaching writing was developed. This was based on Graham, Harris, MacArthur, and Fink's (2001) survey. ${ }^{67}$ Graham and colleagues investigating teachers' beliefs in the North American context - identified three dimensions of belief, including: (i) agreement with natural learning approaches (similar to whole-language approaches); (ii) agreement with explicit teaching of skills; and (iii) the valuation of correctness

\footnotetext{
${ }^{66}$ Further discussion of scale locations is included in the results section of the present chapter.

${ }^{67}$ See Chapter Five for a more detailed description of this study.
} 
in writing. It was hypothesized that these three dimensions would also emerge in the New Zealand context, as well as a fourth dimension - agreement with socio-cultural approaches currently promoted by the New Zealand Ministry of Education. ${ }^{68}$

Some of Graham and colleagues' survey items were used (with minor changes made to their wording), and other items were added. These additional items were developed to investigate the fourth hypothesized dimension (agreement with socio-cultural approaches); approaches to feedback (of particular relevance to the Fast Feedback intervention of 2015); and the use of certain methods which may be particularly widespread in New Zealand schools, and which may reflect the continuing influence of Graves' Process Writing approach (specifically, the use of personal experiences as writing topics, the acceptance of "messy" or unconventional layout in students' books, and an unwillingness to allow students to use rubbers for corrections). 69

As with Graham and colleagues' survey, the present instrument included two sections. The first section measured beliefs (comprising 32 items), and the second practices (comprising 29 items). The practices items were selected to correspond to the beliefs items (although not on a one to one basis). This was to allow for an assessment of the construct validity of the survey by analysing relationships between teachers' reported beliefs and practices.

Four-point Likert scales were used to assess teachers' endorsement of each item. For the beliefs items, which were all expressed as statements, teachers were asked to rate their level agreement, selecting from strongly disagree, disagree, agree and strongly agree. For practices items, teachers were asked to indicate how often they used a practice on one of two scales, either: never, sometimes, often and almost always (for items such as my feedback to students'

\footnotetext{
${ }^{68}$ Graham and colleagues' study, as well as other international research in this area, is discussed in Chapter Five. An article by Jesson and Cockle (2016) illustrates how socio-cultural approaches may be applied to the teaching of writing. See Chapter Three for some further discussion. A review of the NZ MOE's advice to teachers can be found in Chapter Four.

${ }^{69}$ An interest in these particular methods has developed from the primary researcher's first hand experience teaching in New Zealand schools over the past 16 years.
} 
writing includes attention to sentence structure); or never, about once a term, about once a week, and more than once a week (for items such as I explicitly teach punctuation use). All survey items are listed in the table below. They are grouped according to the four hypothesized dimensions of beliefs and practices.

Table 1: Survey Items: Explicit Teaching. Beliefs items are listed in column one, and practices items in column two.

\begin{tabular}{|c|c|}
\hline Explicit Teaching: Beliefs (8 items) & Explicit Teaching: Practices (12 items) \\
\hline $\begin{array}{l}\text { Students should learn the conventions of a } \\
\text { range of writing genres. }\end{array}$ & $\begin{array}{l}\text { When conducting writing exercises, I } \\
\text { expect students to write in a genre } \\
\text { selected by me. }\end{array}$ \\
\hline $\begin{array}{l}\text { Explicit teaching of handwriting is } \\
\text { essential. }\end{array}$ & I explicitly teach handwriting. \\
\hline Explicit teaching of spelling is essential. & I explicitly teach spelling. \\
\hline $\begin{array}{l}\text { It is important to teach strategies for } \\
\text { planning for writing. }\end{array}$ & $\begin{array}{l}\text { I explicitly teach students how to develop } \\
\text { their ideas for writing. }\end{array}$ \\
\hline $\begin{array}{l}\text { Writing programmes are most effective } \\
\text { when developed on the basis of research } \\
\text { findings. }\end{array}$ & $\begin{array}{l}\text { When planning writing programmes, I } \\
\text { consider research evidence about effective } \\
\text { practice. }\end{array}$ \\
\hline $\begin{array}{l}\text { Teachers should monitor students' } \\
\text { progress in order to select appropriate } \\
\text { learning goals for them. }\end{array}$ & I select students' learning goals for them. \\
\hline $\begin{array}{l}\text { Learning goals should be introduced and } \\
\text { explained by teachers. }\end{array}$ & $\begin{array}{l}\text { I introduce and explain learning goals to } \\
\text { students. }\end{array}$ \\
\hline \multicolumn{2}{|l|}{$\begin{array}{l}\text { It is important to teach strategies for the } \\
\text { revision of writing. }\end{array}$} \\
\hline & $\begin{array}{l}\text { My feedback to students includes attention } \\
\text { to punctuation. }\end{array}$ \\
\hline & $\begin{array}{l}\text { When students are unsure of how to spell } \\
\text { a word, I encourage them to copy the } \\
\text { correct spelling from a dictionary, word } \\
\text { card or wall display. }\end{array}$ \\
\hline & $\begin{array}{l}\text { My feedback on students' writing includes } \\
\text { attention to sentence structure. }\end{array}$ \\
\hline & I explicitly teach punctuation use. \\
\hline & $\begin{array}{l}\text { I explicitly teach correct sentence } \\
\text { structure. }\end{array}$ \\
\hline & I conference with students one-on-one. \\
\hline
\end{tabular}

Table 2: Survey Items: Valuation of Correctness in Writing. Beliefs items are listed in column one, and practices items in column two.

\begin{tabular}{|l|l|}
\hline $\begin{array}{l}\text { Valuation of Correctness in Writing: Beliefs } \\
\text { (7 items) }\end{array}$ & $\begin{array}{l}\text { Valuation of Correctness in Writing: } \\
\text { Practices (3 items) }\end{array}$ \\
$\begin{array}{l}\text { Students should be encouraged to keep } \\
\text { their draft books tidy. }\end{array}$ & My feedback to students includes \\
& reminders to keep their writing tidy.
\end{tabular}




\begin{tabular}{|l|l|}
\hline $\begin{array}{l}\text { Students should use rubbers to correct } \\
\text { mistakes in their draft books. }\end{array}$ & $\begin{array}{l}\text { When children make errors in their } \\
\text { writing, I encourage them to correct them } \\
\text { using a rubber. }\end{array}$ \\
\hline $\begin{array}{l}\text { It is important to teach children to } \\
\text { structure sentences correctly. }\end{array}$ & $\begin{array}{l}\text { After reading a student's writing, I request } \\
\text { that the student corrects any errors in } \\
\text { their work. }\end{array}$ \\
$\begin{array}{l}\text { It is important to teach children correct } \\
\text { punctuation use. }\end{array}$ & \\
$\begin{array}{l}\text { It is important that students learn to use } \\
\text { writing conventions correctly. }\end{array}$ & \\
$\begin{array}{l}\text { Students should be encouraged to copy } \\
\text { words they do not yet know how to spell. }\end{array}$ & \\
$\begin{array}{l}\text { Students should be encouraged to re-read } \\
\text { and correct their sentence structures. }\end{array}$ & \\
\hline
\end{tabular}

Table 3: Survey Items: Whole Language/Process Writing Approaches. Beliefs items are listed in column one, and practices items in column two.

\begin{tabular}{|c|c|}
\hline $\begin{array}{l}\text { Whole Language/Process Writing: Beliefs } \\
\text { (11 items) }\end{array}$ & $\begin{array}{l}\text { Whole Language/Process Writing: Practices } \\
(10 \text { items) }\end{array}$ \\
\hline $\begin{array}{l}\text { Students should have frequent } \\
\text { opportunities to write about their personal } \\
\text { experiences. }\end{array}$ & $\begin{array}{l}\text { When conducting writing exercises, I } \\
\text { encourage students to write about their } \\
\text { personal experiences. }\end{array}$ \\
\hline $\begin{array}{l}\text { Students should select their own topics for } \\
\text { writing. }\end{array}$ & $\begin{array}{l}\text { When conducting writing exercises, I } \\
\text { encourage students to choose their own } \\
\text { topics. }\end{array}$ \\
\hline $\begin{array}{l}\text { Instead of telling students how to spell } \\
\text { words, teachers should encourage them to } \\
\text { spell as best they can. }\end{array}$ & $\begin{array}{l}\text { When students are unsure of how to spell } \\
\text { a word, I encourage them to approximate } \\
\text { it, rather than providing the conventional } \\
\text { spelling. }\end{array}$ \\
\hline $\begin{array}{l}\text { The most important aspect of a student's } \\
\text { writing is the ideas it expresses. }\end{array}$ & $\begin{array}{l}\text { After reading a student's writing, I request } \\
\text { further development of ideas expressed in } \\
\text { the writing. }\end{array}$ \\
\hline $\begin{array}{l}\text { Teachers' feedback should focus primarily } \\
\text { on students' ideas. } \\
\text { When students are motivated to write, } \\
\text { their writing skills develop naturally - } \\
\text { without the need for explicit instruction. }\end{array}$ & $\begin{array}{l}\text { My feedback on students writing includes } \\
\text { attention to the ideas that they express. } \\
\text { When conducting writing exercises, I } \\
\text { encourage students to engage in free } \\
\text { writing, with no set learning goals. }\end{array}$ \\
\hline $\begin{array}{l}\text { Students' writing skills develop by sharing } \\
\text { their work with peers. }\end{array}$ & $\begin{array}{l}\text { I facilitate students sharing their writing } \\
\text { with each other. }\end{array}$ \\
\hline $\begin{array}{l}\text { Students should be encouraged to select } \\
\text { their own learning goals for writing. }\end{array}$ & $\begin{array}{l}\text { Students select their own learning goals } \\
\text { for their writing. }\end{array}$ \\
\hline $\begin{array}{l}\text { A "messy" draft book may be a sign of deep } \\
\text { engagement in the writing process. }\end{array}$ & $\begin{array}{l}\text { I accept unconventional layout in my } \\
\text { students' draft writing books. }\end{array}$ \\
\hline $\begin{array}{l}\text { Writing programmes are most effective } \\
\text { when developed on the basis of teachers' } \\
\text { personal judgment. }\end{array}$ & $\begin{array}{l}\text { When I plan writing programmes I use my } \\
\text { personal judgment about what will work. }\end{array}$ \\
\hline $\begin{array}{l}\text { Students' engagement in the writing } \\
\text { process is more important than the quality } \\
\text { of the written work they produce. }\end{array}$ & \\
\hline
\end{tabular}


Table 4: Survey Items: Socio-cultural items. Beliefs items are listed in column one, and practices items in column two.

\begin{tabular}{|l|l|}
\hline Socio-Cultural Approaches: Beliefs (4 items) & $\begin{array}{l}\text { Socio-Cultural Approaches: Practices (3 } \\
\text { items) }\end{array}$ \\
\hline $\begin{array}{l}\text { It is good practice to let students write in } \\
\text { their own dialects rather than insisting on } \\
\text { conventional English. }\end{array}$ & $\begin{array}{l}\text { When conducting writing exercises, I } \\
\text { encourage students to write in their own } \\
\text { dialects. }\end{array}$ \\
\hline $\begin{array}{l}\text { Writing tasks are most effective when they } \\
\text { reflect the cultural backgrounds of } \\
\text { students. }\end{array}$ & $\begin{array}{l}\text { When conducting writing exercises, I } \\
\text { encourage students to write on topics that } \\
\text { relate to their cultural backgrounds. }\end{array}$ \\
\hline $\begin{array}{l}\text { It is important that students have } \\
\text { opportunities to lead discussions during } \\
\text { writing lessons, with the teacher taking on } \\
\text { a facilitator role. }\end{array}$ & $\begin{array}{l}\text { When I conduct whole-class discussions } \\
\text { during writing lessons I encourage } \\
\text { students to lead. }\end{array}$ \\
\hline $\begin{array}{l}\text { It is important that students have } \\
\text { opportunities to use their cultural } \\
\text { knowledge during writing lessons. }\end{array}$ & \\
\hline
\end{tabular}

\section{(ii) Fast Feedback Marking Rubric}

A tool commonly used in New Zealand for direct writing assessment is e-asTTle, first released by the Ministry of Education in 2003 and updated in 2012. Because it uses a comparatively reliable analytic scoring system, and because I have had considerable experience using this tool as a classroom teacher, I used it for both studies. I needed, however, to modify it for my specific purposes. There were two reasons for this: (i) e-asTTle incorporates an analytic rubric, which scores seven aspects of writing (ideas, structure and language, organisation, vocabulary, sentence structure, spelling and punctuation). Children write to set prompts, and for the structure and language aspect criteria differ depending on which prompt is used. Since the draft samples were written in my absence I was not always aware of the specific tasks that had been set, and of their associated purposes or genres. This meant that I could not mark the e-asTTle "Structure and Language" component. (ii) An e-asTTtle assessment begins with a brief teacherled discussion. Students then write for up to 40 minutes, with no spelling aids available for checking (Ministry of Education, 2015). However, I needed to assess, on the basis of draft writing samples, samples produced under normal classroom conditions (rather than in test-like 
conditions). Other modifications were also made in an attempt to more clearly distinguish levels of achievement and more clearly describe indicators for each level.

The modified rubric (Appendix ii) assesses seven aspects of writing: handwriting, spelling, sentence structures (with a focus on grammatical correctness), punctuation, ideas (in terms of their coherence), organisation, and language features (focusing on impact). Handwriting was included to identify any participants with a handwriting difficulty. Three categories were applied here: (i) beginning writers who are not yet able to write any letters; (ii) students who, while they are able to form letters, demonstrate confusions and difficulties (reversals, for example); (iii) those who have no apparent difficulties. Handwriting - which is not part of e-asTTle - aside, it should be noted that while e-asTTle assesses Structure and Language in terms of its purpose, the modified rubric assesses this aspect only indirectly, through the indicators provided for the assessment of higher level ideas and language. It should also be noted that my rubric generally employs fewer levels than e-asTTle. This is because I needed to assess students working at levels one to three of the curriculum. I also needed to revise the vague and thus potentially confusing wording of some indicators of e-asTTle. For example, for punctuation, Level one is described in e-asTTle as "Little, no or random punctuation", and Level two as "Experimentation with sentence punctuation". In the modified rubric, Level one is described as "Punctuation is used randomly or not at all", and Level two as "Minimal correct use of sentence punctuation".

The rubric was initially tested by me and a research group made up of two post graduate students and two lecturers. It was trialled with 12 coded samples, and an inter-rater-reliability correlation (of all aspects combined) was established: $r=0.79$. Some small difficulties in using the rubric were discussed by this group. They included a degree of inconsistency in the wording used for indicators, an unpopulated stage in the structure aspect, and too great a differentiation between the first spelling stages (with no levels to mark the earliest progressions of emergent writers). Changes were made accordingly. Forty samples were marked for a second time by one 
of the supervisors of the project, and this produced a stronger level of inter-rater reliability $(\mathrm{r}=0.89)$.

Certain criteria governed the selection of writing samples for assessment: They were to be taken from students' draft writing books; it was required that they were produced at two time points, at the beginning of the school year (late January or early February) and at the end of the second term (approximately 20 school weeks on, in late July or early August); prose writing was chosen over poetry; and samples were checked for any evidence of copying from a teacher model.

(iii) Interview Schedule

Eight case-study teachers were interviewed. The primary purpose of these interviews was to obtain qualitative data that could be used to assess the validity of the survey data. It was also hoped that these qualitative data would help to illustrate the complexities of teachers' beliefs, which are impossible to capture with a survey alone. Two survey items, in particular, were of interest as they showed nearly unanimous response patterns across the whole sample. These were: Students should be encouraged to use rubbers to correct mistakes in their draft books (92\% of respondents disagreed or strongly disagreed), and It is important that students have frequent opportunities to write about their personal experiences (to which $98 \%$ of respondents agreed or strongly agreed). Finally, the interviews were used to obtain some information on teachers' use of technology for the teaching of writing - something that had not been investigated in the survey. The following interview schedule was emailed to the teachers a few days before our meeting:

1. Could you describe some key aspects of your writing programme?

2. Could you describe your philosophy for the teaching of writing?

3. Can you identify some influences on you as a writing teacher?

4. How do you evaluate the effectiveness of your writing programme? 
5. Do you use digital technology for teaching writing? What do you see as the pros and cons of using technology for the teaching of writing?

6. In your survey, you indicated that you [strongly agree/agree/disagree/strongly disagree] with the item: Students should use rubbers to correct mistakes in their draft books. Please talk about your response to this item.

7. In your survey, you indicated that you indicated that you [agree/agree/disagree/strongly disagree] with the item: Students should have frequent opportunities to write about their personal experiences. Please talk about your response to this item.

Six of the eight case study teachers were Wellington-based, and so these interviews were held in person. The non-Wellington teachers were interviewed over the phone. All interviews were recorded, transcribed and coded.

\section{Procedure}

The survey was administered in March and April 2018. Following a factor analysis, it was possible to identify teachers who were extreme on the dimensions of belief and practice allowing for clearer comparison. Thirty-three of these teachers were approached via email with a request for writing samples from the students in their classes, and nineteen agreed to participate. Of the 19 teachers who shared writing samples, 17 worked at schools in Wellington. This made it possible for me to photograph student writing myself, without inconveniencing the teachers. Student writing was photographed from all students who had work available from both time points. The two non-Wellington teachers took the photos of student work themselves, and shared these by email. These teachers were asked to provide work from all of the students in their classes, or to randomly select half their students (by photographing the work of every second student on their alphabetically-ordered class roll). One teacher provided samples for her whole class, and the other provided just half. Names were replaced with codes on all samples to protect the anonymity of the students. In total, the work of 207 students was marked, yielding a total of 414 writing samples. 
Correlations between measures of student progress and teachers' beliefs and practises were calculated to determine which were associated with greater and lesser rates of progress. Interviews were held with eight teachers in order to assess the validity of the survey, and to gain a more nuanced understanding of the nature of their beliefs. Interview transcripts were coded, allowing for single case and cross case analysis of teachers' beliefs and practices.

\section{Analysis}

For teachers' beliefs items, a principal components analysis with varimax rotation was used. For both beliefs and practices sections, items that were negatively correlated with other items associated with the same dimensions were reverse coded.

Individual items associated with each dimension (principal component) were calibrated using a single-parameter graded response model (see Samejima, 1969), and teachers' scale locations for each factor were identified. Writing rubric items were similarly calibrated, and students' scale locations at each time point were identified. This calibration procedure produces a measurement scale with interval properties - as opposed to the ordinal properties of the individual aspects of the rubric - allowing for a quantitative measure of progress. This was necessary in order to investigate the possibility that certain beliefs and practices are associated with greater (or lesser) rates of progress. Correlations of teachers' scale locations for beliefs and practices, with students' progress over time were calculated - for dimensions of beliefs and practices, as well as for individual survey items.

Teacher interviews were coded following the phases of thematic development identified by Creswell (2013). For interview comments related to beliefs, the process began with a set of four predetermined codes, based on the four hypothesized beliefs dimensions (explicit teaching, the valuation of correctness, socio-cultural approaches and process writing approaches). Seven further codes were generated during the analysis process, in order to more accurately capture detail in the data (for example, from the explicit teaching code, subcodes including the explicit 
teaching of technical skills, and explicit teaching of writing content, were generated). This process resulted in a total of eleven beliefs-related codes.

In a second phase, a single case study model was used to explore whether individual teachers' interview data appeared to be aligned with their scale locations for dimensions from the survey. Trends in the coding from each teachers' interview was compared with their survey scale locations. This allowed for some exploration of the validity of the survey data.

Interview comments relating to uses of technology, erasing by students, and personal experience writing, were initially coded to indicate whether teachers had expressed agreement or disagreement with the approaches in question. The comments were then sorted according to sub-codes that reflected teachers' reasoning. A cross-case analysis was applied to explore the variations and complexities of teachers' beliefs about these approaches.

\section{Ethical Considerations}

Ethical approval was granted by the Victoria University of Wellington Human Ethics Committee in December 2017. Care was taken to avoid placing pressure on teachers and schools to participate: Teachers and principals were provided with written information which outlined the aims and the methods of the study, and the ways in which the information would be used. It was explained that participation was voluntary, and that participants could withdraw from the study at any time before October, 2018. Methods for data collection and storage were designed to protect participants' anonymity: Participants' names were to be known only to the researcher and her supervisors, and not revealed in any publications. Information provided by participants were to be kept securely and destroyed on the $1^{\text {st }}$ of January, 2019. Examples of the informations sheets and consent forms used are provided as Appendices (VI-X). 


\section{RESULTS}

\section{Beliefs Survey: Principal Components Analysis}

A principal components analysis revealed three dimensions of teachers' beliefs, characterized by agreement with explicit teaching, socio-cultural, and process writing approaches. ${ }^{70}$

These three dimensions accounted for $16.7 \%, 11.3 \%$ and $5.5 \%$ of the total variance respectively, with an evident plateauing of the proportions of variance explained by additional dimensions. For example a fourth dimension explained $4.7 \%$ of variance, almost as much as the third and little more than an individual item would have accounted for if the data were unstructured. Furthermore, this solution retained all but four of the items, with minimal cross loadings, and all three dimensions were readily interpretable. They were comparable with dimensions of belief identified in international research (for example, Graham et al. 2002), and reflected approaches described in New Zealand writing research (for example, Jesson and Cockle, 2016). Five survey items did not have substantial associations with any of the three dimensions. Table 5 lists the items associated with each dimension.

\footnotetext{
${ }^{70}$ Without wanting to over-simplify the problems of definition, these categories are based on my review of the literature. The use of succinct labels is necessary to maintain coherence in the discussion that follows.
} 
Table 5: Items associated with each of the three dimensions of the beliefs survey, with association strengths. Negatively correlated items are displayed in bold. Factor loadings less than .3 are suppressed.

\begin{tabular}{|c|c|c|c|}
\hline & $\begin{array}{l}\text { Explicit } \\
\text { Teaching }\end{array}$ & $\begin{array}{r}\text { Socio- } \\
\text { cultural } \\
\text { approaches }\end{array}$ & $\begin{array}{r}\text { Process } \\
\text { writing } \\
\text { approaches }\end{array}$ \\
\hline Eigenvalue: & 4.7 & 3.2 & 1.5 \\
\hline Percentage of variance accounted for: & 16.7 & 11.6 & 5.5 \\
\hline It is important to teach children correct punctuation use. & 0.75 & & \\
\hline It is important that students learn to use writing conventions correctly. & 0.69 & & \\
\hline Explicit instruction in writing skills is essential. & 0.67 & & \\
\hline $\begin{array}{l}\text { Students should be encouraged to re-read and correct their punctuation } \\
\text { use. }\end{array}$ & 0.63 & & \\
\hline $\begin{array}{l}\text { Students should be encouraged to re-read and correct their sentence } \\
\text { structures. }\end{array}$ & 0.63 & & \\
\hline It is important to teach children to structure sentences correctly. & 0.59 & & \\
\hline It is important to teach strategies for revision of writing. & 0.55 & & \\
\hline $\begin{array}{l}\text { Teachers should monitor students' progress in order to select } \\
\text { appropriate learning goals for them. }\end{array}$ & 0.52 & & \\
\hline Explicit teaching of spelling is essential. & 0.52 & -0.32 & \\
\hline It is important to teach strategies for planning for writing. & 0.51 & & \\
\hline Learning goals should be introduced and explained by teachers. & 0.48 & & \\
\hline Explicit teaching of handwriting is essential. & 0.44 & -0.4 & \\
\hline Students should learn the conventions of a range of writing genres. & 0.36 & & \\
\hline $\begin{array}{l}\text { It is important that students have opportunities to use their cultural } \\
\text { knowledge during writing lessons. }\end{array}$ & & 0.62 & \\
\hline $\begin{array}{l}\text { It is important that students have opportunities to lead discussions } \\
\text { during writing lessons, with the teacher taking on a facilitator role. }\end{array}$ & & 0.6 & \\
\hline $\begin{array}{l}\text { Students should be encouraged to select their own learning goals for } \\
\text { writing. }\end{array}$ & & 0.53 & \\
\hline Students should be encouraged to keep their draft books tidy. & 0.35 & -0.49 & \\
\hline $\begin{array}{l}\text { A "messy" draft book may be a sign of deep engagement in the writing } \\
\text { process. }\end{array}$ & & 0.47 & \\
\hline $\begin{array}{l}\text { Writing tasks are most effective when they reflect the cultural } \\
\text { backgrounds of students. }\end{array}$ & & 0.47 & 0.31 \\
\hline Students should select their own topics for writing. & & 0.4 & \\
\hline $\begin{array}{l}\text { Students should use rubbers to correct mistakes in their draft } \\
\text { books. }\end{array}$ & & -0.35 & \\
\hline $\begin{array}{l}\text { The most important aspect of a student's writing is the ideas it } \\
\text { expresses. }\end{array}$ & & & 0.64 \\
\hline Teachers' feedback should focus primarily on students' ideas. & & & 0.63 \\
\hline $\begin{array}{l}\text { Student's engagement in the writing process is more important than the } \\
\text { quality of the written work they produce. }\end{array}$ & & & 0.56 \\
\hline $\begin{array}{l}\text { It is good practice to let students write in their own dialects rather than } \\
\text { insisting on conventional English. }\end{array}$ & & & 0.46 \\
\hline $\begin{array}{l}\text { When students are motivated to write, their writing skills develop } \\
\text { naturally - without the need for explicit instruction. }\end{array}$ & & & 0.44 \\
\hline Student's writing skills develop by sharing their work with peers. & & 0.33 & 0.39 \\
\hline $\begin{array}{l}\text { Instead of telling students how to spell words, teachers should } \\
\text { encourage them to spell as best they can. }\end{array}$ & & & 0.36 \\
\hline
\end{tabular}

All of the hypothesized explicit teaching items were correlated with the explicit teaching

beliefs dimension, and five of the hypothesized correctness beliefs were also associated with this 
dimension. In sum, the explicit teaching dimension reflects a prioritization of the teaching of transcription skills, sentence structures, writing processes (planning and revising), and the conventions of a range of genres. Teachers with affiliation to this dimension tend to select learning goals for their students and to encourage them to revise their writing.

Three of the four hypothesized socio-cultural items emerged in the socio-cultural beliefs dimension, as did an additional three items that had been hypothesized to correlate with process-writing beliefs: students should select their own goals for writing, students should select their own topics for writing and, a "messy" draft book may be a sign of deep engagement in the writing process. Two other items, hypothesized to reflect a valuation of correctness in writing, were negatively associated with this dimension. These were, students should be encouraged to keep their draft books tidy, and students should use rubbers to correct mistakes in their draft books. Overall, the socio-cultural beliefs dimension reflects the prioritization of student choice and leadership in the classroom, the use of cultural knowledge as motivation for writing, and a reluctance to impose standards of correctness or tidiness on students.

Six of the eleven hypothesized process-writing items were associated with the process writing beliefs dimension, as well as an additional item that had been hypothesized to be associated with the socio-cultural dimension (it is good practice to let students write in their own dialects rather than insisting on conventional English). The process-writing dimension reflects emphasis on motivation and implicit learning, and on students' ideas as a focus for teaching. Tolerance of invented spelling and sharing work with peers are other key elements of this dimension.

Notably, the co-dimensionality of the explicit teaching and correctness items shows that these beliefs amount to a broad school of thought, distinct from socio-cultural and processwriting philosophies. As we have seen, there was some crossover in these two latter dimensions, with items predicted to load on one, actually loading on the other. This may reflect the shared constructivist ideology from which these movements have developed. 
An item predicted to correlate with the process-writing dimension, students should be given frequent opportunities to write about their personal experiences, did not actually load with any of the three dimensions, due to a lack of variability in responses. It received very high levels of agreement across the sample - $98 \%$ of teachers expressed agreement or strong agreement with this statement. Other items which did not load on any dimension include, writing programmes are most effective when developed on the basis of research findings; writing programmes are most effective when developed on the basis of teachers' personal judgement; and children should be encouraged to copy words they do not yet know how to spell. Responses to these items were relatively evenly distributed across the four-point scale.

A fourth dimension, a valuation of correct writing, hypothesized on the basis of Graham and colleagues' survey (2002) did not emerge. As we have seen, under a three-dimension solution, most of these items were subsumed within the explicit teaching dimension, and two further items (Students should use rubbers to correct mistakes in their draft books and Students should be encouraged to keep their draft books tidy) were dis-endorsed by $92 \%$ and $52 \%$ of survey respondents respectively, and were negatively correlated with the socio-cultural approaches dimension.

\section{Explicit teaching beliefs}

Figure 1 shows the distributions of responses to the explicit teaching items. Survey respondents were quite homogenous in their beliefs in respect of this dimension. Over $80 \%$ expressed agreement or strong agreement with each of the explicit teaching items. 
Figure 1: Distribution of teachers' responses to the individual items associated with the belief in explicit teaching dimension. Vertical bars denote standard errors of percentages.

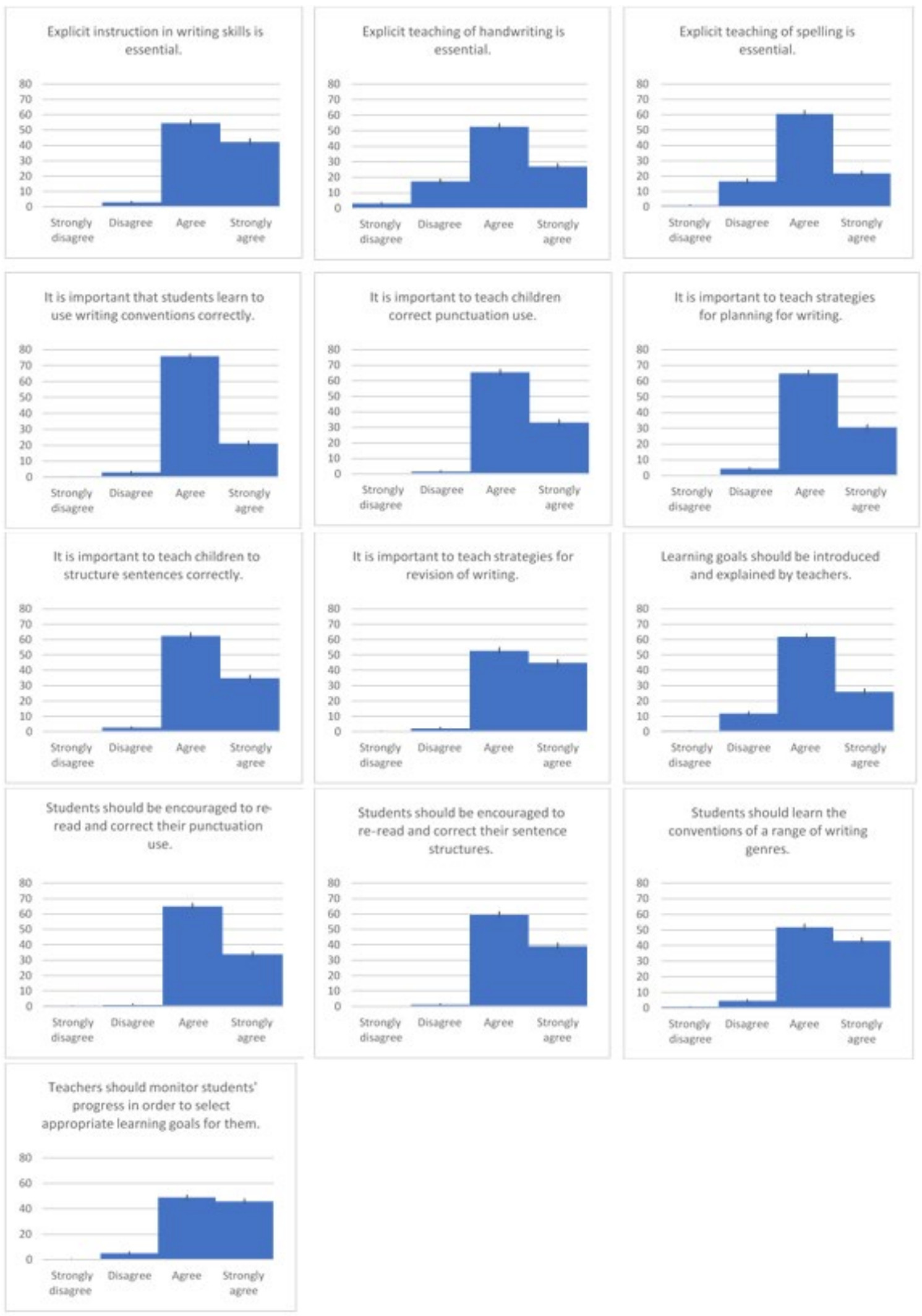


Socio-cultural beliefs

Figure 2 shows the distributions of responses to the socio-cultural beliefs items. There were slightly lower levels of agreement with these items, than with explicit teaching items. Over $80 \%$ of teachers expressed agreement or strong agreement with five of the seven items, and over $50 \%$ expressed disagreement or strong disagreement with the remaining two, both of which were negatively correlated with the socio-cultural beliefs dimension. 
Figure 2: Distribution of teachers' responses to the individual items associated with the belief in socio-cultural approaches dimension. Vertical bars denote standard errors of percentages.
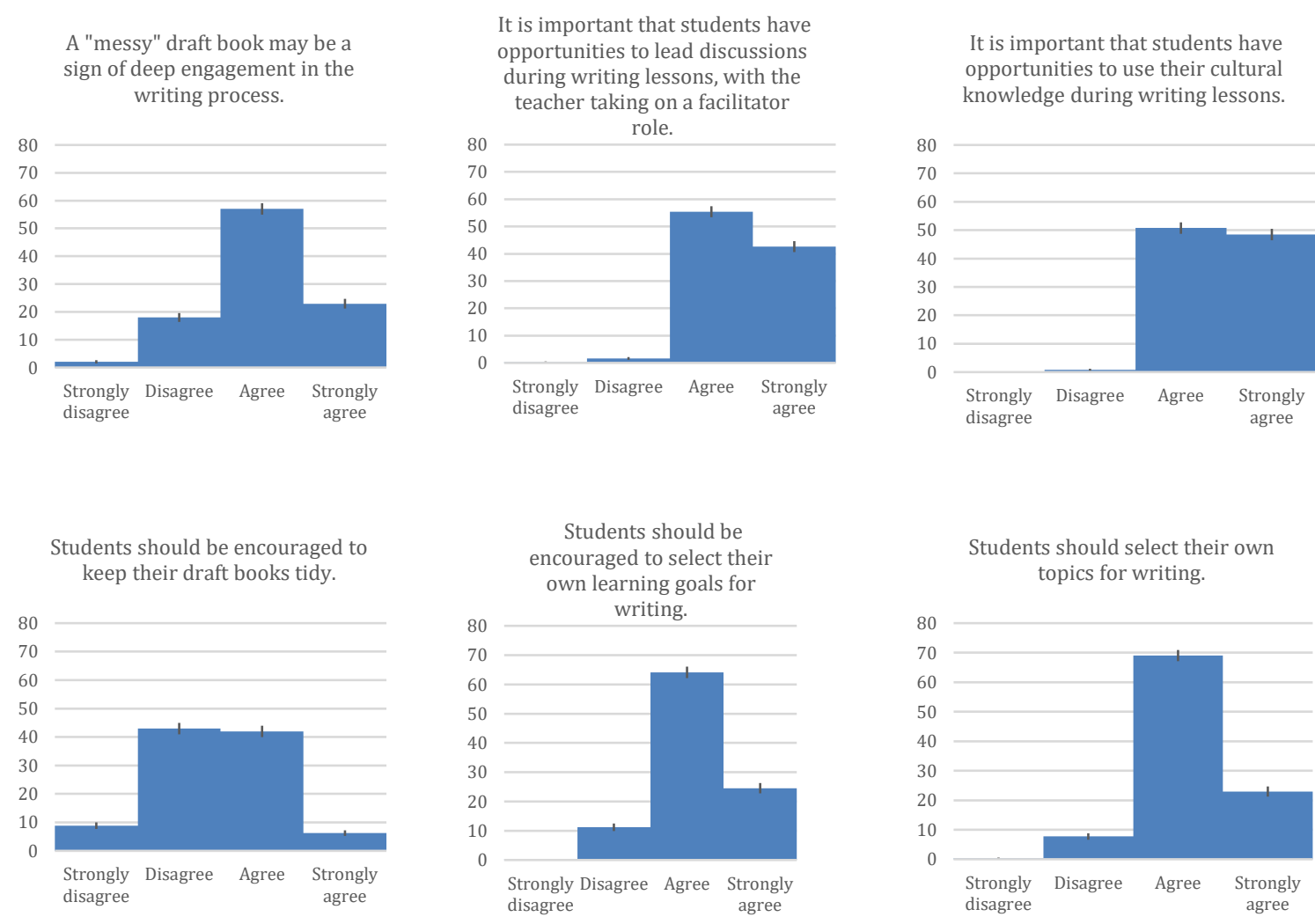

Students should use rubbers to correct mistakes in their draft books.

Writing tasks are most effective when they reflect the cultural backgrounds of students.
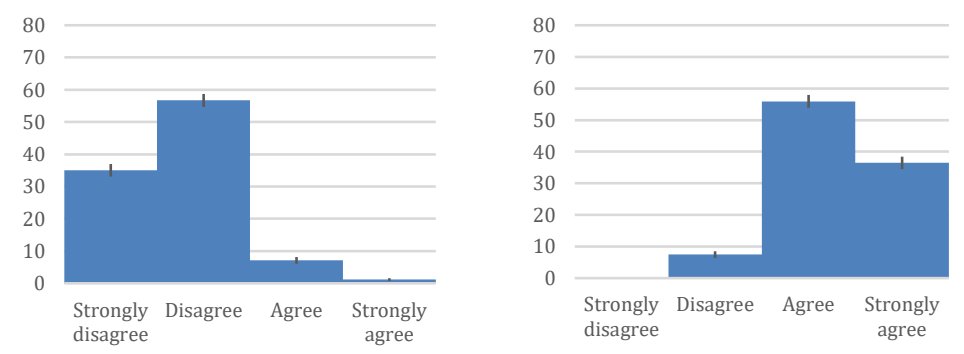

\section{Process writing}

Figure 3 shows distributions of response to the process-writing beliefs items. Over $70 \%$ of teachers expressed agreement or strong agreement with five of the seven process writing items.

The sample was more divided on two other items - almost equal numbers agreed or disagreed 
with the statements, feedback should focus primarily on students' ideas, and when students are motivated to write, their skills develop naturally, without the need for explicit instruction.

Figure 3: Distribution of teachers' responses to the individual items associated with the belief in process writing approaches dimension. Vertical bars denote standard errors of percentages. Component loadings of less than .3 are suppressed.
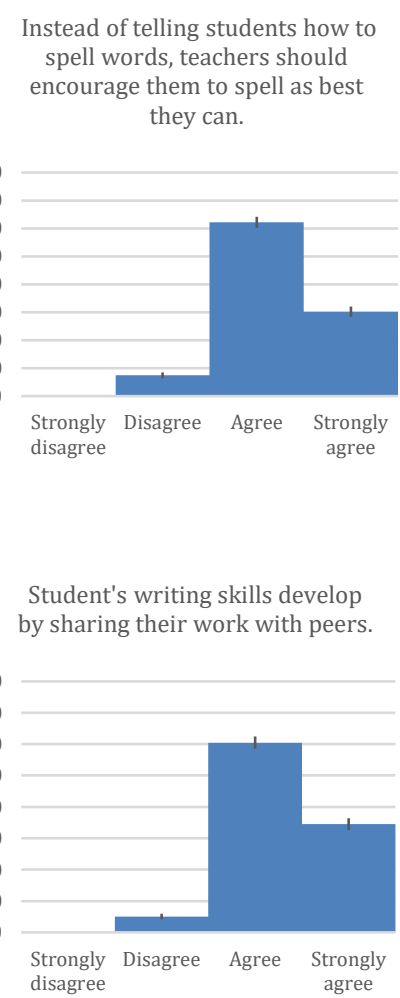

When students are motivated to write, their writing skills develop naturally - without the need for explicit instruction.

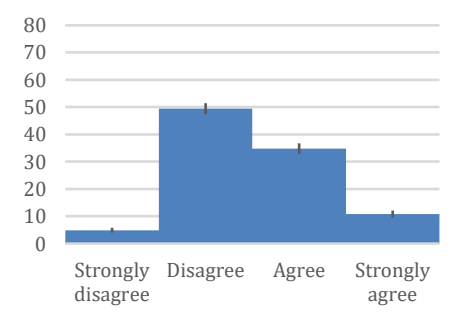

It is good practice to let students write in their own dialects rather than insisting on conventional English.

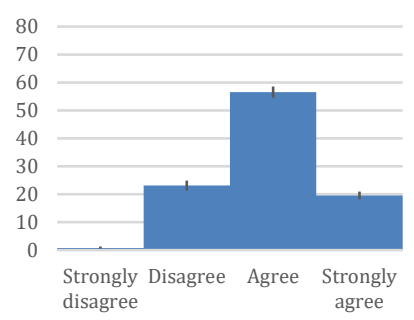

Teachers' feedback should focus primarily on students' ideas.

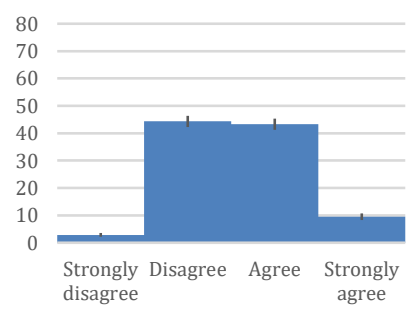

Student's engagement in the writing process is more important than the quality of the written work they produce.

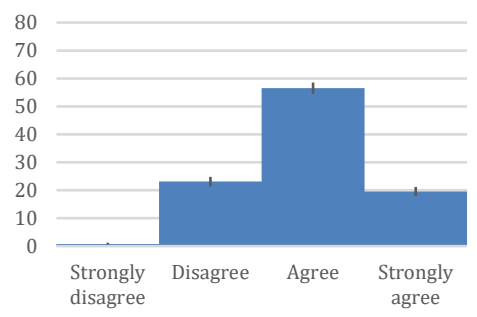

The most important aspect of a student's writing is the ideas it expresses.

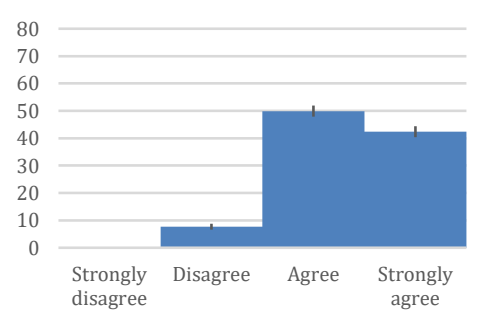

Items that did not load in any of the beliefs dimensions

Figure 4 shows distributions of response to the items that did not load in any of the beliefs dimensions. An overwhelming majority of respondents - 98\% - agreed or strongly agreed with 
the item, students should have frequent opportunities to write about their personal experiences; so that it did not correlate more strongly any one dimension. Responses to the three remaining items were more evenly distributed, with just over $50 \%$ of all respondents expressing agreement or strong agreement with them: students should be encouraged to copy words they do not yet know how to spell; writing programmes are most effective when developed on the basis of research findings; and writing programmes are most effective when developed on the basis of teachers' personal judgement.

Figure 4: Distribution of response to the items that did not load in any of the beliefs dimensions
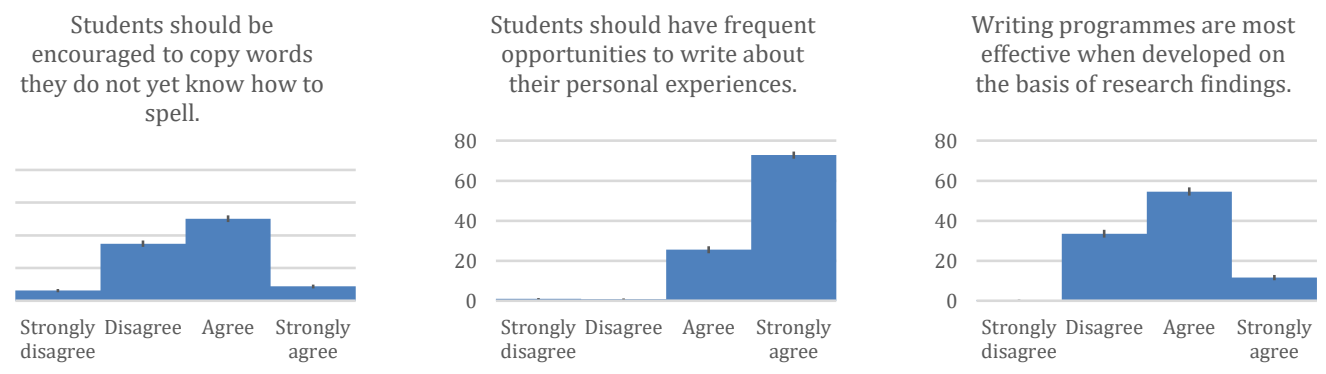

Writing programmes are most effective when developed on the basis of teachers' personal judgement.

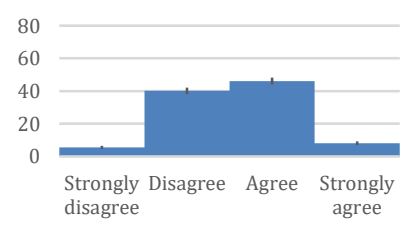

\section{Practices Survey: Principal Components Analysis}

A six-component solution was selected for the principal components analysis of the practices questionnaire, including (i) the use of explicit and structured practices, (ii) the use of process writing and socio-cultural approaches, (iii) an emphasis on surface features, (iv) an emphasis on advanced writing skills, (v) an emphasis on basic writing skills and (vi) the use of student goal selection. The greater number of practices dimensions than beliefs dimensions may be explained by the division of hypothesised explicit teaching items into three separate dimensions, and by a negative correlation between the basic writing practices dimension and 
teaching higher year levels ( $\mathrm{r}=-0.51)$. This finding supports the hypothesis that the basic writing dimension describes junior school teaching practices. It would have been possible to select a five-dimension solution, but this would have resulted in a slightly less interpretable structure on some of the dimensions, with more between-dimension cross-loadings occurring. The sixfactor solution was a break point in the scree plot after which the eigenvalues plateaued. The correlations of each item to its associated dimension are presented in Table 6.

Six of the twelve hypothesized explicit teaching practices items were associated with the explicit and structured practices dimension, and one hypothesized process-writing item (I facilitate students sharing their work with others). This dimension reflects explicit teaching of spelling, punctuation, sentence structure and the development of ideas, and the use of structured pedagogy, including teacher selected goals, one-on-one conferencing and students sharing writing with each other. This final item appears something of an anomaly - though it may reflect an intentional approach to classroom routines on the part of the teacher.

The second practices dimension reflected both process writing and sociocultural approaches. It describes practices that encourage student choice and leadership, the provision of opportunities for free writing, and the use of tasks that reflect students' cultural knowledge. Teachers high on this dimension tend to encourage their students to write in their own dialects, and to accept unconventional layout. It is interesting that process writing and socio-cultural approaches produced two distinct dimensions for beliefs, but in the practices data these merged into a single dimension.

The third practices dimension has been labelled attention to surface features. It included five items that were hypothesized to load in the explicit and correct writing dimensions. This dimension represents a focus on technical aspects of writing such as sentence-structure, punctuation and tidy work, and on correctness (the use rubbers to correct errors, and of spelling resources to correct misspelt words). 
The fourth dimension was labelled advanced writing practices. It represents a variety of practices, and included items that were hypothesized to load on explicit teaching, process writing and correctness dimensions. The items collectively reflect high expectations of students across a range of skills. These include writing for a range of genres, development of ideas beyond a first draft, and correction of errors.

Dimension five, labelled basic writing included just three items. These three practices seem most likely to be used with younger or less skilled writers. They include the use of personal experiences as topics for writing, the use of approximated spelling, and the explicit teaching of handwriting.

The sixth dimension, teacher chooses goals, included just two items: I select students' learning goals for them and the negatively correlated, students select their own learning goals for writing. Evidently, this dimension reflects agreement with just one practice - teacher goal selection.

The only item that did not load in any of the practice dimensions was, when I plan writing programmes I consider research evidence about expected practice. Responses were spread across all four points of the scale, though more than $50 \%$ of teachers reported that they engaged with research 'often', or 'almost always'. 
Table 6: Items associated with each of the six practices dimensions, with association strengths. Negatively correlated items are displayed in bold. Factor loadings less than .3 are suppressed.

\begin{tabular}{|c|c|c|c|c|c|c|}
\hline & $\begin{array}{r}\text { Explicit } \\
\text { teaching }\end{array}$ & $\begin{array}{r}\text { Socio- } \\
\text { cultural } \\
\text { approaches }\end{array}$ & $\begin{array}{r}\text { Attention } \\
\text { to surface } \\
\text { features }\end{array}$ & $\begin{array}{r}\text { Advanced } \\
\text { writing } \\
\text { skills }\end{array}$ & $\begin{array}{r}\text { Basic } \\
\text { Writing } \\
\text { Skills } \\
\end{array}$ & $\begin{array}{r}\text { Student } \\
\text { goal } \\
\text { selection }\end{array}$ \\
\hline Eigenvalues: & 3.4 & 3.1 & 2.3 & 1.7 & 1.4 & 1.2 \\
\hline Percentage of variance: & 12.3 & 11.1 & 8.4 & 6.2 & 5.1 & 4.1 \\
\hline I explicitly teach punctuation use. & 0.74 & & & & & \\
\hline I explicitly teach correct sentence structure. & 0.74 & & & & & \\
\hline I explicitly teach students how to develop their ideas for writing. & 0.62 & & & & & \\
\hline I explicitly teach spelling. & 0.60 & & & & & \\
\hline I introduce and explain learning goals to students. & 0.55 & & & & & \\
\hline I conference with students one-on-one. & 0.52 & & & & & \\
\hline I facilitate students sharing their work with others. & 0.42 & & & & & \\
\hline $\begin{array}{l}\text { When conducting writing exercises, I encourage students to } \\
\text { choose their own topics. } \\
\text { I accept unconventional layout in my students' draft writing } \\
\text { books. }\end{array}$ & & 0.62 & -0.37 & & 0.38 & \\
\hline $\begin{array}{l}\text { When conducting writing exercises, I encourage students to } \\
\text { engage in free writing, with no set learning goals. }\end{array}$ & & 0.60 & & & & \\
\hline $\begin{array}{l}\text { When conducting writing exercises, I encourage students to write } \\
\text { on topics that relate to their cultural backgrounds. }\end{array}$ & & 0.53 & & & 0.31 & \\
\hline $\begin{array}{l}\text { When conducting writing exercises, I encourage students to write } \\
\text { in their own dialects. }\end{array}$ & & 0.53 & & & & \\
\hline $\begin{array}{l}\text { When I conduct whole-class discussions during writing lessons I } \\
\text { encourage students to lead. }\end{array}$ & & 0.46 & & & & \\
\hline
\end{tabular}

My feedback to students includes reminders to keep their writing tidy.

My feedback to students includes attention to punctuation.

My feedback on students' writing includes attention to sentence structure.

When students make errors in their writing, I encourage them to correct them using a rubber.

When students are unsure of how to spell a word, I encourage them to copy the correct spelling from a dictionary, word card, or wall display.

After reading a student's writing, I request further development of the ideas expressed in the writing.

After reading a student's writing, I request that the student corrects any errors in their work.

When conducting writing exercises, I expect students to write in a genre selected by me.

When I plan writing programmes I use my personal judgement about what will work.

My feedback on students' writing includes attention to the ideas

they express.

When conducting writing exercises, I encourage students to write about their personal experiences.

When students are unsure of how to spell a word, I encourage them to approximate it, rather than providing the conventional spelling.

I teach handwriting explicitly. 0.418

$-0.34$

I select students' learning goals for them. 
Practices Survey: Distribution of teachers' responses to individual items

(i) Explicit and structured approaches

Figure 5 shows the distribution of responses to items in the explicit and structured approaches dimension. A majority of teachers indicated that they use explicit and structured approaches regularly. Over $80 \%$ reported that they use all of the practices in this dimension at least once $a$ week, or more than once a week. 
Figure 5: Distribution of teachers' responses to the individual items associated with the explicit and structured practices dimension. Vertical bars denote standard errors of percentages.

I conference with students one-on-

one.

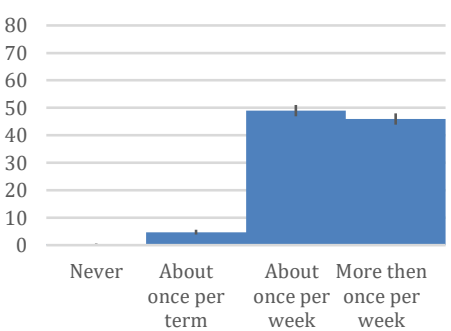

I explicitly teach spelling.

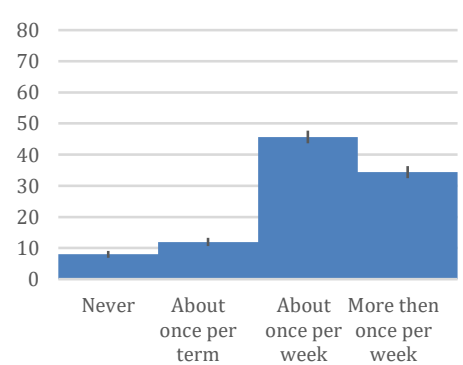

I introduce and explain learning goals to students.

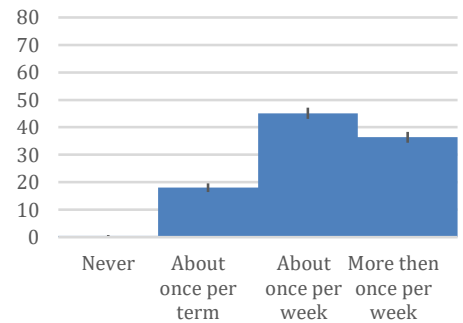

I explicitly teach correct sentence structure.

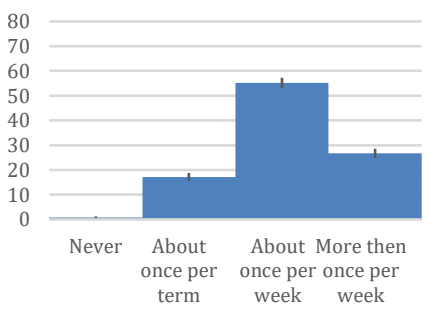

I explicitly teach students how to develop their ideas for writing.

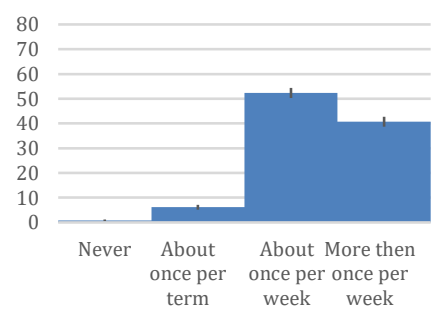

I explicitly teach punctuation

use.

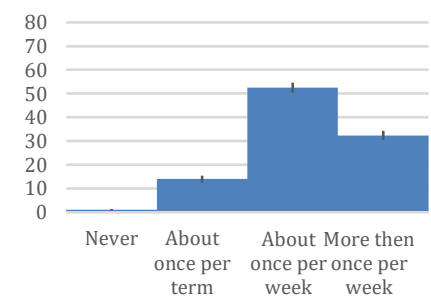

I facilitate students sharing their work with others.

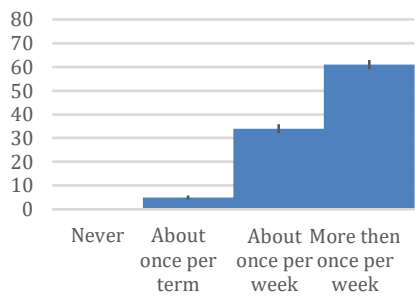

(ii) Process-writing and sociocultural practices

Figure 6 shows distributions of responses to items in the process-writing and socio-cultural practices dimension. A smaller proportion of teachers reported using process-writing and sociocultural approaches than explicit and structured approaches. Less than $50 \%$ indicated that they accept unconventional layout of student work, or encourage students to engage in free writing often, or almost always. Just over 50\% of teachers indicated that they encourage 
students to choose their own topics, to lead writing lessons, and to write on cultural topics, often or almost always.

Figure 6: Distribution of teachers' responses to the individual items associated with the processwriting and socio-cultural practices dimension. Vertical bars denote standard errors of percentages.
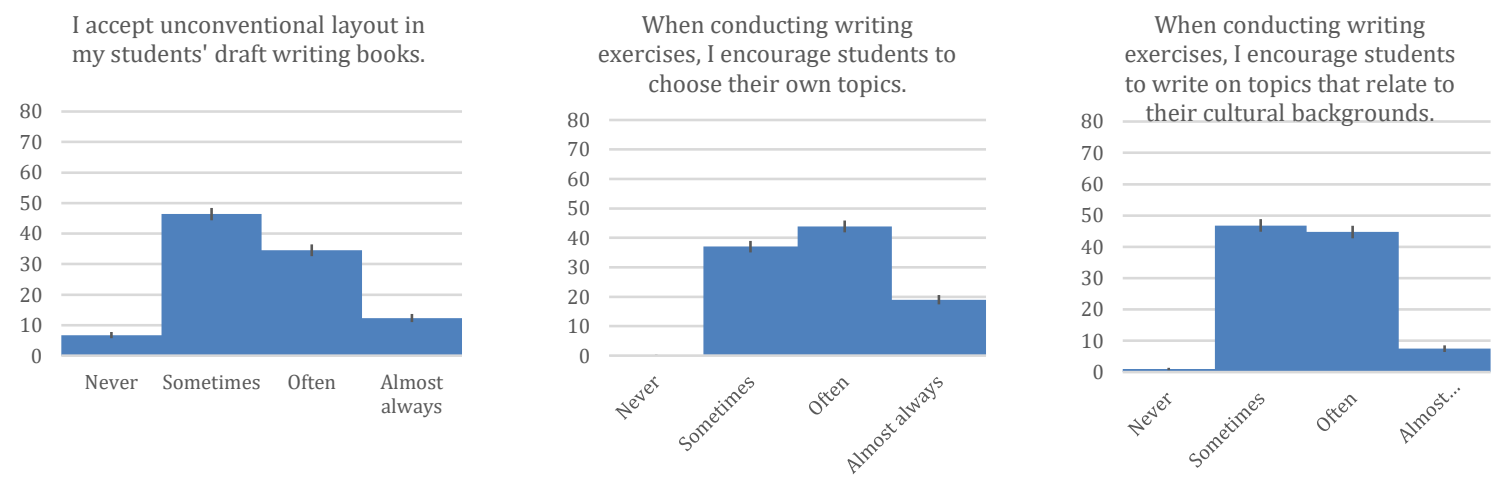

When I conduct whole-class discussions during writing lessons encourage students to lead.

When conducting writing exercises, I encourage students to engage in free writing, with no set learning goals.
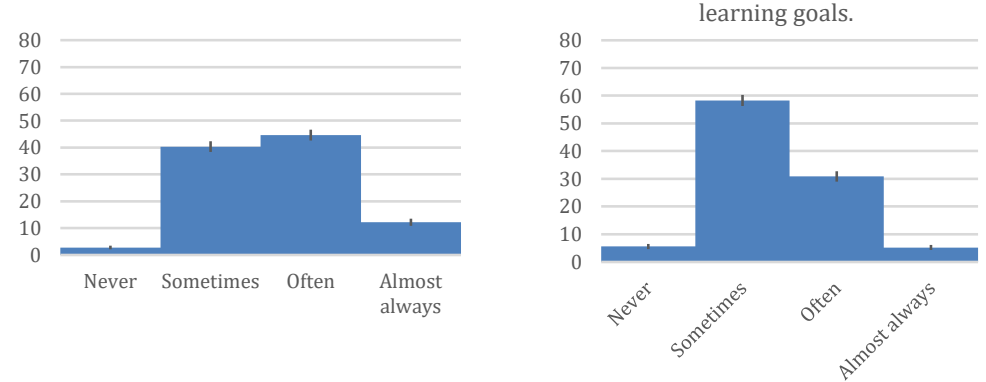

When conducting writing exercises, I encourage students to write in their own dialects.

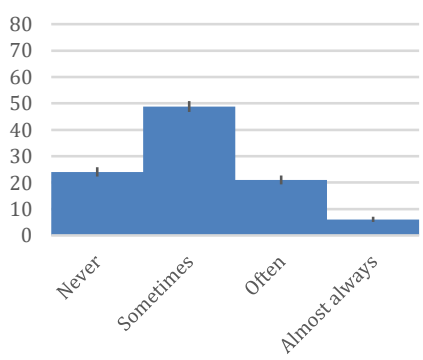

(iii) Attention to surface features

Figure 7 shows distribution of response to items in the attention to surface features dimension. Fewer than $50 \%$ of teachers indicated that they use any of the attention to surface features practices often or almost always. A particularly low proportion reported using the two hypothesized correctness items. Just 14\% remind students to keep work tidy often, or almost always, and just 7\% encourage students to correct errors always, or almost always. 
Figure 7: Distribution of teachers' responses to the individual items associated with the attention to surface features practices dimension. Vertical bars denote standard errors of percentages.
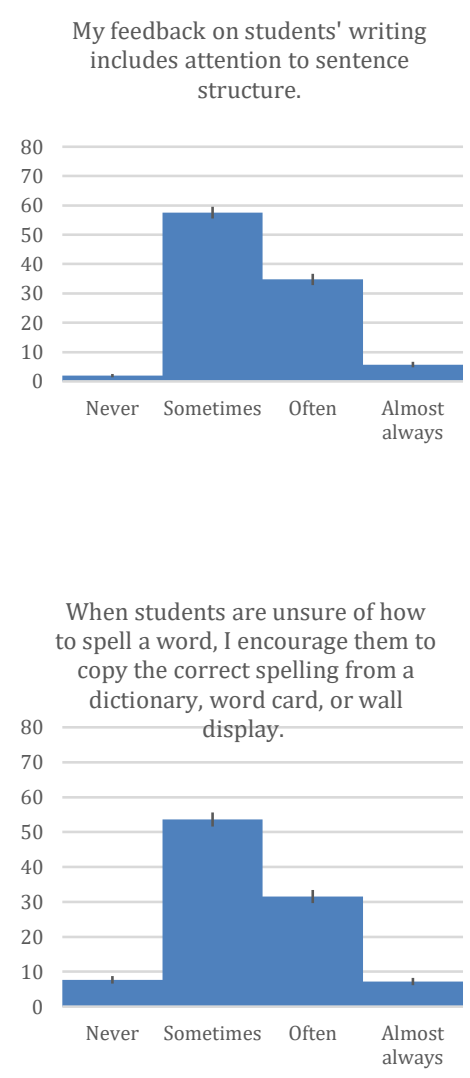

My feedback to students includes attention to punctuation.

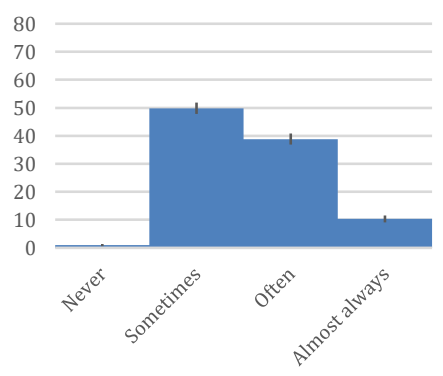

When students make errors in their writing, I encourage them to correct them using a rubber.

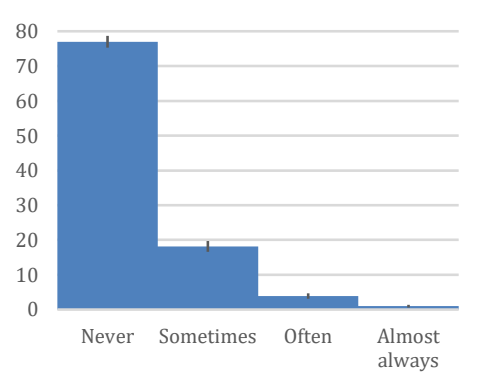

My feedback to students includes reminders to keep their writing tidy.

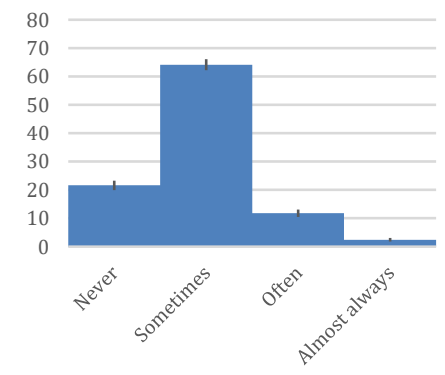

(iv) Advanced writing

Figure 8 shows distributions of response to items in the advanced writing dimension. Two advanced writing items were favoured by less than $50 \%$ of respondents. Thirty-one percent indicated that they ask students to correct errors often, or almost always, and 34\% indicated that they expect students to write in a teacher-selected genre often or almost always. Between $52 \%$ and $63 \%$ of teachers indicated that they apply the remaining three practices often or almost always. It is worth noting that the least-favoured item was, again, a hypothesized correctness item, and that two of the most widely-endorsed items describe teaching related to students' ideas. 
Figure 8: Distribution of teachers' responses to the individual items associated with the advanced writing practices dimension. Vertical bars denote standard errors of percentages.

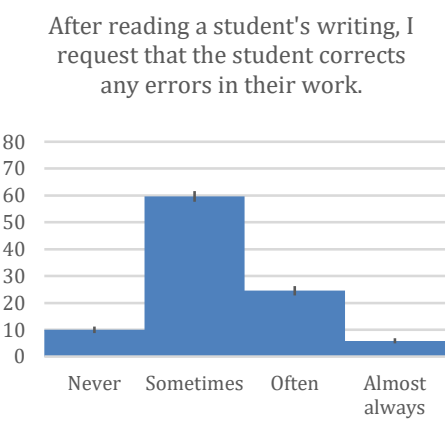

When I plan writing programmes I use my personal judgement about what will work.

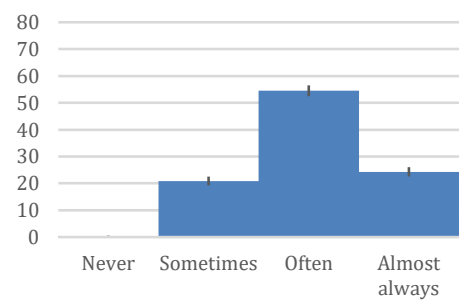

After reading a student's

writing, I request further

development of the ideas

expressed in the writing.

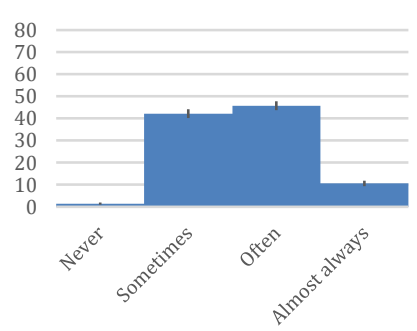

When conducting writing exercises, I expect students to write in a genre selected by me.

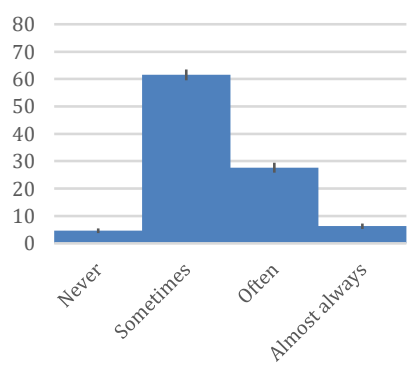

My feedback on students' writing includes attention to the ideas they express.

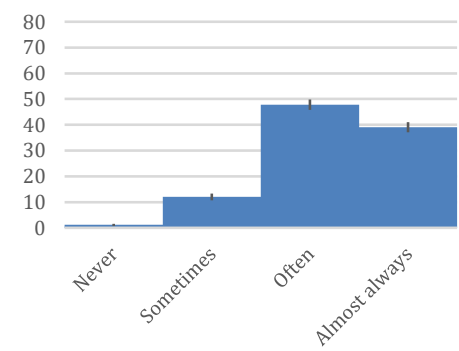

(v) Basic writing

Figure 9 shows distributions of response to items in the basic writing dimension. The use of personal experiences as writing topics, and accepting approximations for spelling unknown words, were reported to be used often or almost always by $89 \%$ and $87 \%$ of respondents respectively. Sixty-six percent of respondents also reported teaching handwriting explicitly about once a week or more than once a week. 
Figure 9: Distribution of teachers' responses to the individual items associated with the basic writing practices dimension. Vertical bars denote standard errors of percentages.
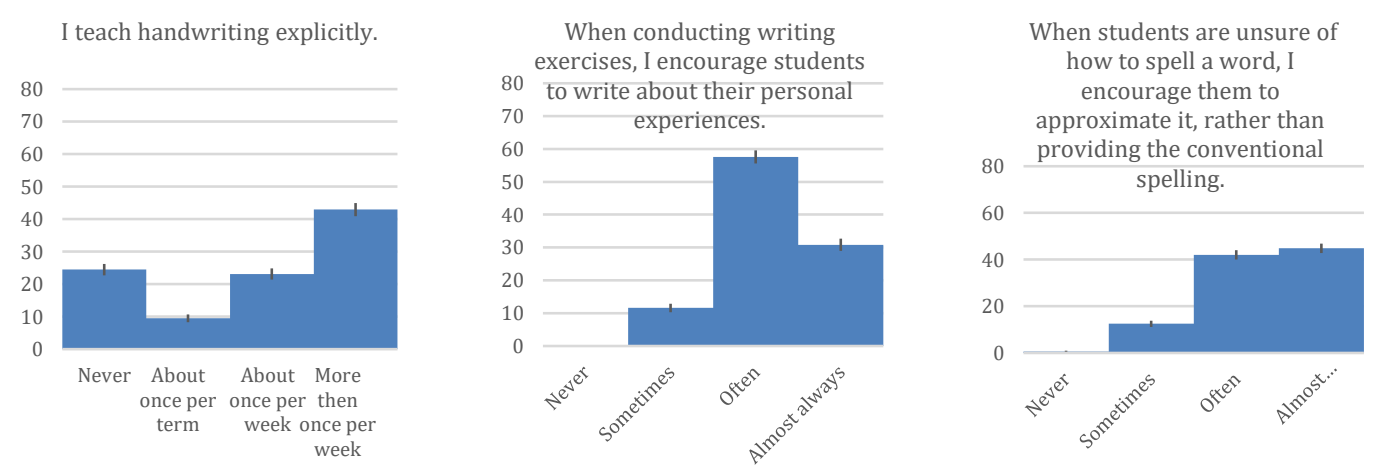

(vi) Teacher goal selection

Figure 10 shows distribution of response to items in the teacher goal selection dimension, which included just two items. The item students select their own learning goals for writing was negatively correlated with I select students' learning goals for them. While neither of these practices was favoured by more than half of the total sample, a greater number of teachers (54\%) indicated that students select their own goals often or almost always.

Figure 10: Distribution of teachers' responses to the individual items associated with the teacher goal selection dimension. Vertical bars denote standard errors of percentages.
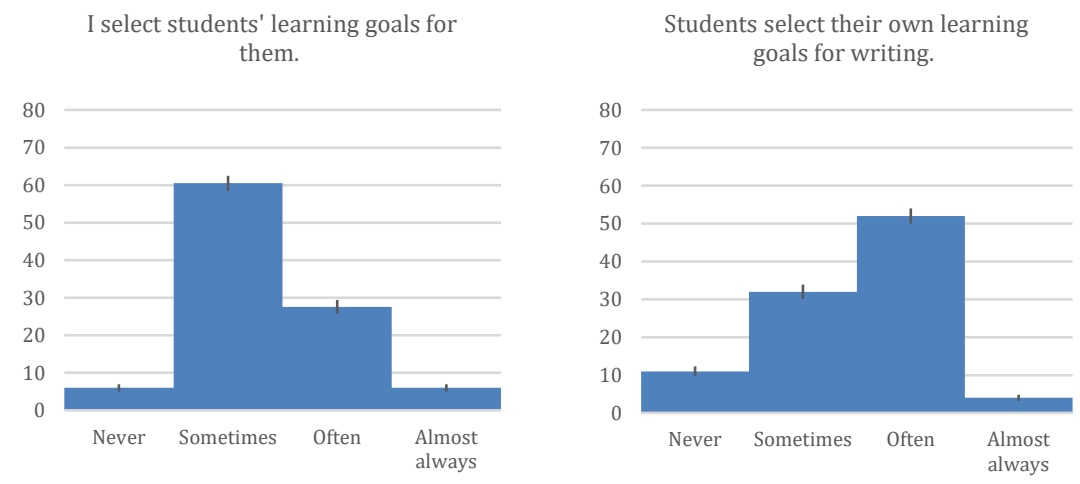

One item did not load with any of the practices dimensions. Responses to the item, when planning writing programmes I consider research evidence about what will work were spread quite evenly between sometimes, often and almost always, with $66 \%$ of teachers indicating that they engage with research often or almost always. 
Figure 11: Distribution of teachers' responses to the item, when planning writing programmes I consider research evidence about what will work. Vertical bars denote standard errors of percentages.

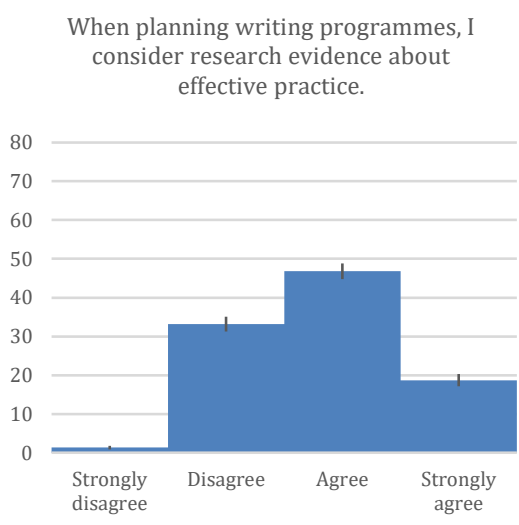

\section{Correlations between teachers' beliefs and practices}

Correlations between beliefs and practices dimensions are presented in Table 7. The correlations demonstrate intuitive relationships between beliefs and their associated practices: The explicit teaching beliefs dimension showed a moderate positive correlation with explicit and structured practices ( $\mathrm{r}=0.29)$, and a weak, negative correlation with the socio-cultural practices dimension ( $\mathrm{r}=-0.10)$. Explicit teaching beliefs were also moderately correlated with attention to surface features $(\mathrm{r}=.42)$. This dimension prioritizes the technical aspects of writing, including sentence structures, spelling and punctuation.

The socio-cultural and process writing dimensions were both moderately correlated with socio-cultural practices $(\mathrm{r}=.48$, and $\mathrm{r}=.38$, respectively). As we have seen, this practices dimension merges aspects of both approaches, including the use of tasks which reflect students' cultural backgrounds, as well as student choice of topic and opportunities for free writing. Socio-cultural beliefs were negatively correlated with attention to surface features ( $\mathrm{r}=-.21)$ and teacher goal selection $(\mathrm{r}=-\mathrm{24})$, dimensions which emphasize technical aspects of writing. Process writing beliefs were positively correlated with basic writing practices $(\mathrm{r}=.28)$. This is a dimension which emphasises student self expression, and de-emphasises the importance of correctiness in writing. 
Table 7: Correlations between beliefs and practices dimensions. Statistically significant correlations are presented in bold.

\begin{tabular}{|c|c|c|c|}
\hline & $\begin{array}{l}\text { Beliefs: } \\
\text { Explicit } \\
\text { teaching }\end{array}$ & $\begin{array}{r}\text { Beliefs: } \\
\text { Sociocultural } \\
\text { approach }\end{array}$ & $\begin{array}{r}\text { Beliefs: } \\
\text { Process } \\
\text { writing } \\
\text { approach }\end{array}$ \\
\hline Practices: Explicit and structured practices & 0.29 & 0 & -0.01 \\
\hline Practices: Attention to surface features & 0.42 & -0.21 & -0.08 \\
\hline Practices: Teacher chooses goals & 0.10 & -0.24 & -0.10 \\
\hline Practices: Sociocultural practices & -0.10 & 0.48 & 0.38 \\
\hline Practices: Advanced writing & 0.24 & 0.05 & 0.12 \\
\hline Practices: Basic writing & 0.14 & 0.14 & 0.28 \\
\hline
\end{tabular}

\section{Correlations between teachers' beliefs and practices and year levels taught}

Correlations between beliefs and practices dimensions and average year levels taught, are presented in Table 8. While the process writing and socio-cultural beliefs dimensions are negatively correlated with the teaching of higher year levels ( $\mathrm{r}=-0.40$ and $\mathrm{r}=-0.30$ respectively), the merged practices dimension is positively correlated with the teaching of higher year levels $(\mathrm{r}=0.43)$. Considering the practices dimension (which, as we have seen, describes opportunities for student leadership, free choice of topic, genre and layout) it seems likely that senior teachers employ these practices to suit the age and maturity levels of their students. The teachers' use of these practices may therefore have very little to do with the broader ideological contexts with which they are associated in the academic literature. 
Table 8: Correlations between the average year level taught by teachers and their locations on dimensions of beliefs and practices. Significance values with $p>.10$ suppressed.

\section{Correlation(r) Significance (p)}

\begin{tabular}{lcc}
\hline Beliefs & & \\
Explicit teaching & -0.44 & 0.06 \\
$\begin{array}{l}\text { Sociocultural approach } \\
\text { Process writing }\end{array}$ & -0.30 & \\
approach & -0.40 & 0.09 \\
\hline Practices & & \\
$\begin{array}{l}\text { Explicit and structured } \\
\text { practices }\end{array}$ & -0.35 & \\
Sociocultural practices & 0.43 & 0.07 \\
Attention to surface & & \\
features & 0.07 & \\
Advanced writing & -0.19 & 0.03 \\
Basic writing & -0.51 & \\
Teacher chooses goals & 0.02 & \\
\end{tabular}

\section{Correlations: Beliefs and Practices Dimensions and Student Progress}

The principal components analysis of the writing rubric data yielded a single dominant component, with all rubric aspects loading at 76 or higher. The eigenvalue associated with this component was 5.47 , accounting for $78.1 \%$ of the total variance.

Correlations between the beliefs and practices dimensions and average student progress from the classes of the 19 teachers are presented in Table 9. The explicit teaching dimensions were both moderately correlated with student achievement $(r=.43$ for beliefs, $r=$ .41 for practices). Sociocultural beliefs were weakly, and non-significantly correlated with student achievement $(\mathrm{r}=.22)$, although sociocultural practices were moderately and negatively correlated with achievement ( $\mathrm{r}=-0.46)$. The number of teachers who participated in this stage of the study was low. Only the negative correlation of socio-cultural practices with achievement was significant at $\mathrm{p}=.05$, although two other correlations showed a trend towards significance, with p-values of less than .10 . These correlations are presented in bold. 
Table 9: Correlations between the average progress of students aggregated by class and the locations on dimensions of beliefs and practices of their teachers. Significance values with $p>.10$ suppressed.

Correlation (r) Significance (p)

\begin{tabular}{lrl}
\hline Beliefs items: & $\mathbf{0 . 4 3}$ & .07 \\
Explicit teaching & 0.22 & \\
Sociocultural approach & 0.08 & \\
Process writing approach & & .09 \\
\hline Practices items: & $\mathbf{0 . 4 1}$ & .05 \\
Explicit and structured practices & $\mathbf{0 . 4 6}$ & \\
Sociocultural/Process writing practices & 0.27 & \\
Attention to surface features & 0.14 & \\
Advanced writing & 0.27 & \\
Basic writing & 0.30 & \\
Teacher chooses goals &
\end{tabular}

\section{Correlations: Individual Survey Items and Student Progress}

Correlations with $\mathrm{p}<.10$ between individual survey items and students' progress are shown in Table 10. Six items show positive and significant correlations with student achievement: Explicit teaching of handwriting is essential; I explicitly teach spelling; I explicitly teach students how to develop their ideas for writing; my feedback on students' writing includes attention to sentence structure; when conducting writing exercises, I expect students to write in a genre selected by me; and I teach handwriting explicitly. A further four items were positively correlated with student achievement and produced $\mathrm{p}$ values equal to or less than 0.10 . These include, explicit teaching of spelling is essential; it is important to teach children correct punctuation use; I conference with students one-on-one; and I explicitly teach punctuation use. Two items were negatively correlated with student achievement, and these correlations were statistically significant: I facilitate students sharing their work with others; and when conducting writing exercises, I encourage students to engage in free writing, with no set learning goals. 
Table 10: Correlations between individual items and student progress in writing with $p<.10$.

\section{Beliefs items}

Explicit teaching of handwriting is essential.

Explicit teaching of spelling is essential.

It is important to teach children correct punctuation use.

\section{Practices items}

I conference with students one-on-one.

I explicitly teach punctuation use.

I explicitly teach spelling.

I explicitly teach students how to develop their ideas for writing.

I facilitate students sharing their work with others.

When conducting writing exercises, I encourage students to engage in free writing, with no set learning goals.

My feedback on students' writing includes attention to sentence structure.

When conducting writing exercises, I expect students to write in a genre selected by me.

I teach handwriting explicitly.

$\begin{array}{rr}\text { Correlation }(r) & \text { Significance }(p) \\ 0.56 & 0.01 \\ 0.44 & 0.06 \\ 0.40 & 0.09\end{array}$

0.39

0.10

0.45

0.06

0.61

0.01

0.51

0.03

$-0.65$

0.00

$-0.55$

0.02

0.47

0.04

0.51

0.03

0.60

A connection between teachers' beliefs and practices and their students' achievement emerges when teachers' scale locations for each factor are translated to percentiles in rank order. In tables 11 and 12, teachers are listed in order of their students' progress, with their percentile ranking for each belief and practice dimension. ${ }^{71}$ If one considers the highest and lowest ranked teachers and their levels of agreement for each dimension, certain trends emerge. Regarding dimensions of belief, a pattern may be most obvious in relation to the explicit teaching dimension. Percentile rankings of the five most effective teachers were generally high for explicit teaching (four of these teachers were ranked above the $50^{\text {th }}$ percentile), while rankings for the five least effective teachers were low (only one scored above the $50^{\text {th }}$ percentile, and three were ranked in the first and second percentiles). Regarding dimensions of practices, we find that the five most effective teachers expressed relatively high levels of agreement with

\footnotetext{
${ }^{71}$ Students' levels of achievement are provided in logits. This allows for the representation of negative rates of progress, as well as for a comparison of relative rates of progress between students. For an explanation of Rasch model logit estimates, see Ludlow \& Haley, 1995. Teachers percentile rankings were calculated from the survey data for the entire group of 626 survey respondents.
} 
explicit teaching practices, and with teacher goal selection (correlated with explicit teaching beliefs), and that the five least effective teachers expressed relatively high levels of agreement with socio-cultural practices.

Table 11: Teachers' percentile locations for each beliefs factor. Teachers are listed in order of the progress their students made

\begin{tabular}{rrrrr}
$\begin{array}{r}\text { Progress } \\
\text { (rank }\end{array}$ & $\begin{array}{r}\text { Average } \\
\text { Progress } \\
\text { order) }\end{array}$ & $\begin{array}{r}\text { Explicit } \\
\text { (logits) }\end{array}$ & $\begin{array}{r}\text { Sociocultural } \\
\text { teaching }\end{array}$ & $\begin{array}{r}\text { Process } \\
\text { writing } \\
\text { approach }\end{array}$ \\
\hline 1 & 5.1 & 46 & 29 & 90 \\
2 & 2.9 & 56 & 70 & 19 \\
3 & 2.2 & 100 & 42 & 63 \\
4 & 2.0 & 93 & 75 & 90 \\
5 & 2.0 & 86 & 65 & 45 \\
6 & 1.3 & 42 & 99 & 98 \\
7 & 1.1 & 36 & 74 & 99 \\
8 & 0.3 & 46 & 84 & 84 \\
9 & 0.2 & 37 & 49 & 49 \\
10 & 0.2 & 50 & 1 & 45 \\
11 & 0.2 & 72 & 28 & 34 \\
12 & 0.0 & 30 & 75 & 2 \\
13 & -0.5 & 98 & 47 & 60 \\
14 & -0.5 & 21 & 12 & 25 \\
15 & -0.5 & 2 & 8 & 86 \\
16 & -0.9 & 1 & 38 & 69 \\
17 & -1.1 & 58 & 49 & 96 \\
18 & -1.4 & 1 & 18 & 82 \\
19 & -2.1 & 14 & 64 & 69
\end{tabular}


Table 12: Teachers' percentile locations for each practices factor. Teachers are listed in order of the amount of progress their students made.

\begin{tabular}{rrrrrrrr}
$\begin{array}{r}\text { Progress } \\
\text { (rank } \\
\text { order) }\end{array}$ & $\begin{array}{r}\text { Average } \\
\text { Progress } \\
\text { (logits) }\end{array}$ & $\begin{array}{r}\text { Explicit } \\
\text { teaching } \\
\text { practices }\end{array}$ & $\begin{array}{r}\text { Sociocultural } \\
\text { practices }\end{array}$ & $\begin{array}{r}\text { Attention } \\
\text { surface } \\
\text { features }\end{array}$ & $\begin{array}{r}\text { Advanced } \\
\text { writing }\end{array}$ & $\begin{array}{r}\text { Teasic } \\
\text { writing }\end{array}$ & $\begin{array}{l}\text { chooses } \\
\text { goals }\end{array}$ \\
\hline 1 & 5.1 & 75 & 29 & 82 & 43 & 81 & 92 \\
2 & 3.0 & 100 & 18 & 33 & 49 & 6 & 92 \\
3 & 2.2 & 90 & 7 & 94 & 89 & 57 & 92 \\
4 & 2.0 & 31 & 87 & 87 & 82 & 86 & 92 \\
5 & 2.0 & 52 & 53 & 68 & 57 & 63 & 92 \\
6 & 1.3 & 23 & 72 & 12 & 35 & 100 & 92 \\
7 & 1.1 & 46 & 70 & 9 & 26 & 71 & 9 \\
8 & 0.3 & 33 & 91 & 55 & 18 & 35 & 35 \\
9 & 0.2 & 52 & 63 & 39 & 93 & 17 & 9 \\
10 & 0.2 & 42 & 34 & 31 & 12 & 65 & 92 \\
11 & 0.2 & 100 & 30 & 15 & 27 & 57 & 35 \\
12 & 0.0 & 42 & 41 & 60 & 11 & 2 & 9 \\
13 & -0.5 & 87 & 52 & 90 & 93 & 81 & 69 \\
14 & -0.5 & 49 & 54 & 39 & 12 & 86 & 69 \\
15 & -0.5 & 7 & 83 & 23 & 32 & 70 & 69 \\
16 & -0.9 & 59 & 85 & 57 & 82 & 37 & 69 \\
17 & -1.1 & 72 & 77 & 52 & 74 & 7 & 97 \\
18 & -1.4 & 46 & 75 & 30 & 35 & 17 & 9 \\
19 & -2.1 & 3 & 56 & 39 & 19 & 35 & 9
\end{tabular}

\section{Interviews: Single Case Analyses}

A primary purpose of the teacher interviews was to assess the validity of the survey. In what follows, I compare two sets of data for each of the eight case study teachers, including, (i) their levels of agreement with dimensions of beliefs and practices emerging from the survey, and (ii) the more detailed comments about beliefs and practices which these teachers provided during interviews. Following this discussion, I provide some commentary on writing samples from students in the teachers' classes. While the relative progress of each of these teachers' classes was calculated, this information is omitted for ethical reasons. ${ }^{72}$ Every teacher was able to achieve positive gains for their students, and the writing samples have been selected to

\footnotetext{
${ }^{72}$ While these teachers may not have been identifiable to others, they would have been identifiable to themselves.
} 
demonstrate this point. It is interesting to observe that these teachers' preferred approaches often appear to be a response to their students' needs. Case studies are presented in increasing order of year levels. The names of teachers have been replaced with pseudonyms.

Following this summary of individual teachers is a cross-case discussion detailing some of the nuances of beliefs, impossible to capture using a survey alone. Specifically, this section covers teachers' attitudes towards the use of technology for writing (items relating to which were omitted from the survey), the use of personal experiences as motivation for writing, and the use of rubbers by students (two items of particular interest as patterns of response were remarkably consistent in the survey data).

(i) Elizabeth; 4 years experience; Year 1 teacher; Decile 9 school (Wellington)

Elizabeth's survey responses placed her in the $42^{\text {nd }}$ percentile for explicit teaching beliefs, and the $99^{\text {th }}$ and $98^{\text {th }}$ percentile for socio-cultural beliefs and process writing beliefs respectively. For practices, her responses placed her below the $50^{\text {th }}$ percentile for explicit teaching, attention to surface features, and advanced writing practices, and above the $50^{\text {th }}$ percentile for sociocultural practices, basic writing, and teacher selection of goals. ${ }^{73}$

In the case of Elizabeth, there are some discrepancies between her survey and interview - during which she emphasized explicit approaches. When asked about key aspects of her programme, for example, Elizabeth described the explicit teaching of phonics (specifically those of Allcock), ${ }^{74}$ and handwriting - using a programme developed by Brann (2000). ${ }^{75}$ As well as explicitly teaching these technical skills, Elizabeth reported using "the Seven Steps" ${ }^{76}$ with her more advanced writers - a programme which guides children with seven specific elements for writing an interesting story (for example, "sizzling starts", "tightening tension", and so on).

\footnotetext{
${ }^{73}$ It must be noted, however, that due to generally high agreement with explicit approaches across the sample, being low in the percentile ranking does not necessarily reflect disagreement with these.

${ }^{74}$ See, https://www.joyallcock.co.nz/. Retrieved 19/12/18.

${ }^{75}$ Brann's handwriting programme is recommended in the writing manual created for the Fast Feedback teachers (see appendix iii). It was used by one of the most effective teachers in the 2015 intervention. ${ }^{76}$ See, https://www.sevenstepswriting.com. Retrieved 18/11/18.
} 
Elizabeth's other priorities were to encourage children to write for themselves (instead of a teacher writing for them - as may be the case in some junior classes); to provide a strong oral language programme; to provide opportunities for regular writing practice (in a variety of enjoyable ways - such as having children write on the concrete outside); and to select writing topics of relevance to the children's own lives. These practices are difficult to categorize in terms of the beliefs they may reflect. Only one was directly addressed by the survey - that is, the use of personal experience writing - and this item was not associated with any of the three beliefs dimensions.

Figure 12 and Figure 13 show writing samples from one of Elizabeth's students, taken at time points one and two respectively.

At the beginning of the year this student was able to form letters correctly, spell some high frequency words, and leave spaces between words. Though the sample is short, it demonstrates competence with early writing skills.

The second sample is much longer and is the work of an enthusiastic and confident writer. It recounts a meal at Denny's (a family restaurant), followed by a trip to the beach. Perfect spelling is perhaps the most striking aspect of this Year One writer's piece. It demonstrates knowledge of spelling patterns and rules (for example, the ea vowel grapheme in "cream" and "beach", and the doubling of the middle consonant in "yummy"). This may reflect Elizabeth's commitment to the teaching of transcription skills.

The second sample also illustrates some of the difficulties personal experience writing may present for young writers. Possibly uninspired by the reality of her family day, this writer has included imagined details (such as jumping off the boat "into shark water"), and the result is unconvincing. A narrative structure would support this child to present imagined content with much greater impact. 
Figure 12: Student $A$ at Time Point One

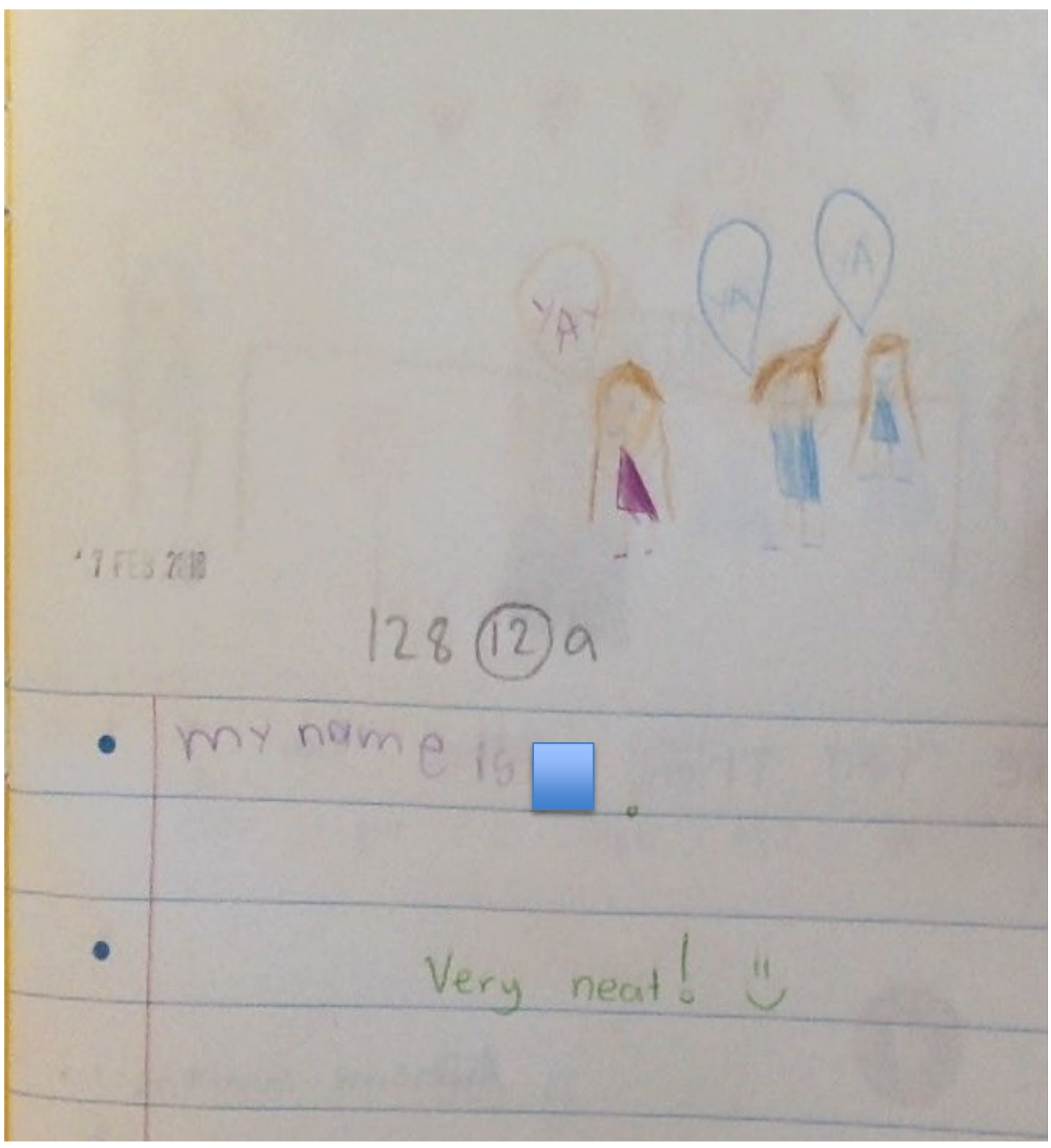


Figure 13: Student A at Time Point Two

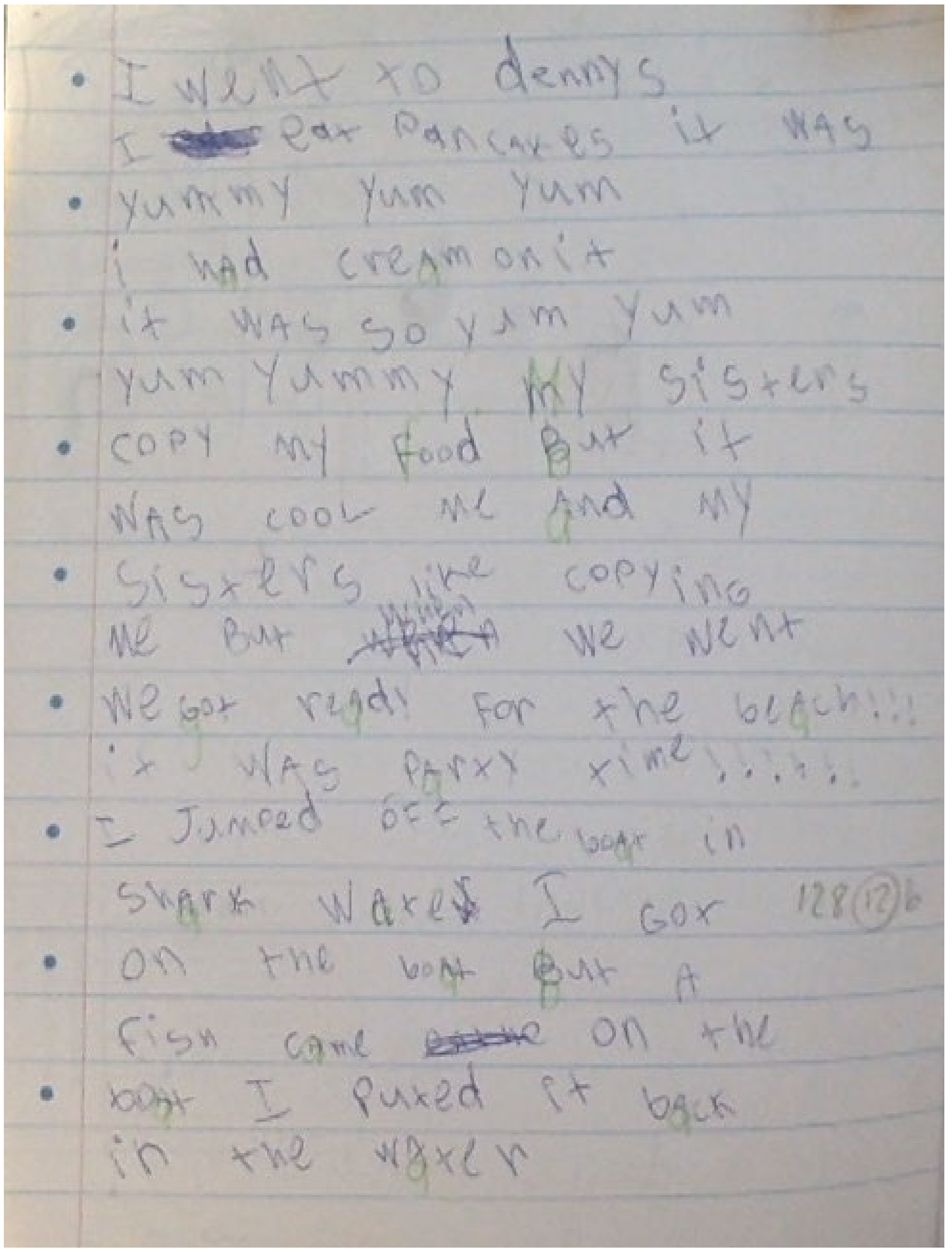

(ii) Ngaire; 39 years experience, Year 2-4 teacher, Decile 4 school (Westport)

Ngaire's survey responses indicate high levels of agreement with all three beliefs factors

(ranked at the $93^{\text {rd }}$ percentile for explicit teaching, the $75^{\text {th }}$ percentile for socio-cultural 
approaches, and the $90^{\text {th }}$ percentile for process writing approaches). Ngaire's survey responses suggest relatively low use of explicit practices (ranked in the $31^{\text {st }}$ percentile), and relatively high use of all other practices (for these, her responses place her between the $82^{\text {nd }}$ and $92^{\text {nd }}$ percentiles).

When discussing key aspects of her programme, Ngaire referred several times to the explicit teaching of sentence structure. She described her use of "mentor sentences", whereby she helps her class to analyze examples of well-constructed sentences, and then sets the expectation that they will apply the same techniques, by including at least one "challenging sentence" in their writing each day. Ngaire also emphasized the importance of teaching handwriting, and explained that correct letter formation is often the first goal she selects for new students as they enter her class.

Other priorities for Ngaire were student engagement and student self-expression. Additionally, she emphasized the importance of regular and closely guided writing practice.

Did the survey accurately reflect Ngaire' beliefs and practices? Her high levels of agreement with all three dimensions of belief were evident in her description of what could be considered a balanced approach, characterised by clear goals and structure, with attention also paid to student engagement and student self-expression.

Writing samples from one of Ngaire's male students from time-points one and two are shown in Figures 14 and 15 respectively.

In the first sample the writer recounts a family holiday, and includes some details about an unsuccessful fishing trip. A small number of high frequency words are spelt correctly, and there is some correct use of sentence punctuation. However, letter formation difficulties are significant, spaces have not been left between some words, and spelling approximations are difficult to decipher. These technical problems make parts of the writing indecipherable. 
The second sample is a report on the Great White shark, and covers details about the animal's feeding habits, speed and teeth - so sharp "that you can not feel them slice into you". Letters are formed correctly and spacing is used consistently between words. Most high frequency words are spelt correctly, as well as other less common words (great, white, and seal). While there is one ungrammatical sentence, this writer has attempted to use sentence structures for effect, introducing new information with "did you know?" to draw the reader in.

It seems that Ngaire's prioritization of handwriting and sentence structures was entirely appropriate for this child. As his difficulties with technical skills have been addressed, significant progress has been made in all aspects of writing. 
Figure 14: Student B at Time Point 1

$5 x+531.1$

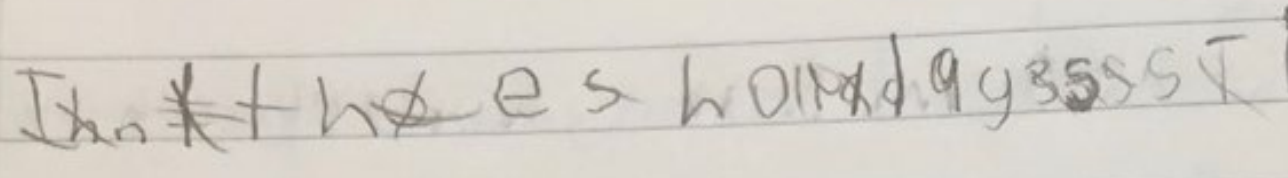
Wwent tokmon lkikni f f our fikee hity s.W wo Went fixshinge But werdidint cach ende flksh Bxcause arxifishingrodts whernt wipergihe is waterb as the

145 
Figure 15: Student B at Time Point Two

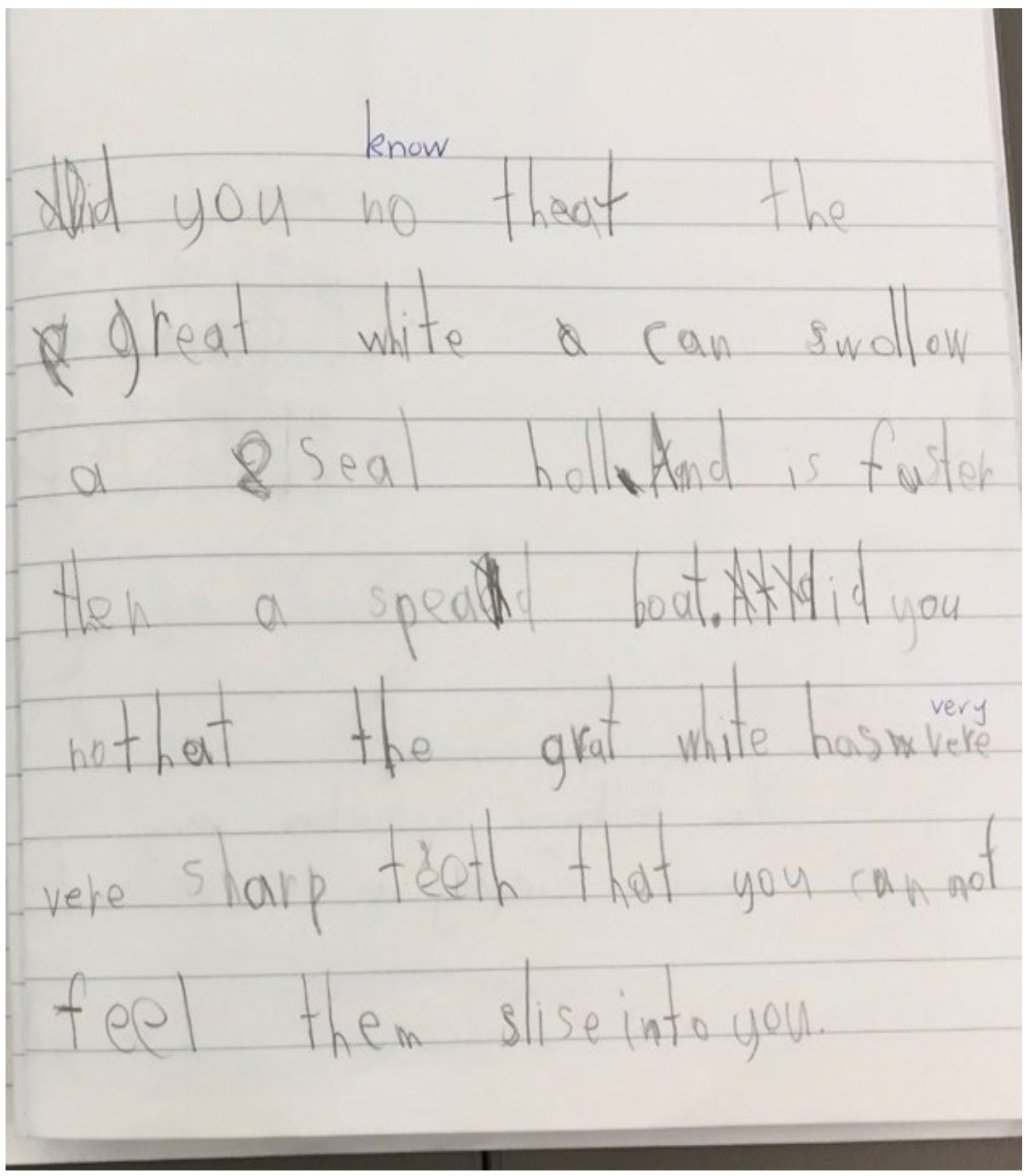


(iii) Jenny; 40 years experience; Year 3-4 teacher, Decile 9 school (Kapiti Coast)

Jennys' survey responses indicate average levels of agreement with explicit and process approaches (ranked in the $50^{\text {th }}$ and $45^{\text {th }}$ percentiles respectively), and relatively low agreement with socio-cultural approaches (ranked in the $1^{\text {st }}$ percentile). Her responses for practices ranked below the 50th percentile for all practices, except for basic writing (ranked in the $65^{\text {th }}$ percentile) and teacher goal selection (ranked in the $92^{\text {nd }}$ percentile). ${ }^{77}$

Although Jenny's survey did not indicate particularly strong agreement with explicit approaches, her interview showed that the explicit teaching of grammar, handwriting and spelling was key. Although Jenny's survey indicated very low agreement with socio-cultural approaches, her interview identified peer discussion and student leadership as other important aspects of her programme (practices which some would associate with a socio-cultural approach). Significantly, Jenny stressed the importance of several methods that were not covered by the survey. These included: (i) the use of authentic tasks (tasks with a genuine purpose - beyond that of just learning how to write better), and of students having a sense of the purpose and audience for their writing; (ii) the use of closely guided practice - she described a system in which three children would write in a small teacher-guided group every day; (iii) the importance of students having many opportunities to practice writing, throughout the day, in a range of curriculum areas.

Writing samples from a boy in Jenny's class, from time-points one and two, are displayed in Figures 16 and 17 respectively. The first sample is a recount about going ice-skating. It is short, and also repetitive - "it was so much fun [...] and I was having fun. and it was extrodinery". Letter size is inconsistent and a missed line mid-sentence indicates a lack of control over layout

\footnotetext{
77 It must be emphasized that these rankings indicate levels of agreement compared to the rest of the survey respondents. They do not reflect, in any useful detail, the absolute level of agreement of individual teachers.
} 
in general. Early high frequency words have been spelt correctly, though the repetition of content may indicate a reluctance to attempt other spellings, and sentence punctuation is not yet mastered.

The second sample is the first chapter of a fast-paced adventure story involving a plane crash, the discovery of a Jurassic world, and a dinosaur chase. While there is no significant improvement in sentence punctuation, every other aspect of the writing is more controlled and sophisticated. Letter size is consistent, and spelling is correct for a range of high frequency and less common words. The small number of invented spellings demonstrate good knowledge of sound to letter correspondences (for example, veilloser raptors, in which all sounds and syllables are represented). Vocabulary is varied and interesting.

The progress made over two terms suggests that Jenny's explicit teaching of the technical skills (as she described in her interview - though she was not ranked particularly highly for these dimensions in the survey data), combined with an emphasis on purposeful and stimulating tasks, have been immensely helpful for this child. ${ }^{78}$

\footnotetext{
${ }^{78}$ It is important to point out that, because all beliefs dimensions were relatively strongly endorsed, low percentile rankings can be misleading: they do not actually reflect low levels of endorsement - just lower levels when compared to other survey respondents.
} 
Figure 16: Student C at Time Point One

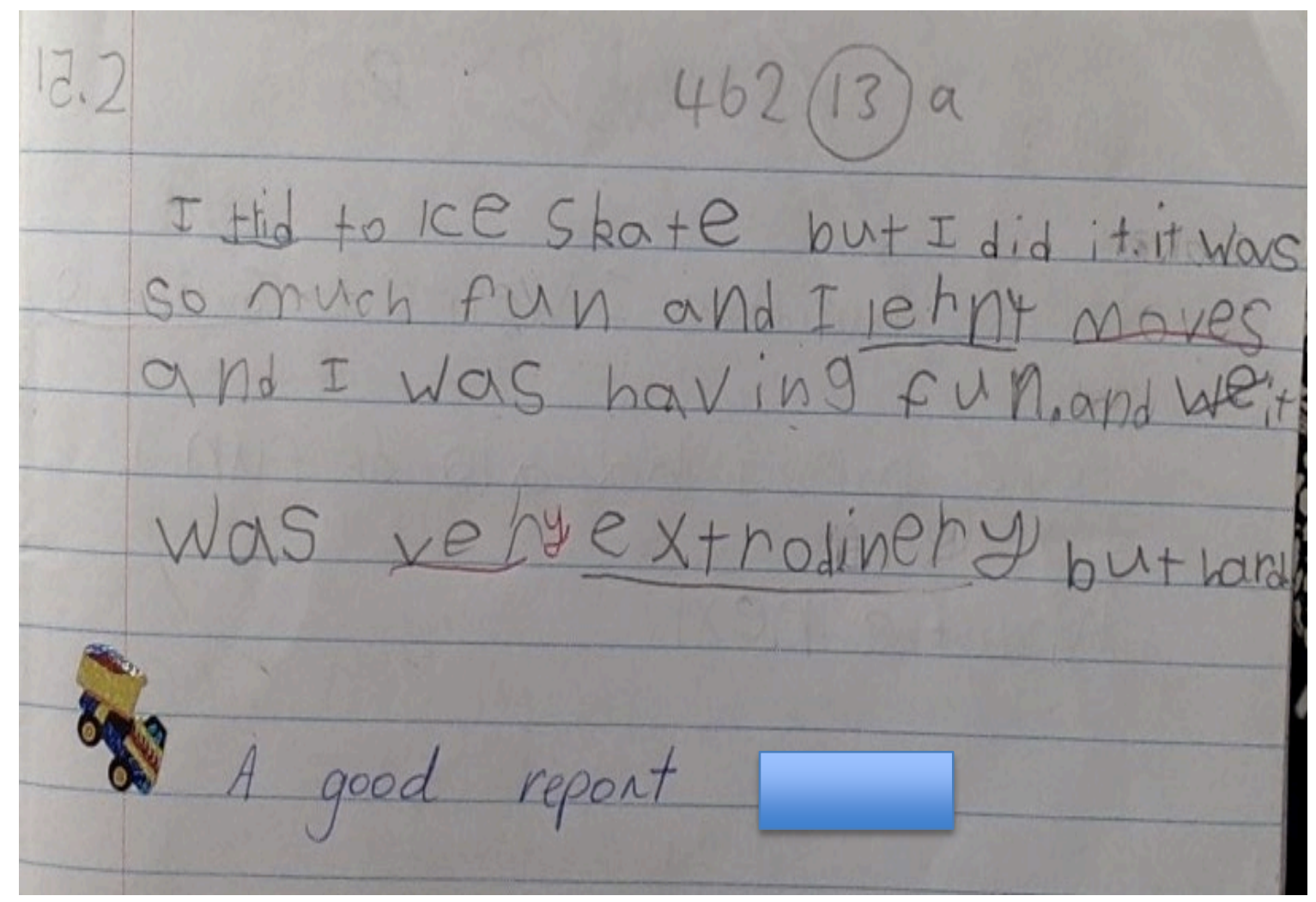


Figure 17: Student C at Time Point Two

$46213(6)$

Chaptersomel When we got out of the smashed plane ithead pod and Black parther set of toge catch Iron rist athey found $a$ old building rrom a jurassic Wadrthegl alsc they follnd sane w Veilloser rapters and a vivery big teranner scrus rex had

Wiltch Wverry hig bleod vissis feeth that Warted to eat us it chased arter us for hours and hours urtitt he saut a pachifcafuller solirus and if ate it of we ran anay se we cood get on with ou' mission to arten itd fis

150 
(iv) Daniel; 23 years experience; Year 5-6 teacher, Decile 9 school (Kapiti Coast)

At the time of our interview, Daniel and Jenny were teaching at the same school. According to his survey, Daniel's beliefs ranked in the $46^{\text {th }}$ percentile for explicit teaching, and the $84^{\text {th }}$ percentile for both socio-cultural and process writing approaches. His practices ranked in the 93rd percentile for socio-cultural approaches, the $55^{\text {th }}$ percentile for attention to surface features, and the $35^{\text {th }}$ percentile or lower for all other dimensions.

Daniel's interview comments support the findings of the survey. As a boy he had "hated" writing at school, due in large part to the technical difficulties he experienced as a left handed writer - being required to write with a fountain pen. He had also disliked the high level of teacher-imposed structure. Daniel explained that these experiences had been formative in his development as a writing teacher. His priority now was to make writing as enjoyable as possible, by giving children freedom to choose their topic and genre, and by focusing on content in the first instance - with discussion of technical matters postponed until the end of the drafting process.

Daniel is a strong advocate of the use of technology for teaching writing. He described typing as "a great leveler" - as it removes the challenge of handwriting, for those who struggle with this skill. His students write on computers most of the time, and also use a number of apps for self-assessment, and for publishing their writing in interesting ways.

Figure 18 (Time Point One) and Figure 19 (Time Point Two) are the work of one of Daniel's year 6 boys, drafted on computers with spell check available. Technical aspects of the writing - in particular the use of punctuation and paragraphing - were already well developed in the first sample, and only minor improvements with these aspects can be observed in sample two.

It is with the content of the writing that we notice the most significant changes. While the first sample demonstrates an awareness of narrative structure, and attempts to include humour, the overall impact is rather flat. In contrast, the second sample is fast paced and 
exciting, describing a dramatic scene in language appropriated from American action movies (for example, "take out the trash", and "I did inject him with a mixture of illegal items"). It is interesting to consider Daniel's commitment to the student's expression in relation to this piece. It is clear that this student feels inspired, writing in a style that he finds exciting and is familiar with.

Regarding the use of computers, it is difficult to comment on their particular benefits without some more detailed investigation of a greater number of teachers and students. However, these samples suggest that the student has responded to opportunities for layout with dialogue presented on alternate lines, and capitalization used to add impact to sound effects (BAMM, AHHHH). 
Figure 18: Student D at Time Point One

Once upon a time there were 3 sloths.

Daddy sloth, Mummy sloth and Baby little sloth. One day Baby sloth was very thirsty "I'm thirsty I need a drink" He screeched. So Daddy sloth said he would get him one. "I will be back by noon" Daddy sloth said confidently. So he set off to get a drink.

He came back at noon about 2 hours later with coffee. Baby sloth had never tried coffee. So he poured it down his throat. "I feel dizzy" Baby sloth said. "Maybe you should've got him a different drink" said Mummy sloth.

"Ah ah AHHH" Baby sloth screamed as he zoomed off through the forest.

"Yea maybe your right" Said Daddy sloth.

Figure 19: Student D at Time Point Two.

"Doctor he's gone." screeched Timmy.

"WHAT! I thought you had the suspect in maximum security." the Doctor roared back.

"Hmm about that he escaped, It turns out that the injection you did gave him some sort of superpower." Timmy said scared for his life about what the Doctor might do.

The Doctor stomped out of the room and called every police officer in the city. He then tracked down the location geared up and shouted "Timmy take out the trash."

Exactly 43 minutes later

"Officers he's in there," Doctor said. 
"You... you mean that big burning skyscraper thats falling down." Officer Squeaky squeaked.

"Yea that one now hurry up." Doctor roared. The officers charged and then exited the building after having their guns burned to crisp.

"Doctor what did you do to that man." General Waffle shouted.

"Well I did inject him with a mixture of illegal items making him a complete monster." The Doctor said like he wasn't next to an entire city worth of officers.

"You're under arrest Doctor if that is your real name." Roared General Waffle.

“Ok fair enough and my real name is actually Doctor." He Replied.

BAMM!!!

"Uhh what was that." Officer Squeaking screamed.

"The skyscraper which is about to fall on us after it crashes through that coffee shop." Doctor replied.

“AHHHHHHHH.” Everyone screamed.

(v) Anahera; 2 years experience; Year 5-6 teacher, Decile 1 school (Porirua)

Anahera's survey responses indicated relatively low levels of agreement with explicit approaches (ranked in the $1^{\text {st }}$ percentile), below average agreement with socio-cultural approaches (ranked in the $38^{\text {th }}$ percentile), and above average agreement with process writing approaches (ranked in the $69^{\text {th }}$ percentile). For practices, Anahera expressed above average agreement with all practices with the exception of basic writing.

Anahera's interview comments were generally aligned with her survey responses. In the interview she described a system for teaching genre, whereby she offered optional workshops 
(her students were free to choose which they would attend). Evidently, explicit teaching has some importance to Anahera - her low percentile on this dimension notwithstanding - though student choice and self-directed learning is equally (or even more) important to her. In relation to Anahera's high agreement with process writing approaches, she identified student interest as a key aspect of her programme. She described a number of creative approaches for capturing student interest, including the selection of writing topics with personal relevance (for example, a poetry unit in which many of her boys had chosen to write about "gaming"); the use of art to stimulate writing; and the use of the students' own writing as models (rather than taking examples from professional writers). Anahera also discussed approaches not covered by the survey. She emphasized the importance of using authentic writing tasks, and the importance of building strong and positive relationships with students.

Figures 20 (Time Point One) and Figure 21 (Time Point Two) are the writing of a male student in Anahera's class. The first sample is a recount, describing a family trip to Auckland. Technical skills are mostly controlled, apart from some minor errors with sentence structures and spelling. As observed with Elizabeth's student (Figure 13) this boy appears to have struggled with the recount task - essentially listing rather boring details about the day, and introducing each with a different sentence starter in an attempt to add interest ("In the holidays [...] After that [....] Finally I").

The second sample describes a science experiment. The level of technical skill is the same as for the first sample, although the student is now organizing his writing into paragraphs. Anahera has used a science experiment as motivation for writing, and this student recalls it with enthusiasm. However, the piece lacks a clear structure and purpose. It seems likely that explicit guidance about the conventions of scientific reports would have extended this child and improved the quality of his work. 
Figure 20: Student E at Time Point One

Wenstay $31^{\text {th }}$ January 2018

136590

In the holiday's I went to Auklard.

At Auckland I was eating breakfast. Then I wentato do fitness around

the house. After that I wen: to gat reade Rambowsend. When We gat there to ga

I had to were these bands.

Eureally I gate go on a ride and the ride was called the feat drop. After that I went I go to the bumper gecarts. Then I ven to have a be out side rein bows. Finally I want hame and had a nap. Well done, great start to the year well

156 
Figure 21: Student E at Time Point Two

Today after we took went to room 8 we did a science pro sect in room 13 we did som thing like dancing coles that we did the other day.

So the thing that we did today was we gut with on a plate than we put food coloring in then we mixed it a little bit in the middle.

Theme put Then we got dishwashingliquad on testy then we gut our colin stick init Just a bit then we put the stick in the middle os the milk and the food coloring when we gut the collin stick in withe the dish washing liquad it started to make like a explosion wave but the liquid. stayed there and then the food covering made a explosive wave but the milk a did'ntxmove but the real question was how did it do that

157 
(vi) Belinda; 11 years experience; Year 5-6 teacher, Decile 9 school (Rotorua)

Belinda's survey responses placed her in the $98^{\text {th }}$ percentile for explicit teaching, the $47^{\text {th }}$ percentile for socio-cultural approaches, and the $60^{\text {th }}$ percentile for process writing approaches. She indicated above average levels of agreement for all five of the six practices dimensions, and an average level of agreement with the sociocultural dimension.

Belinda's high level of agreement with explicit teaching approaches was evident in the interview, supporting the survey findings. She described her writing programme as one that targets clear and specific goals - with a plan in place for each day, term and year. Additionally, she stressed the importance of the explicit teaching of skills such as language use and the conventions of genre, and of naming (for students) the techniques they were learning to use. In a related point, she identified professional development that encouraged the use of structured approaches, and to be specific in teaching and feedback, as having been formative for herself and other teachers at her school. Interestingly, she described this programme as particularly helpful for teachers who had learnt to write during the process-writing era, stating:

For the generation that came up through the whole language, "just write whatever you feel like and we don't know how a sentence is structured" it's huge professional development for those people.

While Belinda expressed strong agreement with explicit teaching, in both the survey and interview, it is worth noting that the teaching she described focused on content and stylistic aspects, rather than technical skills. This sets her apart from other teachers who reported using explicit teaching, including Jenny, Ngaire, Elizabeth and Alison (whose approaches are discussed in what follows).

Belinda's relatively high level of agreement with process writing beliefs seems to be supported by her interview comments which emphasized the importance of student engagement and ownership. She described her use of creative tasks (such as writing in response to music) to encourage "heartfelt writing". What's more, she described draft writing in her class 
as "a free flow write", focused on "high level stuff", with technical aspects dealt with later, in the editing phase.

The use of authentic writing tasks was another priority for Belinda. As we have seen, this is an approach also favoured by Anahera and Jenny. As previously mentioned, the survey did not include any items to capture this approach.

The following two samples are from a male student in Belinda's class. The work in Figure 22 was written at Time Point One and that in Figure 23 at Time Point Two.

The first sample describes go-carting, using the present tense (with some inconsistencies) to create a sense of immediacy and excitement ("321 go [...] I was ehding strat for a tree. The go cart scids and misin the tree"). It is a creative and expressive piece, with paragraphing used appropriately and some correct use of sentence punctuation. Difficulties with spelling and handwriting are significant, and impact on the comprehensibility of the writing. Interestingly, these difficulties have not prevented the student from tackling ambitious content.

The second sample is written in the first person, and describes the experience of a solehuman living on the moon. Like the first sample, this piece is dramatic and engaging, with vocabulary used consciously and skilfully ("evry day I ster up at erhtf I wander if I will be fred from this tretris plas"). Technical aspects of the writing are not markedly improved. There is some correct use of sentence punctuation. There is some correct spelling of early high frequency words, though approximated spellings include sounds missing and added (trap for trapped, sumep thing for something), and demonstrate lack of knowledge of early spelling patterns (sak for shack). Letter formation is somewhat improved though still problematic - with $\mathrm{d}$ written as b throughout the piece.

Belinda prioritized student engagement in writing, and planned creative tasks to stimulate heartfelt responses. She valued the explicit teaching of sentence structures and vocabulary use. Her influence can be seen in both these writing samples, which appear to be the 
work of a motivated writer, one who is committed to interesting content, despite his difficulties with technical skills. 
Figure 22: Student F at Time Point One

Wating in lin to brive a gow cart tiale it was awtorn 32/90 I sumd Ifid to Slodan I waseleding ft Srat for a tree.*E $\delta$ thithe go cart Scids an is in the tree fwas sorleft ailmist it.

Slole I drifdid dawn to the end of the trac I Promist my Salt I wod nevor doit agn dit I sotol didit...

161 
Figure 23: Student F at Time Point Two.

C

every day I wander if some wan will give me something a I tell lonly.evry day I took ster up at exit I wander!! it I will de fred for from from this thetis pleas in Starting *tothelting thiktike thetike days are years and years are bekads. up her it te els like attorn te every day $F$ work out sid oft my hows siting my tea fhiking will I ever ga get apresit? for yearsandgyearcwith nufbik a parfrom $\neq$ my sake. I wader if someone is ting to send me sumer thing. I hat this gray old places. its like in trap it a cage and I cant get out in e every day I wrynder-adut mots on esth w er wen I foot up

162 
(vii) Joe; 3 years experience; Year 5-6 teacher; 79 Decile 9 school (Wellington)

Joe's survey responses for beliefs indicate average levels of agreement with explicit teaching and socio-cultural approaches, and a high level of agreement with the process-writing dimension (ranked in the $96^{\text {th }}$ percentile). His survey responses for practices indicated above average agreement with four of the six practices, average levels of agreement for attention to surface features, and low levels of agreement for basic writing skills (his responses for this dimension being ranked in the $7^{\text {th }}$ percentile).

Joe's interview comments validated the survey analysis, in that he described using a number of approaches associated with the process writing beliefs dimension. For example, Joe's priorities include student engagement and the development of student agency; content as the focus for teaching - with technical skills addressed at the end of the writing process (he commented "if it doesn't read well you have to get technical with it"); and teaching children to critique their own and each others' work. Like Daniel, Joe recalled his own school experiences as boring ("I hated it"), and described these memories as formative in his development as a writing teacher. It is interesting that both Daniel and Joe - the only male interviewees - recalled negative memories of school while none of the female teachers expressed any negative memories.

Figure 24 and Figure 25 show writing by one of Joe's female students at Time Points One and Two repectively. Evidently, this student had already mastered the technical skills of writing at the beginning of the year. Her spelling is near perfect, she uses a range of sentence structures that are grammatically correct, and she uses all punctuation correctly. Content is also sophisticated. Key elements of the narrative are introduced in these opening paragraphs. Attention has been paid to selecting an interesting setting (an orphanage - clearly intriguing for

\footnotetext{
${ }^{79}$ Joe's school operates as a modern learning environment, and uses flexible groupings in which children from a range of classes will work together for particular subject areas, according to their particular strengths and needs.
} 
modern New Zealand children). The main character's feelings of loneliness are highlighted through contrast with the rough and tumble play of the other children.

The second piece of writing is similar in every way. Technical aspects are well controlled, and ideas are detailed and expressed fluently. The only jarring element in this piece is an overuse of descriptive language, occasionally verging on the ridiculous (as in the description of "the banana-shaped moon") though this may attest to the writer's age more than to her writing skills.

Joe's priority was student engagement. He focused on content in the first instance, and worked to develop his students' expressive skills by teaching them to critique their own work and each others' work. Clearly, his students were ready for this. 
Figure 24: Student G at Time Point One.

Charlotte $13 / 2 / 2018$ 1204a

She waited by her dormetry door standing out in the room of luging Widren having pillow fights or playing wi the ragged orphanage dolls. However everything around Charlotte felt $x$ dilly, silent, sad, hopeless. Sh o Charlotte of wailed here every day, hoping that the door woald suddenly open and Miss Sofa, tho owner of the orphanage would burst in grinning madly for Charlotte and announcing that someone wanted to do pt Chudolte. Xt s never sang to hay pan charlotte. And Charlotte turned back to the laughing children.

"Chandote, why arentyou happy?" A fancy hele-year-old, Daisy, maned. "For once" Goral Nary snickered. Everyone laughed. Charlotte turned

165 
Figure 25: Student G at Time Point Two

Free Writing

Midnight

$\frac{9 / 8 / 18}{120(4) b}$

Molly stared out of her bedroom window glumly, watching the shy turn to ghostly outgo. She felt empty, like the waterless glass we xt to clenched in her hand. It was Thursday, the 19 th August, or in other words, the Day of Deceit', in Molls opinion. She looked slowly upwards to the banana-shaped moon. Stars reflected in her dark eyes. The mon made her face pale. Molly Alexandra Madonna stood there lite an ancient statue in a lost city, a strange rush of gurgling lukewarm liquid flowing through her. Downstairs she could hear the low chat ier of her foster parents fade, the click to turn of the light switch ringing in

166 
(viii) Alison; 27 years experience; Year 7-8 teacher, Decile 1 school (Porirua)

At the time of our interview Alison was teaching a Year 7-8 class at the same Porirua school as Anahera. Her survey responses for beliefs ranked in the $30^{\text {th }}$ percentile for explicit teaching, the $75^{\text {th }}$ percentile for socio-cultural approaches, and the $1^{\text {st }}$ percentile for process writing approaches. For practices, her responses were ranked at the $60^{\text {th }}$ percentile for attention to surface features, and below the $50^{\text {th }}$ percentile for all other practices (with particularly low rankings for basic writing practices and teacher goal selection).

In our interview, Alison emphasized the importance of the explicit teaching of writing genres, structures and styles, as well as of technical skills - sentence structure, spelling and punctuation. She also stressed several aspects of teaching which had not been investigated in the survey: Strong, positive relationships with students and a warm class culture were clear priorities, as well as the provision of opportunities for students to express and process their emotions. Another important approach was the use of authentic tasks, and the integration of curriculum - so that meaningful opportunities for writing practice were created throughout the day.

Overall, Alison's survey and interview responses demonstrate some alignment. Alison's above-average agreement with socio-cultural approaches, according to the survey, also is reflected in the commitment she expressed to creating positive classroom relationships (see Bishop et al., 2009, for a discussion of the importance of relationships as an aspect of culturally responsive teaching).

Figures 26 and 27 show writing samples from two different students in Alison's class. Both were written in diaries, which Alison uses to help students to express and process emotions, and also as a means of communication between the students and herself. The first sample was written by a male student. He descibes his annoyance with the sunlight on his working table and asks to be moved. The formal structure and attempts at persuasion, combined with naturally expressed warmth and character, make this writing quite remarkable. 
Though Alison's written reply to the student is partly obscured in the photograph, she suggested that the class write to the school principal to ask for new curtains. As she has since explained to me, the class did write to the principal, and the new curtains were purchased. Alison's comittment to authentic tasks is illustrated by this example. The diary writing and resulting letter writing activities served a purpose beyond the practice of writing skills. Furthermore, Alison supports a culture of democracy by allowing her students to express their opinions honestly, and by responding to them in a considered way.

The second sample (Figure 27) is written by a girl at the beginning of the school year. It is a short piece in which the student asks for help with her schoolwork, and expresses anxiety about going to college the following year. Alison's response is warm and reassuring, and illustrates her expressed comittment to developing positive relationships with her students. 
Figure 26: Student H at Time Point One

dear diary.

385

(10) $b$

Today I have nothing to say but 1 thing. a couple or bays age to I moved tables. I want to move again because the people our side cire distracting and it gets really hot because of the sun. It makes it lard to trows focus. Just now I spent. about 2 minutes taring my salk. This is teary angus annoying.

If its Possible I wan to moved awe y from the windows.

I thine Cataibs. Tewothe T.) and Minus feel the same way.

I hope that if we write letters we can get some

169 


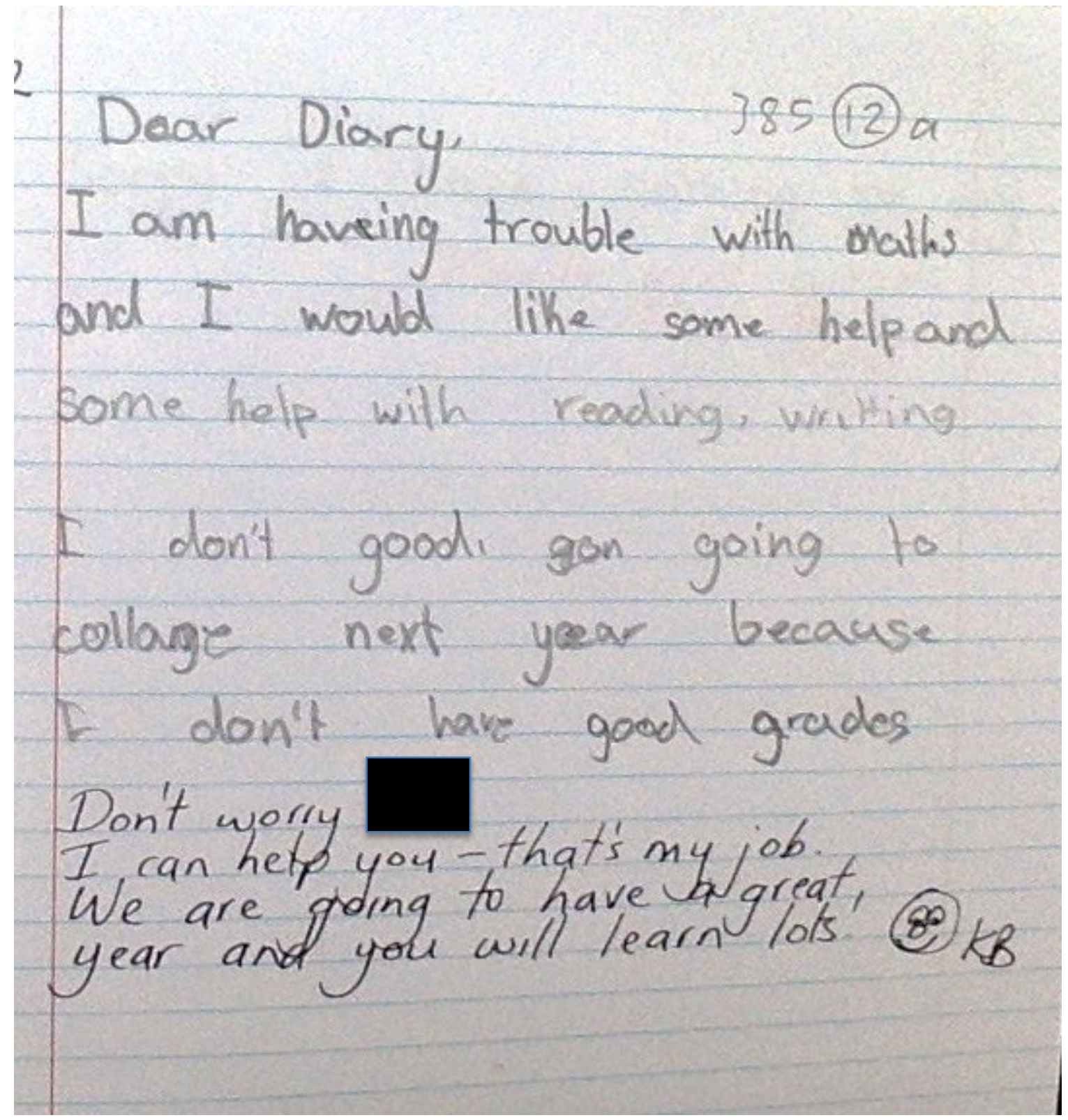

\section{Summary}

In general, interview comments supported the validity of the survey. An exception is Elizabeth, whose survey indicated high levels of agreement with socio-cultural and process approaches, but an only average level of agreement with explicit teaching. However, during her interview Elizabeth emphasized the use of explicit teaching for both technical and content-related skills. 
Belinda's data also require some further reflection. Her survey indicated high levels of agreement with explicit teaching dimensions, and this was supported by her interview comments. However, Belinda referred to explicit teaching only in relation to the teaching of content and stylistic aspects of writing. Unlike other teachers who favoured explicit approaches, she did not appear to prioritize the teaching of technical skills. This suggests that there may be some division in the way explicit approaches are applied. It is a possibility which may have some significance, but which was not anticipated at the outset of the study, or in the design of the survey.

These interviews revealed other beliefs and practices not anticipated during the development of the survey - and therefore not captured in the survey data. Four valued approaches emerged, including, (i) the use of authentic tasks; (ii) an emphasis on positive relationships between teachers and students; (iii) the facilitation of regular opportunities for writing practice, across the curriculum; and, (iv) closely guided writing practice.

Finally, the writing samples from every class demonstrate the significant influence of teachers' approaches on their students' work. All teachers were able to achieve positive results for students, in terms of motivation as well as the development of writing skills. The samples also demonstrate the ways in which school writing can provide opportunities for student selfexpression and contribute to a culture of mutual respect.

\section{Interviews: Cross-Case Analysis}

The purpose of this cross-case analysis was to investigate case study teachers' uses of technology for teaching writing, and to explore their thinking around two particular survey items: It is important that students have frequent opportunities to write about their personal experiences (a statement with which $98 \%$ of respondents agreed), and students should be encouraged to use rubbers to correct errors in their draft books (a statement with which $92 \%$ of survey respondents disagreed). 
(i) Uses of technology for the teaching of writing

All the case study teachers reported using technology in their writing programmes, with seven out of the eight teachers allowing students to compose some or all of the time on computers. Elizabeth was the exception. She preferred that her junior students practice handwriting as often as possible.

All teachers cited motivation as a key reason for composing on a screen. Other benefits included the ability to revise work and to track changes - thus enabling reflection at a later date (emphasized by Daniel and Joe); and the greater ease of typing for some students who struggle with letter formation (identified as a benefit by Ngaire, Daniel and Anahera). Alison simply asserted that "you can't get away from it, it's their world" and a similar sentiment was expressed by Joe, "it's where education's going whether we like it or not".

When questioned about any disadvantages of writing on a screen, Jenny, Ngaire, Anahera and Alison emphasized the importance of a balance between digital and book writing. Ngaire specifically identified the importance of practice with the physical act of handwriting as a reason for this, and Anahera and Alison reported that their students tend to rush through revision and editing when working on a screen. Joe identified distraction being an issue for some children - as they were able to access music on their computers while writing.

While the use of technology for composition is of greatest relevance to the present study, teachers incorporated technology into their programmes in a wide variety of other ways too. A summary of the case study teachers' uses of technology is provided below: 
Teachers' uses of technology

\begin{tabular}{|c|c|}
\hline Ngaire (Year 2-4) & $\begin{array}{l}\text { Composition during independent writing sessions } \\
\text { 'Storybird' - a website which provides prompts for writing, and } \\
\text { allows students to write collaboratively with people acroos the } \\
\text { globe. } \\
\text { Class blog } \\
\text { 'Write about this NZ' - an app that provides writing prompts and is } \\
\text { also a platform for publishing. }\end{array}$ \\
\hline Jenny (Year 3-4) & $\begin{array}{l}\text { Composition - a buddy system was in place so that the year 7-8s } \\
\text { could teach her year 3-4 students how to use computers for } \\
\text { writing. }\end{array}$ \\
\hline Daniel (Year 5-6) & $\begin{array}{l}\text { Composition - using google docs. } \\
\text { 'Booktrack' - an app which allows writers to publish their work as } \\
\text { audiobooks, with sound effects. } \\
\text { 'Literacy planet' - an online programme for practising literacy } \\
\text { skills, and which provides opportunities to compete with students } \\
\text { in other countries in tests of these skills. }\end{array}$ \\
\hline Alison (Year 7-8) & $\begin{array}{l}\text { Publishing - google docs, including google slide shows } \\
\text { Research }\end{array}$ \\
\hline Joe (Year 5-6) & Composition - google docs \\
\hline Elizabeth (Year 1) & Apps for practising phonemic awareness \\
\hline
\end{tabular}


Teachers' uses of technology ctd.

\begin{tabular}{|l|l|}
\hline Belinda (Year 5-6) & $\begin{array}{l}\text { Showing youtube clips as inspiration for writing. } \\
\text { Talk to text for students who struggle with handwriting. } \\
\text { Digital audio recordings of students saying the sentence they want } \\
\text { to write - to be played back during composition. } \\
\text { Online dictionaries for accessing difficult spelling words. }\end{array}$ \\
\hline 6) & Publishing using google docs - including slide shows \\
& \\
\hline
\end{tabular}

(ii) Personal experience writing

The beliefs survey item, students should have frequent opportunities to write about their personal experiences, was predicted to form part of the process writing dimension, but did not load with any dimension, possibly due to lack of variability across the sample $(73 \%$ of respondents strongly agreed and 25\% agreed with the statement). Its correlation with achievement was weak, possibly for similar reasons. The interviews were used as an opportunity to explore reasons for the popularity of this item, and each case study teacher was asked to explain why they considered personal experience writing to be important (or why they didn't, in the case of two teachers).

Three teachers who agreed with the frequent use of personal experience writing (Jenny, Ngaire and Elizabeth) reported that this kind of writing was easier for students as the details and language were already in their minds. Daniel explained that his students enjoyed sharing information about themselves. Both Alison and Anahera focused on the emotional benefits of personal experience writing. These two teachers used journaling with their students, to help 
them to express and process difficult emotions, and also as a means of communication between student and teacher (Alison reported that some of her students found writing and easier way to tell her about sensitive issues). A final point was made by Anahera, who stressed the value of students having a record of significant personal and family events, which they could return to as adults. She spoke of her appreciation of the richness of her students' lives in their multi-cultural community, recalling student writing which recorded such profound experiences as visiting a dying relative in hospital.

Many of the case study teachers who agreed with the use of personal experience writing incorporated it carefully into their programmes, to extend children's knowledge of genre beyond the obvious recount type exercises. Jenny and Ngaire described ways in which they facilitate hands-on experiences for their students (such as science experiments, or visits to places of interest), which students can then use as topics for their writing.

Joe and Belinda reported that they neither agreed nor disagreed with this item. Joe explained that while it sometimes worked, over-used topics such as "what I did in the holidays" were boring for students. Belinda felt that personal experience writing was appropriate for some children, but not for others, as many of her students did not have happy home lives to write about.

\section{(iii) The Use of Rubbers}

The item Students should use rubbers to correct mistakes in their draft books was negatively correlated with items in the socio-cultural beliefs dimension, and was overwhelmingly rejected by survey respondents $(92 \%$ of teachers disagreed or strongly disagreed with the use of rubbers). This item is of particular interest as rubbers were used in the classrooms of the more effective teachers who participated in the Fast Feedback intervention. Case study interviews were used to further explore teachers' attitudes to the use of rubbers.

Elizabeth, Daniel, Alison and Anahera all disagreed with the use of rubbers by students. They identified two main reasons for this, the first being that they wanted to be able to see the 
mistakes that their students made, in order to direct future teaching (Joe, otherwise neutral about the use of rubbers, shared this concern). These teachers also interpreted student erasing as a sign of anxiety and unwarranted perfectionism. They wanted, instead, for their students to understand that mistakes were a valuable part of learning. Anahera also noted that erasing could be a time wasting strategy and Belinda (otherwise neutral about the use of rubbers) shared this view. ${ }^{80}$

Ngaire and Jenny described novel approaches to rubber use. While Ngaire expressed disagreement with the use of rubbers by students for their independent writing "because they rub out too much", she used them herself during guided writing sessions, so that at the end of these, students had a corrected version - useful as a model of correct writing but also for future publishing. Jenny was quite different from the rest of the group, and allowed students to use rubbers freely (she provided one for each table group as an essential stationary item). Jenny described this as a "no brainer". She had observed that children don't like to see their mistakes, and questioned why we should impose this on them. She regarded rubber use as another skill for writing, and one that should be taught. She acknowledged that some children did spend too much time rubbing out, but interpreted this as a sign of a bigger problem, and would respond by talking with them "to see what's going on'.

\section{DISCUSSION}

\section{Summary of results}

Three dimensions of beliefs emerged from the survey data, relating to explicit teaching, process writing, and socio-cultural beliefs. All of these were predicted, on the basis of a review of local and international literature. A fourth predicted dimension - the valuation of correct writing did not emerge: some items hypothesized to correlate with a 'correctness' dimension correlated instead with explicit teaching items. Two other items were disendorsed by a majority of

\footnotetext{
80 The reluctance of these teachers to allow students to use rubbers seems inconsistent with their enthusiasm for writing using computers, during which deletions can easily be made.
} 
respondents and were negatively correlated with the socio-cultural beliefs dimesion. These results differ with those of the US study of Graham et al. (2002), in to which explicit teaching and a valuation of correctness emerged as two distinct dimensions. Interestingly, the commitment of New Zealand teachers to socio-cultural approaches appears to be unique (as evinced by international studies, for example, Graham et al., 2002; Troia, Lin, Cohen \& Munroe, 2011; Ritchey, Coker \& Jackson, 2015).

The present study supports previous research that indicates that the different dimensions of teachers' beliefs are not mutually exclusive (see Zhang, 1996, for further discussion). Over $80 \%$ of respondents expressed agreement with all of the explicit teaching beliefs items; and 70\% also expressed agreement with five of the seven process writing items. Over $80 \%$ of teachers expressed agreement with five of the eight socio-cultural items. A higher proportion of teachers expressed agreement with explicit items in the study of Graham et al., than in the present study, though roughly the same proportion favoured 'natural learning' approaches (equivalent to process writing). ${ }^{81}$

Explicit teaching and socio-cultural beliefs appear to be dominant in New Zealand. However, the continued influence of process writing may be more widespread than the lower levels of agreement with the process-writing dimension suggested. This influence is evident in the consistency of response to two items in particular, both hypothesized to load in the processwriting dimension, though in fact they did not. Students should have frequent opportunities to write about their personal experiences was almost unanimously endorsed, whereas students should use rubbers to correct mistakes in their draft books was almost unanimously disendorsed and was negatively correlated with socio-cultural beliefs. A high valuation of personal experience writing, and the use of crossing out - rather than erasing, are both consistent with

81 The term process writing has been used in this study as practices in this dimension reflect the influence of the movement of the 1980s, described in Chapter Three. Both process writing and socio-cultural approaches align with natural learning approaches, however. 
process writing values. Both ideas can be directly traced to the work of Donald Graves, Lucy Calkins, and Donald Murray (among others - see Chapter Three for a review of their work).

Analysis of the practices survey revealed six dimensions, including explicit approaches, socio-cultural and process approaches, attention to surface features, advanced writing practices, basic writing practices, and teacher goal selection. Significantly, the hypothesized socio-cultural and process writing items merged to form a single practice dimension, possibly reflecting their common roots in the broader constructivist tradition. Like the study of Graham et al., the predicted relationships between beliefs and practices were largely confirmed: Explicit teaching beliefs correlated positively with explicit teaching practices, and negatively with process and sociocultural practices. They positively correlated with all of the other practice dimensions. Socio-cultural beliefs correlated with process writing and socio-cultural practices. They positively correlated with three of the other practices dimensions (including a weak correlation with explicit approaches), and negatively correlated with attention to surface features and teacher selection of goals. Process writing beliefs positively correlated with process writing and socio-cultural practices. They also positively correlated with advanced writing and basic writing practices, and negatively correlated with explicit practices, attention to surface features and teacher selection of goals.

Interviews with eight study teachers supported the validity of the survey data. These teachers' own explanations of their approaches were largely consonant with their scale locations on the survey dimensions. ${ }^{82}$

A second stage of the research investigated whether certain teacher beliefs are associated with greater rates of student progress than others. This involved an examination of

\footnotetext{
${ }^{82}$ A qualification is necessary: teachers did not use the terminology such as "process writing", "sociocultural approaches" or "constructivist approaches" (though some did make direct reference to explicitness).
} 
correlations between the average progress of classes and their teachers' reported beliefs and practices. This analysis produced three sets of results.

(i) Strong - although, due to the small sample of teachers, only marginally significant correlations were found between progress in writing and both explicit teaching beliefs and practices. Strong correlations were also found between a number of individual explicit teaching items and progress. These items described the explicit teaching of both technical and contentrelated skills. ${ }^{83}$

(ii) A substantial negative (and significant) correlation was found between process and socio-cultural practices and progress.

(iii) Student progress was negatively correlated with increasing year level. Explicit teaching beliefs (associated with greater rates of progress) were also negatively (though not significantly) correlated with higher year levels, as were explicit teaching practices. In contrast, process writing and sociocultural practices were positively (though not significantly) correlated with increasing year level. This finding corroborates the others - low rates of progress in the senior levels may be attributable to the teachers' lower levels of agreement with explicit teaching beliefs and practices. The picture is not entirely straightforward however, as sociocultural and process writing beliefs were also negatively (though not significantly) correlated with the year levels they taught.

Correlations between explicit approaches and student achievement were unsurprising inasmuch as the efficacy of explicit pedagogy has been demonstrated in numerous empirical studies. It must be acknowledged, however, that research into teachers' beliefs and their relationship to achievement is limited, and the studies that do exist have produced inconsistent results. While New Zealand writing researchers Parr and Limbrick described the importance of

\footnotetext{
${ }^{83}$ Regarded from a purely mathematical basis, these correlations may be better described as moderate. However, given the nature of the data - and the variables in question - I believe the term strong to be more accurate.
} 
explicitness in their mixed methods study (2010), British researchers, Poulson, Avramidis, Fox, Medwell and Wray (2001) found that the most successful writing teachers tended to actually downplay the importance of teaching handwriting and spelling skills. Ritchey et al. (2015) investigated the relationship between beliefs and student writing performance in the US, and found that there were limited effects for teachers' orientations, and that no single orientation emerged as a predictor of student achievement.

Negative correlations between progress and both process writing and socio-cultural practices require some considered analysis. These correlations call into question many of the pedagogical recommendations characteristic of Ministry of Education materials and the New Zealand research literature. While the findings cannot be considered definitive, they do suggest that further appraisal of this advice is needed.

The qualitative information for the eight case study teachers is illuminating. This provides a more nuanced picture than the quantitative data. We are reminded that there are a variety of purposes for school writing (including its potential social and emotional benefits), and that the age and stage of students is key in determining the most appropriate approach.

While the quantitative data could be taken to suggest that process writing and sociocultural practices are not conducive to student success in composition, it is interesting to consider how these were used to encourage student self-expression. These practices may well have deepened students' sense of belonging, even when a direct impact on their writing progress was not observable. An example of this is Alison's use of diary writing, which enabled students to share their thoughts and emotions with her. In one example, a student explains his dissatisfaction with the class seating arrangements, and the problems with sun at his working table. Alison responded to this by supporting her students to write letters to the principal to ask for new curtains. In so doing, Alison showed the student that she valued his opinion, and demonstrated the power of writing to achieve change. In a second example, a Year 8 girl expressed her anxiety about schoolwork and going to college. Alison responded in writing, 
demonstrating genuine care with her warmly reassuring comments. This must have helped her student to feel comfortable and welcome in the classroom, a necessary precondition for learning and (needless to say) of the utmost importance for its own sake.

Process writing approaches may have significant motivational benefits, particularly for more advanced student writers. An example is Joe's use of these techniques with his Year 5-6 class. While readily definable improvements were not observed in the second of his student's two samples, both samples demonstrated total commitment to the writing tasks at hand. Moreover, the writing in both samples was technically perfect, as well as being sophisticated in style and content. Joe's use of student self-reflection, and what he referred to as "universitystyle critiquing", seem much more appropriate in the case of this particular student, than explicit and teacher-directed learning would have been.

On the other hand, the explicit teaching of technical skills such as handwriting, spelling and sentence structures, was immensely helpful for the younger, and less advanced writers in Elizabeth, Ngaire and Jenny's classes. As these students overcame difficulties in the technical aspects of their writing, the broadly expressive aspects of their writing also improved. Comparisons of these students' writing, over time demonstrate dramatic rates of progress.

The convergence of seemingly disparate beliefs was clearly demonstrated in the case of Belinda, who emphasized the explicit teaching of content and stylistic features, but not technical skills, and who described a number of approaches consistent with process writing. Belinda prioritized student engagement in personally meaningful writing tasks. Her approach to draft writing mirrors the recommendations of Graves and Calkins (she described it as a "free flow write", and regarded attention to technical details as a distraction from the primary goal of self expression). The writing of Belinda's student is expressive and interesting, though technical difficulties persist at time point two. It seems likely that a greater emphasis on the explicit teaching of these skills would have been helpful for this child. 
Taken together, the survey and case study data indicate that, while process and sociocultural approaches have much to offer, they are not - in themselves - enough to accelerate progress for our lowest achieving writers. To do this, teachers must ensure that technical constraints are overcome by teaching these explicitly.

\section{The ongoing influence of Graves}

The survey indicated widespread agreement with two survey items that appear to be consistent with process writing approaches. Students should have frequent opportunities to write about their personal experiences was agreed with by over $98 \%$ of respondents; and Students should use rubbers to correct mistakes in their draft-books, was disagreed with by $92 \%$ of teachers. The use of personal experiences for writing, and the prohibition of erasing are recommended by advocates of process writing, despite a lack of evidence to support them. In the present study, the near-unanimous response to these items meant that alternative approaches were not profiled. It is interesting to reflect on teachers' commitment to these two pedagogical principles, both of which originate in the work of Graves.

\section{(i) Personal experience writing}

Graves's valuation of personal experience writing has been critiqued, for example by Stotsky (1995). Stotsky describes how teaching of the writing process and the use of personal experience writing were (unnecessarily) fused in process writing approaches, in part because personal experience writing facilitates more efficient movement through the stages of planning, drafting and revision - without the need for research. She identifies three major limitations of this approach. First, many children (and particularly boys) prefer to write informational reports (see Martin, 1985, and Sowers, 1981, cited in Stotsky, 1995). Second, because personal recounts predominantly follow a chronological order, students gain little practice with reasoning out the logical order for other kinds of information and ideas. Third, the prevalence of personal experience writing may be limiting - there are other kinds of writing that students may enjoy more and that they need to learn to use. In addition, Stotsky reflected that, as personal writing 
has been given prominence in many American classrooms since the 1980s, levels of writing performance (as indicated by National Assessment of Educational Progress reports) have not improved. Furthermore, the assumptions of process writing theorists as to which kinds of personal experiences constitute worthwhile topics require examination. Calkins, for example, viewed family life as a topic with depth and meaning, while dismissing some children's interest in superheroes as superficial. This, arguably condescending, judgment is inconsistent with the movement's other ideal of child-centred learning.

Encouragingly (given the research described above) case study teachers who agreed with the use of personal experience writing took a more pragmatic view. They explained that, for students, writing about what they know simplifies the writing process, as the ideas and language are already familiar to them. Furthermore, these teachers expanded the definition of personal writing, to include writing about anything of which the children had first-hand experiences. Rather than relying on home life as inspiration, the teachers encouraged them to draw on interesting class experiences such as science experiments and trips.

This broader approach appeared to be motivating for many students (for example, see Figure 21 in which one of Anahera's students describes a science experiment with enthusiasm). In contrast, the (commonly-used) task - to recount out of school experiences, generally resulted in less successful writing. This can be observed in the case of Elizabeth's Year 1 writer (Figure 13) who blends real and imagined detail in her description of a visit to the beach. The use of imaginary content is not in itself a problem, though without a clear purpose and supportive narrative structure, the writing lacks impact.

\section{(ii) The prohibition of rubbers in favour of crossing out} Graves (2003) described draft writing as a creative process (with writers working "on the edge of consciousness", p. 234), and recommended that conventions (i.e. "correctness") be left to a final editing stage. As discussed in chapter two, Graves' reliance on case study research means that his findings are not generalizable. Furthermore, the practice of crossing out appears not to 
have been investigated in any recent empirical work. ${ }^{84}$ As already intimated, this seemingly innocuous practice needs to be re-evaluated, and should be a priority for future research. This conviction is based primarily on observations described in detail in the following chapter.

During this fieldwork, it was clear that rubbers allowed students to make tidy revisions - and to keep their writing comprehensible. This made re-reading (the basis of self-regulation) less of a hurdle. The use of rubbers also appeared to have motivational benefits, as students took satisfaction in presenting work that they knew to be correct, and which looked tidy.

Case study teachers who favoured crossing out explained (i) that they needed to see students' mistakes in order to direct future teaching; (ii) that the practice of leaving errors visible encouraged students to accept them as a part of learning; (iii) that the practice of erasing could become a task-avoidance strategy. These arguments invite interrogation. Assessment of learning needs can be achieved through observations of students while they write, without requiring a record of errors to be retained in the writing itself. While mistakes are a part of learning, the only constructive response to an error is to correct it. If students are rubbing out too much, perhaps this is a sign of some other problem - a lack of motivation, or a lack of knowledge about how to approach the writing task purposefully. ${ }^{85} \mathrm{~A}$ final point: students now regularly write on computers that allow for easy deletions.

Figures 28 and 29 demonstrate one of the ways in which crossing out may be counterproductive. In these samples, untidy corrections make re-reading difficult. Even when the writer's intentions are decipherable, the confusing layout interrupts the flow of the sentences. When one considers the central role of self-regulation in the writing process it becomes clear that difficulty with re-reading may be a significant barrier to progress.

\footnotetext{
${ }^{84}$ The only reference I could find to rubber use is in Richard Benton's (1986) paper describing the impacts of particular patterns of classroom interaction. Benton observed that frequent erasing by students was associated with successful learning as it "enabled ideas to be clarified and inappropriate statements to be corrected mentally as well as on paper" (p.18).

85 This point was also made by Jenny, the only case study teacher who allowed her students to use rubbers when writing independently.
} 
Figure 28: Junior-level writing with crossing out.

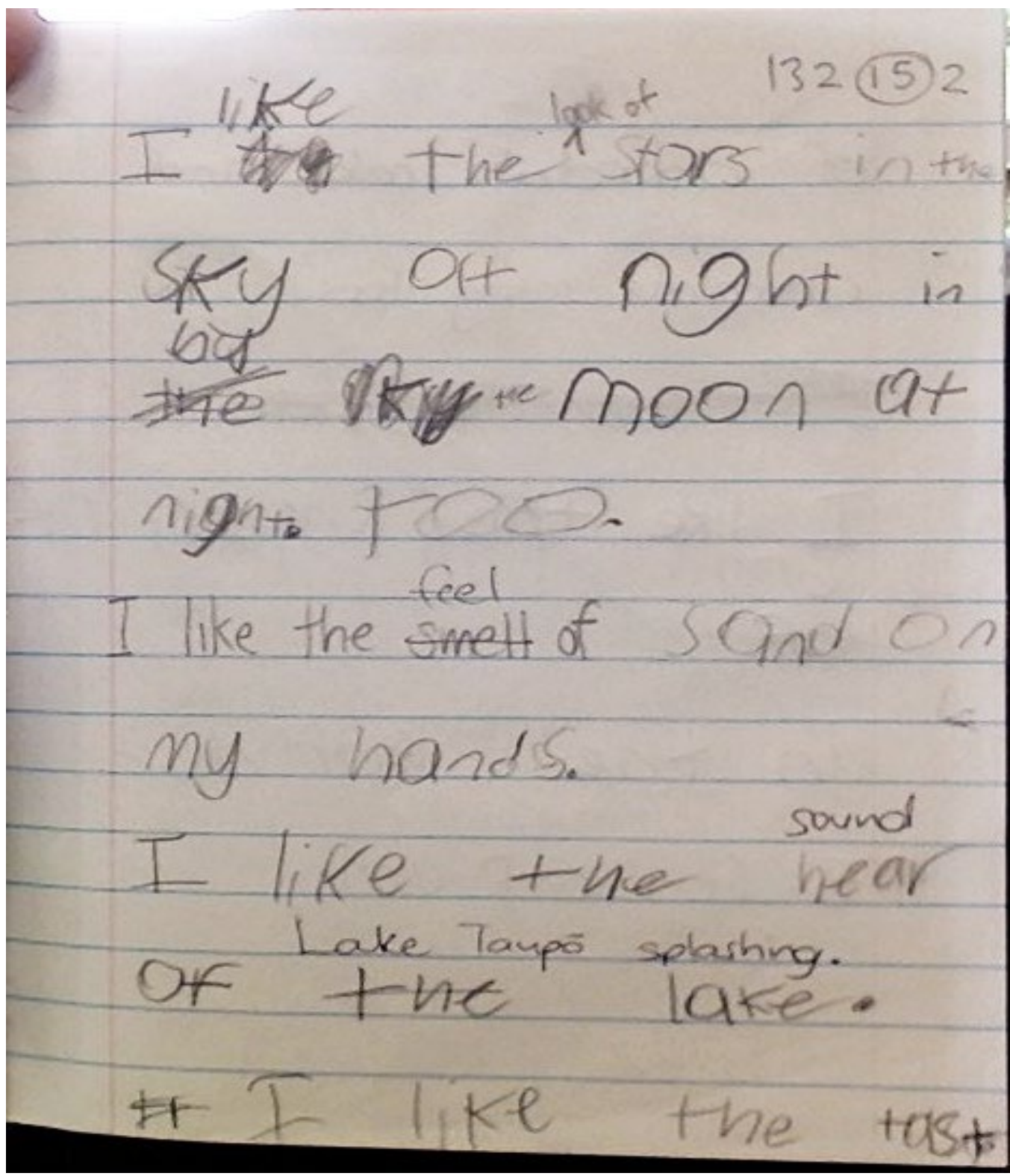


Figure 29: Senior-level writing with crossing out.

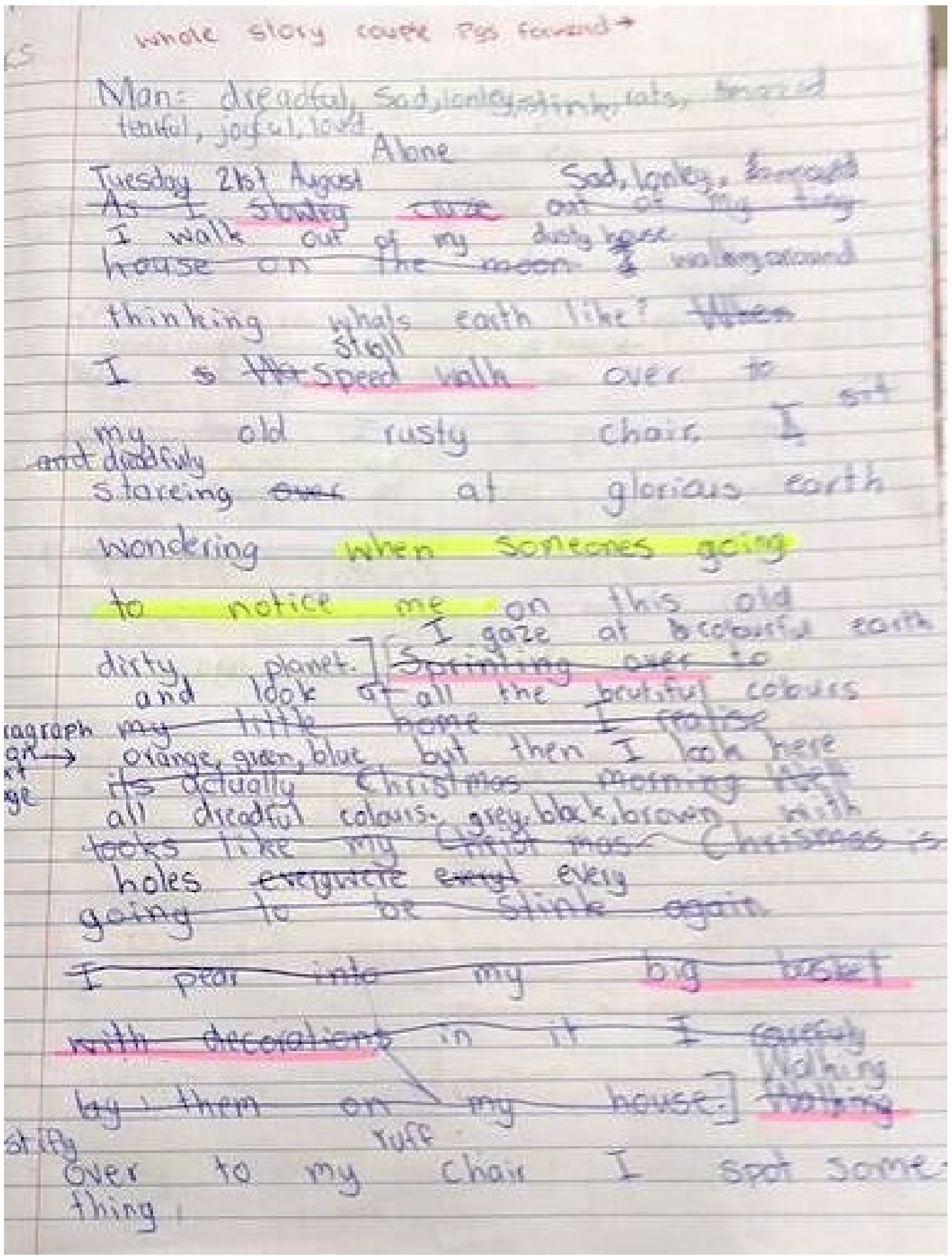

Being prevented from erasing could reduce students' motivation to revise their work. Figure 30 demonstrates the visual impact that corrections without erasing can have. The $\mathrm{D} / \mathrm{d}$ corrections 
dominate this sample, and are the first thing the reader sees. Somewhat ironically, these errors would not be so noticeable had they not been corrected.

Figure 30: D/d corrections dominate.

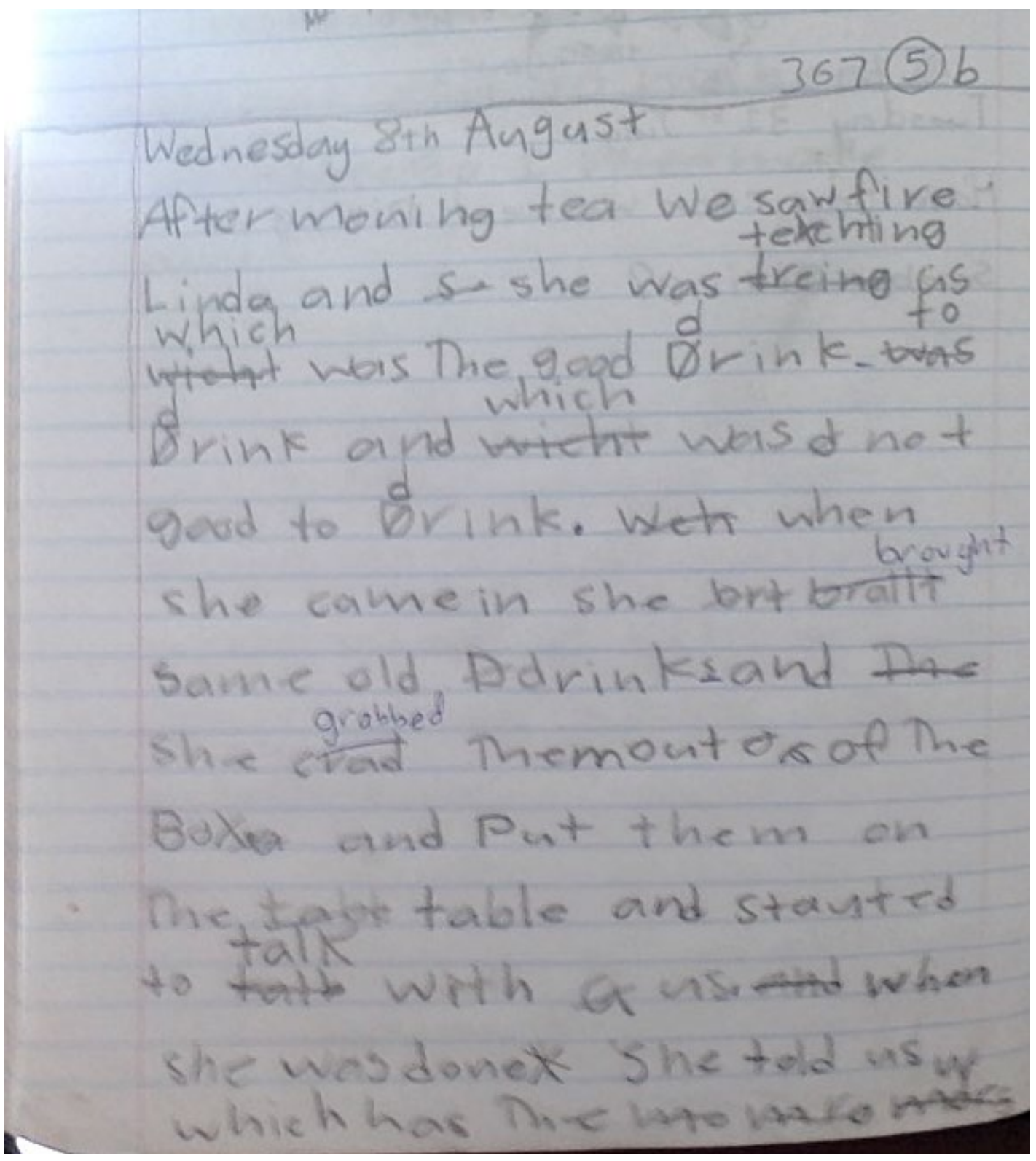

The final sample (Figure 31) has been selected to demonstrate the way in which a reluctance to use rubbers reduces learning opportunities for students. In this sample, the teacher has corrected the first letter to a capital over the child's own writing. If sentence punctuation was a teaching focus, this would have been better reinforced had the child been asked to erase and re- 
write the letter herself. Any ambivalence about corrective feedback becomes irrelevant as the teacher has already drawn attention to the error.

Figure 31: Teacher corrections may represent a missed opportunity for student learning.

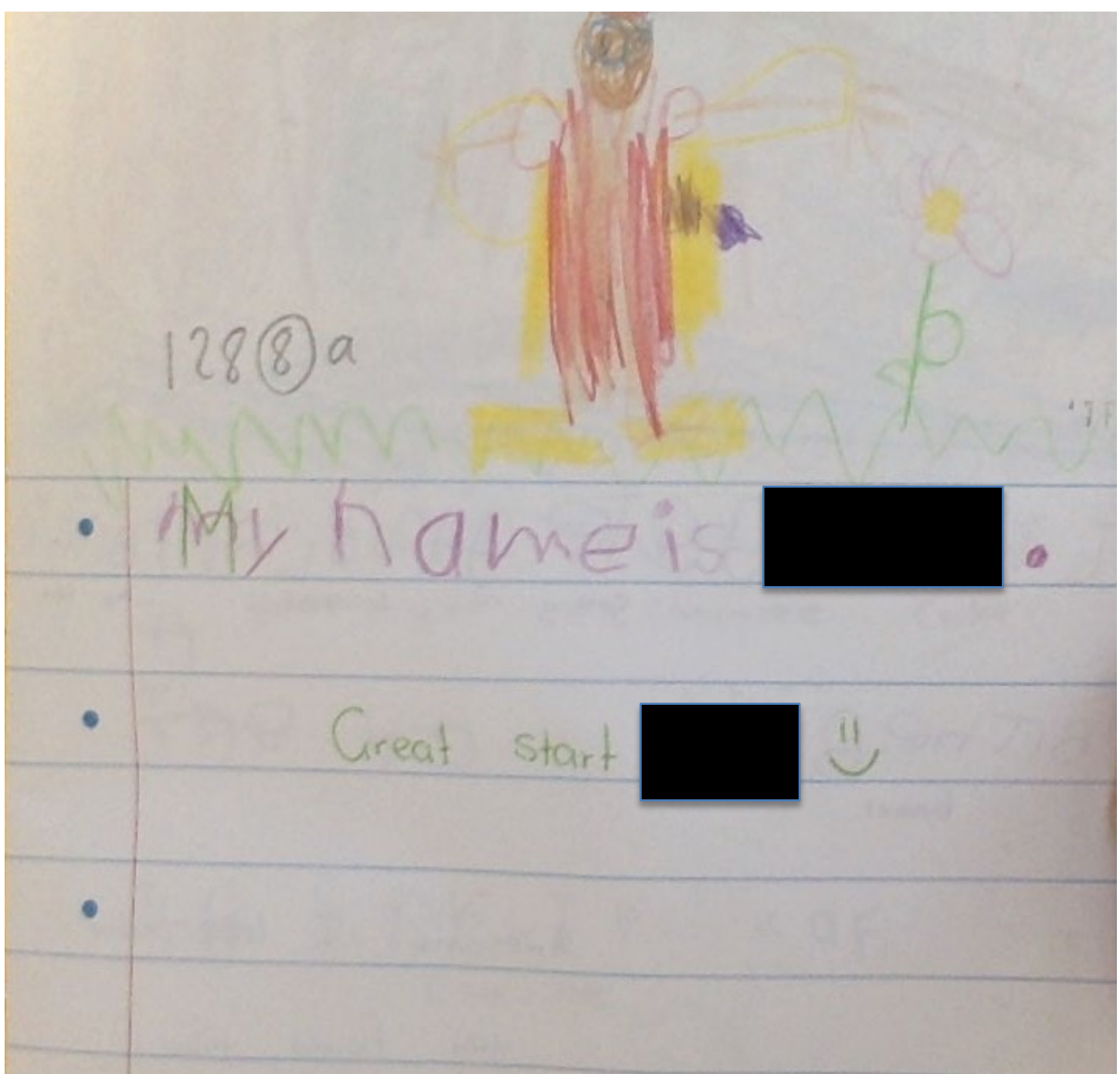

Widespread ambivalence about the importance of correct and tidy work is reflected in patterns of response to other items also. A large majority of participating teachers agreed that instead of telling students how to spell words, teachers should encourage them to spell as best they can; and that a "messy" draft book may be a sign of deep engagement in the writing process. Though only the first of these items actually loaded in the process-writing dimension, they are all symptomatic of the process writing school of thought and indicate a strong, ongoing acceptance of some of the ideologically-based assumptions of proponents such as Graves. Rigorous appraisal is beyond the scope of the present study. It is nevertheless possible that a re- 
evaluation of the role of correctness and tidy presentation could have profound (and positive) impacts on student achievement nationally.

\section{Limitations of the study}

There were limitations in the design of the survey tool. First, in the wording of the practices item which did not load in any dimension, "when planning writing programmes, I consider research evidence about effective practice". This item was hypothesised to load with explicit teaching items, and yet (as it did not specify empirical research) may have been interpreted as referring to research from other theoretical frameworks. Another consideration is that the interviews (administered after the survey) generated new insights about beliefs and practices. On reflection, these beliefs (such as the importance of relationships for student learning) were highly relevant and should have formed part of the survey.

In the second stage of the study, the numbers of teacher and student participants were small. A larger sample size would have added strength to statistical findings. A further weakness was the limited information collected about student participants. More detailed information about students' genders, ethnicities and school deciles would have enabled in-depth analysis of the impacts of certain methods, for particular groups of students. Finally, the omission of observations of participating teachers means that it is impossible to know whether teachers' self-reported practices align with their actual practices, or how well teachers' understandings of the survey items were aligned with those of the researcher.

\section{Summary}

This study began with a survey of over 600 New Zealand teachers. Predicted dimensions of beliefs and practices were largely confirmed, and the validity of these dimensions was supported by qualitative data gathered from interviews with a sub group of eight case study teachers. 
In a second phase, 19 teachers shared writing samples and these were assessed using a modified e-asttle rubric, a tool which showed acceptable measures of inter-reliability in three separate trials. Measures of average progress from each teacher's class were compared with their survey data, and the comparison produced positive correlations between the explicit teaching practice dimension and student achievement, and individual explicit teaching items and student achievement. In contrast, the socio-cultural and process writing practices dimension (and two individual items from the same dimension), were negatively correlated with achievement.

Interviews with case study teachers, and the progress of their students, largely corroborated the quantitative findings. While many of these teachers used socio-cultural and process writing approaches to enhance student engagement and promote inclusivity, only those who explicitly addressed the technical skills of writing - handwriting, spelling and sentence structure - were able to substantially improve their students' writing.

The present findings raise questions about the pedagogical directions adopted by the New Zealand Ministry of Education, although, clearly, further research is needed. Such research should, ideally, supplement the study presented here, in a number of ways. It could introduce additional lines of enquiry (picking up on the beliefs of the teachers interviewed) and classroom observations (as they relate to teacher values). Finally, the sample size should be enlarged to produce more statistically robust results.

Already, on the limited basis of the findings summarized above, one might want to question the Ministry's promotion of broadly "constructivist" methods - and, especially, its rejection of other approaches. New Zealand teachers are committed to serving their students. It is the responsibility of researchers and the Ministry of Education to provide them with practical and objective information about effective teaching methods. If this were to happen, the alarming disparities between the skill-levels of students, like those who participated in this study, may be greatly reduced. 
CHAPTER EIGHT, STUDY TWO: A QUASI-EXPERIMENTAL TEST OF FAST FEEDBACK

\section{PEDAGOGY}

\section{INTRODUCTION}

Social cognitivist research has contributed a great deal to our knowledge of writing, and of how to teach it effectively. This literature shows that the writing process is recursive and complex, with interactive cycles of planning, transcription and revision occurring throughout composition. Self-regulation is a key skill, with the conscious 'writing monitor' overseeing coordination of different writing processes (Flower \& Hayes, 1981). For beginning writers, transcription skills - spelling and handwriting - add significant constraints: These skills need to be automatized in order to free capacity-limited working memory (Berninger, 1999; McCutcheon, 1996). Graham \& Harris (1997) synthesized the results of empirical writing research to make certain recommendations for teaching: Explicit instruction should be used to teach transcription skills, as well as writing processes. These should be practised by students in the context of a range of authentic writing tasks. Peer collaboration and positive feedback by teachers should be used to encourage student self-regulation skills.

Comprehensive studies (e.g., Hattie \& Timperley, 2007; Locke \& Latham, 2002; and Kluger \& De Nisi, 1996) have demonstrated that feedback can increase learners' self-efficacy and self-regulation skills, when applied in certain ways. Most effective feedback has several defining characteristics: (i) It is given in relation to goals which are specific, clear and challenging - and which address learning processes (rather than outcomes); (ii) It acknowledges progress towards set goals, and may use visual displays to communicate this to students; (iii) Conferences should involve just one student at a time, to avoid unhelpful selfcomparison with others; and (iv) Feedback should be inextricably linked to ongoing formative assessment. 


\section{Fast Feedback}

Fast Feedback is a system for teaching writing, developed in line with social cognitivist writing and feedback research. The pre-eminent aspect of this approach is regular conferencing, during which individual goals are selected for each student and recorded at the back of their writing book. Also during conferences, students' progress towards selected goals is evaluated, and their progress is tracked visually (through a system of ticks - indicating partial achievement, and stickers - indicating full achievement) underneath the goal on the back page of their book. When a student demonstrates full achievement of a selected goal for five days or more, a new goal is selected and the process continues.

Fast feedback conferencing occurs within writing lessons which reflect the recommendations of social cognitivist researchers, such as those of Graham and Harris (1997). Teachers plan interesting writing contexts and tasks. They model processes of planning, reviewing and revising at the start of every lesson, as well as other specific skills - reflecting students' individual conferencing goals. Following this, some time is given for students' planning - either through peer discussion or written notes. The main body of the lesson is for students' writing practice, during which time teachers provide one-on-one guidance, reminding students of their learning goals and clarifying or re-modelling the skills when necessary. With regard to spelling and handwriting, recommended practices align with the findings of Berninger et al. (2002), following methods devised by Brann (2001). Ideally, these skills are taught regularly and explicitly - outside of the composition lesson.

In 2015 I engaged nine teachers to trial Fast Feedback, in seven classrooms at three Wellington Schools. Student achievement data were collected at four time points, and this was compared with data from students at a control school. Teachers were interviewed at the end of the intervention, and were asked to identify the benefits of the Fast Feedback, as well as any particular limitations. Students were surveyed with one question: "How helpful is Fast Feedback for your learning?" which they responded to on a four-point Likert scale. While the 
conferencing system was the key focus for this study, the other research-based approaches to the teaching of writing (described above) were also recommended. These were modeled during visits to the participating teachers' classes, and are described in a writing manual - a copy of which all participating teachers received (see Appendix iii).

This study attempted to answer three focused questions:

1. What impact does Fast Feedback have on student achievement?

2. What are teachers' experiences of using this system with their students?

3. What are students' experiences of Fast Feedback, when it is implemented in their classes?

\section{METHODS}

\section{Participants}

Participants included nine teachers and 139 students, from three schools in Wellington, Lower Hutt and Porirua. There were eight classes in total. One class was taught by two teachers in a job-share arrangement. Another two classes combined for the team-teaching of writing lessons, which meant that these students were taught as one group of 54 .

School principals were approached via email and all teachers at participating schools who volunteered were accepted into the study. These teachers were then asked to select student participants from their classes. Regarding this selection, I initially advised teachers to select the five lowest-achieving writers in their classes, while giving them the option to include all of their students. Two teachers selected just the lowest five writers in their classes; the other teachers selected most or all of their students (although some decided not to include their special needs students). Informed consent was sought from a total of 146 students; two students did not consent. Five other students changed class or school during the intervention, and were therefore withdrawn from the study. Ten out of 11 new entrants began school after the first pre-intervention data collection time point. Three out of the group of 11 began school 
after the intervention had already begun. One Year 4 student also joined a Year 4 class after the intervention had started. These students' data were analysed separately.

All of the participating schools are contributing schools, catering for students from Years 1-6. They represent a range of decile ratings and ethnic compositions. School A is a Decile 2 school in Lower Hutt. Its total number of students is approximately 160, with a large proportion of Māori and Pasifika students (35\% and 37\% respectively).Three classes from School A participated in the study, including two Year 3-4 classes who worked as one group for writing, with 11 participating students, and a Year 5-6 class, with 19 participating students. School B is a Decile 4 school in Porirua. The total number of students is approximately 420 , including $44 \%$ Māori, 41\% European and 11\% Pasifika. Three classes from this school participated, including a New Entrant class (with 11 participating students), a Year 3-4 class (with 27 participating students, including one special needs student), and a Year 5-6 class (with 22 participating students). School C is a Decile 7 Wellington school, with approximately 230 students. Forty-two percent of students at this school identify as European; the others represent a diverse range of ethnicities, including Māori, Pasifika, Asian, Latin American, Middle Eastern and African. Over $50 \%$ of students learned English as a second language, and a number hold refugee status. Additionally, this school has a high number of special needs students. Two classes from School C participated. These were a Year 3-4 class with 24 participating students (including 3 with special needs), and a Year 5-6 class, with 15 participants.

A Decile 5 school was used as a control against which to measure the effectiveness of the intervention. This school has a roll of approximately 360 students, including 45\% European, 28\% Māori and 12\% Pasifika. Data were obtained from three classes, with a total of 55 students. The classes included a New Entrant class, a Year 3-4 composite class, and a Year 5-6 composite class, so that the full range of year-levels of the participants was covered. This school was approached via email and received a $\$ 100$ koha in return for its assistance. 


\section{Instruments}

I created a writing manual (Appendix iii) and a series of graphic organisers (Appendix iv) to guide teachers with their goal selection and teaching. In order to distinguish these resources and ideas from the Fast Feedback system itself, I named these the "Koru Writing Manual", and the "Koru Writing Graphic Organisers". (I chose the term "koru” partly because the koru is a symbol of growth, and also because this is a symbol which conveys the relevance of these resources to New Zealand school students). To summarise each of these resources in turn: (i) The Assessment Guide includes writing samples representing a range of abilities and needs, paired with appropriate Fast Feedback goals. (ii) The Writing Manual describes the Fast Feedback model and how to implement it. It also addresses the teaching of genre and purpose, and provides guidance on the structuring of writing lessons, the discussion of goals, modelling by the teacher, student planning, and the teaching of spelling, handwriting, sentence structures and punctuation. (iii) The Graphic Organisers are a series of student planning templates and check sheets for self and peer assessment. I designed these to assist students with planning for, and assessment of, the genres and goals listed in the manual. Teachers participating in the study were not required to use any of these materials; they were supplied as optional resources. The Writing Manual reflects theoretical models of the writing process (Bereiter \& Scardamalia, 1987; Berninger, 1989; Flower \& Hayes, 1981; McCutcheon, 1999) and manuals for classroom practice (Brann, 2001; Graham, Bollinger, Booth Olson, D’Aoust, MacArthur, McCutcheon, 2012; Hood, 2003). They are also informed by my own classroom teaching experience.

Another key instrument was the modified e-asTTle marking rubric, the development of which was described in the previous chapter. While for Study One, students' writing samples were taken at just two time points, in the present study it was required that these samples were produced at four time points, these marking the beginning of the school year, the week before the intervention started, nine weeks from the start of the intervention, and the end of the intervention (a further nine weeks on). Samples from Time Points One and Two allowed for the measurement of rates of progress prior to the intervention beginning, and these could be 
compared with rates of progress over the same number of weeks, during the intervention (between Time Points Two and Three, and Three and Four). Samples from the control students were collected at just two time points - Time Points One and Four. This allowed for a comparison of overall rates of progress for the participating and control students. ${ }^{86}$ Regarding the selection of writing samples, it was required that these be produced on days on which I was not in the classrooms. As for Study One, prose writing was chosen over poetry, and samples were checked for any evidence of copying from a teacher model.

A student attitude survey was created to find out about student perceptions of the Fast Feedback system. This survey included the question, "How helpful was Fast Feedback for your learning?" Students chose from four points on a Likert scale: not helpful, a little helpful, helpful and very helpful. They completed these anonymously, at the end of the intervention. I was not present in the classrooms at the time. A copy of this survey is included as Appendix v.

\section{Procedure}

The focus of the intervention was the Fast Feedback Formative Evaluation system. ${ }^{87}$ To briefly describe this system and how teachers were advised to implement it: Individualised writing goals are selected and recorded at the back of students' writing books; the goals are discussed, modelled and practised; regular Fast Feedback conferences are used to assess progress towards the goals. The latter consists of a 30-second interaction between teacher and student during the writing lesson. In this time, the teacher makes a positive statement about the content of the writing, before addressing the Fast Feedback goal, and acknowledging any sign of progress towards it. If the goal has been achieved partially, or with support, a tick is recorded next to the day's date at the back of the student's book. If the goal has been achieved fully and independently, a sticker is put beside the date. When stickers have been awarded for the same

\footnotetext{
${ }^{86}$ Ideally, it would have been appropriate to collect samples from the control group at all four time points. However, as I was a guest at this school, with just one afternoon allocated to borrow and photograph writing books, I made a pragmatic decision to focus on the two most critical samples for each student. 87 Though the term "Fast Feedback" is my own, I did not invent this system myself. I first saw it modelled on Hood's (2003) video-recording, The Management of an Independent Writing Programme.
} 
goal for at least five consecutive days, the teacher makes a judgement about whether it is time to introduce a new focus goal. ${ }^{88}$

In late 2014, participating teachers were given an information sheet, describing the system and detailing what their own role in the project would be. It was suggested (as already noted) that teachers trial the Fast Feedback system with the lowest-achieving five to ten writers in their classes, and also that they aim to hold Fast Feedback conferences with these students at least twice a week. Using the Fast Feedback system was the only commitment teachers made. It was hypothesised that, by drawing close attention to student goals and progress, this system would lead to teacher inquiry and growth, and that, concomitantly, other aspects of their writing teaching might also change.

The intervention began on April 20 (2015) at the start of the second primary school term. It ended 18 weeks later, in the week beginning August 31. In the first weeks of the training period, the teachers selected Fast Feedback goals for the participating students. Teachers were advised to look at the draft book and to ask themselves two key questions: "What is the next small step that will make this writing more readable?" and "What is the next small step that will make the process more manageable for the writer?" I made some suggestions regarding goal

88 To illustrate how the system is used, a description of a teacher's actions and discussions with a student may be helpful: A common learning need for younger students is to leave spaces between the words. For a student working on this goal, the teacher would record in the back of their book "[name] is learning to leave spaces between words". He or she would then teach the goal through modelling at the beginning of every lesson, and then through individual support during the students' own writing practice (for example, by reminding them of the goal, by praising when the student remembers to leave a space, or by remodelling and helping them to correct their writing if a space has been forgotten). The next, key aspect of the approach is the fast feedback conference itself. This short conversation involves three stages. First, the teacher makes a positive statement about the content of the writing, for example "you wrote about the shark's teeth and that was so exciting". Second, the teacher addresses the goal in question, acknowledging any work, or sign of progress towards it. They may say (for a partially achieved goal), "you are learning to leave spaces between words and you did it some of the time today. You are working hard at this goal and soon it will be easy for you to remember every time"; or (for a fully and independently achieved goal), "you are learning to leave spaces between words and you did it every time today! Look - I can point to each word and it is easy to read your writing." Finally, the teacher turns to the back of the student's book and records the date and a tick (for partial achievement), or the date and a sticker (for full achievement), talking about this display with the child and explaining the hard work and progress that it represents. 
selection and the specific wording of goals. The extent to which teachers took my advice varied considerably.

I visited every class nine times over the course of the intervention. This included six visits in Term two, and three visits in Term three. The exact timing of these visits varied slightly from class to class due to other timetable pressures. For the first five weeks the visits happened on a weekly basis, and the sixth visit happened two or three weeks later. As the second term was an 11 week term with a two week holiday at the end, there was a gap of five or six weeks between visit six and visit seven. The seventh, eighth and ninth visits happened two to three weeks apart, over the first seven weeks of the third term, so that the final visits happened in the $15^{\text {th }}$ and $16^{\text {th }}$ weeks of the intervention.

Each visit lasted 45 minutes. In this time, I modelled a writing lesson, following the lesson structure outlined in the Writing Manual. The genre and purpose of the writing was planned in consultation with the teacher, so that these lessons fitted the context of the usual writing programme for each class. The lessons began with 5-15 minutes of whole-class discussion and modelling, including a short discussion of the purpose or genre, a short discussion of the Fast Feedback goals, and then modelling by the teacher in the genre (with particular attention paid to Fast Feedback goals). At the end of this part of the lesson, students were given an opportunity to plan their own writing, using the cooperative learning strategy named "Think Pair-Share". According to this strategy, students are given approximately one minute to generate ideas, before sharing these with a partner in a two or three minute discussion. The final part of the lesson was used for 30-40 minutes of independent writing practice. ${ }^{89}$ Students in Years 4-6 usually began with written planning, sometimes using the Graphic Organisers. During independent writing practice the teacher and I would move quickly amongst the students, reminding them of their goals and how to achieve them. In classrooms in which students wrote in pencil, we would use erasers to help the students to correct errors. As

\footnotetext{
${ }^{89}$ Ideally, this independent writing time would last for at least 45 minutes. It was necessarily shorter during my visits to accommodate the participating teachers' class timetables.
} 
students finished their writing for that day, we would use the Fast Feedback conference. On days on which I was present, most or all of the students in one class were conferenced by either the teacher or myself. Students waiting for a conference would sometimes be asked to complete a Fast Feedback peer or self-evaluation sheet.

I intended these visits as training. Initially, teachers were advised to conference with five to ten target students at least twice each week, but (as all but two teachers chose to use Fast Feedback with most of their students) I asked them to "conference" this greater number of students as often as they could manage, with no specified number of times per week. Over the course of the intervention the total number of times feedback was given to students varied greatly within and across classes, with some students receiving feedback just once or twice in total, and others receiving it almost 50 times. ${ }^{90}$

At the end of the intervention I visited the schools to take digital photos of the students' draft writing books, from both the intervention and control groups. A set of criteria governed the selection of these writing samples: One priority was to select samples written proximal to the specified time points. For the intervention participants, these included two pre-intervention time points, and two time points from the middle and end of the intervention. These dates included the week starting the $26^{\text {th }}$ of January, the week starting the $25^{\text {th }}$ of March, the week starting the $22^{\text {nd }}$ of June, and the week starting the $31^{\text {st }}$ of August. There were nine school weeks between each of these time points. For the control group, just two samples were taken, from the Time Points One and Four. A second priority, for the treatment group, was to take samples of writing produced on days when I was not in the classrooms, to avoid any possibility of my having influenced the quality of the writing to be assessed. Other considerations in this selection process of both treatment and control samples were to find examples of prose (not poetry), as this type of writing is most helpful when assessing a student's skills with punctuation, sentence structure and the organisation of their writing (including the use of paragraphs). I also checked

\footnotetext{
${ }^{90}$ Although these differences were not ideal from a research perspective, any educational initiative that is to be successful must be robust to ideosyncratic implementation by classroom teachers.
} 
samples for any evidence of copying. All samples were coded and blind-marked. Pre and post moderation was undertaken by myself, my two supervisors, and two other post-graduate students. Inter-rater reliability was found to be $\mathrm{r}=0.79$ with no bias found towards the treatment group.

A second data collection method involved the student surveys. Students completed these anonymously at the end of the intervention, on a day when I was not visiting their class.

Teacher interviews were undertaken in the final weeks of Term three. Interview questions were emailed to the teachers a few days in advance, and teachers were given the option to respond in writing or in a face-to-face interview. One chose the former, eight the latter. Three key questions were posed: What were the positive impacts of using Fast Feedback? Were there any problems or difficulties? Were there any other aspects of your writing programme that changed as a result of using Fast Feedback? Interviews were recorded, and later transcribed.

\section{Design and Analysis}

This was a quasi-experimental, longitudinal study, using a convenience sample with a selfselected treatment group, and a control group.

Like Study One, the rubric data were calibrated to a measurement scale using a one parameter graded response model (Samejima, 1969). The interval scale resulting from the calibration procedure was necessary for me to quantitatively test the hypothesis that Fast Feedback would accelerate student progress in writing. First, I was able to observe the relative progress made by the treatment and control groups between Time Points One and Four. Second, I was able to compare progress made by the treatment group before the intervention, with progress made by the same students over the same time period during the intervention. Specifically, I compared progress between Time Points One-Two, Two-Three, and Three-Four. 
The initial achievement levels of the treatment and control groups could not be taken to be matched because random allocation to experimental groups was not possible. Therefore the indicator of success for the intervention was not simply greater achievement for the treatment group at the end of the intervention, but greater progress by the treatment group, tested by the (Group x Time) interaction term in the analysis of variance.

\section{Ethical Considerations}

Ethical approval was granted by the Victoria University of Wellington Human Ethics Committee in March 2015. Care was taken to avoid placing pressure on teachers and schools to participate, and to avoid putting pressure on parents to allow their children to participate. Teachers, principals and parents were provided with written information which outlined the aims and the methods of the study, and the ways in which the information would be used. It was explained that participation was voluntary, and that participants could withdraw from the study at any time before December, 2015. Methods for data collection and storage were designed to protect participants' anonymity: Participants' names were to be known only to the researcher and her supervisors, and were not to be revealed in any publications. Information provided by participants were to be kept securely and destroyed five years after to end of the project. Examples of the informations sheets and consent forms used are provided as Appendices (XIXVI).

\section{RESULTS}

\section{Quantitative achievement data}

Figure 32 compares the mean progress made by the treatment group and control groups, from the start of the year to the end of the intervention. Treatment group students made accelerated rates of progress compared with the control group ( $E S=0.5)$. Their average levels of achievement were lower than the control students at Time Point One, and were higher by Time Point Four. 
A two way analysis of variance was carried out to evaluate the effectiveness of the intervention. Time (Time One vs Time Four) was a repeated measure. Group (intervention or control) was a non-repeated measure. There was significant main effect of time, $F(1,112)=20.23, p<.001$, showing that students made progress over time irrespective of group. There was no significant main effect of group; $\mathrm{F}<1$.There was a significant interaction between time and group; $F(1,158)=10.08, p=.002$, showing that the treatment group made significantly more progress between Time One and Time Four than the control group. It is also important to note that the treatment group started behind the control group, and ended ahead, which makes any explanation of the results in terms of $a$ priori differences between the treatment and control groups implausible.

Figure 32: Comparison of progress on the rubric measurement scale made by the treatment and control groups, between Time Point One and Time Point Four. Progress as Time Points Two and Three are not displayed as these data were not available for the control group. Error bars denote standard errors of the mean.

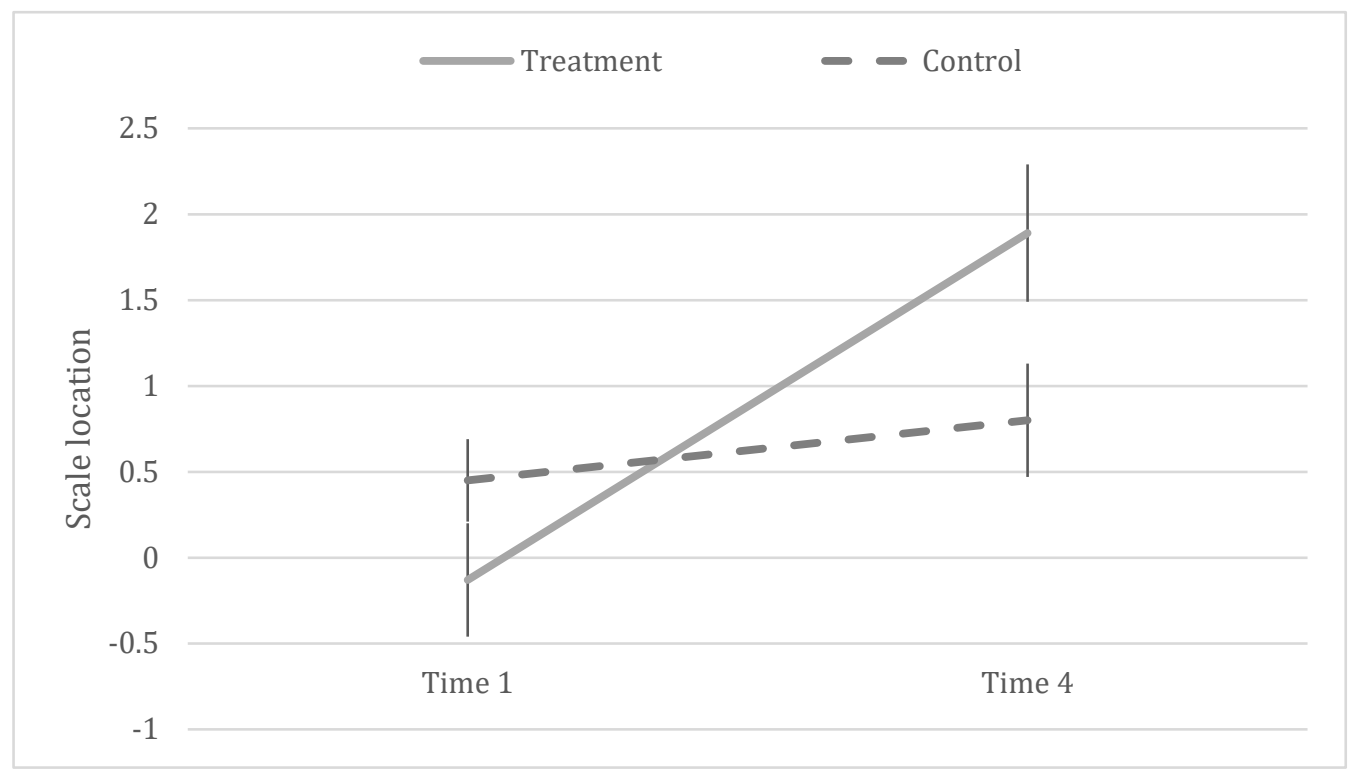

Figure 33 shows the progress made by the treatment group, comparing progress made between Time Points One and Two (the weeks preceding the start of the intervention), with progress made between Time Points Two and Three, and Time Points Three and Four. Progress 
evidently accelerated between Time Points Two and Three, and achievement levels were maintained between Time Points Three and Four, though no further progress was made.

Figure 33: Progress made by the treatment group between the four time points. Error bars denote standard errors of the mean.

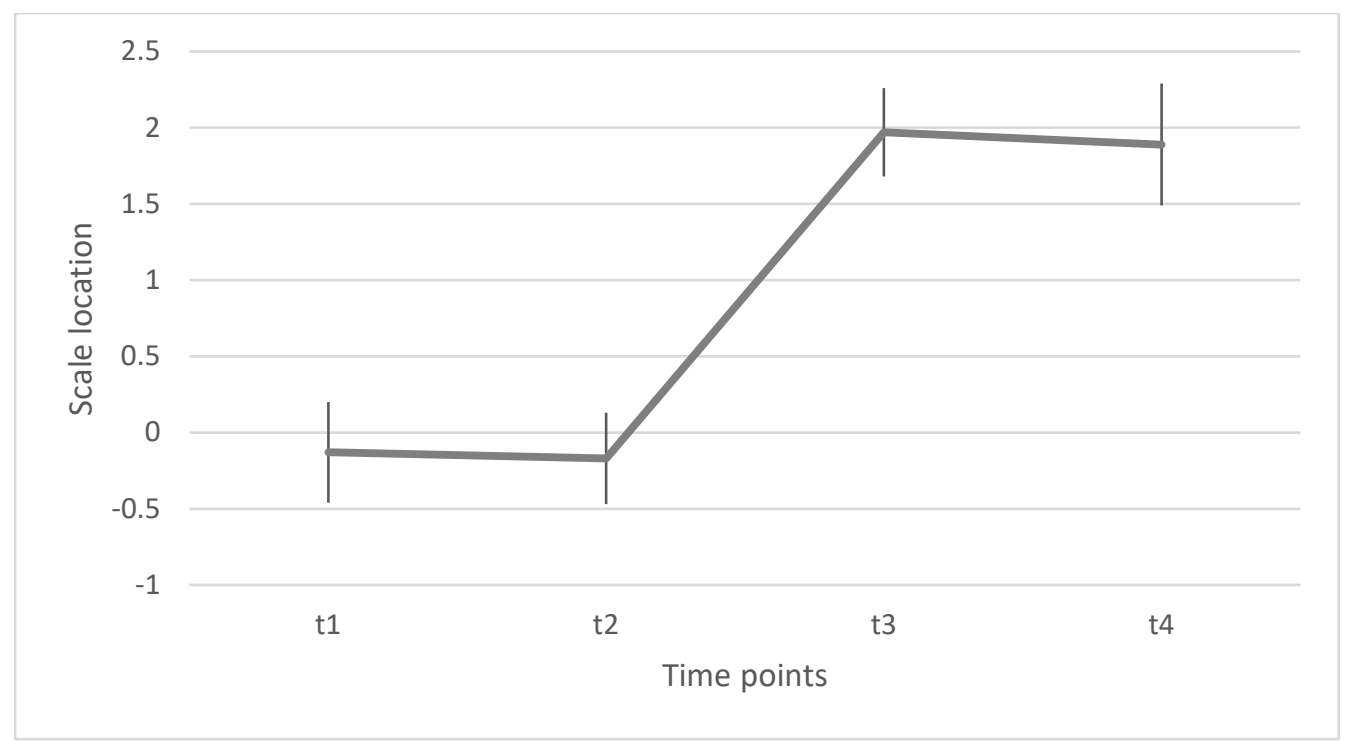

Figure 34 shows the progress made by six individual treatment group classes, over the four time points. Here we see that the pattern of accelerated progress between Time Points Two and Three was common for all classes. The New Entrant class data are not displayed as these children started school at different times over the course of the intervention. 
Figure 34: Progress of six treatment group classes over the four time points. The New Entrant class data are not displayed.

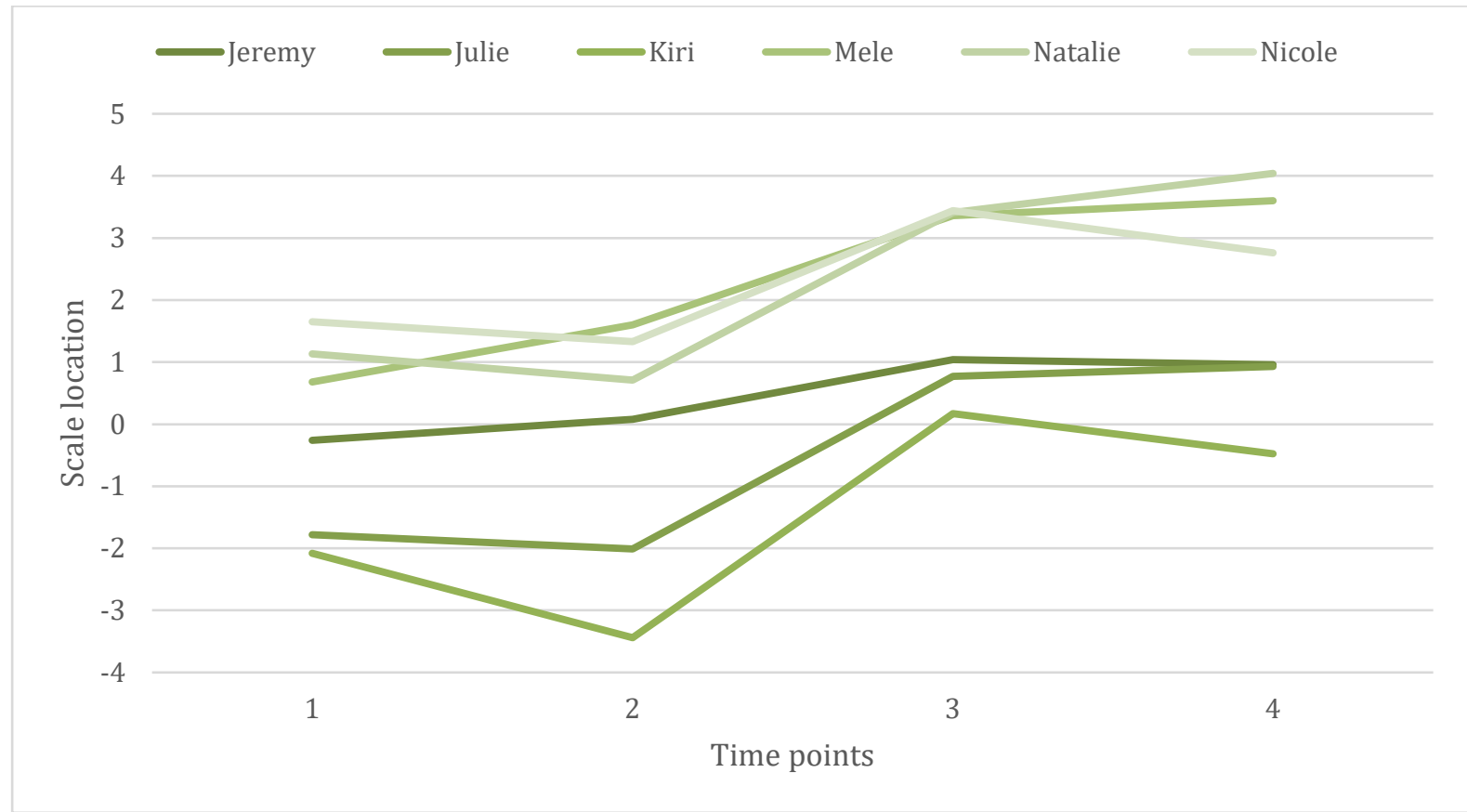

Figure 35 compares the progress made by individual treatment group classes, between Time

Points One and Four. Here we see that students in Natalie, Julie and Kiri's classes made slightly more progress overall than those in the other classes.

Figure 35:The overall progress of students in each of the six treatment group classes. Two classes shared two teachers, Jeremy shared his class with Sophie, and Kiri shared her class with Hine. Just one teacher's name is recorded for each class. The number of of units of progress is the mean number of units of progress on the modified rubric, for each class overall. Error bars denote standard errors of the mean.

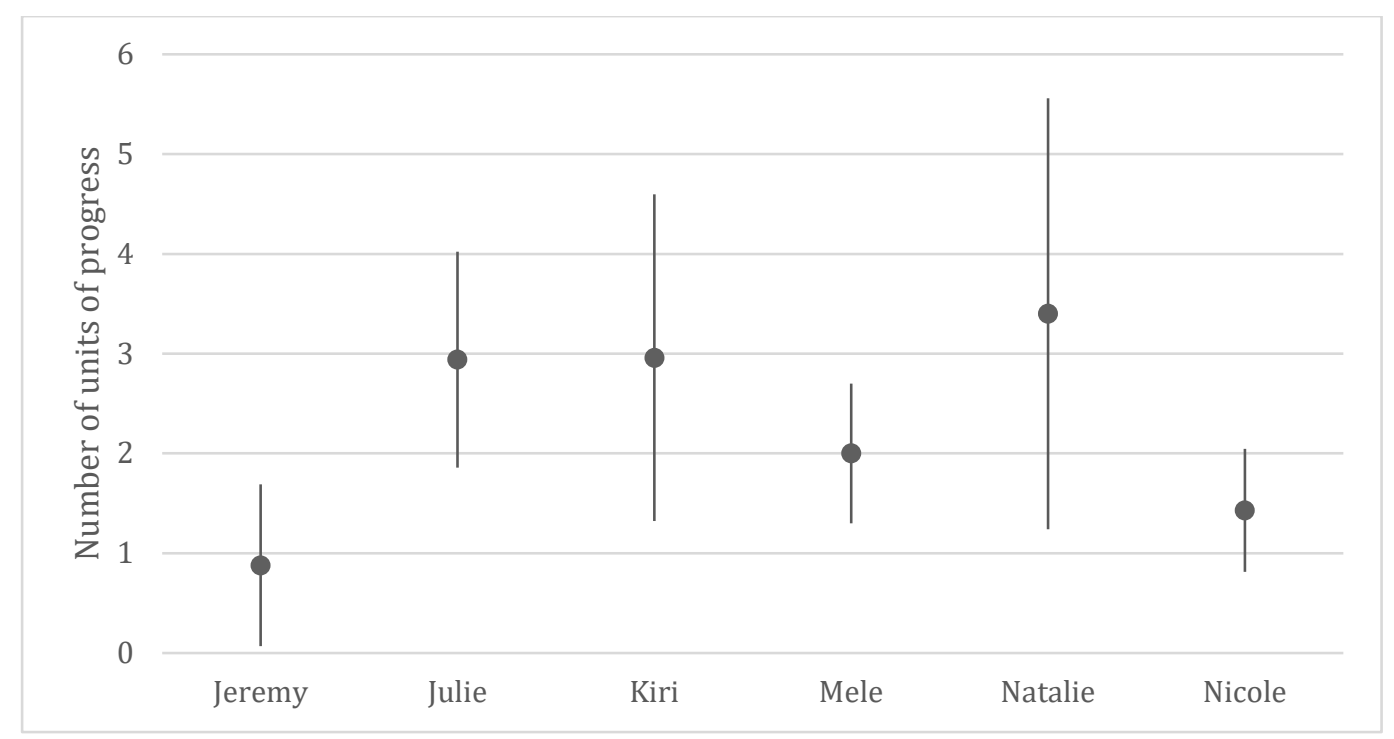


Figure 36 shows the level of effectiveness of some of the most commonly used goals. Evidently, the goal "to write in perfect sentences" was one of the most effective. Interestingly, this was much more effective than the differently worded sentence-writing goal "to use capital letters and full stops correctly". Another effective goal was "to write stories, including a setting, characters and a problem". Two graphs indicate greater progress for students who did not have the goal, than for those who did. These less effective goals were "to write x number of sentences", and "to use exciting words". 
Figure 36: A comparison of the effects of commonly used goals. Each vertical axis denotes scale locations, and each horizontal axis denotes the four data collection time points. Error bars denote standard errors of the mean. The "yes" gradients represent students who worked on the goal in question. Note that the final graph shows a different range on the scale.

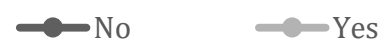

To write in paragraphs

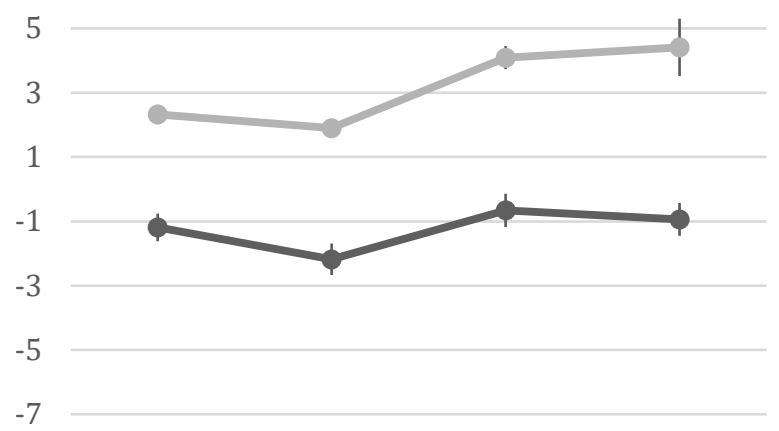

To write stories, including a setting, characters and a problem

5

3

1

$-1$

$-5$

$-7$

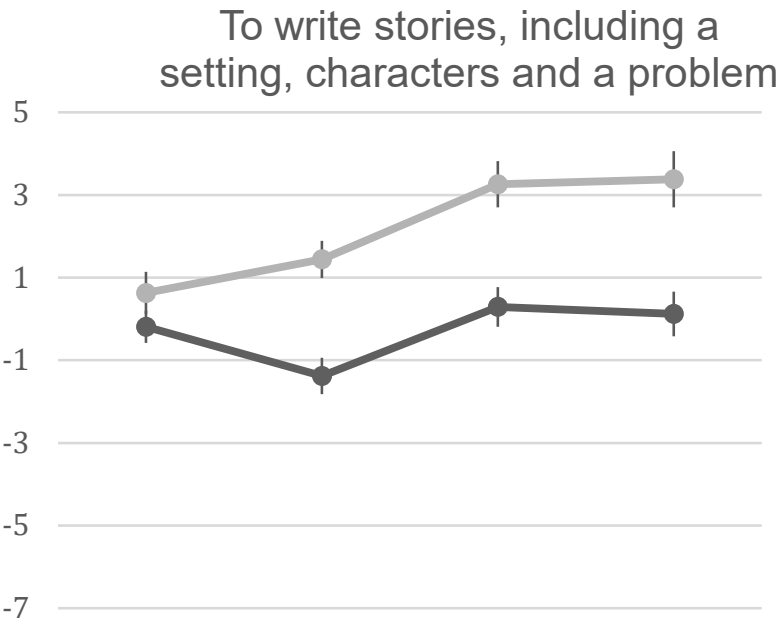

To write in perfect sentences

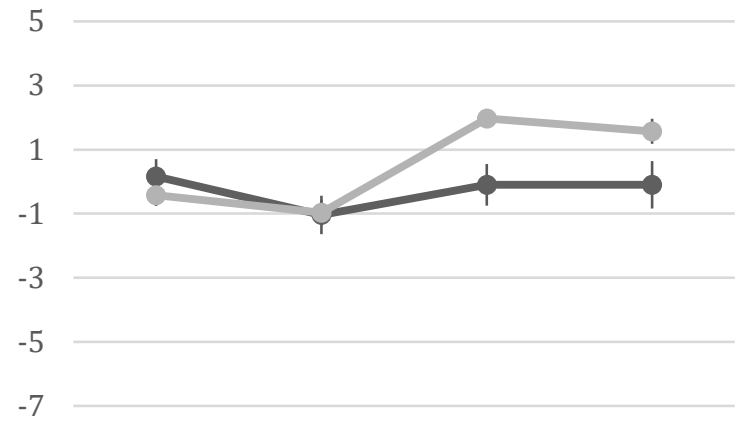

To write (x) number of sentences

3

1

$-1$

$-3$

$-5$

$-7$
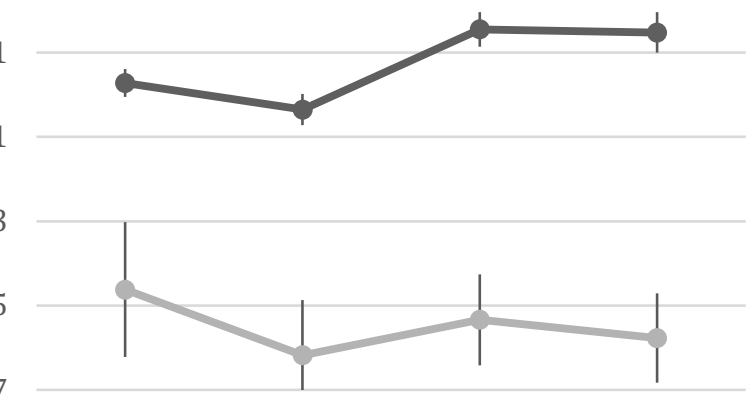
Figure 36 ctd.

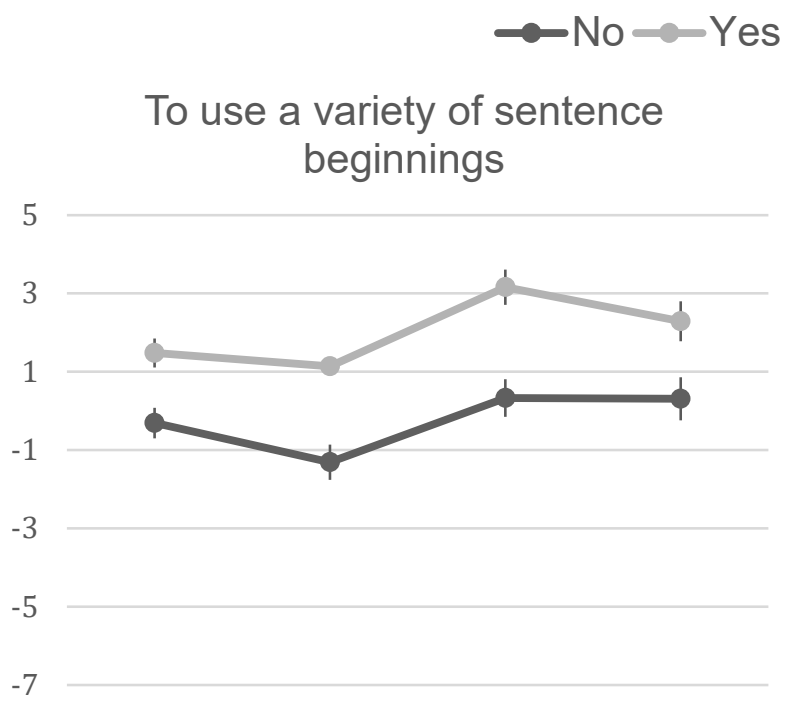

To use exciting words

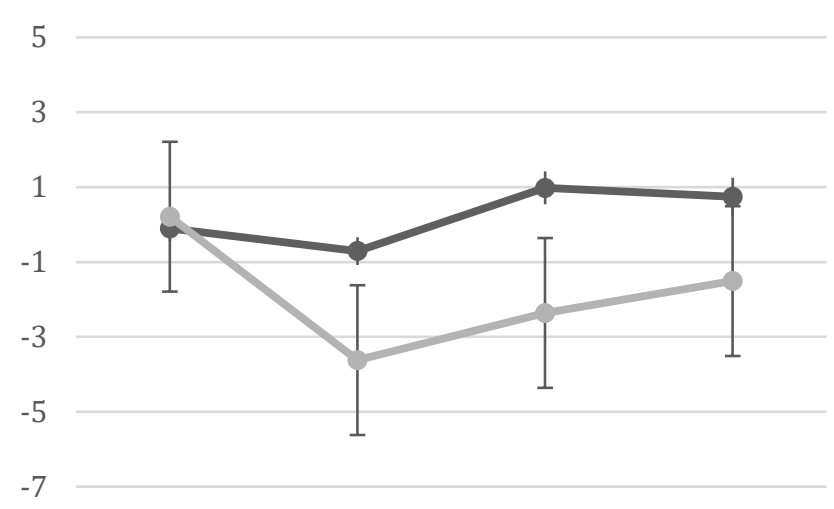
To use capital letters and fulls stops correctly

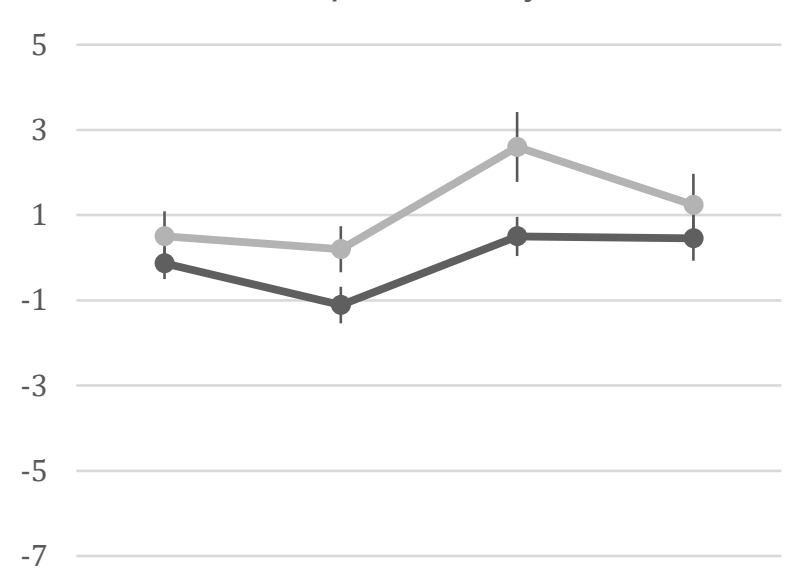

To listen to sounds in words and choose letters to write

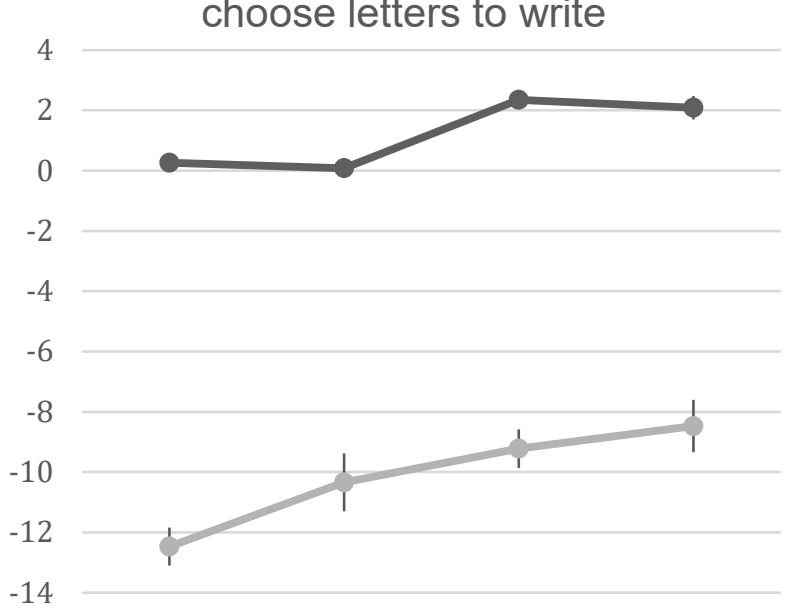

Figure 37 depicts a dot plot showing the position on the measurement scale, of the difficulty of each stage of each aspect of the rubric for all students at Time Point One. The seven rubric aspects are displayed horizontally across the graph, including (from left to right) handwriting, spelling, sentence structure, punctuation, ideas, organisation and language. ${ }^{91}$ Dots are positioned vertically to represent the difficulty of any given stage for any given aspect.

\footnotetext{
${ }^{91}$ A copy of the marking rubric is provided as Appendix II.
} 
This graph helps to illustrate the relative difficulty of stages in the rubric, with the higher stages of each aspect more likely to be achieved by those students positioned at higher overall scale locations. In particular, we see that the top stages of the content-related aspects (aspects 5, 6 and 7) are more difficult than top stages of technical aspects. For example, boundaries between the third and fourth stages for Aspects five and seven (ideas and language), are positioned at scale locations 4.38 and 3.39, compared with scale locations of $-10.29,0.24$ and 1.62 respectively, for spelling, sentence structures and punctuation.

It is also possible to trace the typical profile of a student at a particular scale location, reading horizontally across the dot points. For example, if we select a scale location of - 0.13 (the mean scale location for the treatment group at Time point 1), we can identify the typical skills for students achieving in this region of the scale. Students at this scale location are likely to have handwriting difficulties (stage 2). For spelling, they will be able to record the dominant sounds in words and may spell around fifty high-frequency words correctly (stage five). They will be writing several sentences with some grammatical errors (stage three), and with minimal correct use of sentence punctuation (stage two). In terms of content, a student at this scale location is likely to be writing several coherent ideas (stage three), presented in a logical sequence (stage 2), with a small number of topic specific or descriptive words (stage three)

It emerges that stage two of the spelling aspect is a redundant stage, with very few students achieving in this category. This stage describes writing in which a small number of letters correspond to sounds in words. Most early spellers in the study achieved either stage one, writing letter-like shapes, or stage three, where a small number of letters correspond to sounds in words and there are some spaces between words. 
Figure 37: Dot plot showing the levels of achievement in the aspects assessed and how these relate to each other in terms of a typical profile of treatment group students. There are a different number of stages displayed for each aspect, reflecting the structure of the modified rubric.

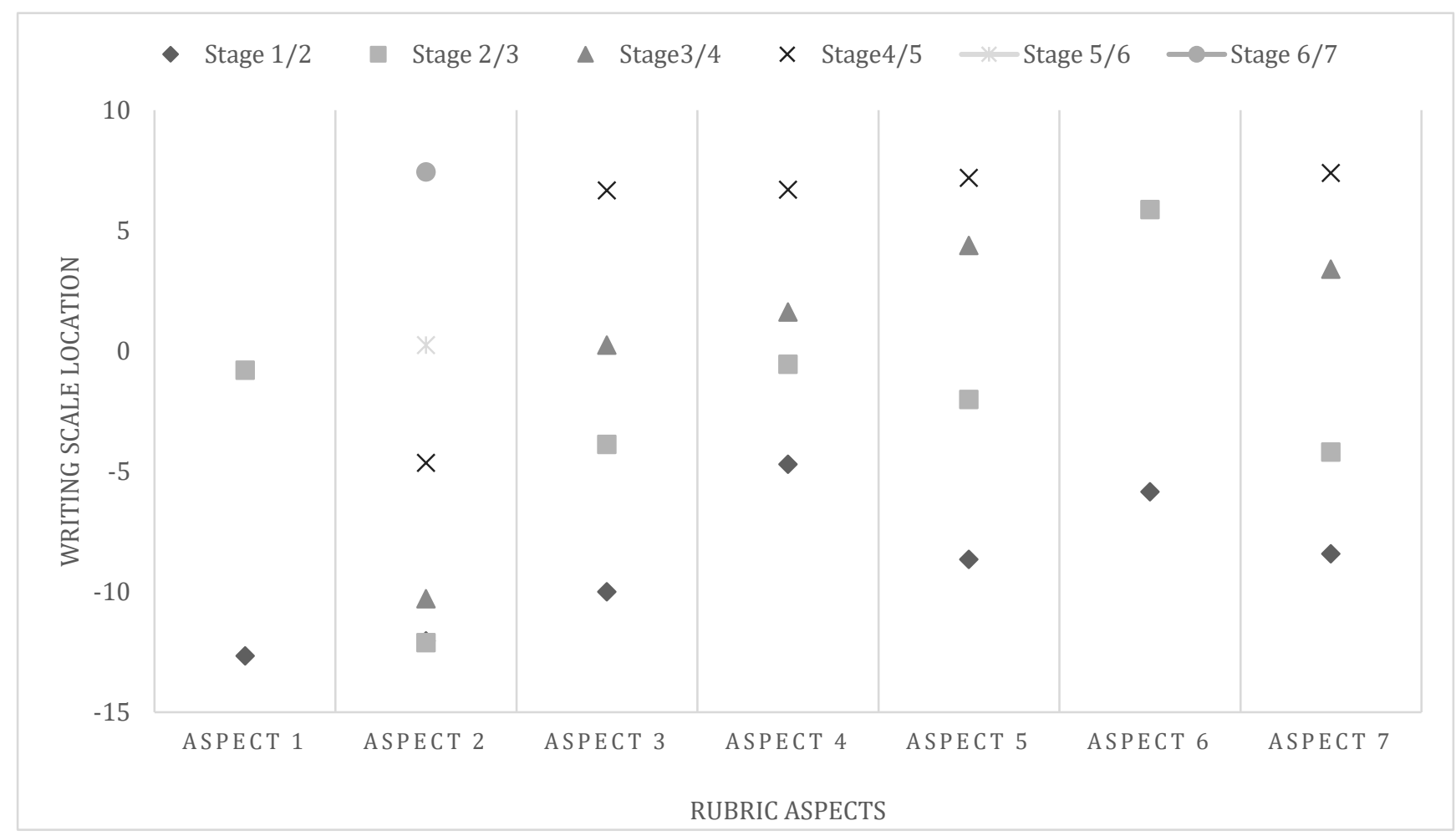

\section{Teacher interviews}

As noted in the previous chapter, interviews with teachers were carried out in the week after the final writing samples had been recorded. Three key questions were asked: What were some positive impacts of using the Fast Feedback system? What were some difficulties with using the system? Were there any other aspects of your writing programme that changed as a result of using Fast Feedback? One teacher responded via email. The two job-share teachers discussed their responses before the interview and just one was present at the actual interview. The teachers' comments were perceptive. Several positive themes emerged: 
(i) Accelerated progress.

Seven out of the nine teachers specifically mentioned accelerated progress. Mele commented that the draft books showed "strong evidence of learning", with her students demonstrating improvements in language features, punctuation, paragraphs and sentence writing. Sophie, a teacher from the job-share class, observed that all of the students in the class had moved more than students in previous years, and that the system was so effective it was now going to be implemented school-wide. Natalie perceived the system to be more powerful for the lowest achieving writers, and those with technical needs, saying, "It really does shift the bottom end really quickly". Julie described the impact in her high needs class, saying "For kids who weren't achieving, it's shifted them massively".

\section{(ii) Focus}

All teachers used words such as focus, motivation, independence and confidence to describe their students' behaviours and attitudes during Fast Feedback lessons. They observed that Fast Feedback helped students to know what was expected and to become more self-aware. Students responded well to the structure and accountability, and loved the conferences and getting the ticks and stickers. A related impact was efficiency, with teachers describing shorter, more productive writing lessons.

\section{(iii) Independence}

Increased student independence was particularly noted by Charlie, the New Entrant teacher, and Julie, who used Fast Feedback with three special needs students, all writing at an emergent level at the start of the intervention. Charlie identified student independence as the biggest impact of Fast Feedback. Julie described the change she had observed in a student with high learning needs (Mark, whose progress is discussed in more detail later in this chapter), who had also been in her class in 2014:

All last year it never even registered. Even just being able to put something on a page was so difficult. Now he has really good writing habits. He's got his word card, knows he needs 
a pencil, he's got a rubber, he's got his book. He knows that he's capable of putting something on the page. Before he just sat helpless, hoping that someone would write something he could just copy.

\section{(iv) Teacher reflection}

Perhaps the most exciting result was the way in which teachers internalised the Fast Feedback system to formatively assess in a meaningful way, provoking deep inquiry into their own practice. Nicole described the sense of purpose and direction Fast Feedback had brought to her teaching. She described part of the Fast Feedback process as, "seeing what takes children a long time to achieve and if there's a pattern with that". Charlie made a similar comment, describing using the draft books to see patterns and select goals for whole class modelling. Mele reported that she had learnt to set achievable goals, "using writing gaps and achieving these gaps quickly rather than time marching forward and not addressing their specific needs". Julie also described Fast Feedback as something fundamental, saying, "It is the whole writing programme".

(v) The relevance of the goal: "To write in perfect sentences".

A highly relevant goal for a majority of student participants was to write in sentences. In classes in which Fast Feedback was implemented most effectively, teachers took the wording for this goal from the Koru Writing Manual. The learning intention is: "[Student name] is learning to write in perfect sentences. [Followed by the success criteria]: Think of an idea; write it down; read it and check that is sounds right and makes sense; check that is starts with a capital letter and ends with a full stop".

Natalie, Mele and Julie all described the sentence writing goal as particularly relevant and helpful to their students. Although Julie identified accountability and structure as the most powerful aspects of Fast Feedback, she also highlighted the wording of this goal, saying,

The wording of the goal is really clear, it has to make sense before they check if it's got a capital letter and full stop... Because that was the bigger issue. For a large number of the kids there was very little sense in their writing. Now they have a habit of re-reading 
every sentence instead of waiting until the end, they don't do screeds of nonsensical pages.

Natalie made a similar comment, observing that the wording of this goal "made them re-read in a way that was quite sharp". Mele commented on the student work, observing "Clean sentences that were crafted".

\section{(vi) Other aspects}

When describing other aspects of their writing programme that had changed as a result of the project, three teachers specifically mentioned refining their teacher modelling to make it shorter and more focused. Two teachers mentioned that the writing templates for self and peer assessment had also helped their students. Mele adapted her modelling as a result of watching me. She noticed how helpful it was for students to see the teacher modelling a process of thinking of ideas, and discussing them, before writing. This seemed to encourage students to plan more effectively using the 'Think Pair Share' cooperative learning strategy. Charlie had also changed the structure of her lesson to make planning discussions more useful for students. Before the project her students had all drawn pictures to plan for writing. She changed this to have them pair-share, tell the teacher, and then begin writing straight away so that they were not distracted by the picture between the discussion and writing practice.

\section{(vii) Difficulties with using Fast Feedback}

Two main difficulties were noted by all teachers:

The first was that it was difficult to conference everyone in the class in one writing lesson. Nicole reflected that she would have done better to start using Fast Feedback with a small group. Natalie observed that it was harder to give feedback to the top writers, who often had more in-depth goals, such as writing in paragraphs. Julie had found ways to negotiate this problem, such as asking these paragraph-writing students to describe the structure they had used, so that she didn't have to read every word. She also gave explicit directions to her 
independent writers about solving problems independently, and practising waiting for their turn to conference.

Five teachers explained that they were sometimes unsure about when to change a goal, often feeling that five consecutive stickers was not enough for the new learning to be completely consolidated. Julie and Nicole dealt with this difficulty by introducing new goals but reminding students to continue to practice their previous goal. Kiri commented that some children seemed to take a very long time to habitually use correct sentence punctuation, even though they knew how to do it. When asked for a potential solution to this problem she wasn't sure. My own observation was that feedback was not happening regularly enough in Kiri's class for these habits to become ingrained.

Nicole discussed problems with using Fast Feedback when the students were using chrome books. She explained that there was not an easy way to give the same kind of immediate feedback, as she would have had to type any comments or symbols into her own computer to then have the message displayed on the student's work.

Teachers were remarkably consistent in their comments about both positive and negative impacts. Their insights would be extremely helpful to any teacher hoping to implement the system in their own classroom.

\section{Student survey results}

A total of 119 student participants were surveyed about how helpful Fast Feedback was for their learning. They were asked to score the system using a likert scale with response categories of not helpful, a little helpful, helpful, and very helpful. Results indicate that the vast majority of students found Fast Feedback to be either helpful or very helpful. These are summarised in Table 13. 
Table 13: Student responses to the question "How helpful is Fast Feedback for your learning?" $(n=119)$

$\begin{array}{lllll}\text { Class } & \text { Not helpful } & \text { A little helpful } & \text { Helpful } & \text { Very helpful } \\ \text { Mele } & & 2(9 \%) & 5(22 \%) & 16(69 \%) \\ \text { Kiri } & & 2(19 \%) & 9(81 \%) \\ \text { Jeremy } & & 10(43 \%) & 9(39 \%) \\ \text { Nicole } & 1(5 \%) & 3(14 \%) & 11(52 \%) & 6(28 \%) \\ \text { Julie } & & 3(14 \%) & 5(24 \%) & 13(61 \%) \\ \text { Natalie } & 2(10 \%) & 4(20 \%) & 10(50 \%) & 4(20 \%) \\ \text { Total } & \mathbf{3 ( 3 \% )} & \mathbf{1 6 ( 1 3 \% )} & \mathbf{4 3 ( 3 6 \% )} & \mathbf{5 7 ( 4 8 \% )}\end{array}$

\section{Writing samples from three special needs students}

The three treatment group students with the highest academic needs were three Year 4 boys, all members of Julie's class in School C. Most excitingly, Fast Feedback appeared to positively transform these boys' writing skills in the short intervention time period. A summary of each boy's particular needs and a description of their progress is included below, and is accompanied by writing samples from the beginning and end of the intervention. I refer to these boys as (i) Abe, (ii) Si and (iii) Mark.

(i) Abe

Abe arrived in Julie's class at the end of Term two (just before Time Point Three, mid-way through the intervention). Abe is an American-born child, and English is his first language. While he is very articulate when speaking, he demonstrated significant difficulties with both reading and writing, as well as poor confidence - Julie noted that on his first day in her class he said “I can't read and I can't write”. Abe's first sample is shown in Figure 38. This was recorded just before Time Point Three. This sample is mostly unreadable, with just the words "said", "to", "is", "A" and "EXIT" spelt correctly, and the spelling approximations for other words mostly indecipherable. The page layout is also chaotic, with spaces between words often missing, and inconsistency with skipping lines. Additionally, there are errors with letter formation, including reversals of $y, s$ and a, and capital letters used a number of times mid-sentence. There is no 
punctuation in this sample. Abe's second sample, shown in Figure 39, was taken at Time Point Four, just nine weeks later. The writing recounts a trip to get pizza and the ideas are presented clearly and logically. This sample is entirely readable, with 13 high frequency words spelt correctly, and other approximations demonstrating an awareness of dominant sounds ("drving" for "driving", "hogrey" for "hungry", and "rle" for "really"). There are no letter reversals, and the layout of the page is orderly, with writing on every second line. The writing is three sentences long (including two compound sentences), and full stops are used correctly at the end of every sentence.

Figure 38: Abe's writing sample at Time Point Three.

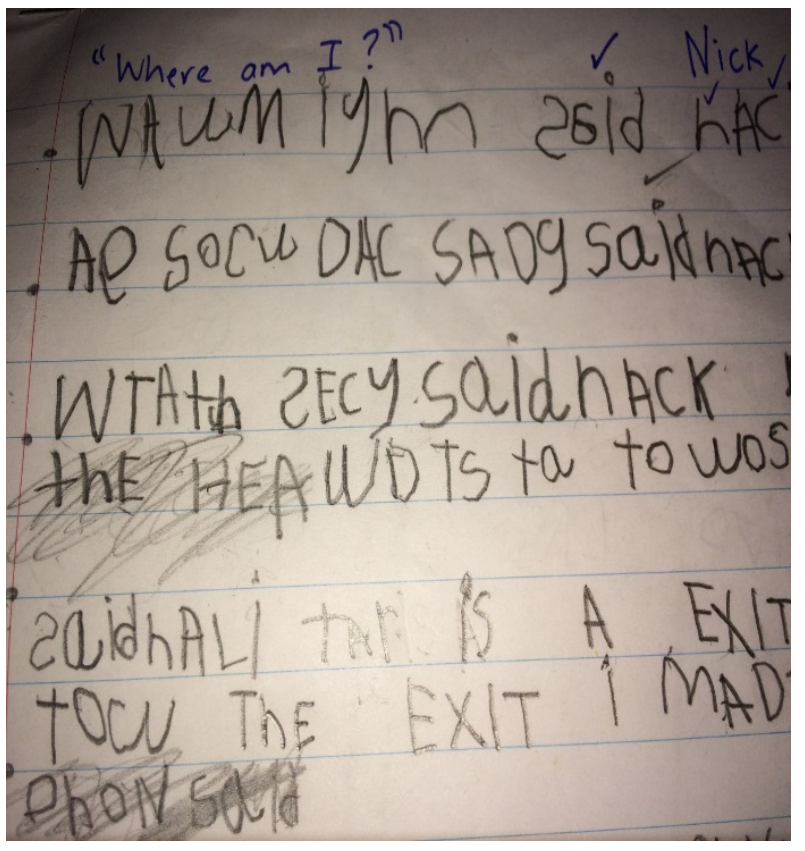


Figure 39: Abe's writing sample at Time Point Four.

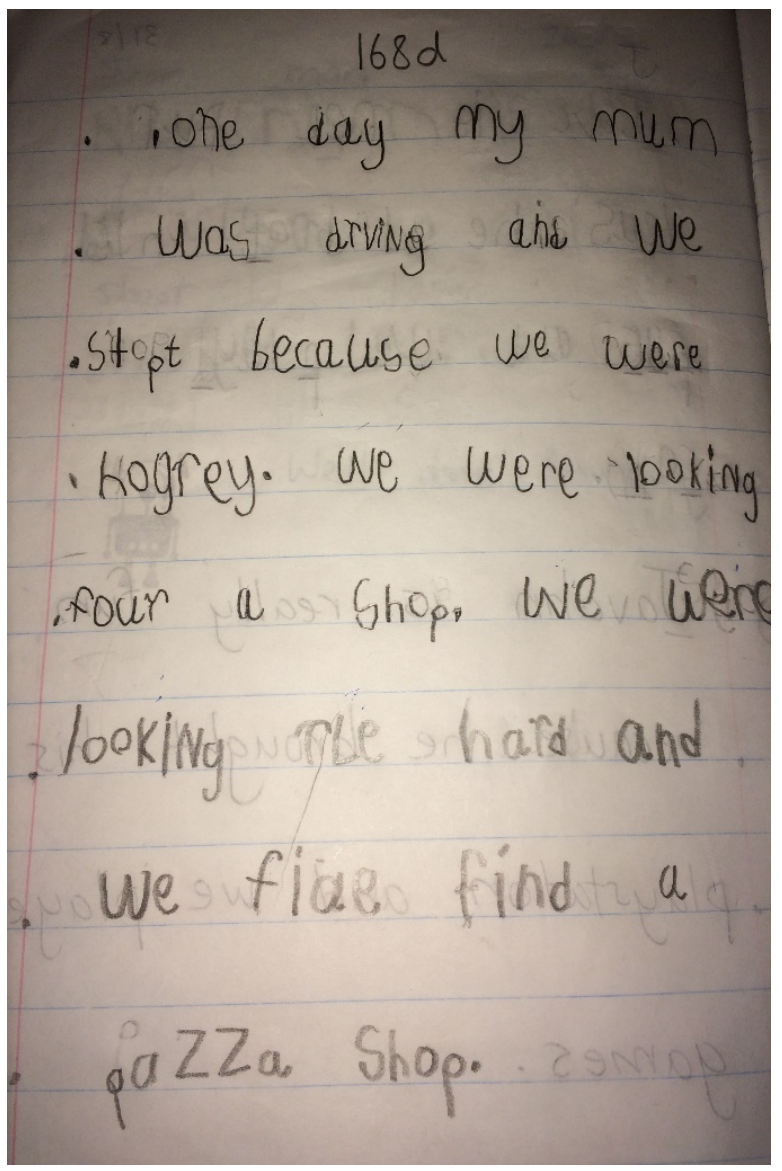

(ii)Si

The following two samples are those of Si. Si has been diagnosed with Foetal Amphetamine Syndrome, causing an intellectual disability. He is also frequently absent from school. Si's first language is English, and he participated in the Reading Recovery programme as a 6 year old. He has difficulty retaining information, and often needs to be reminded of the sentence he had planned to write. Si's first writing sample, shown in Figure 40, was taken at Time Point One. While some words are decipherable ("If", "Me" and "and"), the message remains indecipherable. A handwriting difficulty is evident, with "a" and " $d$ " reversed and capital letters used midsentence. A dot at the end of the first line of writing may indicate a full stop. There are no spaces between words and seemingly random letters are included at the margin of lines with no other words written. Si's second sample, shown in Figure 41, was recorded at Time Point Four. This 
recounts a day in which Simon's dog Mayce fell down the stairs and needed to be taken to the vet for his broken leg. Ideas are presented logically, and some interesting detail is included (for example, Si comments that he can "write on the plaster"). This sample is mostly readable. Six high-frequency words are spelt correctly, and approximations include most dominant sounds (for example "ysda" for "yesterday", "fl” for "fell”, and "dn" for "down”). There are spaces between every word, and just one small inconsistency in layout (with the first two lines separated by one line with no writing, and then writing on every line to the end of the sample). The writing includes three sentences, with one compound sentence, and full stops are used correctly every time.

Figure 40: Si's writing sample at Time Point One.

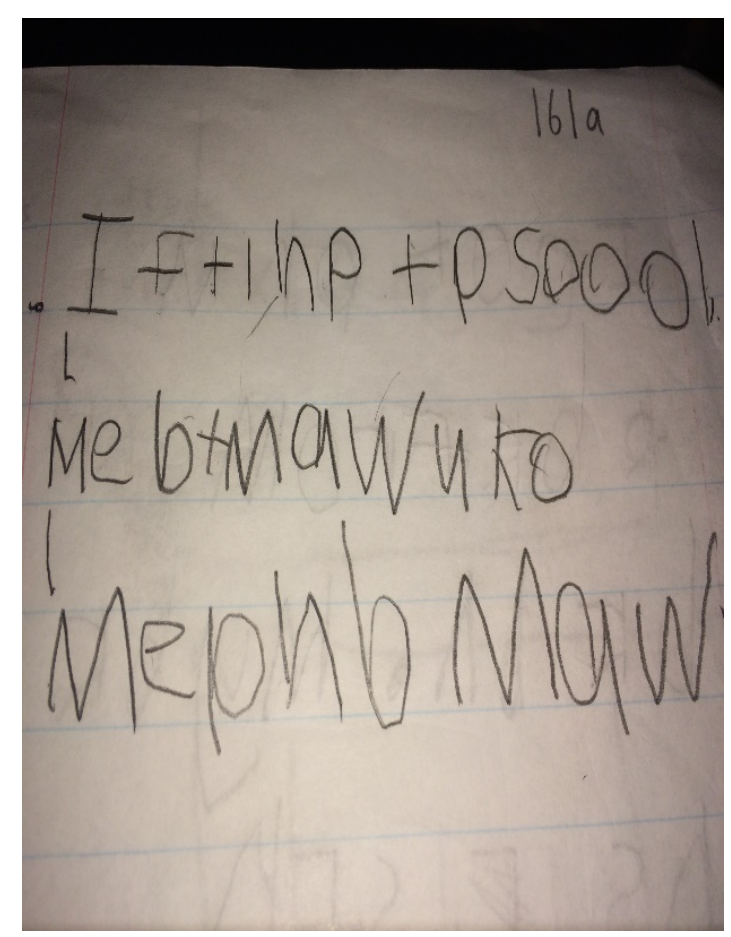


Figure 41: Si's writing sample at Time Point Four.

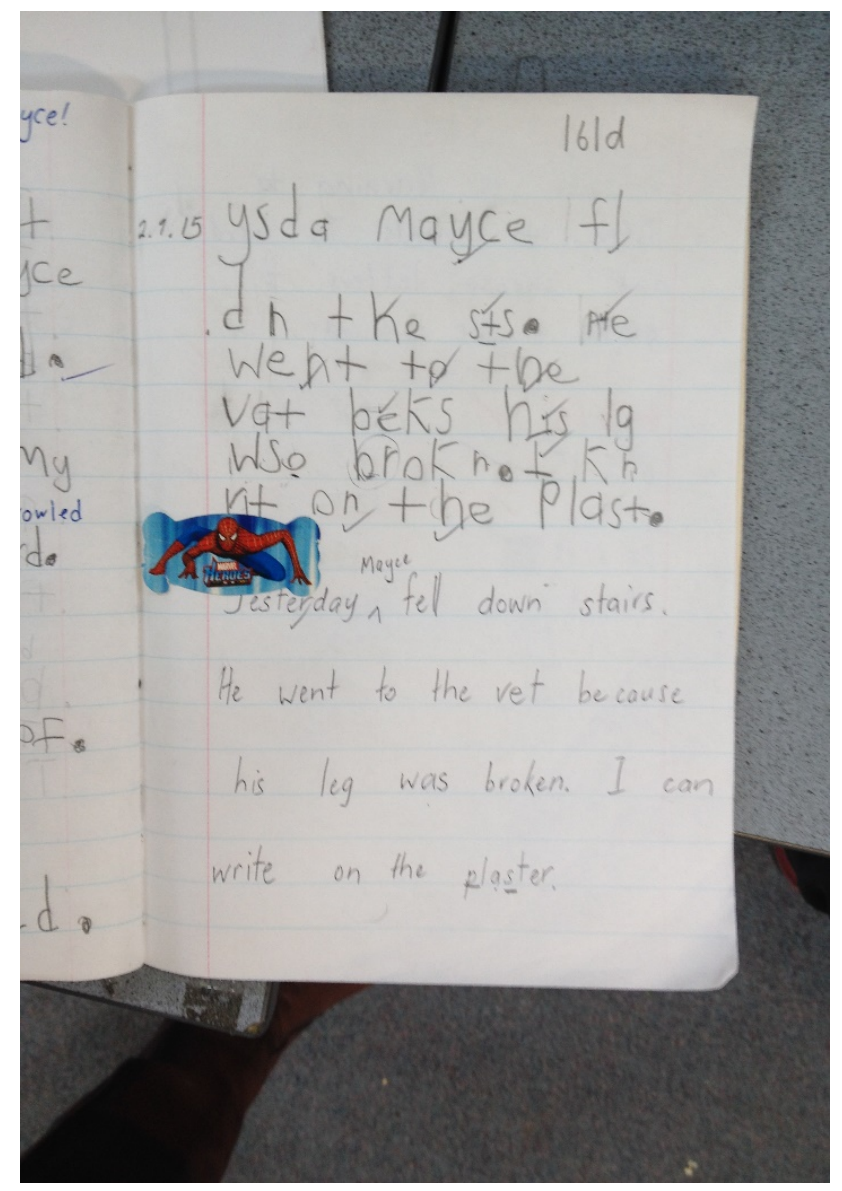

(iii) Mark

Mark was the highest needs child in the whole of the treatment group. He is classified as intellectually disabled, possibly due to a lack of oxygen at birth, and will receive High Learning Needs funding until he is 18 years old. This is the second highest level of funding available in New Zealand schools, and targets those students who are not expected to ever achieve above Level One of the curriculum (Level One corresponds roughly with the skills of average-ability students in Years 1 and 2, aged five and six years old). A particularly obvious difficulty of Mark's is with memory, and the retention of new information, so that even holding a simple sentence in his head for longer than a few seconds is extremely difficult for him. Mark is originally from Ghana and English is his second language. He had, at the time of the intervention, spent two of his three full school years in Ghana. Julie taught Mark for the 2014 school year, so 2015 was his second year in her class. Marks's first sample, shown in Figure 42, was recorded at Time Point 
One. In this sample he has copied a title from the whiteboard ("The first day of school"), and has drawn pictures about the day. A teacher has then written the names of these objects onto the page for him. Mark's second sample, shown in Figure 43, was recorded at Time Point Four. For this writing, Mark thought of his own sentences to write, and told these to his teacher. The teacher then supported him at his desk, reminding him of the sentences he had planned to write and prompting him to listen to sounds and then to choose letters from his alphabet card to approximate spellings. Mark has written two sentences about Hulk, he has spelt "is" and "he" perfectly, and has been able to choose letters to record most dominant sounds. There are spaces between words and full stops are used correctly. While this work was heavily guided, it still represents a much greater skill level than merely copying words from the board and drawing pictures. 
Figure 42: Mark at Time Point One.

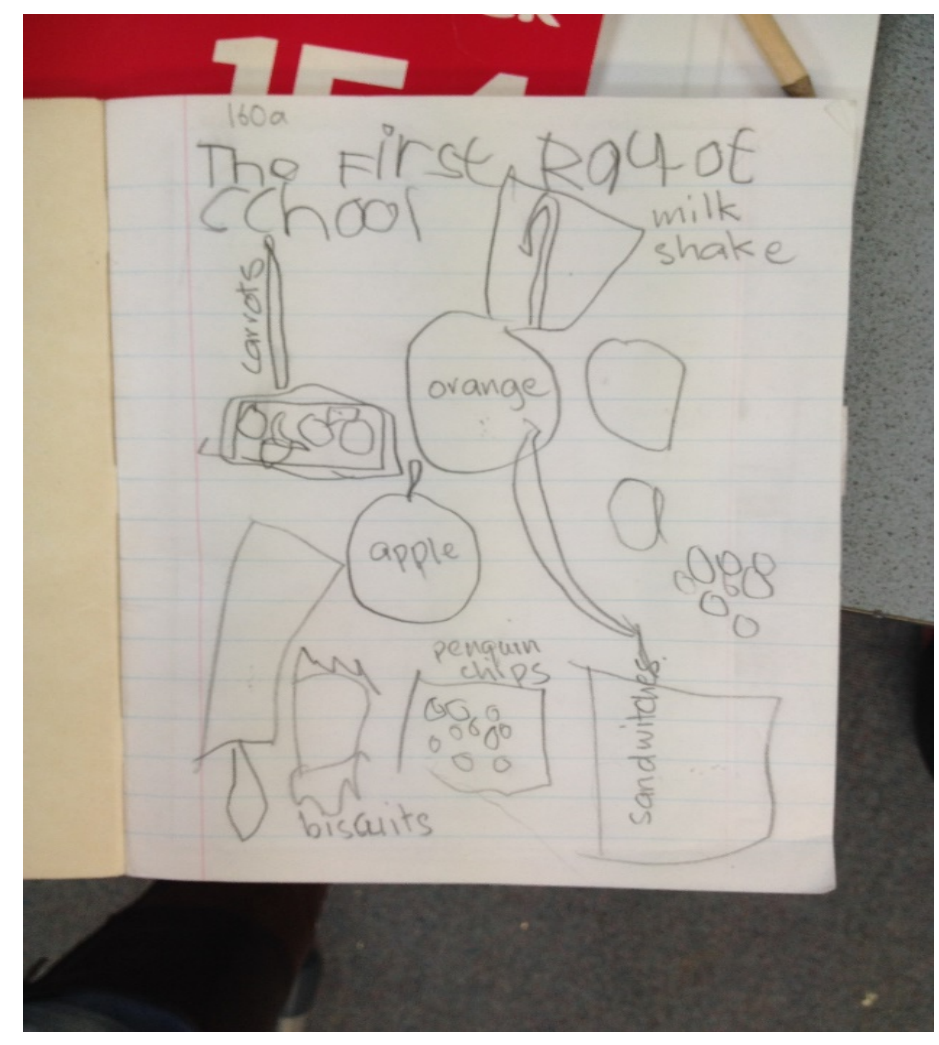

Figure 43: Mark at Time Point Four.

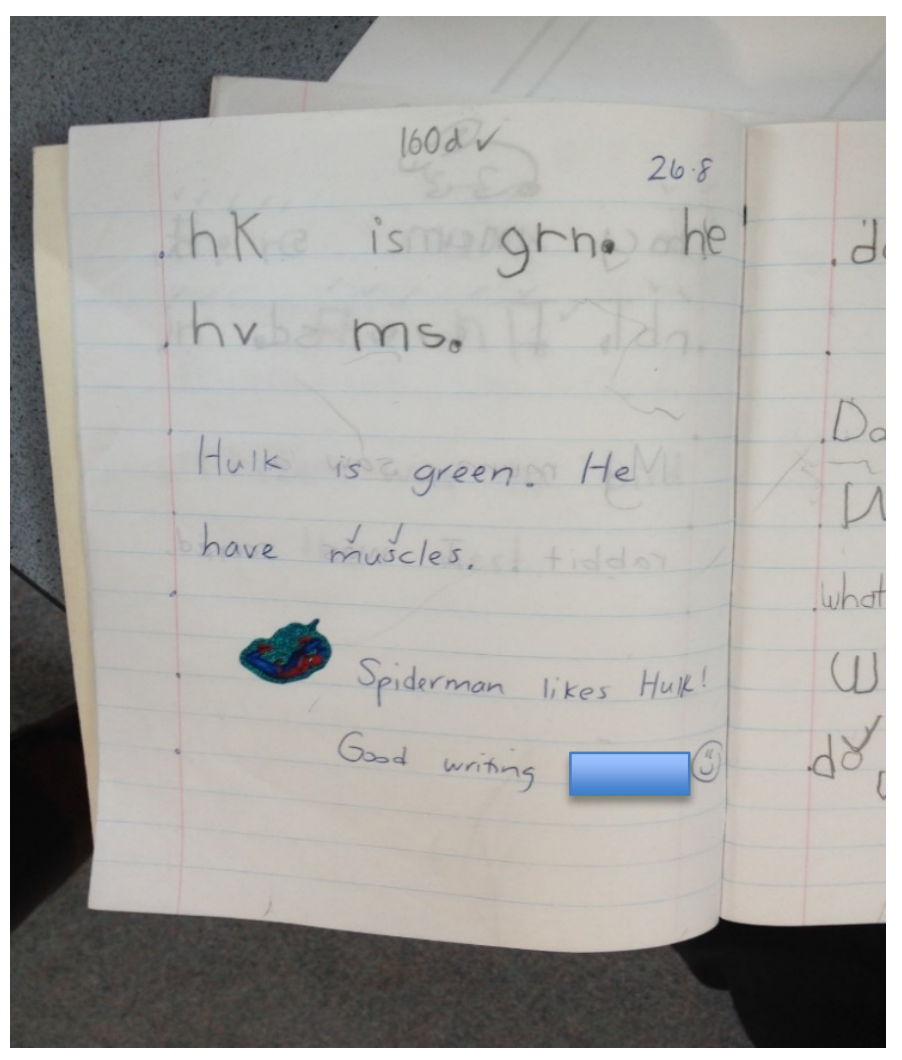




\section{DISCUSSION}

Fast Feedback had a significant and positive impact on student achievement. Within this broad finding, specific details are interesting. First, "to write in perfect sentences", was by far the most effective goal, inviting some consideration as to why. Second, increased student independence was noted by all teachers, an observation which is particularly intriguing when one considers the highly structured and teacher-directed nature of the intervention. Finally, Fast Feedback was used successfully not only for normally-achieving students but also for students with high learning needs. This finding too, prompts further consideration.

The greatest achievement gains were made during the first half of the intervention (term two). Relatively little progress was made in the second half (term three). This was a consistent pattern in all six classes, with three classes demonstrating no progress at all in term three. This result requires analysis.

As we interrogate the data, we encounter certain difficulties. First, since the feedback system was combined with a multi-faceted approach to writing pedagogy, it is difficult to identify which factors may have been most crucial. Second, while I coached participating teachers in a number of feedback and writing teaching techniques (through the use of modelled lessons), I was unable (except occasionally and informally) to observe the teachers at work, and remain somewhat uncertain as to how closely (or otherwise) particular teachers implemented my methods. My judgements of teacher practice are, of necessity, based on incidental observations (made on the days I spent working in intervention classrooms), the teachers' written marking of students' writing, and information from the teacher interviews.

\section{The 'perfect sentences' goal}

This was one of the most effective Fast Feedback goals: "We are learning to write in perfect sentences. We think of an idea. We write it down. We read it and check that it sounds right and makes sense. We read it and check that it has a capital letter at the start and a full stop at the end". The wording of this goal appears to have been critical. Differently worded sentence 
writing goals were used in two classrooms much less effectively (the two classes using these less effective sentence goals are also the two classes identified as having made the least overall progress, see Figure 35). Less effective sentence writing goals included some that attempted to teach a process of checking but lacked clarity in terms of what this process actually involved (for example, "To write a sentence, check it, tick it"), and goals which targeted the skill of using sentence punctuation without addressing the whole sentence as a grammatical unit of meaning and sense (for example, "to use capital letters and full stops for sentences").

We may consider this goal as one which addresses grammar, defined as it has been by Harste (1985) as "the set of formal patterns which speakers of a language use automatically to construct and construe larger meanings" (Harste, cited in Wyse, 2001, p. 411). Accordingly, the question arises as to how grammar may be taught most effectively. Wyse (2001) synthesizes empirical research in the area. He concludes that grammar teaching - when implemented out of the context of real writing - may be demotivating for students, and "has negligible positive effects on improving [...] writing" (p.422). Wyse goes on to provide a set of recommendations for more effective instruction, including: (i) teaching within a meaningful writing purpose; (ii) clear feedback, which avoids the oversuse of technical 'metalanguage'; and (iii) teaching "at the point of teacher/learner interaction during the process of writing" (p. 423). The teaching of the perfect sentences goal - within the context of Fast Feedback lessons - appears to align closely with these recommendations.

Finally, the usefulness of the perfect sentences goal invites explanation, in social cognitivist terms, as a goal that teaches a process of self-regulation, a process which will occur for every sentence and therefore throughout the whole of the student's writing (see Chapter Two for a summary of self-regulation research, and for evidence of the importance of processoriented goals).

Figures 44-49 demonstrate the impact of this goal on the writing of three students, from three different intervention classes (I refer to these students as PJ, Jen and Tom). It is notable 
that, as well as demonstrating a general improvement in sentence punctuation, the second writing samples are broadly more readable and more interesting.

Figure 44: PJ's writing at Time Point One

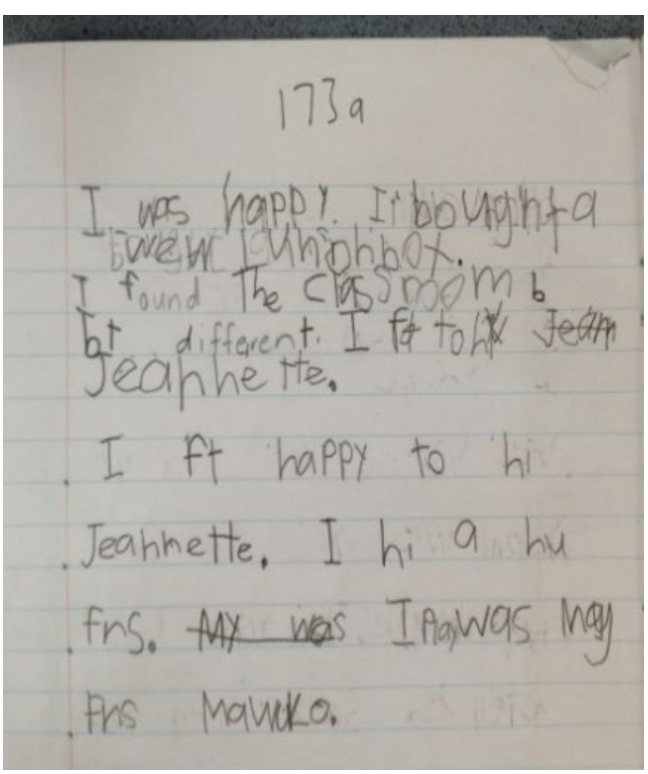

Figure 45: PJ's writing at Time Point Three

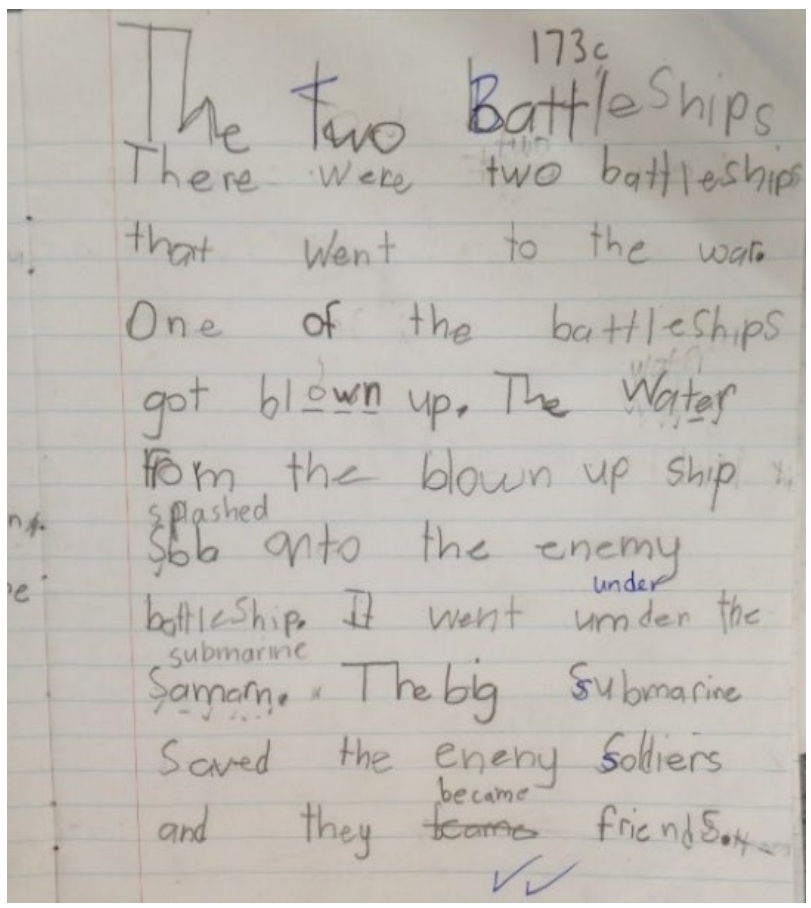


Figure 46: Jen's writing at Time Point One

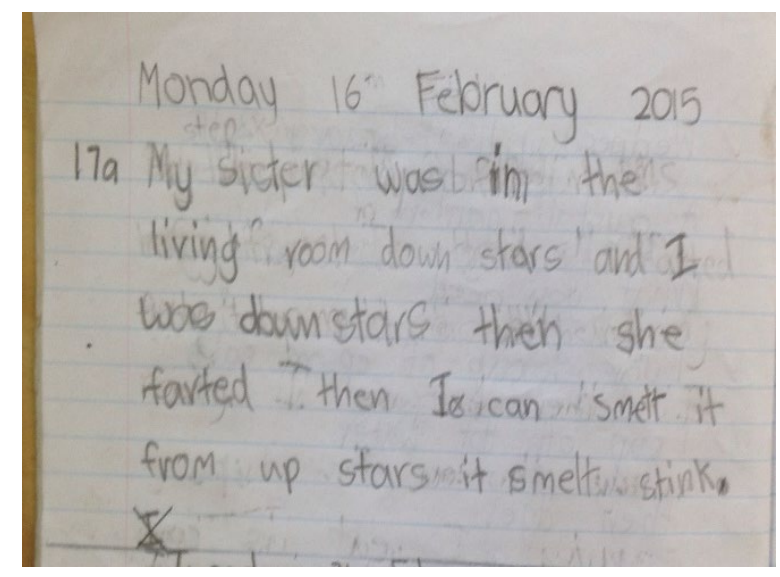

Figure 47: Jen's writing at Time Point Four

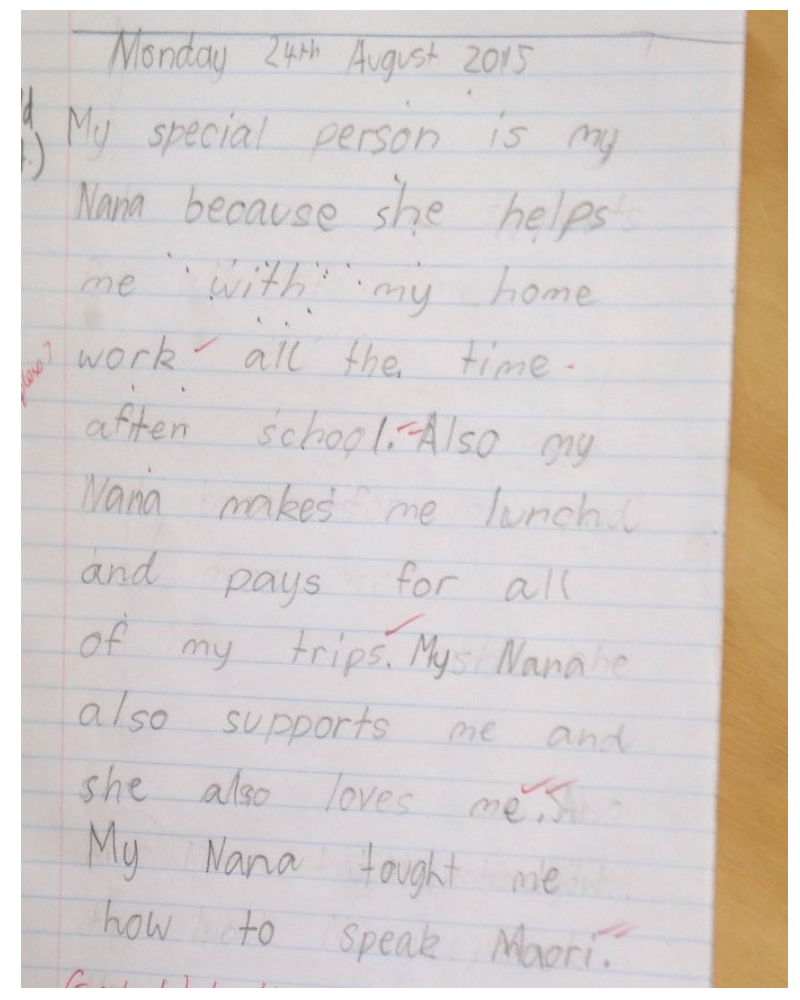

Figure 48: Tom's writing at Time Point One

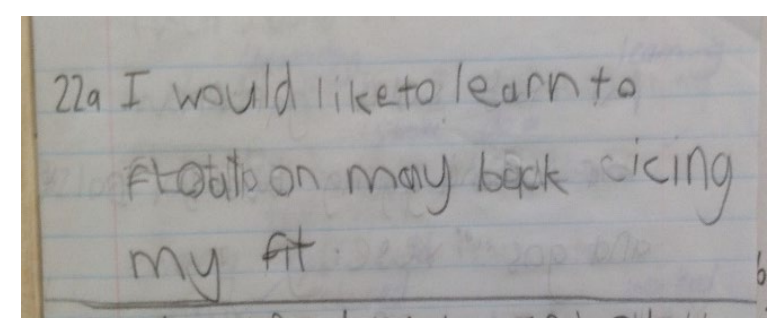


Figure 49: Tom's writing at Time Point Four

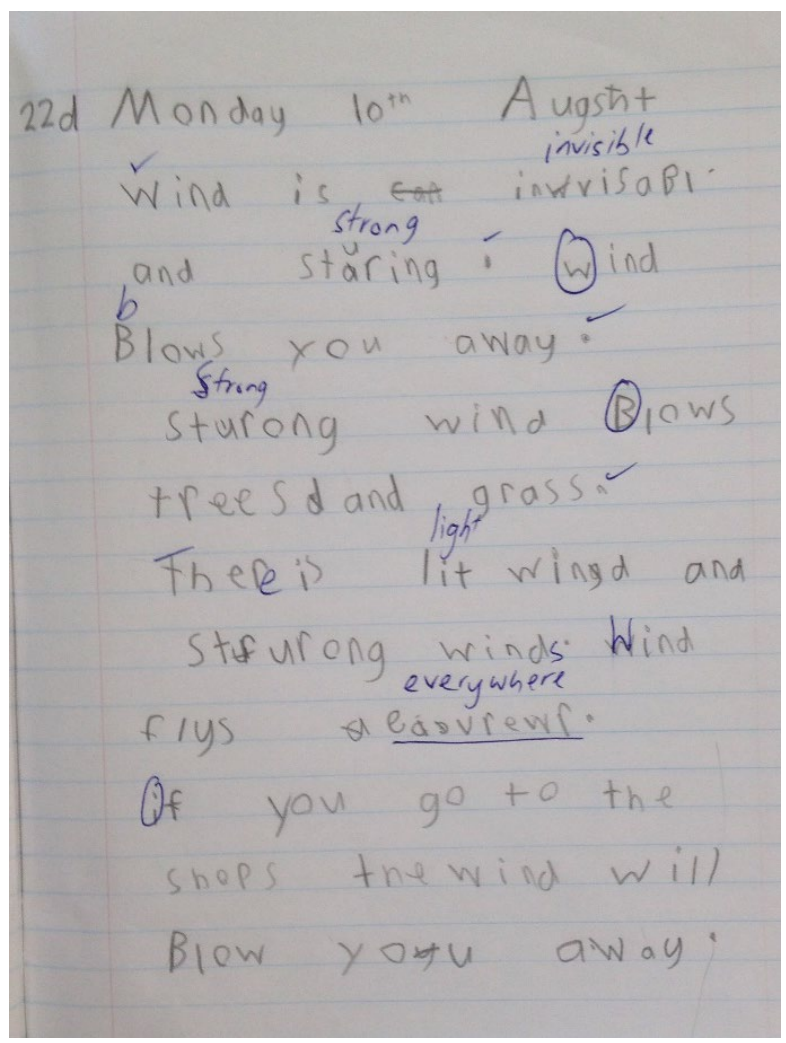

\section{Student independence}

Teachers attributed increases in student independence to the predictable structure of Fast feedback lessons, and the sense of accountability that the goals and regular feedback encouraged. Self-regulation, as validated by social cognitivist research, appears (once again) as a result of the method and a factor in its success. Zimmerman's multi-level model of selfregulatory training (summarised in Chapter Two) is highly relevant here, for two reasons. First, this model describes learning as a transition from social support to self-regulation - implying therefore that self-regulation and independence are essentially the same thing. Second, we find that the lesson structure used for Fast Feedback exactly reflects the four stages of the multilevel model. In Fast Feedback lessons, new skills are introduced to students by teacher modelling (Zimmerman's stage one). Students then practise with individual, tailored support, including additional modelling, prompting and feedback (Zimmerman's stage two). Next, students are required to demonstrate independent achievement of the skill (Zimmerman's stage 
three), and a new goal is chosen when the original goal has become habitual and is therefore likely to be used for a variety of future writing tasks (Zimmerman's stage four).

Increased student independence is perhaps most noticeable in the New Entrant work samples, though it was observable in the habits and attitudes of older students too. Below are two samples from one of the New Entrant participants (Ana). In the first sample, Ana has copied over words written by the teacher. ${ }^{92}$ In the second sample, she has recounted an experience of making beeswax candles, generating her own ideas and writing them herself. ${ }^{93}$ This second sample demonstrates a number of recently acquired skills; letters are formed correctly, high frequency words are spelt correctly and dominant sounds are recorded for other words. There are spaces between words, and the sentences are grammatical and correctly punctuated.

Figure 50: Ana's writing at Time Point One

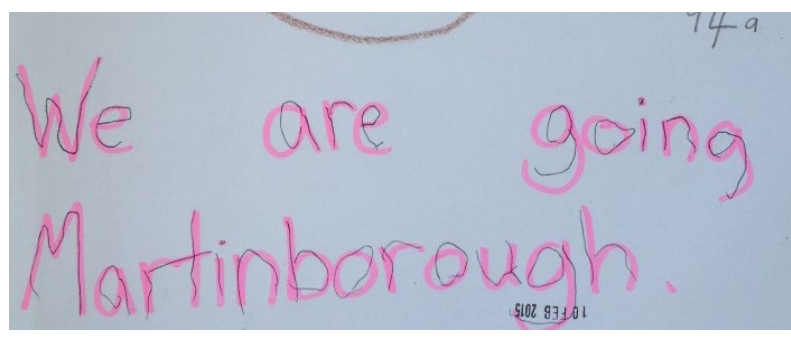

${ }^{92}$ Student copying over teacher-scribed words is not recommended in the writing manual. Two intervention teachers were using this approach with their lowest achieving writers in term one, before the intervention began.

${ }^{93}$ This second sample is actually two pages long, though I have only included the first page here. 
Figure 51: Ana's writing at Time Point Four

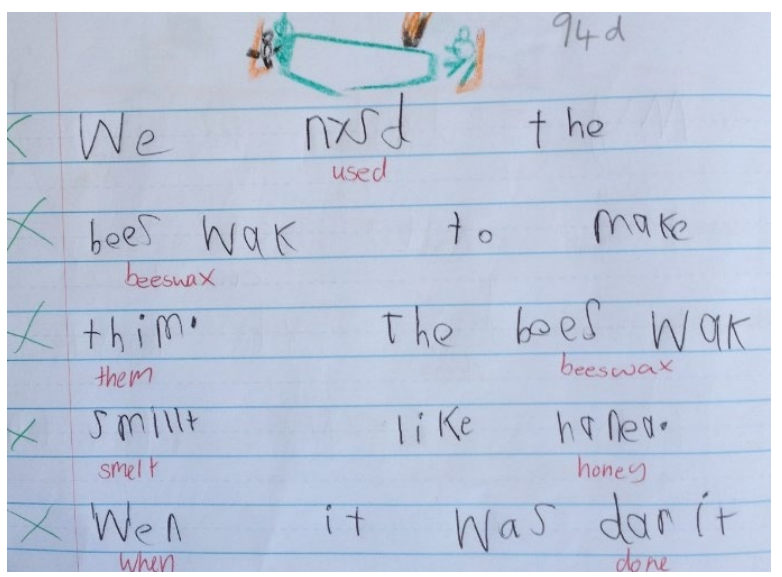

\section{Success with high needs students}

I turn now to the exciting results achieved by Julie, with Abe, Si and Mark. What made Fast Feedback effective for these boys when other approaches had failed? Julie herself identified structure, accountability and high expectations as crucial. Not surprisingly, we also find explanations in the self-regulation research literature, as invoked in Zimmerman's cyclical phase model (summarised in Chapter Two). Applying the principles of this model, it seems that Fast Feedback supported these previously helpless students to apply an effective 'proactive' process. The individualised, process-oriented goals clarified the writing process and were empowering. Feedback which demonstrated progress was motivating, leading to sustained effort and continued achievement gains.

\section{The term 3 plateau}

The question must be asked as to why the rapid rates of progress achieved in Term 2 were not sustained in Term 3. As feedback was the essential approach under investigation, I first investigated whether Fast Feedback conferences had occurred as regularly in Term 3 as they had been in Term 2. Interestingly, using the feedback tracking pages in the backs of student books I found that teachers had given feedback equally regularly in each term. Additionally, counting the number of times feedback was given over the entire intervention by those teachers identified as most effective (Julie, Natalie and Kiri), it appears that they gave feedback no more 
regularly than the other three teachers. Declining frequency of feedback does not therefore, appear to explain the stalling of student progress.

A second possible explanation for the lack of progress in Term 3 is that this term was a time of consolidation of the new learning. Two main considerations work against this explanation. First, the feedback system itself allows time for consolidation, with a minimum period of at least five days consistent and independent achievement with a goal before a new goal is selected. Second, having used Fast Feedback in my own classrooms for the past 12 years, I have never observed my own students "plateauing" in this way. ${ }^{94}$

What other factors may have caused this result? I was present in all classrooms twice as often in Term 2 as I was in Term 3 (six and three times respectively), in order to support teachers in establishing the system during the early weeks of the project. Additionally, the classes of those teachers who followed my example most closely did continue to make some small achievement gains in the final time period. It seems therefore, that the precise way in which certain teaching methods were implemented was critical. In what follows therefore, I have described some specific practices which I use, and which were adopted by the most effective teachers, and compare these with the practices of the least effective teachers.

\section{Goal selection}

The first area of interest here is goal selection. Mele, Julie and Natalie used only those goals suggested in the writing manual, including "to write in perfect sentences", "to organise my writing into paragraphs", "to spell thoughtfully - listen to sounds, check that my spelling looks right, and use my word card for checking", and "to write stories - including a setting, characters and a problem". With reference to feedback intervention theories (see Chapter Two), these

\footnotetext{
${ }^{94}$ The "Hawthorne" effect may also be considered as a factor in the rapid rates of progress observed during the first half of the intervention, though, according to Cook \& King (1968) ideas about this phenomenon, "lack sufficient validity [...] to warrant their serious consideration by researchers in the planning and operational development of their projects as well as in the interpretation of results" (p. 95).
} 
goals might have been more effective because they addressed processes. ${ }^{95}$ In contrast, the other three teachers chose to write their own goals. Often, these focused on word use, as in "to include at least two wow words in my writing", "to start each sentence with a different word", and "to use at least two exciting words". These goals place the focus on the written product rather than the writing process itself. They are also vague: how, for example, might "wow words" and "exciting words" be defined? Is any word acceptable at the beginning of a sentence, just as long as it has not been used before in that particular text? Another less effective goal specified the quantity of writing that needed to be done, in terms of numbers of sentences per day. Clearly, this goal too addresses the product as opposed to process. (It also ignores the issue of writing quality.) I have already discussed the different sentence writing goals used in these classrooms. One addressed punctuation but failed to encourage habitual checking of sentences in terms of their structure and meaning. Another attempted to encourage re-reading and checking but was worded in such a way that it did not really clarify the points to which the students should attend. A final problem with the goal selection of those less effective teachers was too great a degree of individualisation. There were sometimes up to 15 goals operating in these classrooms at any one time, making daily discussion and modelling of most of these goals impossible.

In my discussion of writing samples thus far I have focused on student progress with the more technical aspects of writing. However, Fast Feedback has the potential to enhance student creativity too. The goal: "To write stories, including a setting, characters and a story problem", appears to have been a helpful one. Figures 52 to 55 demonstrate the progress of two students, from two different intervention classes, who worked on this goal in the later weeks of the intervention. Figures 52 and 53 are the samples of Siu, who worked on the perfect sentences goal and the story-writing goal. Figures 54 and 55 are the samples of Ben, who worked on the paragraph writing goal and the story-writing goal.

95 Though it is not obvious from the wording of the goal, "to write stories- include a setting, characters and a story problem", also invoked a process as it was taught using a story-web planning template (see Appendix IV). 
Siu's first sample retells a funny moment looking for a set of keys at home. The writing is gently humorous and the writer's voice is sincere, though events are retold out of sequence so that the overall structure is confusing. Additionally, errors with sentence punctuation make the writing difficult to read. Siu's second sample is the first part of a story about pirates. ${ }^{96} \mathrm{He}$ describes the setting and characters - using some descriptive language to add interest - and begins to introduce a story-problem. Though there are some errors with sentence punctuation, this aspect of the writing has improved significantly. Additionally, Siu has used an exclamation mark, communicating humour in the idea of a pirate who "was drinking beer every day".

${ }^{96}$ I sometimes collected samples of unfinished work. See Methods, for a description of the collection of draft writing samples. 
Figure 52: Siu's writing at Time Point One

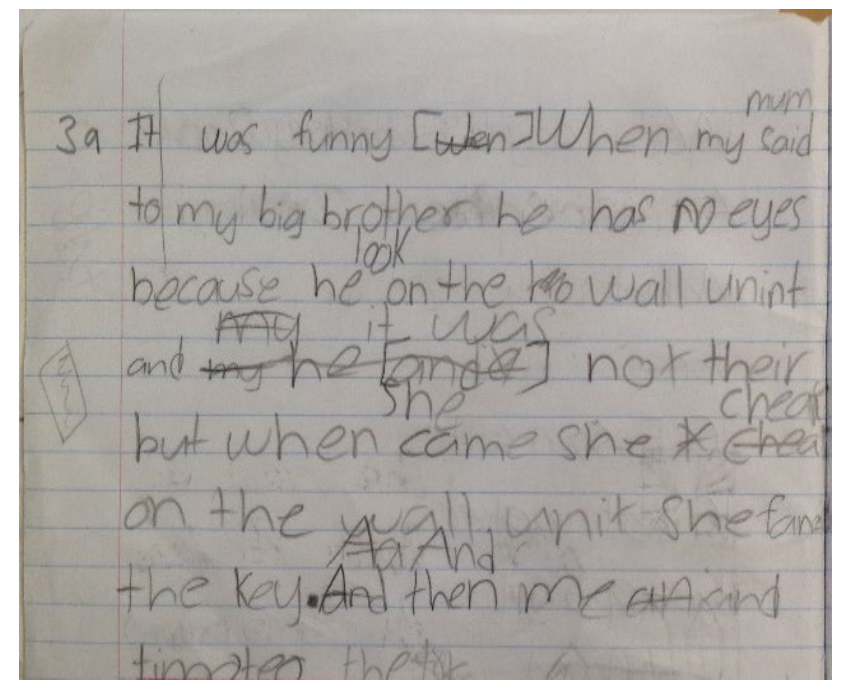

Figure 53: Siu's writing at Time Point Four

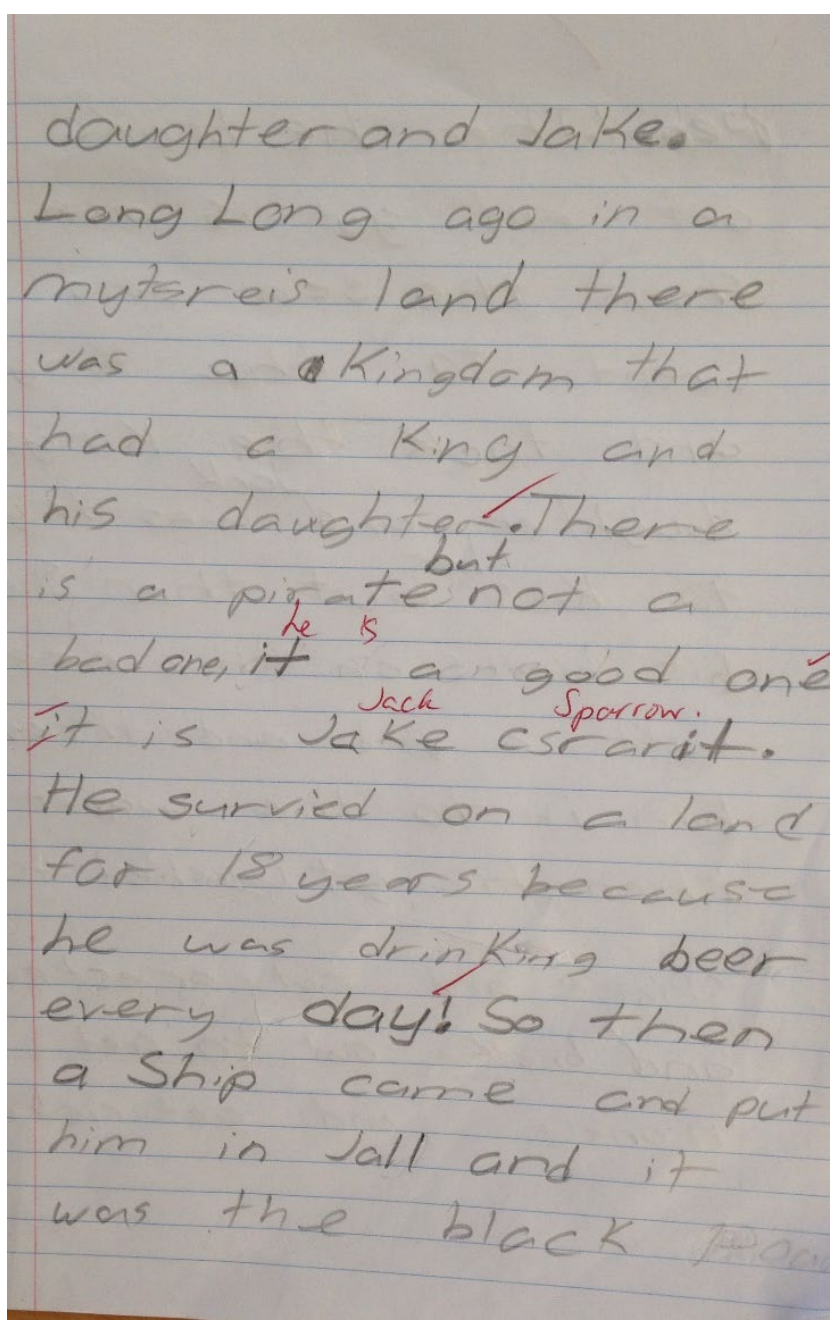


Ben's writing at Time Point One is a description of a battle between giants and wizards. It is an interesting and creative piece, including fantasy characters, direct speech to bring a sense of immediacy, and specific, descriptive vocabulary. His Time Point Two sample is the first page of a narrative about boys staying at a haunted camp. Here, Ben continues to practice the creative techniques demonstrated at Time Point One. What is more, the story is organised in well-crafted paragraphs, making it more coherent and suspenseful. Finally, punctuation use is improved - for sentences and for direct speech.

Figure 54: Ben's writing at Time Point One

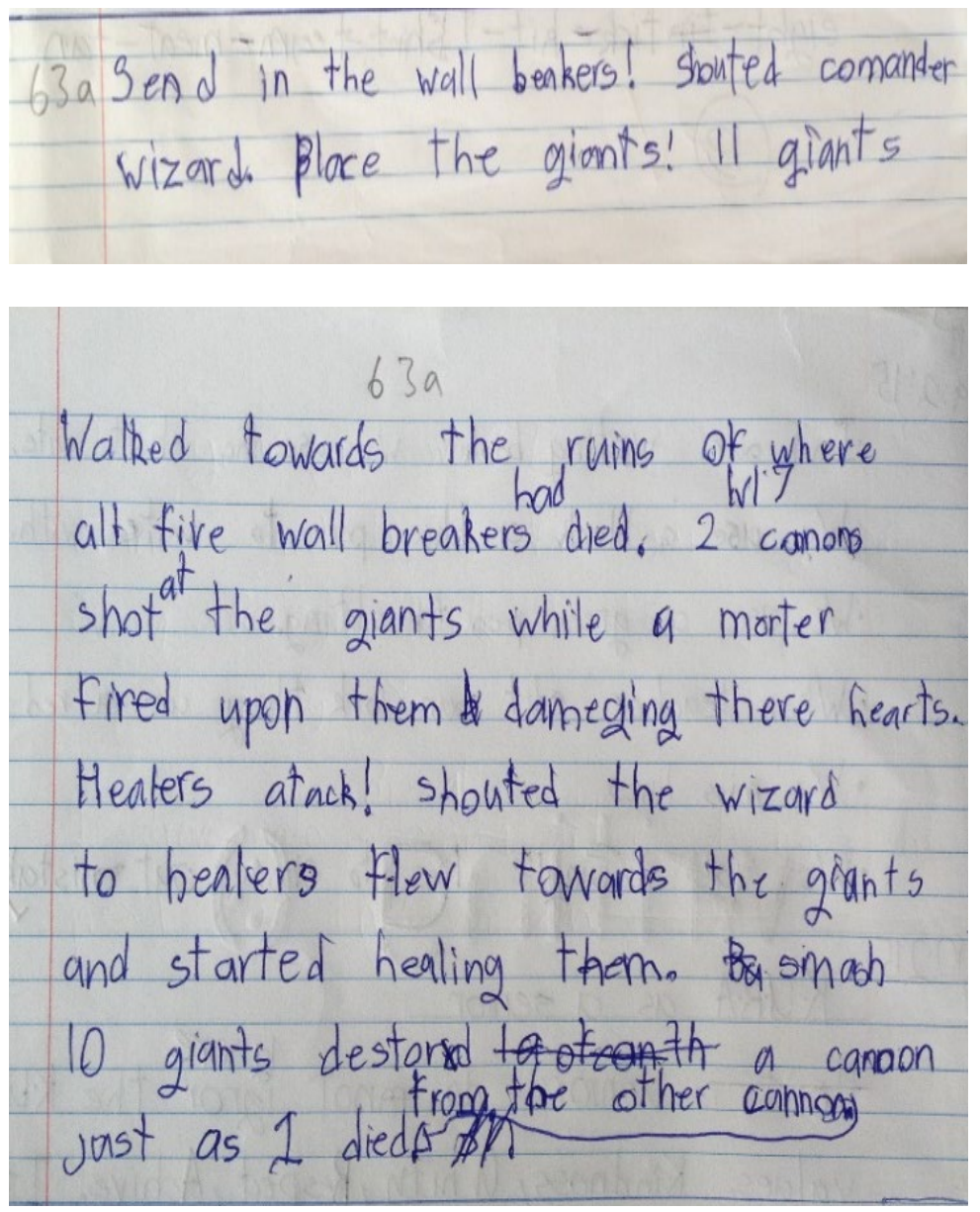


Figure 55: Ben's writing at Time Point Four

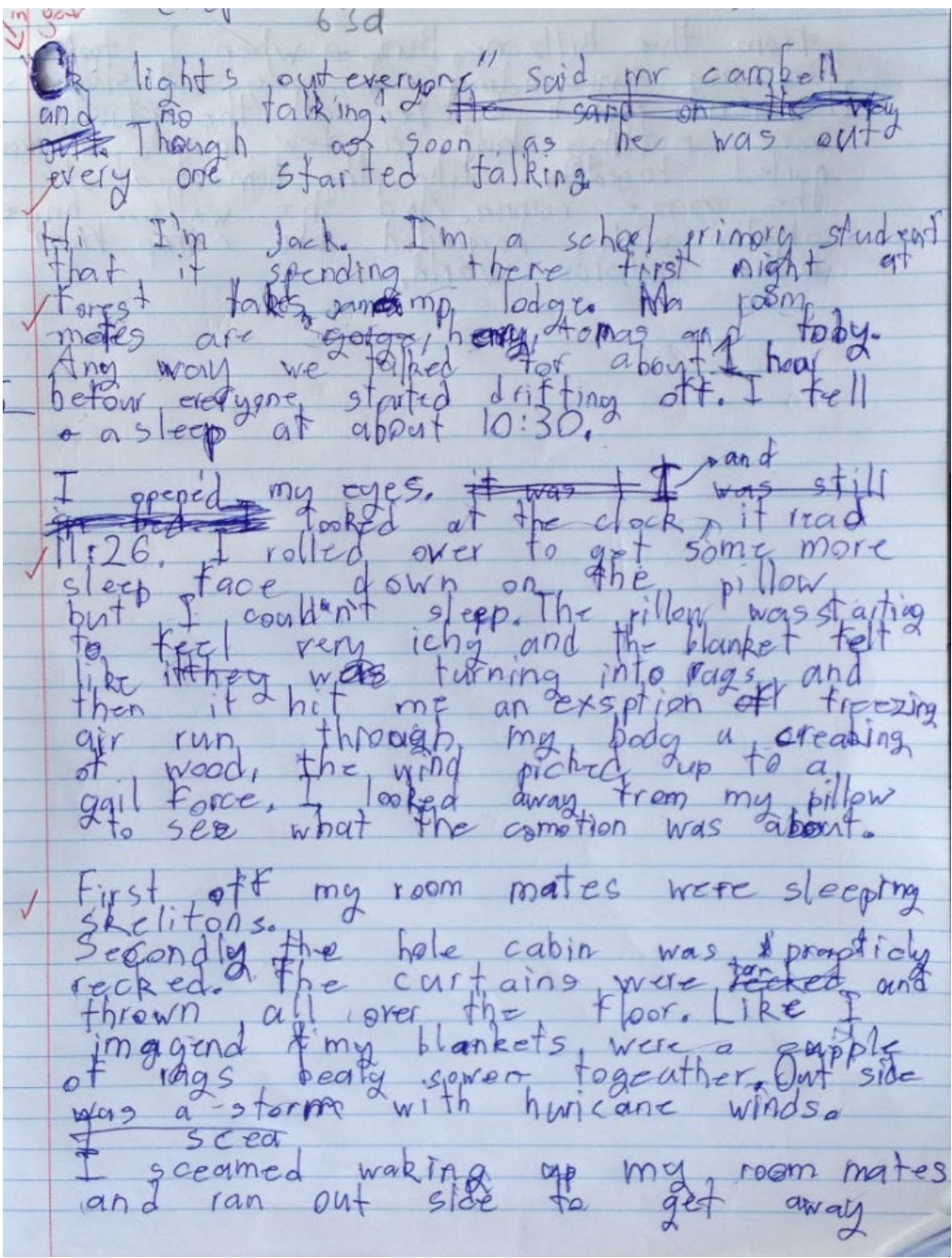

The display of ticks and stickers

While the feedback conferences were delivered quite consistently by all teachers, there was some variation in the way in which ticks and stickers were displayed at the back of student books. My advice regarding the tracking pages was to display these ticks and stickers in a vertical line, so that the number of consecutive days of partial or full achievement was clear (see Chapter Two, for a discussion of data display). All teachers but Jeremy followed this system, and it is interesting to note the dramatic visual impact of this small change. In a positive development from my model, Mele used this tracking page for some more in-depth qualitative and positive comments, and students in Julie's class began to give feedback to themselves in a similar way. Examples of these different techniques are given in Figures 56, 57 and 58. 
Figure 56: Mele uses the tracking page to provide qualitative positive feedback in the form of written comments.

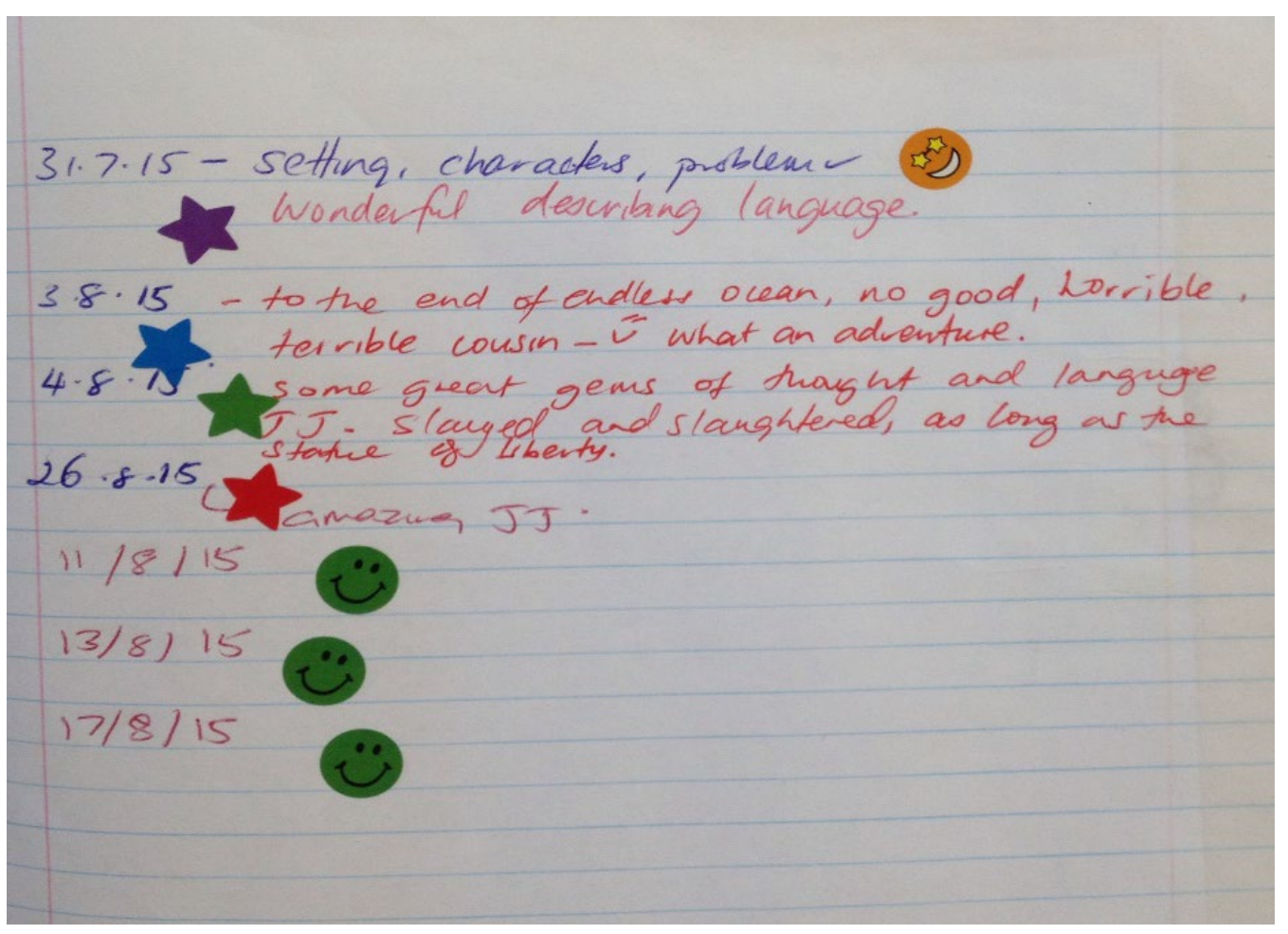


Figure 57: A student has written his own positive self-evaluations alongside Julie's tracking with ticks and stickers.

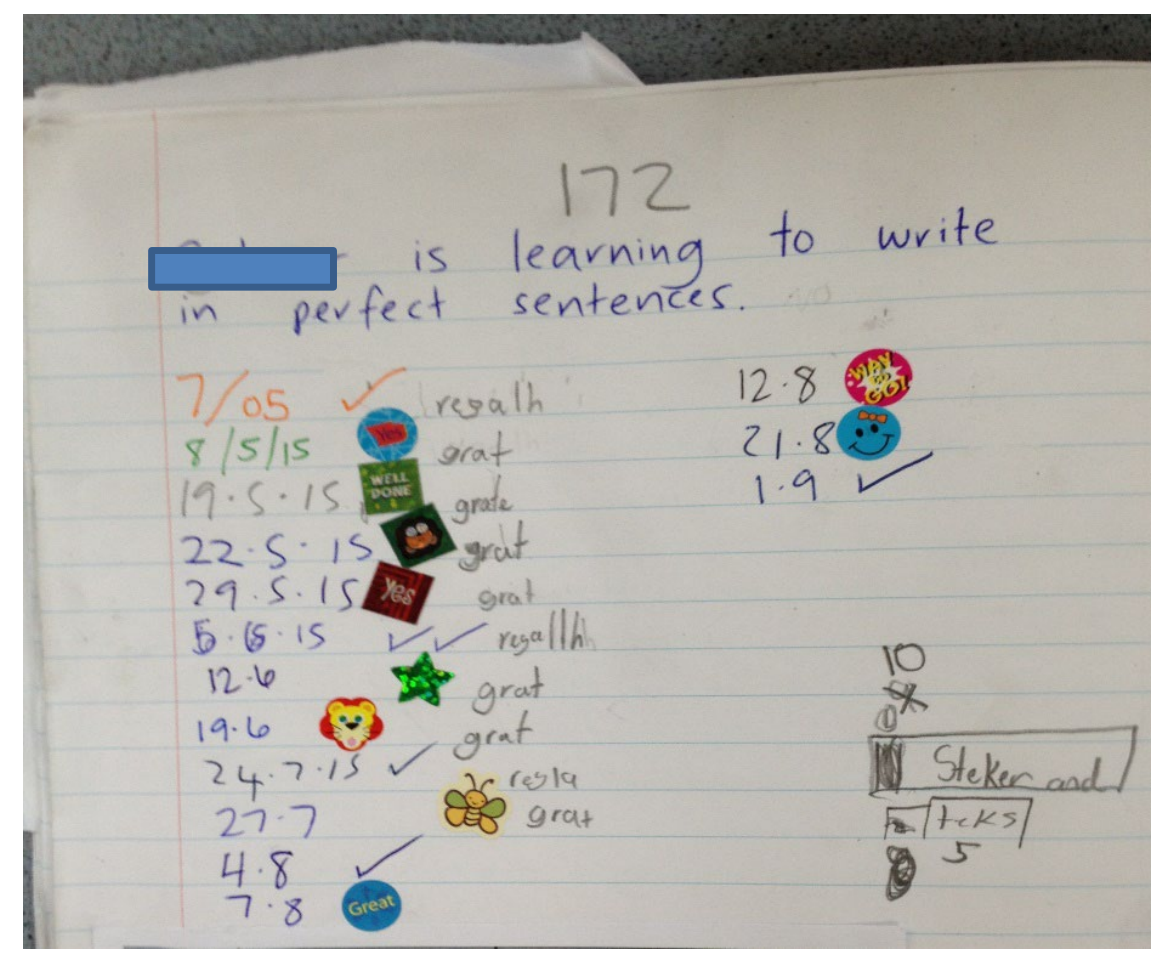


Figure 58: Progress is tracked horizontally on Jeremy's tracking sheet.

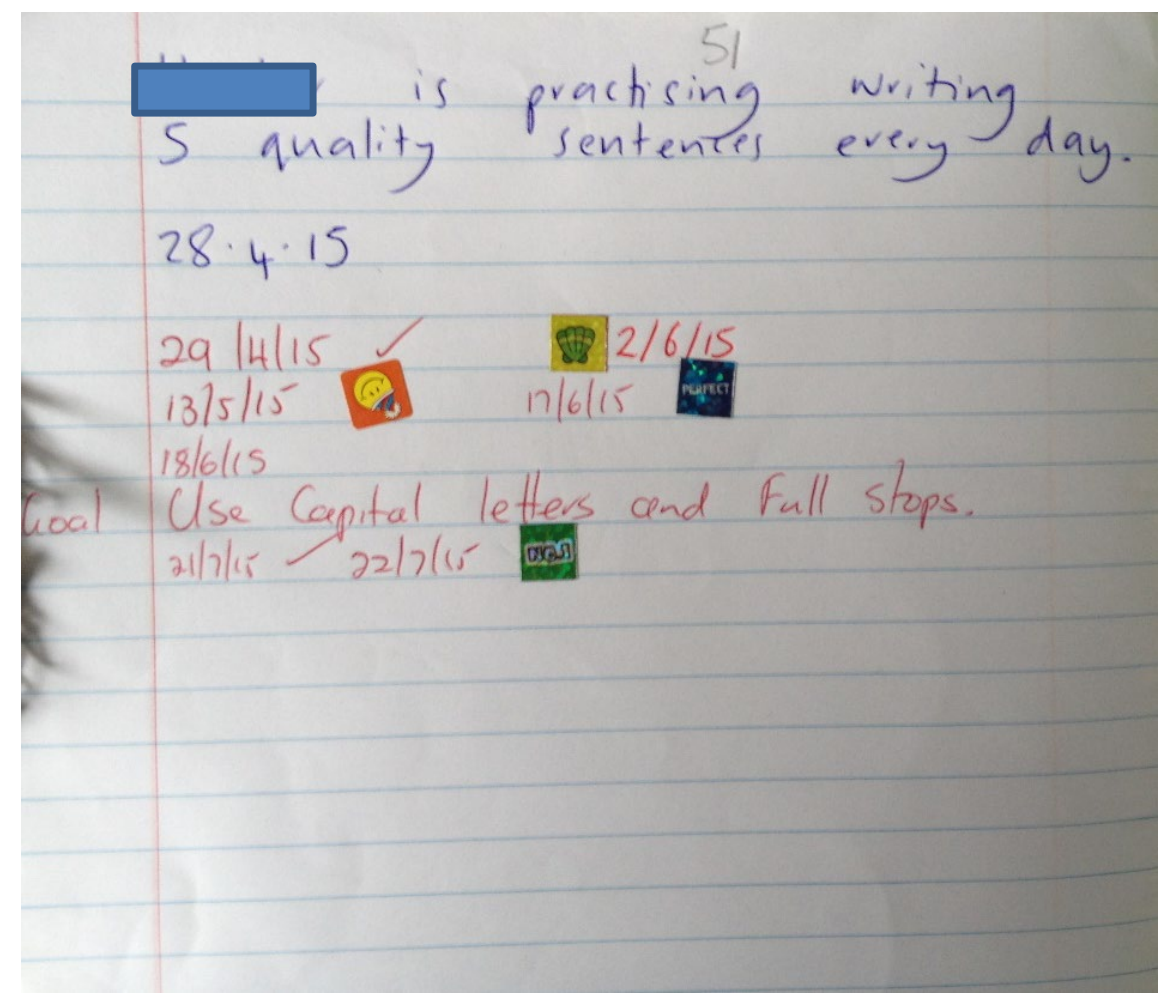

\section{Writing instruction}

As Fast Feedback was clearly defined for teachers, and feedback was given equally regularly across the two terms of the intervention, other aspects of teachers' writing instruction may be quite significant in explaining the greater rates of progress observed in Term 2 , as well as the greater degrees of effectiveness of those teachers who adopted more of the Koru Writing Manual recommendations (Appendix III). These approaches are, of course, informed by social cognitivist writing research (most usefully synthesised by Graham and Harris, summarised in Chapter Two). They are based on an underlying understanding of the beginner's writing process. This process is complex, and technical difficulties compound its complexity. Selfregulation makes the process more manageable, and student motivation is key. I would suggest that the practices that reflect these understandings achieve superior results for students.

\section{Teaching spelling and handwriting}

I emphasise the importance of spelling and handwriting and recommend the evidence-based methods of Barbara Brann for teaching these skills (see the writing manual, Appendix III). Mele, 
Julie and Natalie shared my interest in the mechanics of writing. In Natalie's Year 5-6 class, spelling was tackled using the Fast Feedback spelling goal, and also by giving one particularly low ability speller a laminated card with just two common words to check every time he wrote. Mele, teaching Year 4-5 students, identified spelling as a key priority for her students, and included the learning of spelling words as a weekly homework task. Julie used Barbara Brann's handwriting programme and daily phonemic awareness practice activities with a number of her high needs Year 4 students. In contrast to these approaches, less effective teachers did not have a clear plan for tackling spelling and handwriting difficulties. ${ }^{97}$ While I am not in a position to comment on these teachers' approaches in any detail, I observed practices which appeared somewhat haphazard and ill-informed. For example, in Kiri and Hine's Year 3-4 class I suggested making a list of topic words available for writing, and Hine's response was that by doing this "we give them too much". On the other hand, a high needs student in this room had been given a word card with a large number of words (more than 30) handwritten onto it. The layout of this card was confusing and untidy, with no consistency in the size and shape of the lettering, and no clear system for grouping these words. An additional and important point is the large numbers of students in these classes who demonstrated difficulties with spelling and handwriting. These difficulties were obvious in Jeremy's Year 3-4 class, and Nicole's Year 5-6 class. In Kiri and Hine's Year 3-4 class, eight out of the ten participating students had handwriting difficulties that persisted throughout the intervention. Comparing writing samples of these students from the beginning and end of the intervention, it is clear that very limited progress has been made in any aspect of their writing (see samples of "JJ" and "Lex", Figures 59, 60, 61 and 62).

\footnotetext{
${ }^{97}$ It is important to note however, that all of these teachers were interested in learning more about how to teach these skills. Unfortunately, due to the limited time I had to work in each classroom, and as the focus of the intervention was feedback, I was not able to give more than superficial guidance in this important area.
} 
Figure 59: JJ's writing at Time Point One

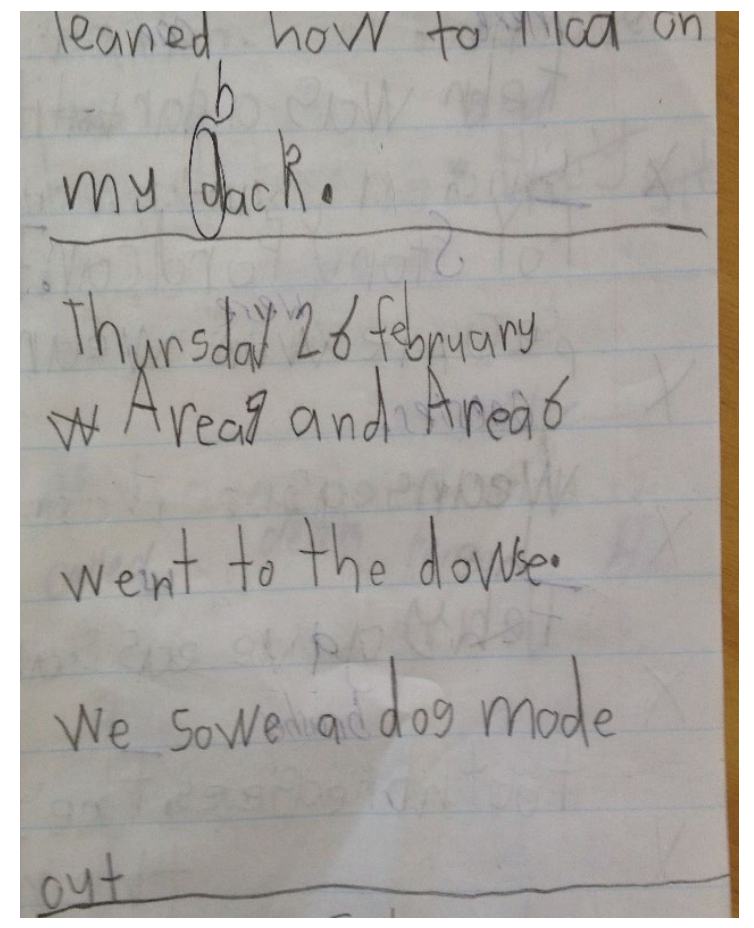

Figure 60: JJ's writing at Time Point Four

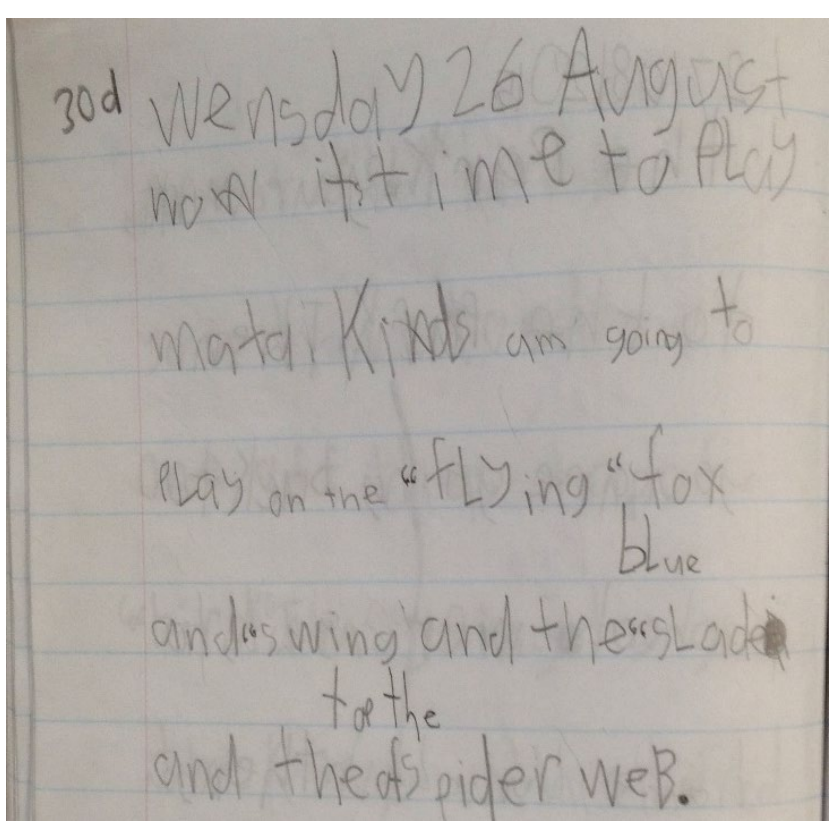


Figure 61: Lex's writing at Time Point One

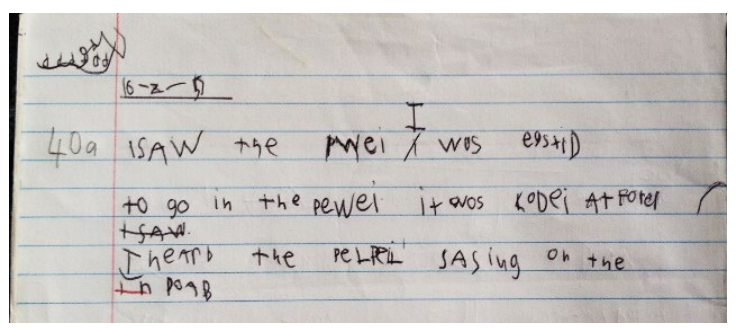

Figure 62: Lex's writing at Time Point Four.

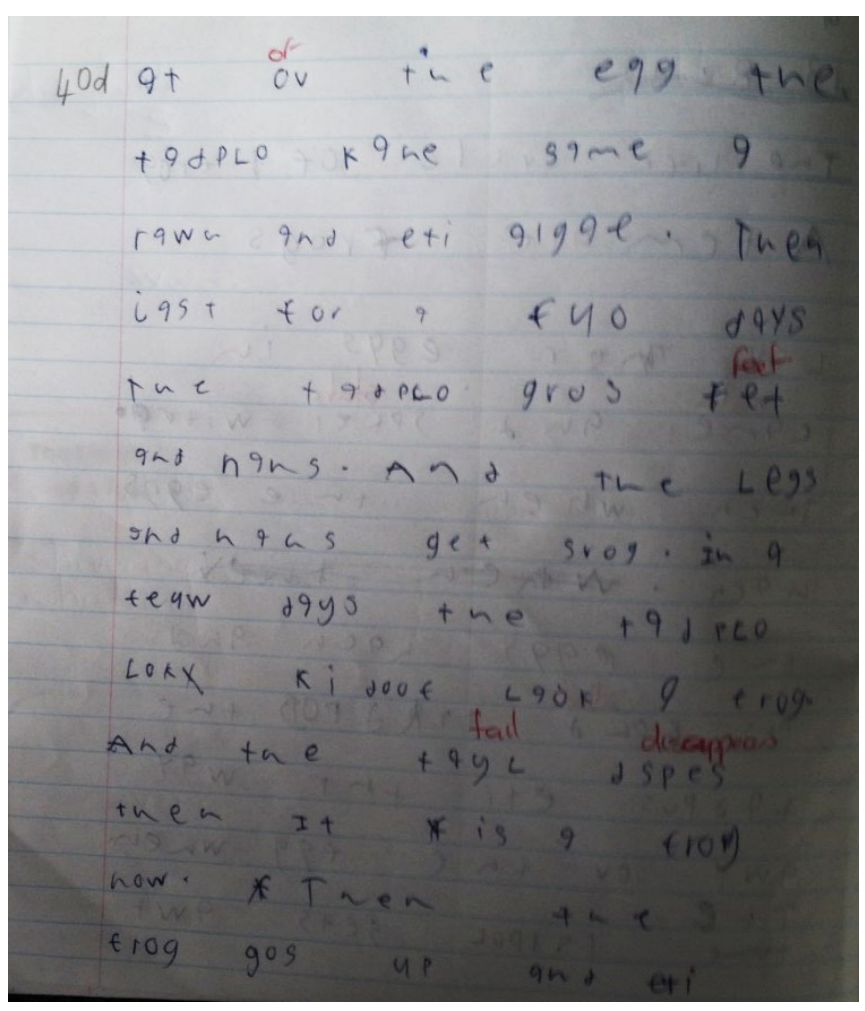

Pencils and rubbers

I recommend that students write in pencil, and use rubbers to correct errors. This practice may encourage self-regulation as it enables students to make tidy changes, and ensures that their writing remains readable. In contrast, students writing in pen must use crossing out, and can only add new text by inserting it above the line. This often results in very messy work, making it difficult for both the student and teacher to read the writing. Additionally, it draws attention to errors in the work, which may be discouraging and affect student motivation. The four most effective teachers used pencil and rubber. Figures 63 and 64 demonstrate the problems with correcting in pen. 
Figure 63: The use of pen (i).

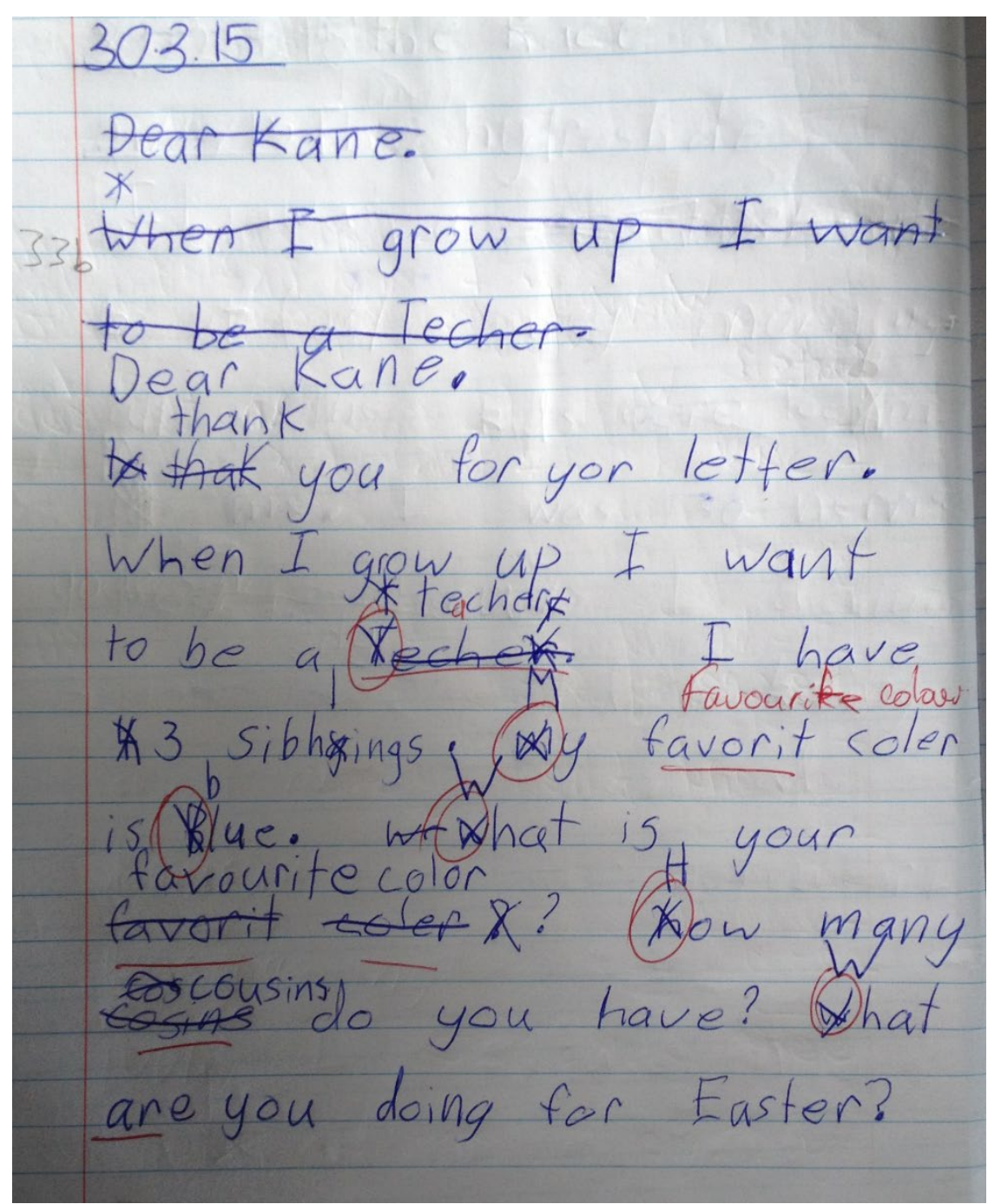

240 
Figure 64: The use of pen (ii)

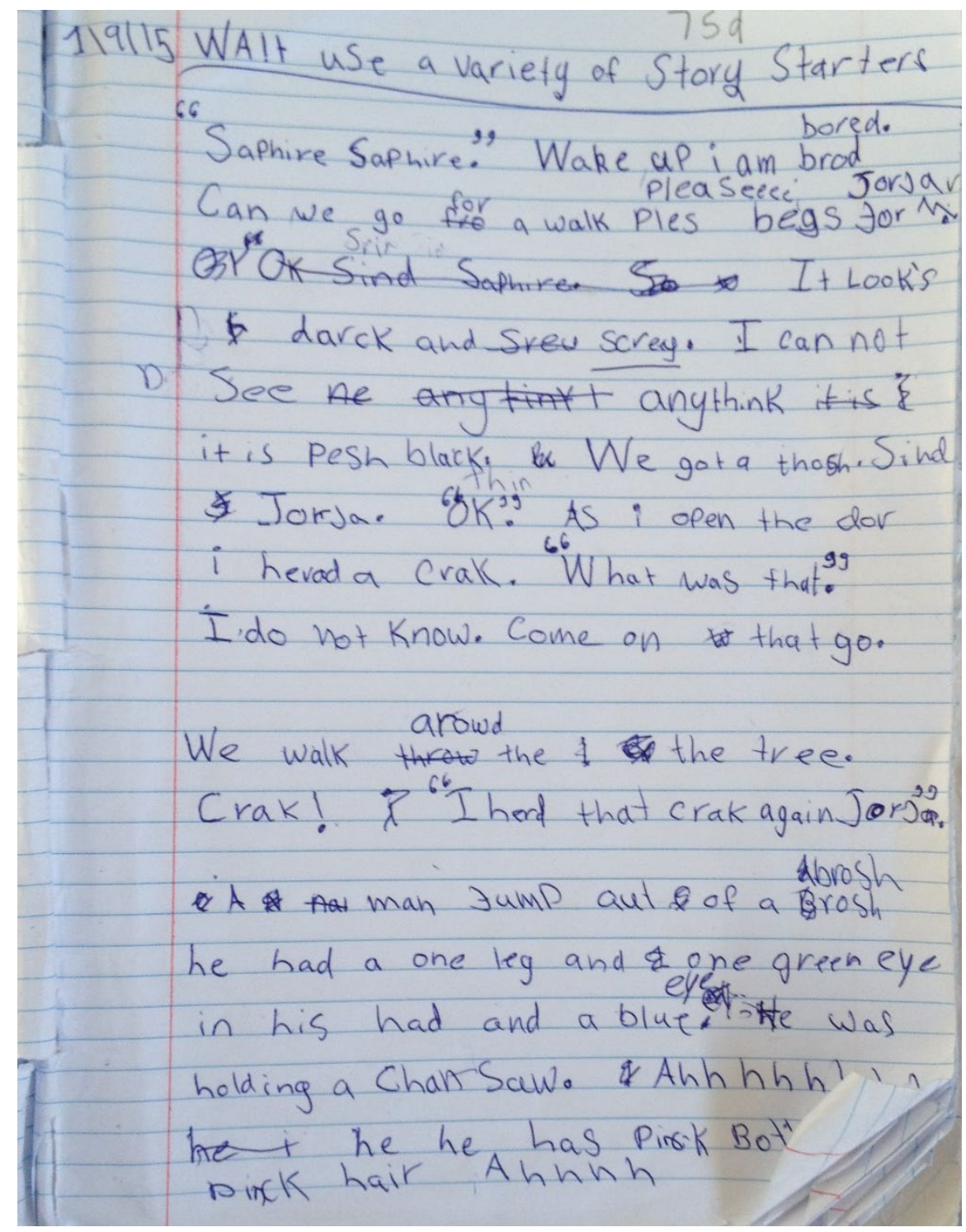

\section{Teacher editing}

With regards to written marking, I advise teachers to avoid editing which draws attention to errors, as this may be discouraging. Participating teachers' approaches to written marking were very variable, with different methods used in every room, and some teachers changing their approach over the course of the intervention. It is interesting to view a variety of marked writing samples and to consider the impact of the teacher's editing from a personal point of view. Some of the most comprehensive editing actually obscures the writing of the student and 
makes the text impossible to read. Other, more selective marking communicates a more positive message. ${ }^{98}$

Figure 65: Every incorrectly spelt word is corrected by Julie.

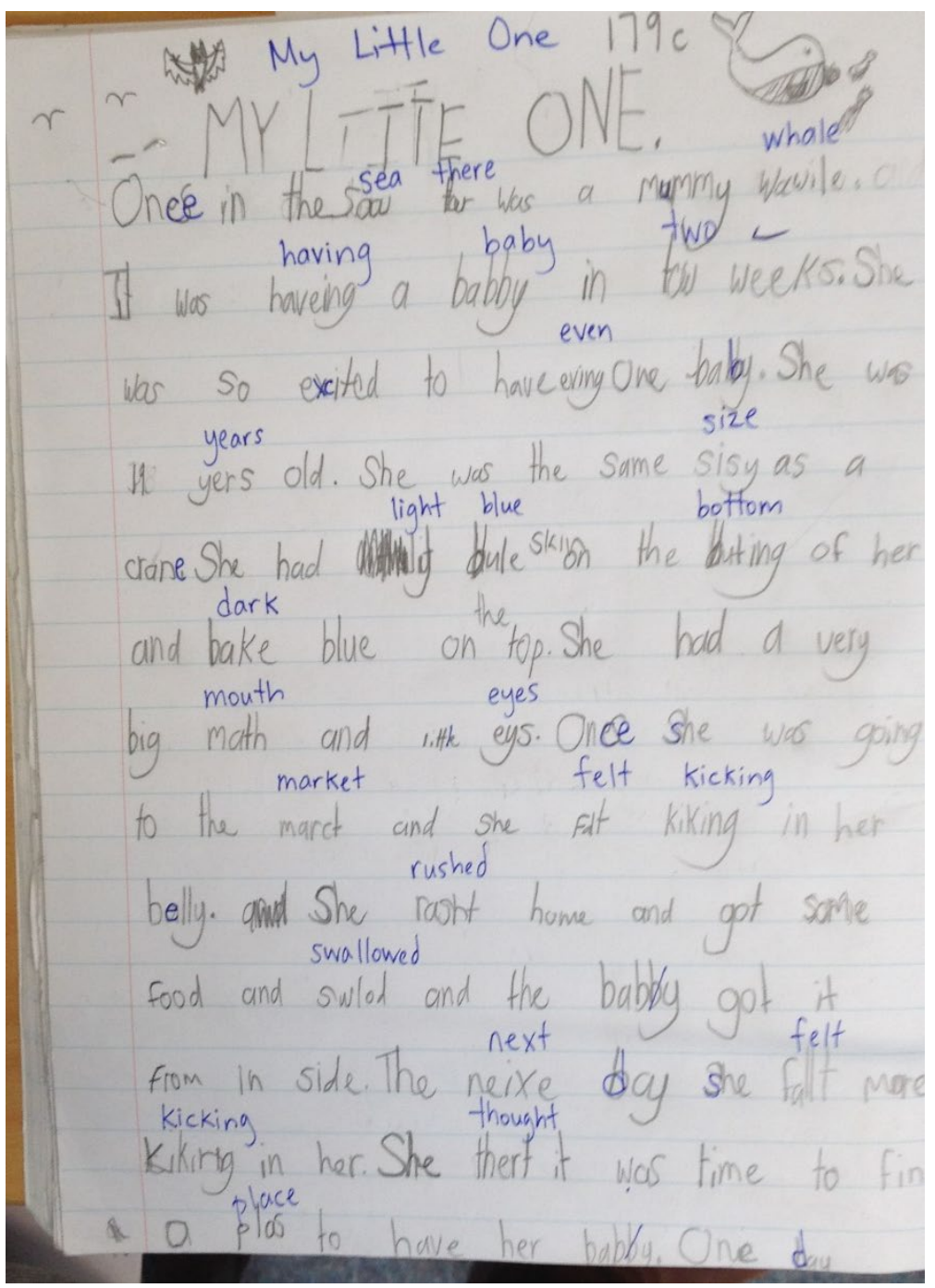

98 There may be some pressure on teachers to edit written work as a way to show students how to improve. Of course, the Fast Feedback system indicates ways to improve, though this occurs through discussion, with the tracking page providing the only evidence of conferencing. 
Figure 66: Natalie chooses to make one positive written comment and to reinforce the positive message with a colourful stamp.

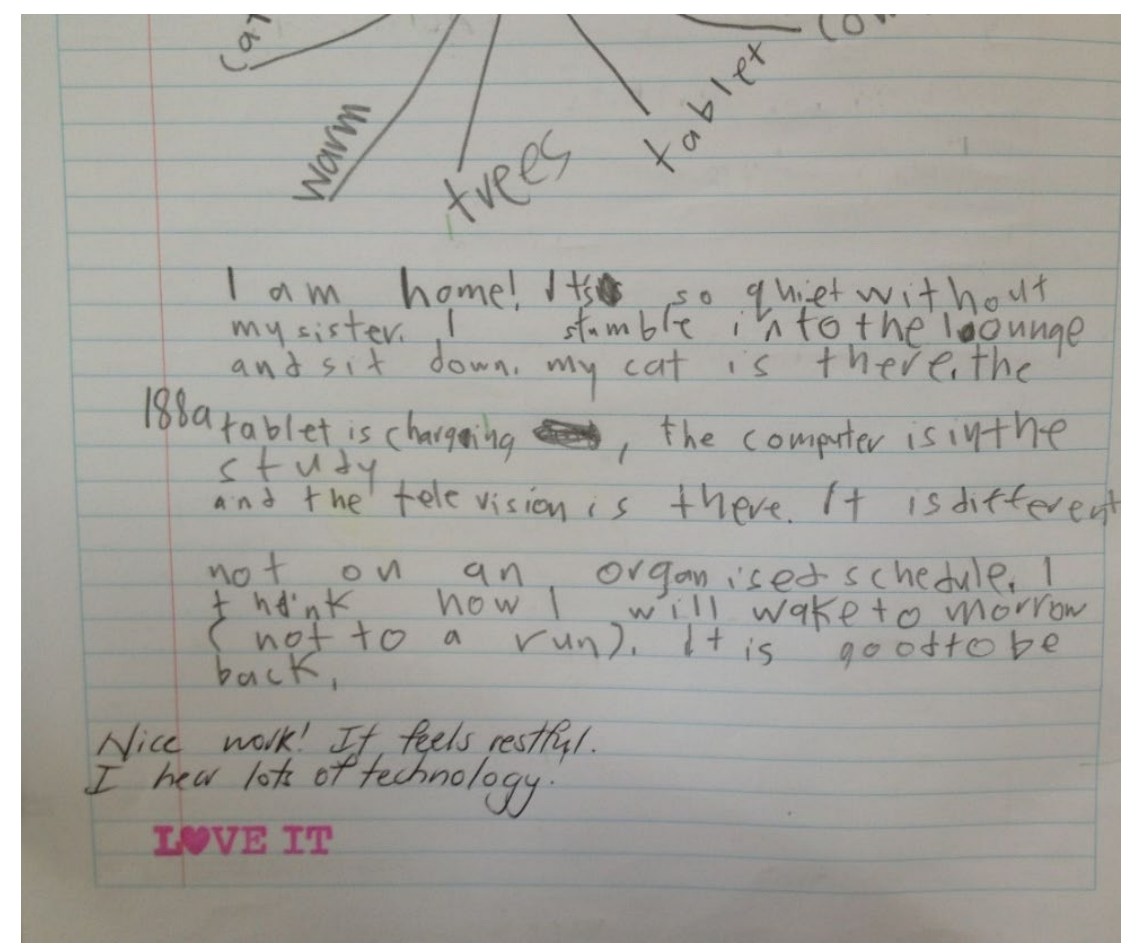

Figure 67: Kiri corrects every spelling error and re-arranges the structure of two sentences. She also uses ticks throughout the piece.

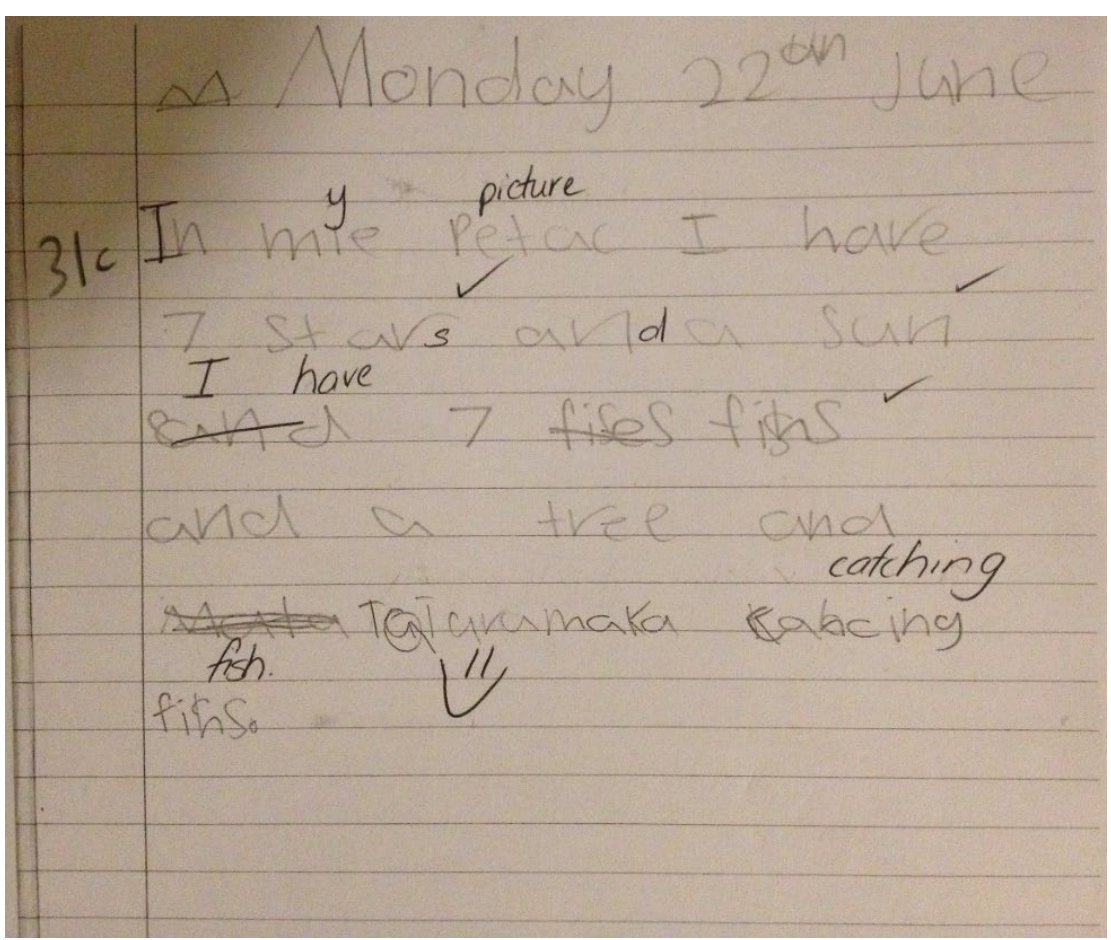




\section{Other factors}

Other (ostensibly trivial) details may have unintended negative consequences for students. Three of these, I believe, are particularly significant. Because these are difficult to demonstrate through the use of writing samples, and because their impact is impossible to isolate in the data, I have had to rely on anecdotal descriptions here. First, in a number of classes, students were asked to write the date at the top of their page each day. For beginning writers, this presented a major challenge, and interrupted the flow of the lesson, effectively turning their attention away from the learning goals discussed during the teacher modelling time. Second, a number of teachers seemed uneasy about setting expectations for the content of the writing, with some favouring 'free writing', or refusing to specify the genre for students to write within. A contrasting (but equally unhelpful) approach to content was being overly restrictive. In Jeremy's classroom, after I had modelled writing a story based on a real life problem, students asked if they could write imaginary stories. Jeremy discouraged this, saying that students would get "carried away writing about fairies, princesses and so on". Finally, regarding the feedback system itself, on several occasions I observed students who had achieved their first goal asking for a new goal, and then having to wait for, at times, more than a week before getting one. In these cases, teachers were failing to capitalize on the increased motivation and momentum generated by Fast Feedback.

\section{Limitations of the study}

Key limitations relate to the extraneous variables, not well controlled for in the design of the study. These include significant variability in the class contexts (class size, school decile, and so on), as well as in the wide range of approaches teachers were using to teach aspects of writing (spelling and handwriting, for example), not directly related to the use of the fast feedback model itself.

Another limitation was the omission of observations of classroom teachers using fast feedback. This would have allowed for (i) refining of their feedback practices based on advice 
from the researcher; (ii) more information about how well the methods were being applied in each classroom.

Two other aspects were problematic: first, that the first author was regularly involved in the teaching of student participants - modelling in each class nine times over the course of the intervention; second, the control group was relatively small, and was from a single school. In addition, very little was known about the practices of teachers at this school.

\section{Conclusion}

The achievement data clearly indicate that Fast Feedback accelerated student progress, even (or especially) for those students with learning difficulties. Student survey results and teachers' observations (considered in the light of social cognitivist research) suggest that the system encourages self-regulation, and, in turn, enhances student motivation. A more difficult question is precisely which aspects of this comprehensive approach are most powerful. An answer here is essential in order to ensure that Fast Feedback can be used successfully by all teachers, with continuing success throughout the school year. Future research could address this question through systematic observation of the subtly different ways in which teachers implement the methods involved.

A deeper analysis invites reflection on the constructivist orientation of our school system, and the role of Fast Feedback in such a system. It is certainly the case that participating teachers demonstrated an impressive level of reflectiveness and willingness to improve their practice. At the same time, few of these teachers knew, at the outset of the intervention, how to address all of the most fundamental skills of writing. Given evidence-based advice, all of these teachers were able to achieve accelerated progress in their decile two, four and seven schools, compared to teachers in the decile five control school. The most successful teachers were those who followed the advice most closely. There may be an argument here for a more explicit and directive approach to teachers' professional development. 
As teachers responded to clear and specific instructions, students likewise responded to clear and specific learning goals. The most effective goals were those that were meticulously and explicitly worded, describing writing processes in useful detail. Daily modelling and guidance were used for further clarification, and feedback encouraged students to reflect on how closely, or otherwise, they were following advice. Structure and routines were also key, with regular Fast Feedback conferences, in particular, greatly enhancing students' accountability and sense of self-responsibility. It is significant that this system, characterized by explicitness and structure, achieved remarkable results for both special needs and gifted students. A number of the highest needs students learnt the basic skills of writing in just two terms, and were able to write interesting and readable sentences by the end of the intervention. Highly achieving writers worked with greater confidence within the structured environment, with their final writing samples demonstrating enhanced creativity, as well as greater control over punctuation, spelling, grammar and the organisation of their texts. It seems, therefore, that what constructivists may describe as a "teacher-directed" approach, rather than devaluing or minimising student engagement and voice, actually had the opposite effect, as carefully planned and taught learning sequences equipped students with essential writing skills and enabled them to express themselves with greater freedom.

When it comes to the broader impacts of accelerated achievement, the most striking result of the intervention, unfortunately impossible to capture entirely as data, was the excitement and pride that all of the participating students displayed. Student empowerment is a goal and a result of Fast Feedback. Rigorous teacher training and clearly defined learning progressions are essential to the success of this programme. 


\section{GENERAL DISCUSSION}

As we have seen, New Zealand's educational outcomes are inequitable. While constructivist approaches to curriculum and pedagogy attempt to address inequality as a social ill, these approaches have gone hand in hand with resistance to the explicit teaching of skills - skills that children need if they are to hold their own. The overarching implication of the present work is that some re-evaluation of these standard approaches is required. The two empirical studies at the centre of this work provide data with which to assess the relative efficacy of constructivist, and social-cognitivist approaches for the teaching of writing.

While the Ministry's position is stated clearly in its handbooks to teachers, prior to the present work, New Zealand teachers' adherence to constructivism had yet to be investigated. The Teachers' Beliefs and Practices survey of Study One has gone some way to addressing this question. Three, readily interpretable dimensions of beliefs emerged from the survey data: explicit teaching, socio-cultural and process writing approaches. Six (predictably correlated) dimensions of practice also emerged. As expected from a review of previous research (for example Graham et al., 2002; McCarthy \& McKhise, 2013; Ritchey, Coker \& Jackson, 2016), explicit teaching beliefs and practices items were distinct from process writing and sociocultural ones, whereas items from the latter two theoretical positions merged in one practices dimension - perhaps reflecting their common roots in the broader constructivist tradition.

A second stage of Study One investigated the critical question of relationships between teachers' beliefs and practices and their students' achievement. Only a small number of studies have attempted to address this question previously, none of them in the New Zealand context. These have produced inconsistent results (for example Ritchey et al., 2015; Poulson, Avramidis, Fox, Medwell \& Wray, 2001). The present study has therefore made a contribution to this small body of work. Comparisons of teachers' scale locations for the survey dimensions with the average rate of progress of students in their classes revealed positive and significant 
correlations between explicit teaching items and student progress, and negative and significant correlations between the socio-cultural beliefs dimension and student progress. Two items in the socio-cultural/process writing practices dimension were also negatively and significantly correlated with progress. These findings - while they refute current Ministry advice - were not unexpected. They align with the findings of social cognitivist writing researchers (for example Graham \& Harris, 1997; McCutcheon, 1996; Berninger et.al, 2002) who have demonstrated the importance of explicitly teaching transcription skills and writing processes, and of having students practise these in a range of writing genres.

In Study Two a quasi-experimental design was used to test a social cognitivist approach to the teaching of writing - the 'Fast Feedback' intervention - with greater rigor. Nine teachers were engaged to trial particular methods for teaching and feedback, ${ }^{99}$ and the progress made by their students over two terms was compared with progress made by students at a control school. Data analysis revealed that the participating group of 136 students made significantly more progress than the control group, and that the greatest rates of progress were achieved by students of teachers who selected clearly-worded, process-oriented goals, and who prioritised the teaching of technical skills. What is more, data from a student survey and teacher interviews indicate that these methods served to enhance student motivation and enjoyment of writing lessons. As with Study One, the positive effects of these approaches were unsurprising in the context of the extensive, international research.

The results of these two studies converge in a cogent manner, and lend weight to arguments made by Tunmer and Chapman (2015) and Patel (2010), that the Ministry's commitment to constructivism requires some re-evaluation. The clearest finding, overall, may be the emergence of explicit teaching as a key aspect of effective pedagogy. This is evident in consideration of the positive correlations between explicit teaching items and student progress in Study One, as well as the explicit teaching and feedback which defines Fast Feedback

\footnotetext{
99 These methods align with recommendations made by researchers such as Berninger, 2002; Graham \& Harris, 1997; Hattie \& Timperley, 2007; Kluger \& DeNisi, 1996; and Zimmerman \& Reisemberg, 1997.
} 
methods. As explicitness, by necessity, entails a high degree of teacher-directedness, its importance has been downplayed by constructivists - possibly in an attempt to redress problems of power, ever-present in the educational context. However, student writing from both studies demonstrate that explicitness and clear direction from the teacher often results in greater freedom of expression for their students. For example, we may consider the progress made by students in the classes of Study One teachers who valued explicit teaching. These students' writing at Time Point One was often (i) concerned with the simple retelling of personal experiences, and (ii) sometimes unreadable due to technical difficulties. By Time Point Two many of these students were tackling content of far greater sophistication, and were following the conventions of layout, spelling and punctuation with much greater ease. In Study Two, particularly dramatic changes in student confidence and agency were observed for some of the high-learning needs students.

The explicit teaching of technical skills - spelling, handwriting, sentence writing and punctuation use - appears to be particularly important. In Study One, six of the ten technical skills items positively correlated with achievement, albeit with only marginal significance. Additionally, the most effective of the eight case study teachers emphasized the teaching of these skills during their interviews. In Study Two, it was observed that the goal "to write in perfect sentences" was highly effective for many participating students. This involved the rereading and checking of every sentence as students wrote, guided by prompts "check that it sounds right and makes sense, check that it has a capital letter at the beginning and a full stop at the end". The teaching of spelling and handwriting was also prioritized by three of the most effective teachers in this second study. Significantly, writing samples from both studies indicate that, in the case of students whose handwriting or spelling difficulties were not addressed, content-related and broadly expressive aspects of the writing also failed to improve.

As described in the first chapters of this thesis, the importance of technical skills has been downplayed by constructivist theorists from both process-writing and socio-cultural 
traditions. In the case of process writing, advocates such as Graves advised teachers to focus on student engagement in meaningful writing tasks - in the belief that these skills would develop through practice, and suggested that an undue focus on them may be counter-productive, distracting students from meaning and content. Later, socio-cultural theorists went further, arguing that definitions of literacy should be revised to encompass a range of dialects and 'modes', and that knowledge of the alphabetic code has only limited value - "not enough to merit its fetishication by the back-to-basics people" (Cope \& Kalantzis, 2009, p. 183). While it seems rather too obvious to assert the importance of the content of writing, it is concerning that some educational researchers and policy makers are unwilling to acknowledge that beginning writers must master technical skills in order to be able to write at all.

While achievement data from these two studies does not support the use of constructivist-oriented approaches for raising achievement, it would be simplistic and counterproductive to disregard these approaches entirely. In Study One, interviews with case study teachers provided qualitative data which suggests that these approaches should be valued for their broader impacts. First, a number of the case study teachers spoke of the importance of positive classroom relationships, and described the use of practices which support a culture of inclusivity and mutual respect between themselves and their students. These priorities are clearly of the utmost importance, and have been highlighted by socio-cultural theorists. Second, it must be noted that all these teachers put significant effort into planning interesting tasks for their students - and spoke of the importance of the constructivist-oriented priorities of relevance and authenticity. While (as discussed in Chapter Four) there is a danger that these concepts may be interpreted simplistically - leading to an over-reliance on personal experiences as motivation for writing - all of these teachers took a more nuanced view. They described the use of tasks with great scope for challenge and creativity (poetry about 'gaming', reports about a local river flooding, descriptions of a class science experiment, and so on). Finally, case study teachers planned in response to their students' needs, and for many of the 
more advanced writers in their classes, process writing practices - such as student choice of topic and genre - may have been highly appropriate.

Ideally, researchers and policy makers would value the contributions of a range of theorists, and would investigate a variety of approaches for the particular benefits they may bring. Unfortunately, however, this has failed to happen in the New Zealand context, possibly due to a tendency in the constructivist literature to present oppositions between their own and other approaches. As Moorman and colleagues first described, this is evident in the figurative language found in much of the whole language literature, whereby whole language methods are associated with that which is natural, personal and authentic, and other approaches with artificiality and subordination. A similar tendency is notable in the socio-cultural literature. For example Bishop et al. (2008) associate their Te Kotahitanga programme - a socio-cultural intervention - with life, dynamism and truth, while 'traditional' methods are associated with disease and the imposition of power. Unfortunately, the Ministry of Education has itself perpetuated this tendency towards false dichotomies, as evinced in the statements "Writing is a creative act, not a set of quantifiable skills to be taught in sequence" (ELP, 2003, p.136, italics added), and "There is [...] no place for programmes with prescriptive methods and materials" (p.21, italics added). While empirical research could be used as a means to objectively appraise methods from any theoretical framework, this is also discounted by constructivists as "narrow" and "misconceived" (Goodman, 1992, p.197) and the Ministry of Education follows suit: The research base for $E L P$ is reliant on a small number of qualitative, and mostly local researchers and the advice presented fails to take account of the most important social cognitive work in this area.

In sum, this work appears to confirm that (i) teachers' beliefs matter - they have a strong impact on student achievement; (ii) social-cognitivist approaches, extensively researched overseas, work for New Zealand students too; and (iii) while socio-cultural and process writing approaches should be valued for their emphases on creativity and inclusivity, 
they are clearly not enough, in themselves, to address the 'achievement gap'. These findings have clear implications for Ministry policy, particularly with regards to pre and in-service teacher training. Rather than requiring teachers to make planning decisions based on their personal beliefs, or through a relatively inefficient process of individual inquiry - as currently advocated in the New Zealand Curriculum, ${ }^{100}$ the findings of empirical work should be valued, and proven methods should be shared - with a sense of urgency. In particular, teachers need to be given clear information about key learning progressions, the use of formative assessment to identify particular difficulties, and practical methods for addressing them. While teachers' preferences for professional development were not formally investigated in either study, Fast Feedback teachers responded positively to this kind of clear and specific advice, and all were able to accelerate the progress of their students as a result of implementing new methods.

Future research could build on the present work by addressing certain limitations. First, it could supplement the tentative findings of Study One by broadening the scope of the survey to include a greater range of beliefs; by increasing the sample size of teachers - particularly in the second stage; and by supplementing the self-reported survey data with classroom observations. The approaches investigated in Study Two could be re-examined in true experimental conditions, by using random assignment of participants to treatment and control groups; and by isolating the variety of approaches applied so as to be able to say, with greater certainty, which are the most critical for student success. Additionally, a broader set of questions could be investigated, in order to address more specifically the needs of those students currently most disadvantaged in our system. Data could be collected on the ethnicity and socio-economic status of student participants, in order to assess whether particular methods are more or less effective for certain groups. The students' own experiences of these methods could also be investigated, using quantitative methods - for generalizability, and qualitative methods - for depth of understanding.

100 http://nzcurriculum.tki.org.nz/Teaching-as-inquiry/Making-change 


\section{AFTERWORD}

As noted in the preface, I attended primary school during the 1980s, when process writing reigned supreme. As an avid reader, well prepared for literacy learning by family and pre-school experiences, I enjoyed the emphasis on creativity and did not require much explicit instruction. If - as a teacher - I had fallen back on my personal educational experience to inform my methods, I would have ended up overlooking the needs of many of my students. Fortunately, I had opportunities to engage with empirical research early in my career: these enabled me to provide inclusive programmes within which all of my students could experience success.

The Ministry's constructivist bias notwithstanding, teachers are pragmatic: they value explicit, as well as socio-cultural and process writing approaches. They are therefore likely to prove receptive to some practical advice for the teaching of skills. It is exciting to consider the improvements that could occur if all New Zealand teachers understood the significance of these skills and knew the most effective ways to teach them.

Cope and Kalantzis (2009) associate a "back to basics" approach with "cultural stability and uniformity" (p. 184) - I disagree. The alphabetic code itself is, at the cultural level, relatively neutral - it can be used for any kind of content, in many languages. What is more, by teaching fundamental literacy skills we remove constraints on self-expression. Competence in writing allows for more effective participation in society - including in the political sphere. It is my hope that - in the not too distant future - young people from currently marginalized communities will be using their writing to advocate for social and political changes that, as constructivists would agree, are urgently needed. 


\section{APPENDIX I: Teachers' Beliefs \& Practices Survey}

Teacher Beliefs and Practices Survey

Thank you for taking the time to respond to this survey. Your responses will be used in my post-graduate research, investigating New Zealand teachers' beliefs about teaching writing. Your personal information will remain confidential. You will not be identified personally in any discussion of the research findings.

This survey includes three sections: Section A: Demographic information. Section B: Items relating to beliefs. Section C: Items relating to practice. It will take approximately 15 minutes to complete the survey.

Section A: Demographic Information

Number of years teaching:

Current class year level(s):

Current school decile:

Section B: Beliefs

This section investigates your beliefs about teaching writing. Please rate your agreement with the following statements, by circling your level of agreement, selecting from:

Strongly disagree $\quad$ Disagree $\quad$ Agree $\quad$ Strongly agree

Students should have frequent opportunities to write about their personal experiences.

$\begin{array}{lll}\text { Strongly disagree } & \text { Disagree } & \text { Agree }\end{array}$

Students should learn the conventions of a range of writing genres.

$\begin{array}{llll}\text { Strongly disagree } & \text { Disagree } & \text { Agree } & \text { Strongly agree }\end{array}$

Students should be encouraged to keep their draft books tidy.

Strongly disagree $\quad$ Disagree $\quad$ Agree $\quad$ Strongly agree

Students should select their own topics for writing.

$\begin{array}{llll}\text { Strongly disagree } & \text { Disagree } & \text { Agree } & \text { Strongly agree }\end{array}$

Writing programmes are most effective when developed on the basis of teachers' personal judgement.

Strongly disagree $\quad$ Disagree $\quad$ Agree $\quad$ Strongly agree

Explicit teaching of handwriting is essential.

Strongly disagree $\quad$ Disagree $\quad$ Agree $\quad$ Strongly agree 
It is important to teach strategies for the revision of writing.

Strongly disagree Disagree Agree Strongly agree

The most important aspect of a student's writing is the ideas it expresses.

Strongly disagree $\quad$ Disagree $\quad$ Agree $\quad$ Strongly agree

Explicit teaching of spelling is essential.

Strongly disagree $\quad$ Disagree $\quad$ Agree $\quad$ Strongly agree

When students are motivated to write, their writing skills develop naturally - without the need for explicit instruction.

Strongly disagree $\quad$ Disagree $\quad$ Agree $\quad$ Strongly agree

Writing programmes are most effective when developed on the basis of research findings.

Strongly disagree $\quad$ Disagree $\quad$ Agree $\quad$ Strongly agree

It is important to teach strategies for planning for writing.

Strongly disagree $\quad$ Disagree $\quad$ Agree Strongly agree

It is important to teach children to structure sentences correctly.

Strongly disagree $\quad$ Disagree $\quad$ Agree $\quad$ Strongly agree

Students' engagement in the writing process is more important than the quality of the written work they produce.

Strongly disagree $\quad$ Disagree Agree Strongly agree

Students writing skills develop by sharing their work with peers.

Strongly disagree $\quad$ Disagree $\quad$ Agree $\quad$ Strongly agree

Students should use rubbers to correct mistakes in their draft books.

Strongly disagree $\quad$ Disagree Agree Strongly agree

It is important to teach children correct punctuation use.

Strongly disagree Disagree Agree Strongly agree

It is important that students learn to use writing conventions correctly.

Strongly disagree Disagree Agree Strongly agree 
Students should be encouraged to copy words they do not yet know how to spell.

Strongly disagree Disagree Agree Strongly agree

Students should be encouraged to re-read and correct their sentence structures.

Strongly disagree $\quad$ Disagree $\quad$ Agree $\quad$ Strongly agree

Explicit instruction in writing skills is essential.

Strongly disagree $\quad$ Disagree $\quad$ Agree $\quad$ Strongly agree

It is good practice to let students write in their own dialects rather than insisting on conventional English.

Strongly disagree $\quad$ Disagree $\quad$ Agree $\quad$ Strongly agree

Instead of telling students how to spell words, teachers should encourage them to spell as best they can.

Strongly disagree $\quad$ Disagree $\quad$ Agree $\quad$ Strongly agree

Students should be encouraged to re-read and correct their punctuation use.

Strongly disagree $\quad$ Disagree $\quad$ Agree $\quad$ Strongly agree

Students should be encouraged to select their own learning goals for writing.

Strongly disagree $\quad$ Disagree $\quad$ Agree $\quad$ Strongly agree

Writing tasks are most effective when they reflect the cultural backgrounds of students.

Strongly disagree $\quad$ Disagree Agree Strongly agree

Teachers should monitor students' progress in order to select appropriate learning goals for them.

Strongly disagree $\quad$ Disagree $\quad$ Agree $\quad$ Strongly agree

Learning goals should be introduced and explained by teachers.

Strongly disagree $\quad$ Disagree $\quad$ Agree $\quad$ Strongly agree

Teachers' feedback should focus primarily on students' ideas.

Strongly disagree $\quad$ Disagree $\quad$ Agree $\quad$ Strongly agree

A "messy" draft book may be a sign of deep engagement in the writing process.

Strongly disagree $\quad$ Disagree $\quad$ Agree $\quad$ Strongly agree

It is important that students have opportunities to use their cultural knowledge during writing lessons. 
It is important that students have opportunities to lead discussions during writing lessons, with the teacher taking on a facilitator role.

Strongly disagree

Disagree

Agree

Strongly agree

\section{Section C: Practices}

When conducting writing exercises, I encourage students to write about their personal experiences.
Never
Sometimes
Often
Almost always

My feedback to students includes attention to punctuation.

Never Sometimes Often Almost always

When conducting writing exercises, I encourage students to choose their own topics.

Never Sometimes Often Almost always

My feedback to students includes reminders to keep their writing tidy.

Never Sometimes Often Almost always

When students are unsure of how to spell a word, I encourage them to approximate it, rather than providing the conventional spelling.

Never Sometimes $\quad$ Often Almost always

When conducting writing exercises, I encourage students to write in their own dialects.

Never Sometimes Often Almost always

When conducting writing exercises, I expect students to write in a genre selected by me.

Never Sometimes Often Almost always

I select students' learning goals for them.

$\begin{array}{llll}\text { Never Sometimes } & \text { Often } & \text { Almost always }\end{array}$

I accept unconventional layout in my students' draft writing books.

Never Sometimes Often Almost always

Students select their own learning goals for their writing.

$\begin{array}{llll}\text { Never Sometimes } & \text { Often } & \text { Almost always }\end{array}$ 
When planning writing programmes, I consider research evidence about effective practice.

Never Sometimes Often Almost always

When students are unsure of how to spell a word, I encourage them to copy the correct spelling from a dictionary, word card or wall display.

Never Sometimes Often Almost always

When children make errors in their writing, I encourage them to correct them using a rubber.

Never Sometimes Often Almost always

My feedback on students writing includes attention to the ideas that they express.

Never Sometimes Often Almost always

When I plan writing programmes I use my personal judgement about what will work.

Never Sometimes Often Almost always

After reading a student's writing, I request that the student corrects any errors in their work.

Never Sometimes Often Almost always

After reading a student's writing, I request further development of ideas expressed in the writing.

$\begin{array}{llll}\text { Never Sometimes } \quad \text { Often } & \text { Almost always }\end{array}$

When conducting writing exercises, I encourage students to write on topics that relate to their cultural backgrounds.

Never Sometimes Often Almost always

When I conduct whole-class discussions during writing lessons I encourage students to lead.

Never Sometimes Often Almost always

When conducting writing exercises, I encourage students to engage in free writing, with no set learning goals.

Never Sometimes Often Almost always

My feedback on students' writing includes attention to sentence structure.

Never Sometimes Often Almost always

I explicitly teach students how to develop their ideas for writing.

Never About once a term About once a week More than once a week 
I explicitly teach punctuation use.

Never About once a term

More than once a week

I introduce and explain learning goals to students.

Never

About once a term

About once a week

More than once a week

I explicitly teach correct sentence structure.

Never About once a term About once a week

More than once a week

I explicitly teach spelling.

Never About once a term

About once a week

More than once a week

I facilitate students sharing their writing with each other.

Never About once a term About once a week

More than once a week

I teach handwriting explicitly.

About once a week

More than once a week

I conference with students one-on-one.

Never About once a term About once a week

More than once a week

If you have any further comments you wish to make regarding your beliefs and practices, these are most welcome:

Would you be willing to participate in further research about your teaching beliefs and practices? Do you give consent for me to contact you and your principal to discuss the details of this research, and to request your participation?

Yes/No

Best email for contact: 


\section{APPENDIX II: Assessment Rubric for Draft Writing Book Samples}

\section{Assessment Rubric for Draft Writing Book Samples}

\section{Handwriting}

1

Writes letter-like shapes
2

Writes letters, demonstrates some difficulty (letter reversals, writes predominantly using capital letters, over-sized letters, or writing is difficult to read)
3

Writes all letters correctly and legibly

I included handwriting as part of this rubric in order to identify those students who demonstrate handwriting difficulties. To do this, it is necessary to distinguish between New Entrant writers who are still learning how to form letters (Stage 1), and those writers who have learnt to form letters but lack fluency (Stage 2).

\section{Spelling}

1

Writes letters or letter-like shapes which do not correspond to sounds in words.

(Gentry: Precommunicative)

Or

The writing is copied from a teacher model

A small number of letters correspond to wounds in words.

(n)


For spelling, sentence structures, punctuation, relevance and detail, organisation and language, I have placed students who copy from a teacher model at stage 1 . These students appear to be unable to generate their own writing. Examples are found in the New Entrant samples and for special needs students in other year levels.

\section{Sentence Structures}

1

Intended structure is impossible to decipher

Or

Intended structure is emerging. There may be errors.

There may be other indecipherable words and phrases in the text.

The student writes lists of

Words

Or Just one or two decipherable sentences.

Or

3

Intended structure is clear. Student writes several decipherable sentences with errors.

Structure is clear and correct. Student writes several sentences correctly.
5

Structure is clear, correct and appropriate to purpose. Student writes several sentences correctly and uses variety in sentence beginnings or structures, adding impact to the writing. Tense is consistent throughout the piece.

The writing is copied from a teacher model

I have not specified whether sentences need to be simple, compound and complex at the different stages, except for stage 4 when a student could demonstrate the ability to use different structures consciously - to add impact to the writing.

Unless there is some self-awareness and purpose involved in the use of compound and complex sentences, these sentences do not necessarily indicate a greater level of skill. Compound and complex sentences are used in the speech of pre-schoolers, and many New Entrant students may choose to write a complex sentence on their first day at school (For example: "After we went swimming we went to McDonalds").

To further illustrate this point, many students appear to lack certainty about where a simple sentence begins and ends, and so develop a habit of joining every sentence with "and". This creates long compound sentences, resulting in texts which are often less sophisticated than those composed entirely of simple sentences.

\section{Punctuation}

1

Punctuation is used randomly or not at all

Or

The writing is copied from a teacher model
2

Minimal correct use of sentence punctuation

Or perfect punctuation for just one or two sentences

"and" may be overused to join
3

Some correct use
of sentence
punctuation

May be some correct use of other (more complex) punctuation
4

Mostly correct use of sentence punctuation and

mostly correct use of other punctuation

May be just sentence punctuation included if used
5

Perfect use of all punctuation, with some evidence of more complex punctuation.

Punctuation used is appropriate for the text type. 


$\begin{array}{ll}\begin{array}{l}\text { many simple } \\ \text { sentences }\end{array} & \begin{array}{l}\text { Comma over-use as } \\ \text { a sentence-writing } \\ \text { confusion }\end{array}\end{array}$

Sentence punctuation is the priority when deciding between stages 2 and 3 . The use of exclamation marks, question marks and commas directly relates to sentence structure, and so it is unlikely that a student who has not yet mastered sentence punctuation will be using these other punctuation marks correctly.

The task set influences the degree to which more complex punctuation may be used (for example, narrative text offers opportunities for direct speech and speech marks). For this reason, I have only made the use of more complex punctuation a criteria for the very highest stage.

\section{Ideas: Coherence and Detail}

1

No coherent ideas.

Or

The writing is copied from a teacher model
Or

2

One idea. Or one or two sentences.

Several ideas, extremely difficult to decipher
3

Several ideas that

are mostly coherent.

Detail adds interest and depth
5

The text is thorough and detailed, ideas show originality and

There may be small errors or confusions in the information given

Information may lack detail and interest. flair

Ideas are coherent

When making the judgement, I considered the opportunities provided by the topic of the writing.

\section{Ideas: Organisation}

1

Ideas are presented in a random order

Or

The writing is copied from a teacher model
2

Ideas are presented in a logical sequence
Ideas are organised into paragraphs, there may be minor errors.
4

Ideas are organised into paragraphs. No errors. The text includes a clear introduction and conclusion, or orientation and resolution

Or 
Just one

decipherable

sentence

Though organisation is more complex than paragraphing, paragraph use is quite easily assessed and gives us at least some insight into the student's ability to organise their ideas.

\section{Language}

Indecipherable

Or

The writing is

copied from a

teacher model
Sample is one or two sentences long so the number of topic specific words is very limited

Or

Several sentences, extremely difficult to decipher.
3

A small number of topic-specific or descriptive words is used

Vocabulary and the language of whole phrases are appropriate for the text type and add impact to the writing. There may be some inconsistency in the effectiveness of the language used.
5

Vocabulary and the language of whole phrases are appropriate for the text type and add impact to the writing. Language use is highly appropriate for the type of text and may show originality and flair.

For stages 3 and 4 I have made reference to text type as a way to reduce the subjectivity of judgements about language use. 
APPENDIX III: The Koru Writing Manual

Helen Walls

2015 


\section{Contents}

Introduction

The Koru Writing, Writing Process Model

The Fast Feedback Formative Evaluation System - The Key to Raising Achievement 3

Selecting Goals 3

Inspiring Ideas for Student Writing 4

How to Structure Your Writing Lessons 8

How to Discuss Learning Goals with your Students 9

What Teacher Modelling Should Look Like 9

Teaching Students to Plan

Guided Writing 12

Teaching Spelling

Teaching Handwriting 14

Teaching Sentence Structures and Punctuation 15 


\section{Introduction}

I developed Koru Writing while working as a classroom teacher. The practices I describe here have been informed by my teaching experience, as well as extensive reading of current research. This programme is designed to be highly effective, but also manageable and practical for teachers to implement.

Koru writing could be described as a "nuts and bolts" approach. It focuses first on building basic skills such as writing in sentences, using punctuation correctly and developing an awareness of spelling patterns and rules. As well as this, the programme encourages the use of exciting and authentic contexts for writing, so that students quickly begin to understand the boundless possibilities writing offers. I hope that all Koru writing students will love writing, and will be able to express themselves with confidence and freedom as they progress through school and into the adult world.

The Fast Feedback Model is the heart of Koru writing. This is a simple yet effective, formative evaluation system. It gives students clear information about their goals and progress, leading to greater motivation and accelerated learning. It helps teachers to select appropriate learning goals, reflect on student progress and evaluate and modify their practice as a result. If you are serious about transforming your writing programme and achieving outstanding results, implementing Fast Feedback is the key starting point.

I hope you find this manual useful and that writing becomes an inspiring highlight of your school day.

\section{The Koru Writing, Writing Process Model}

Writing has been described as "an act of juggling a number of simultaneous constraints" (Flower and Hayes, 1981, p.31). Writers must consider the task, purpose and audience. They must plan, write and revise. They must focus on a variety of skills, including use of sentence structures, 
punctuation and spelling. For beginning writers, handwriting or typing can also present major challenges.

These writing processes and skills do not happen in neatly ordered stages, but are intertwined and occur continuously while students write. Planning, for example, will occur even as the writer tackles his or her final paragraph, and will be influenced by the writing already completed. Handwriting, if it is not fluent and automatic, can interfere with all other aspects of a beginning writer's process.

So how do we best support our writers to engage successfully in this highly complex process?

First, we equip them with the basic skills of writing, so that these skills do not take up all of their limited working memory space.

Second, we structure tasks to limit decision-making and confusion. This allows them to focus on a smaller number of demands and practice them to fluency.

Finally, we acknowledge the difficulty and complexity of the process and work to always give clear and positive feedback.

Teachers will understand the writing process better by writing more themselves. Daily modelling in front of a class is a great starting point.

Learning to write well helps students to think clearly, creatively and logically. It will impact on their achievement in every other subject area. 


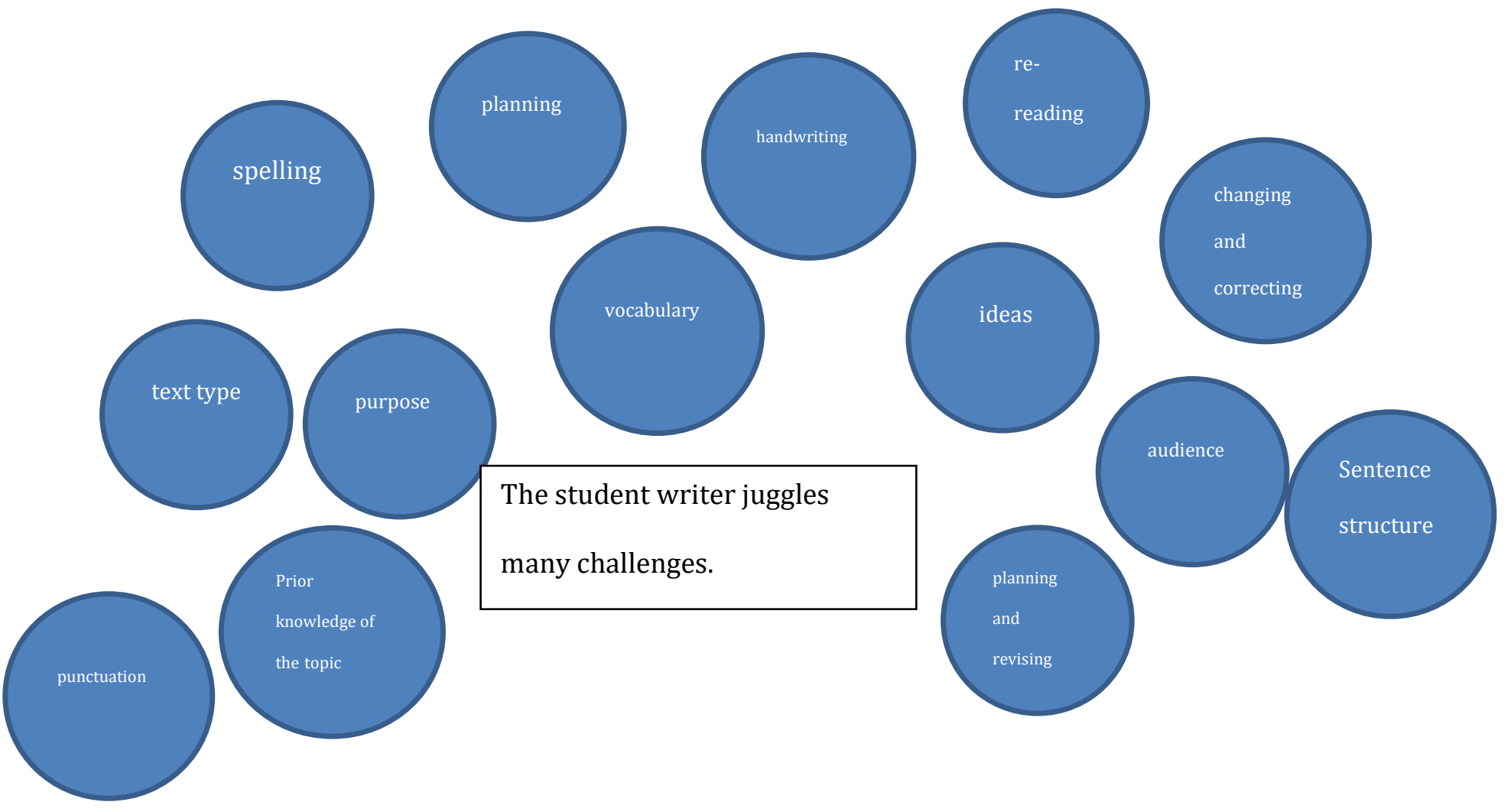




\section{The Fast Feedback Formative Evaluation System}

The Fast Feedback system includes three important actions:

1. Teachers use the draft writing book and observations during writing lessons to select one individualized goal for each student. Goals can be surface-level skills, related to deeper features of the writing, or be process-focused. They are recorded in the back of the student's draft book.

2. Teachers discuss and model these learning intentions, briefly, at the beginning of every writing lesson and prompt and praise during guided/independent writing to help the student achieve success.

3. Finally, and most importantly, teachers use the Fast Feedback conference. This is a conference with clear guidelines to help keep it manageable and effective. The guidelines are as follows:

- First, make a positive statement about the content of the writing.

- Next, praise any sign of progress towards the specific goal.

- Finally, record a tick or sticker at the back of the student's book. A tick is for partial achievement (perhaps achievement with support), a sticker is for independent and consistent achievement.

Please note:

- It is essential that these conferences take no longer than 30 seconds per student.

- It is essential that these conferences happen at least two times each week for each student.

- Fast Feedback can happen at any time during the lesson, as soon as the student has demonstrated partial or full achievement of their learning goal.

\section{Selecting Learning Goals}

Use your student's draft writing book to help select their individual goal. 
Think of 2 key questions:

1. What is the next small step which will make this writing more readable?

2. What is the next small step which will make the writing process more manageable for this student?

Beginning writers should start with just one sentence each day. Possible goals for these beginning writers include:

- To say a sentence before writing it down

- To start my sentence beside the margin

- To listen to sounds in words and write down letters that can make those sounds

- To leave spaces between words

- To spell some words perfectly, using a word card or wall chart

When these goals have been achieved with one sentence, a possible goal could be:

- To write three sentences about my topic.

More advanced goals include:

- To write in sentences, with a capital letter at the beginning of each sentence and a full stop at the end

-think of an idea and say it to myself

-write it

-read and check that the words go together

-check that it starts with a capital letter and that there is a full stop where we need to take a breath

- To re-read every sentence as I write, to check that it sounds right and makes sense

- To spell thoughtfully, by listening to sounds in words, remembering spelling patterns I know, and checking word cards/charts

- To check my handwriting of letters of the a, c, d, e, s, g, o, q group

- To check my handwriting of letters of the y,g group

- To check my handwriting of letters of the $b, p$ group

- To organize my writing into paragraphs

-Think about the subtopics

-Put all the sentences about one subtopic together in one paragraph

-Miss a line to show when a new paragraph is beginning

(This criteria can become more detailed as the students make progress)

Later Goals:

When these early goals have been achieved, select goals relating to the demands of the genre and purpose of the writing. Use the success criteria listed in the following chapter. 


\section{Inspiring Ideas for Student Writing}

Setting a genre gives a structure for students to work within and simplifies a very complex process. Discussing the purpose for your chosen genre and defining success criteria focuses the task even more.

I would suggest sticking to one genre for at least two to three weeks. This will allow students to focus on their individual goal (see the Fast Feedback chapter) as well as the demands of the text. If you change genre too quickly the challenge will be too great for you and the students.

It is easiest to teach a similar genre in reading time as well. And, if you are writing non-fiction, base your writing on a topic which has been studied in class already.

Keep the writing tasks simple and structure them as much as you need to in order for your students succeed.

Here are some simple yet interesting ideas for the different text types and purposes. I have only included ideas which I have actually used myself. Of course, you will have many more of your own ideas to add to every list.

These ideas can be adapted for work with Year 1-2 onwards. For New Entrants, 1 sentence per day is enough writing. This sentence could either be a simple fact, or something imaginary. Discuss the difference with these young children as a way to introduce them to the different genres and purposes for writing.

I have not included poetry ideas as I see practice with prose as being more useful for developing the basic skills of writing.

Genre: Narrative Text

Purpose: We want our stories to be fun and interesting to read.

Possible Success Criteria (choose 2-3 per unit of study): 
- Include a setting, characters and a problem

- Describe the setting, telling about sights, sounds and the feel of the place

- Describe characters (their looks and behaviours)

- Describe how characters are feeling

- Use direct speech to show how characters are feeling

- Use a variety of language techniques to add interest to your writing (similes, metaphors, alliteration, onomatopoeia, strong verbs)

- Use a complex sentence to bring suspense to the story (For example, "While we were swimming, a shark came into the bay.")

- Hook the reader in with a powerful first sentence (use action, description or speech)

Ideas:

- Stories set under the ocean

- Stories set in the jungle

- Stories about witches (mean witches, or funny witches, or sad and lonely witches...)

- Spooky stories

- Retelling traditional stories

- For seniors, survival stories can work well. They could read novels such as Gary Paulsen's Hatchet, or Theodore Taylor's The Cay, and use these writers as models.

Genre: Explanation/Report Texts

Purpose: We are writing to teach our reader something new. We want our writing to be clear and easy to understand. We want our writing to be interesting.

\section{Possible Success Criteria:}

- Include a useful title

- Include only factual information

- Write clearly so that the reader can understand

- Use precise language (perhaps scientific or technical language)

- Introduce the topic in your first sentences, then add more detailed information.

- Introduce the topic in your first paragraph. Use the following paragraphs to write about subtopics.

- End the writing with an inspirational conclusion (ask a question or highlight an interesting point).

Ideas:

- Animal reports

- Explanations of the water cycle

- Reports about the solar system and the different planets in it

- Reports about the weather - including extreme weather such as hurricanes

- Reports about favourite celebrities 
- For seniors, reports and explanations relating to any topic explored in a class novel can work really well. For example, the Cay prompts discussion of the Trans-Atlantic Slave Trade and the geographical features of the islands of the Caribbean.

Genre: Persuasive Writing

Purpose: We are writing to tell our reader what we believe. We want to persuade our reader to think the same as we do.

\section{Possible Success Criteria:}

- Include a useful title

- Include only factual information

- Write clearly so that the reader can understand

- Use precise language (perhaps scientific or technical language)

- Introduce the topic and state your opinion first, then give reasons for your opinion.

- Introduce the topic and state your opinion in the first paragraph. Use the following paragraphs to explain the reasons for your opinion.

- End the writing with an inspirational conclusion (ask a question or highlight an important point).

For this genre, use a human continuam to help generate discussion about the issue. Put an "agree" sign in one corner of the room and a "disagree" sign at the other. Students stand somewhere along the line to show their opinion about a given statement, then explain to the class their reasons why.

\section{Possible statements to discuss and write about:}

- Cats make better pets than dogs

- Learning to swim is more important than learning to read

- Hunting animals is wrong

- New Zealand should be known by everyone as Aotearoa

- Children should not have to go to school

Genre: Letter Writing

Purpose: We are writing to a friend to say hello and share our news. Or, for a formal letter: We are writing to express our opinion on an issue that is important to us (this type of writing could follow on nicely from a persuasive writing unit).

Possible Success Criteria: 
- Use the first sentences to explain why I am writing, then add information or ask questions.

- Use the first paragraph to explain why I am writing, then use the following paragraphs to add information or ask questions.

- When writing to someone we do not know, use polite and formal language.

- Follow letter writing conventions to begin and end the letter (Dear..., Yours Sincerely...).

Ideas:

- Letters to a friend in the class or school

- Thank you letters to people who have helped with the school programmes in some way

- Letters to the school principal to discuss and issue that has arisen or an idea for improving the school

- Letters to organisations to get information about something being studied

\section{Genre: Recount}

Purpose: We are writing true stories about things that have happened to us. We want this writing to be interesting to read.

\section{Possible Success Criteria:}

- Choose an interesting moment to write about

- Describe where you were - the sights, sounds, the feeling of the place

- Describe the people who were there

- Use direct speech to show how people were feeling and what they were doing

- Describe what happened

- Describe how the experience made you feel, or something you learnt from the experience.

Ideas:

- A sad day

- A problem at school

- Making a new friend

- Feeling guilty

- Being brave

Genre: Moment in Time/Response to an Image

Purpose: We are writing to describe something for our reader. This description needs to be interesting. We could use this type of description at the beginning of a story to hook our reader into the story. 
This kind of text can be challenging for the writer. Explaining the purpose is particularly important.

Also, deciding who is narrating the writing is important. Is this the student's own voice? Or is the piece written from the point of view of an imaginary character.

Choose images or moments with plenty of interesting things to see, hear and feel.

\section{Possible Success Criteria:}

- Describe the setting, telling about sights, sounds and the feel of the place

- Describe characters (their looks and behaviours)

- Describe how characters are feeling

- Use direct speech to show how characters are feeling

- Use a variety of language techniques to add interest to your writing (similes, metaphors, alliteration, onomatopoeia, strong verbs)

- Use a complex sentence to bring suspense to the story (For example, "While we were swimming a shark came into the bay".)

- Hook the reader in with a powerful first sentence (use action, description or speech)

Ideas:

- A sailor describes being on a ship during a storm

- A runner describes running the most important race of their life

- A school student describes being left out of games and standing alone in the playground

- A surfer describes being pushed towards the rocks

- A tramper is lost on the tops of the Tararua mountain range

Genre: Procedural Writing

Purpose: We are teaching our reader how to make or do something. We want our writing to be clear and easy to understand.

\section{Possible Success Criteria:}

- Include a useful title

- Explain all the steps

- Explain the steps in order

- Use clear language

- Use precise language

- Include a labelled diagram if this will help the reader to understand

Ideas: 
- Simple recipes (fruit kebabs, banana smoothies, cinnamon toast, fruit crumbles)

- Rules for favourite fitness games (KO, Octopus, Midnight)

- Crafts (salt dough decorations, butterfly prints, paper snowflakes)

- Science experiments or demonstrations relating to your current topic

\section{How to Structure Your Writing Lessons}

Use the same routines every day. This saves time and energy for you and your students.

Modelling every day is important, but keep your modelling short and focused.

Guided/independent writing time is very important. This is the students' practice time. Think of learning to ride a bike and the amount of practice time needed.

During guided/independent writing, the teacher needs to move quickly among the students, reminding them of their learning goals and using quick explanations, modelling and prompting to help support them. Think of 1 minute guiding time for each student.

Feedback is crucial. As it usually comes at the end of the lesson it is often rushed or forgotten. Do not make this mistake. Use the Fast Feedback conferences at least 2 times each week with every student.

The basic lesson structure, for a 50 minute writing lesson:

1. Modelling: Model and discuss learning goals ( 10 minutes, or 5 minutes for New Entrants).

2. Student Discussion Time: Students discuss their ideas using Think Pair Share (2 minutes).

3. Student planning: New Entrants and Year 1 writers practice their sentence aloud by telling it to the teacher. Older writers go to their tables to complete a simple written plan (3 minutes).

4. Guided/Independent writing. The teacher moves quickly about the room, prompting and guiding students to help them achieve their Fast Feedback goals (30 minutes).

5. Feedback: The teacher meets with individual students for a Fast Feedback conference. Students can also complete peer and self-assessment check sheets in this time (15 minutes).

You will notice that the time frames add up to 1 hour. However, the feedback time will overlap with the guided writing time, so that it is possible to complete the lesson in just 50 minutes. 


\section{How to Discuss Learning Goals with Your Students}

A goal discussion needs to happen at the beginning of every writing lesson, just before the teacher modelling. This discussion should take about 2 minutes.

First, discuss the text type and purpose for writing. For example: "Today we are writing spooky stories. We want our stories to be fun and interesting to read. One way to help to make our stories interesting is to include interesting characters. Let's all practise this today."

Second, remind students of their individual goals. For example: "We also need to remember to work hard on the goals in our writing books. Some people are practising spelling words perfectly by using their word cards. Other people are learning to write in perfect sentences, by reading and checking each sentence as they go."

\section{What Teacher Modelling Should Look Like}

Model every day but keep your model short (5-10 minutes per day). Be very clear and direct as you show students exactly what you want them to do in their own writing that day. Plan your model and discussion so that it focuses on the Fast Feedback goals.

At New Entrant to Year 2 level, the model could be 1-3 sentences long. From Year 3 up, the model could be 5-10 sentences long.

When you have students in the class who are using paragraphs, your model will also be organised in paragraphs. For these longer models, you may choose to write just one or two paragraphs per day.

Below are some examples of fiction and non-fiction models for the different year levels.

\section{New Entrant Level}

Baby Tiger was lost in the jungle. 
Sharks have sharp teeth.

Year 1-2 Level

Baby Seal has an Adventure

Baby seal was playing in a rock pool. Suddenly a big wave swept him out to sea. The water was dark and cold. His mother came to find him. He was safe.

The Sun

The sun is a huge ball of fire. It is much bigger than earth. Earth moves around the sun. It takes one year for earth to travel all the way around the sun.

Year 3-4 Level

The Lonely Witch

There was an old witch named Edris who lived alone in a cave. She was very skinny with a crooked nose and a wrinkled brow. People believed that she was evil and dangerous, and so they stayed away from her cave. Actually Edris was kind. She was lonely and longed for a friend.

One day a little black kitten wandered into the forest and was lost from her family. She cried and cried. Edris heard the crying and ran to find the little kitten. She gave the kitten food and milk and a warm blanket to sleep on. 
The kitten stayed with Edris for the rest of their lives. On warm days they played together in the forest. On cold nights they sat beside the fire. Edris was never lonely again.

\section{Water Can Change}

Water is all over planet earth. It is in the oceans, rivers, lakes and seas. It is in clouds, snow and ice too.

We usually think of water as moving and flowing. This is water in its liquid form.

When water is heated it turns into a gas. That means the water particles separate and rise up into the sky. This is what is happening when the jug boils and the steam goes up.

When water gets very cold it freezes. That means the water particles get closer together and stop moving. That is what is happening when water turns into ice.

\section{Year 5-6 Level}

Lost in the Ranges (unfinished)

The Tararua ranges are like a family of sleeping giants. On a still day they sleep peacefully, but in a storm they awaken, becoming wild, unpredictable and ruthless.

I had tramped in the Tararuas before, but this was my first expedition to the tops, where the bush turns to mountain tussock and the views stretch for miles in every direction. I was excited, pushing and panting my way up the hillside at a good pace. "Take it easy," warned my brother Pete, "You might need that energy later". He was right to be worried.

We reached the bush-line by mid-afternoon and were walking along the highest ridges by early evening. The weather had been perfect, and the views were exhilarating. Then, quite suddenly, 
the sky just changed. "I don't like the look of those clouds", said Pete, "I don't know if we can get to the hut before the storm hits".

\section{Volcanic Atolls}

Volcanic atolls are small islands made of coral, rock and sand. They are formed by submarine volcanoes. There are many volcanic atolls in the South Pacific.

These atolls were formed when the submarine volcanoes erupted. The lava from these volcanoes pushed up to the surface, then cooled and hardened. Coral grew on the rocks. Wind and waves caused erosion of the rocks and formed sand. Seeds, spread by the wind and birds, landed on the atolls and trees began to grow.

Volcanic atolls are often ring-shaped, with a lagoon in the centre of the ring. This shows the shape of the crater of the volcano that formed them.

So, if you are ever lucky enough to visit one of these peaceful and beautiful islands, remember that they were originally formed by a violent volcanic eruption.

\section{Teaching Students to Plan}

Model planning your own writing every day. Discuss your ideas with the class, and then, for Year 2 up, you may want to model completing a simple written plan too.

Always give students some time to plan using discussion. Use Think Peer Share every day. New Entrants and struggling writers could also practice saying their sentence to the teacher before writing. 
Do not use "thinking pictures" for New Entrants. They need to start their writing just after seeing the model and practising saying their sentence to the teacher. These children can illustrate their story at the end of writing instead.

From Year 2 onwards, students could begin to work on simple written plans. Use the planning templates included as an appendix to this manual.

\section{Guided Writing}

Asking students to write the date can be a major distraction from the main task. Buy a stamp and ask the students to stamp the page at the end of each day's work.

Encourage your students to write without talking. This will help them to focus on the complex writing process.

Move quickly from student to student, reminding them of their Fast Feedback goal and discussing or modelling to clarify this goal when necessary. Think of spending just 30 seconds with each student before moving on. You can return to the students who need extra support, later in the guided writing time.

Get your students to use pencils. Carry a rubber so that students can practice checking and correcting as they go. After some time using a rubber with the teacher's support, your students may be ready to be given their own rubbers to use.

\section{Teaching Spelling}

Spelling is not about memorisation. It is about teaching a set of useful strategies.

Useful spelling strategies include: listening to sounds in words, remembering common spelling patterns and rules, looking around the room for high frequency words, and using paper and online dictionaries to check unknown words. Students also need to get into the habit of looking at their spelling and asking "does it look right?"

\section{New Entrants/Teaching Phonemic Awareness}


For New Entrants, teaching spelling means teaching phonemic awareness. These beginning writers need to be able to listen to each small unit of sound in a word and choose a letter or letters to make those sounds.

Do this for 5 minutes a day using the junk box method (adapted from Barbara Brann). Put 3 toys in a junk box or kete and take them out one at a time.

Practice listening to each unit of sound in the word, and then record for the students the letters we use to make the sounds and spell the word. For example: t-r-u-ck

When New Entrants write in their books, approximations that have 1 or 2 correct sounds recorded are a great start. Record the correct version underneath the students writing and tick above all their letters that are the same. Praise, praise, praise.

The New Entrant level is quite unique for spelling. At this level, practising approximating spelling is very important, copying correct versions of high frequency words should not be taught until these students are able to record dominant sounds in unknown words.

Phonemic awareness is an important skill for spelling at all year levels. It is the starting point for students when using other spelling strategies.

\section{Spelling Patterns and Rules}

To teach spelling patterns and rules you need to set aside 10 minutes per day, outside of the main writing lesson. Choose one useful pattern or rule per week. On Monday, make a list of words with this pattern and then use this list for practice activities throughout the rest of the week.

Worthwhile practice activities include:

- Put the words into sentences to show their meanings

- Put the words into alphabetical order (this teacher a useful dictionary skill)

- Create a crossword or word find for a friend

- A teacher-led dictation of one or two sentences which include some of the list words.

- Create a dictation for a buddy 
If you are wondering where to start with teaching spelling patterns and rules, here are some useful lessons to begin with. They could be appropriate for students from Year 2 up:

- What vowels are (short and long)

- What consonants are

- What syllables are

- The sh, ch, th, ph "chunks"

- A silent e on the end of words with long vowels such as like, came, make, take, use, smoke

- Take the silent e away before adding ing

- Contractions

- Double the middle consonant when adding endings to short vowel, consonant words: pop/popping, skip/skipping, shop/shopping, run/running etc

- Words with an er ending

- The oi chunk is used in the middle of words, oy is used at the ends of words (noise/boy)

- Y as an ending "pretending" to be a vowel (fly, cry, by, my, sky, may, day, way, happy, skinny, lovely etc)

- Plural version of y ending words: If the y has a consonant before it, change the $y$ to an $\mathrm{i}$ and as es (fly - flies, sky - skies, family - families)

- Words like beautiful, until, bountiful, wonderful all have a single 1 .

- Words with ight, tion, alk, ould "chunks"

- The group of wa words: watch, was, want, what

- Using apostrophes for ownership

This list is short but the knowledge is useful for students. Beginning to study words in this way will give them a general awareness which should be helpful to them.

\section{Finding Correct Spellings to Copy/Dictionary Skills}

To teach looking for correct versions you need to have clear displays of high frequency words and model using them during shared writing. As students write and see the correct versions they will be more likely to remember them in the future.

To teach dictionary skills you need to remind students to listen to sounds carefully. If they can hear at least the first three sounds in a word and identify likely letters, this will make dictionary use much easier for them. Online dictionaries are also very helpful as they will suggest the correct version when a student types their own approximation of a word. 
Use your judgement about which strategies are most helpful to your students at any given time. Phonemic awareness must be in place before other strategies can be taught, even if the student is in Year 8.

Teach a strategy explicitly and then praise when you see a student using it. Do not correct every error in the draft book. Perhaps choose one error per day, record the correct version at the top of the page and ask the student to practice writing it as an independent activity at some time during the day. Give the students blackboards or whiteboards to make this practice more fun (and to avoid using massive amounts of paper).

\section{Spelling Resources}

For New Entrants, use individual alphabet cards.

For all junior students, make a large, clear wall display of high frequency words. Refer to this often. Teach students to find and copy the words when they need to.

For all junior students, an individual word card with high frequency words can also work well.

For junior and senior students, make a list of topic words available.

From about Year 4 on, dictionaries will become useful. Online dictionaries can be really helpful, as students can type in approximated spellings and the dictionary will suggest correct versions. Remember, students are not "cheating" when they look for and copy correct spellings. This actually takes quite a lot of effort and shows commitment. By writing correct spellings, student will be much more likely to eventually remember correct spellings.

\section{Teaching Handwriting}

Handwriting is a very important skill that needs to be taught effectively when students first start school. Ideally, New Entrant students will learn to form all lower case letters correctly and automatically in their first 6 months at school. 
If students have been taught handwriting well at New Entrant level, it should not need to be taught much beyond the first year of school.

If students in Year 2 and up are demonstrating some difficulty with handwriting, then address this as soon as possible. Handwriting difficulties can interfere with every other aspect of the writing process.

The very best programme for teaching handwriting is Barbara Brann's Casey the Caterpillar Programme. You can adapt this programme for remedial work with older students too.

When teaching handwriting, remember:

Teach correct pencil grip ("ducks beak, wings behind").

Teach correct formation (where to start, which way to move the pencil).

Teach by modelling first, and then get students to practice.

Use blackboards and short pieces of chalk for practice. The resistance of the blackboard helps motor memory. The short chalk encourages correct pencil grip.

Monitor students as they practice to avoid bad habits becoming established.

Teach groups of letters with similar formations at the same time:

- Round letters formed in an anticlockwise motion ("open mouth shape" include) c, a, d, g, e, s, q, o

- "Tunnel" letters include h, n, m

- "Possum tail" letters include y, g, j

- "Cup" letters include u, w, y

- "Closed tunnel" letters are b and p. Teach these after the open mouth shape letters are well learnt

\section{Teaching Sentence Structures and Punctuation}

I teach students to use a variety of sentence structures correctly by talking about what "sounds right". I have never taught grammatical rules. 
So, to teach intuitive understanding of the structure of compound or complex sentences, I would model re-reading and using think-alouds such as, "This is a long sentence, but it still sounds right. The ideas and words go together and I can take a breath at the end."

Remember that we all naturally speak in compound and complex sentences. They are not necessarily more difficult to write than simple sentences. Many New Entrants will choose to write compound or complex sentences on their first day at school. For example, a sentence such as, "After we went swimming we went to McDonalds."

If you did want to teach sentence structures more formally, here is a simple progression of key ideas to teach:

A simple sentence has a subject and a verb:

We were swimming.

Or

The sun was shining.

To make a compound sentence, you join two simple sentences together. These are now two clauses in one compound sentence.

We were swimming and the sun was shining.

In complex sentences, one clause is essential and one clause is less important.

One way to make a complex sentence is to use a subordinate conjunction at the beginning of the sentence. This will have the effect of making the first clause a subordinate clause (it cannot stand on its own as a complete thought).

Subordinate conjunctions include: after, although, as, because, before, even if, even though, if, in order, that, once, provided, that, rather, than, since, so that, than, though, unless, until, when, whenever, where, wherever, whether, while, why 
These complex sentences can be used to bring suspense to the sentence. For example, a complex sentence using the subordinate conjunction while:

While we were swimming a shark came into the bay.

Another way to make a complex sentence is by using a relative pronoun in the middle of the sentence.

Relative pronouns include: that, which, whichever, who, whoever, whom, whose, whomever

Here is an example of a complex sentence using the relative pronoun who:

The boy gave a handful of chips to the seagulls who were circling around the picnic table.

\section{Teaching Punctuation}

Teach students to hear the places where they need to use punctuation. Use lots of reading and re-reading your modelled writing aloud. Dictation can also be excellent for helping students to hear where different punctuation marks may be needed.

Full stops can be used by New Entrants on their first day at school. Aim for these students to write just one sentence each day, and get them to put a full stop at the end of that sentence. When a student is able to write 1 perfectly punctuated sentence you can then ask them to write more than one sentence. In this way, use of full stops will be learnt quickly within the first months at school.

If older students have developed a habit of writing many sentences without punctuation, get them slow down. Use the Fast Feedback goal of reading and checking every sentence as they write (think of an idea, write it, check that it sounds right, check that it has a capital letter and a full stop).

More complex punctuation (commas, exclamation marks and question marks), are best introduced during shared reading. During writing modelling time, I make a brief comment only to explain their use. 
To explain a comma, I would say: "I think we need to take a little breath here to help the sentence sound right and make sense."

To explain an exclamation mark, I would say: "I am going to use an exclamation mark at the end of this sentence because it is such an exciting moment in the story."

To explain a question mark, I would say: "This is a question, so we need to use a question mark at the end of the sentence."

Teach speech marks while working on narrative text, and give a clear purpose for their use. Use the Fast Feedback goal for direct speech (I am learning to use direct speech to show how my characters are feeling). Model and discuss the correct ways to use speech marks, give the students many opportunities for practice, and give feedback using the Fast Feedback conference.

Even when you are teaching punctuation in this way, it is always helpful to have a basic understanding of the conventions and rules. Commas can be tricky, so here are some simple guidelines for their use:

\section{Commas}

- Use them when listing three or more items.

- Use them to bring clarity to certain sentences.

- Use them after introductory words in a sentence. For example: Suddenly, the ground started to shake.

- Use them for adding non-essential information to a sentence. For example: Tamati, forgetting it was a holiday, got ready for school as usual.

- You can use commas after the first clause in a compound sentence. For example: I love water sports, and I particularly love surfing. Do not use them in a compound sentence without a conjunction. Use a full stop instead. 
APPENDIX IV: Graphic Organizers 


\section{Buddy Writing Checks (fluent goals)}

Explanation Writing Buddy Check Sheet Writer:

Date:

Buddy:

- Is the writing factual?

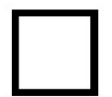

- Is the writing clear?

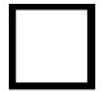

- Is the writing interesting?

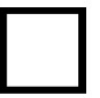

Story Writing Buddy Check Sheet

Writer:

Date:

Buddy:

- Does the story have characters?

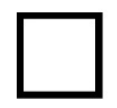

- Does the story have a setting?

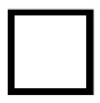

- Does the story have a problem? 


\section{Paragraph Writing Checks}

\section{Paragraph Writing Check Sheet}

Name:

Date:

- Are all the sentences about 1 subtopic grouped together?

- Did I leave a line in between paragraphs?
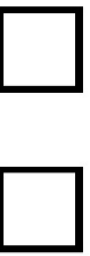

Paragraph Writing Check Sheet

Name:

Date:

- Did I introduce the topic in paragraph 1?

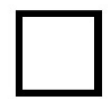

- Did I give information about subtopics in paragraphs 2 and 3 ?

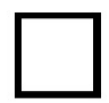

- Did I end with a interesting conclusion?

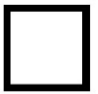




\section{Early Goals Self Assessment Check Sheets}

\section{Sentence Writing Check Sheet}

Name:

Date:

- Can I put all the words together when

I read each sentence aloud?

- Do my sentences start with capital letters?

- Do my sentences end with full stops?
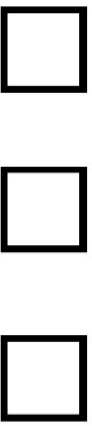

\section{Sentence Writing Check Sheet}

Name:

Date:

- Do the ideas and words in each sentence belong together?

- Do my sentences start with capital letters?
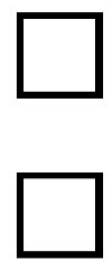

- Do my sentences end with full stops?

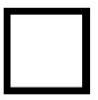




\section{Early Goals Self Assessment Check Sheets}

\section{Re-reading to Check Check Sheet}

Name:

Date:

- Do my sentences sound right?

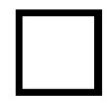

- Do my sentences make sense?

- Have I used capital letters and full stops for every sentence?
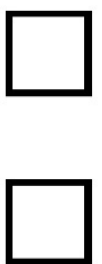

\section{Thoughtful Spelling Check Sheet}

Name:

Date:

- Did I check every unknown word?

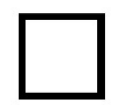

- What resource did I use for checking today?

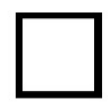

word card

classroom

friend or walls teacher 
Early Goals Self Assessment Check Sheets

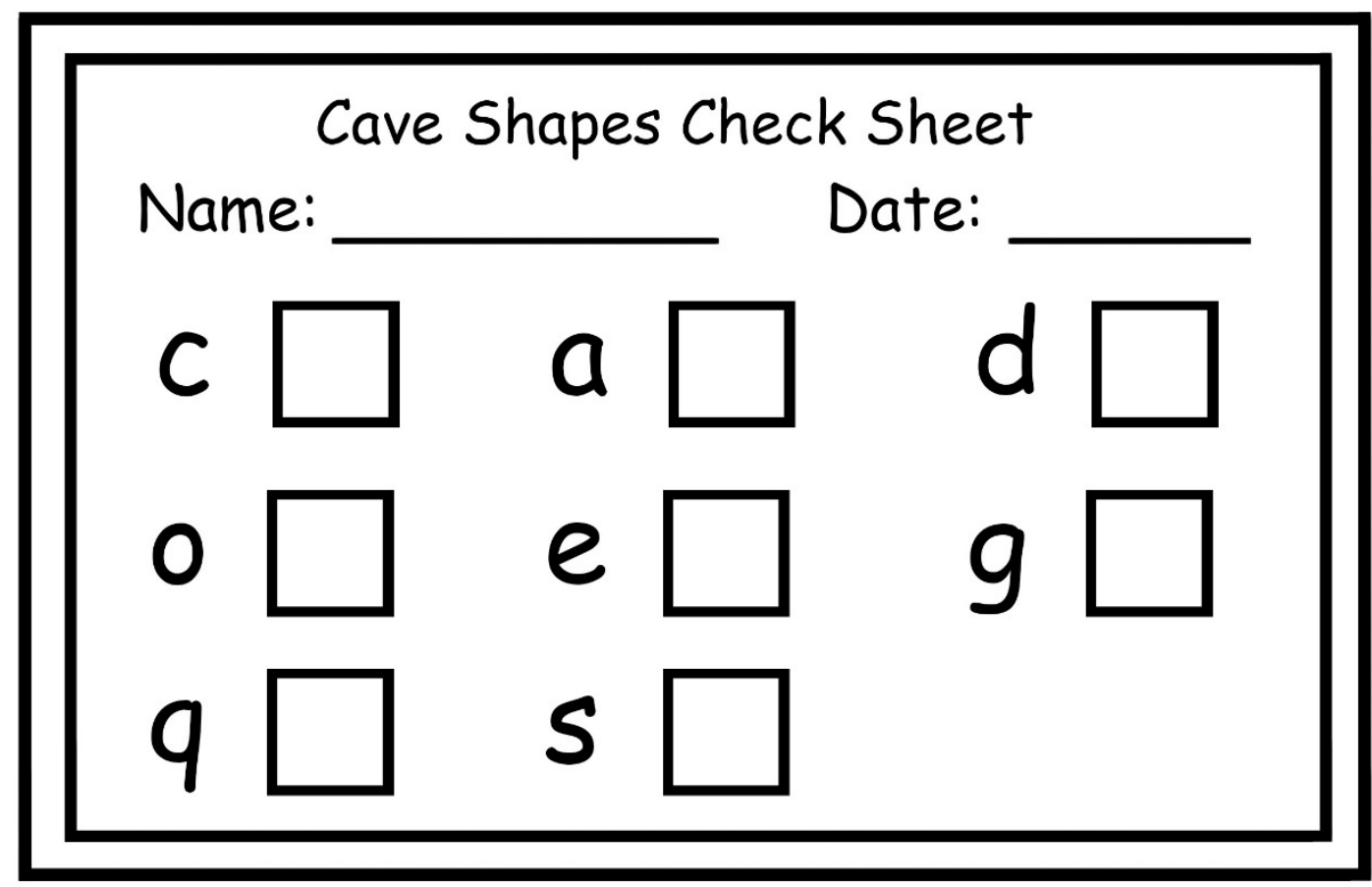

Fish Hook Shapes Check Sheet

Name:

Date:

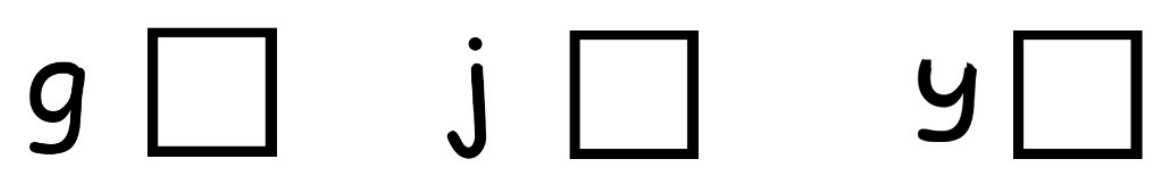

Closed Tunnel Shapes Check Sheet

Name:

Date:
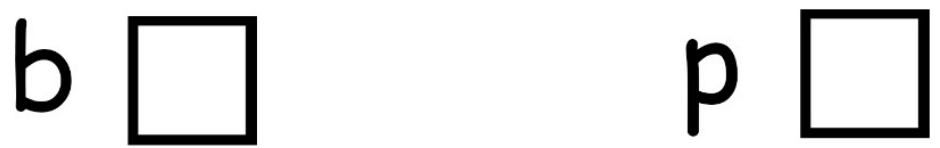


\section{Self Assessment Sheet}

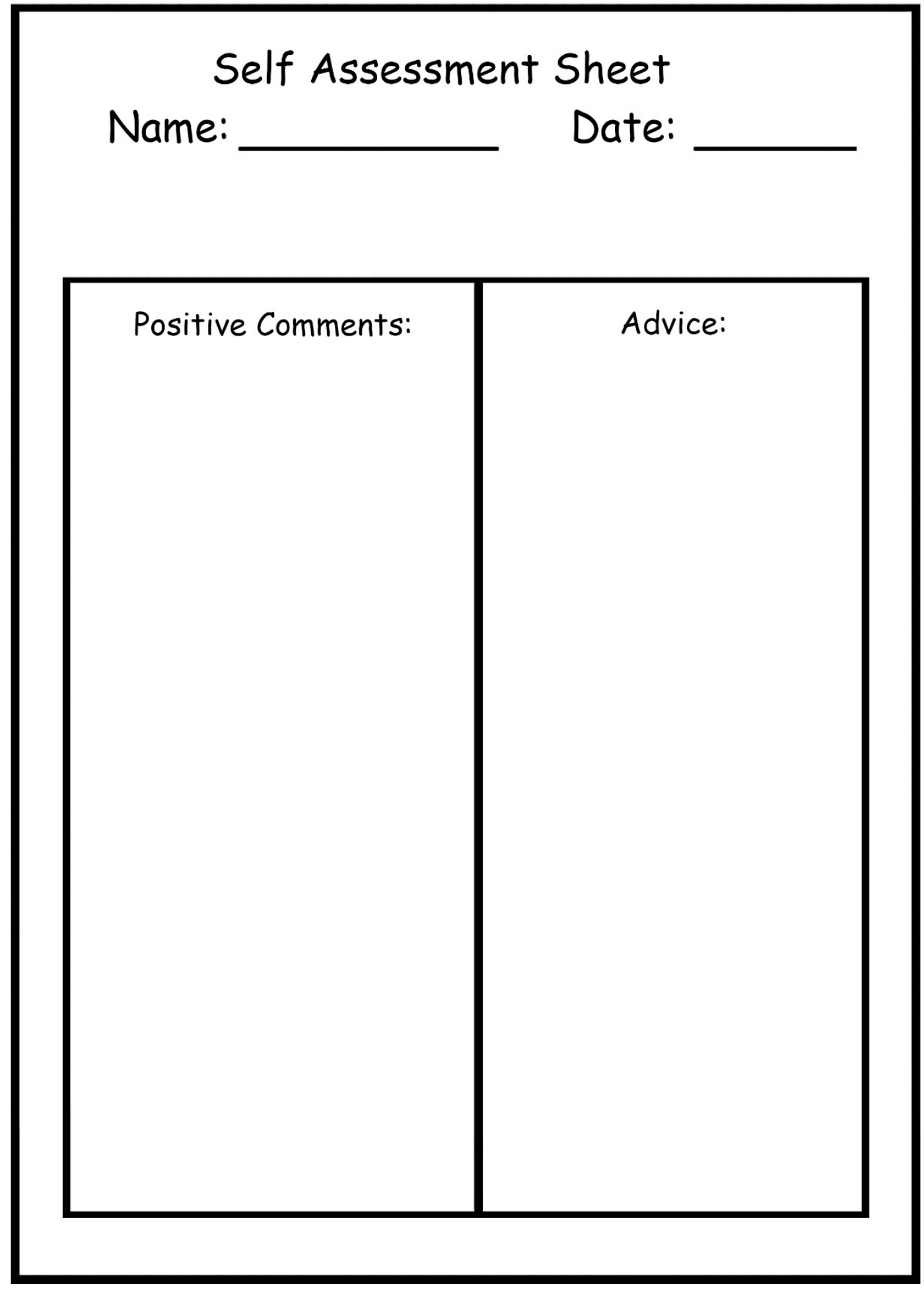




\section{Comment Sheet}

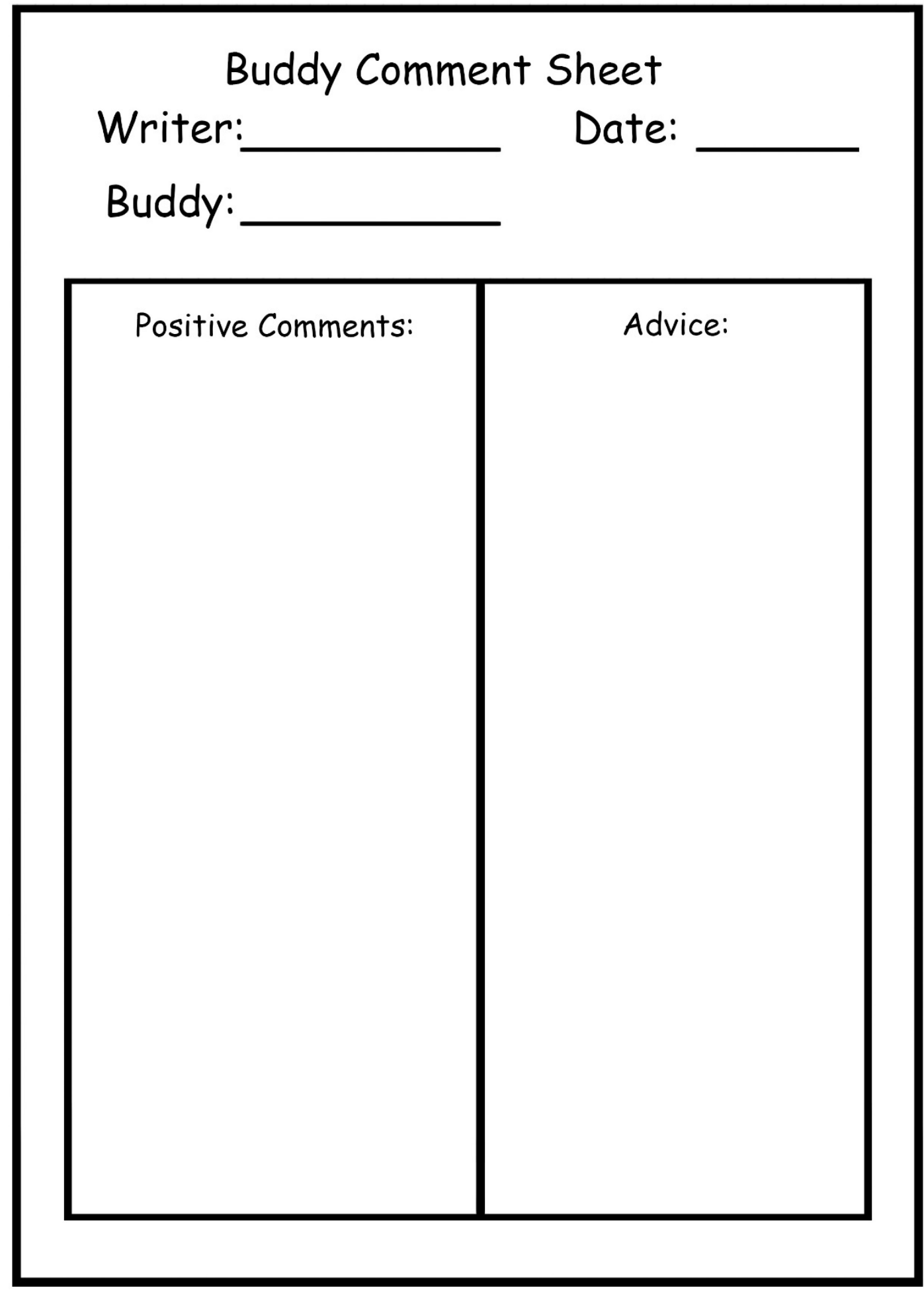




\section{Blank Writing Checks}

Buddy Check Sheet: Writer:

Date:

Buddy:
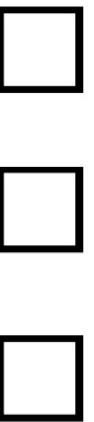

Self Assessment Check Sheet:

Name:

Date:
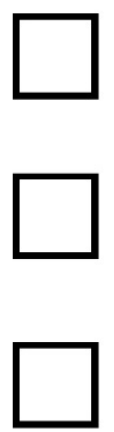
Explanation Writing Planning Template (Junior)

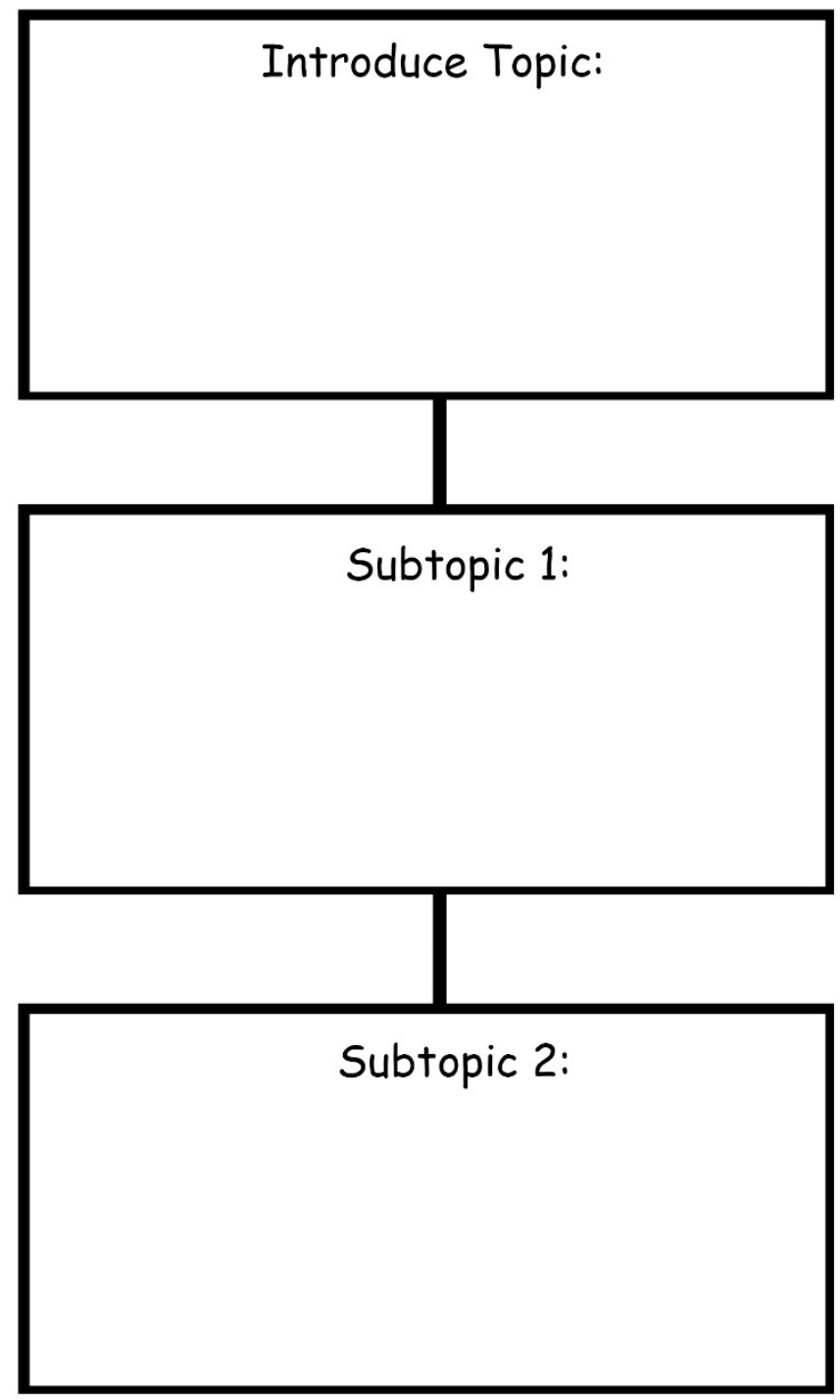




\section{Explanation Writing Planning Template (Senior)}

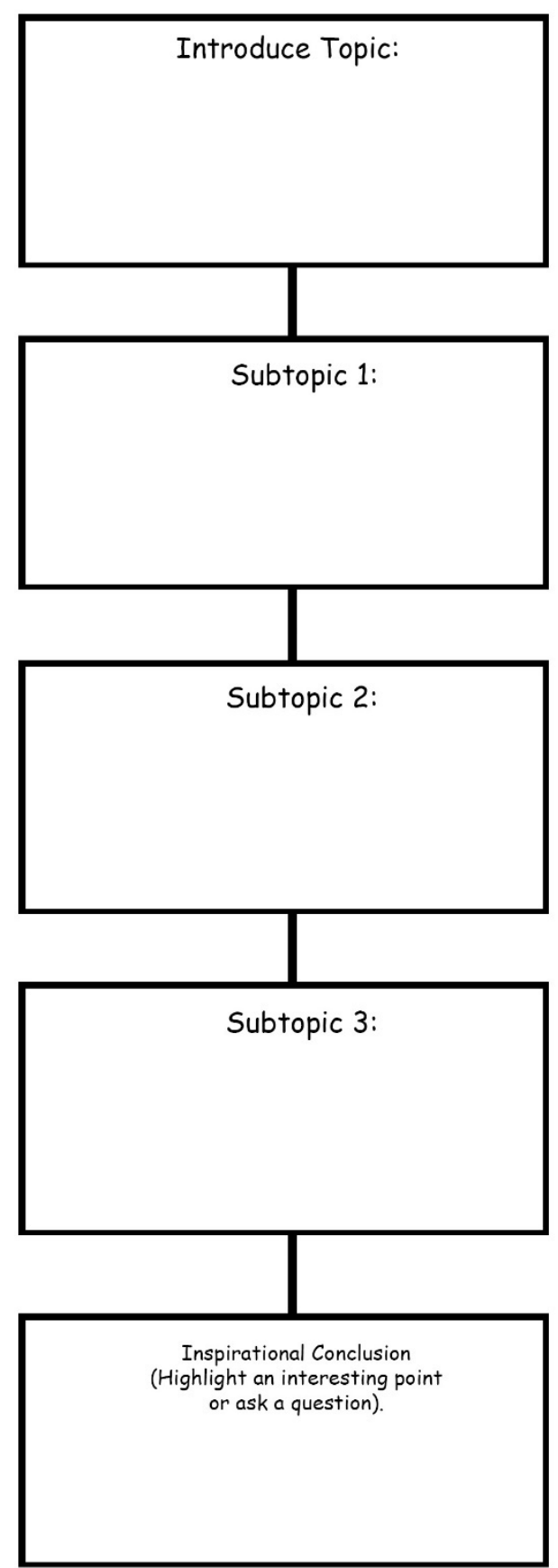




\section{Story Web Planning Template}

(Junior)

Adapted from Hilton Ayrey

Title:

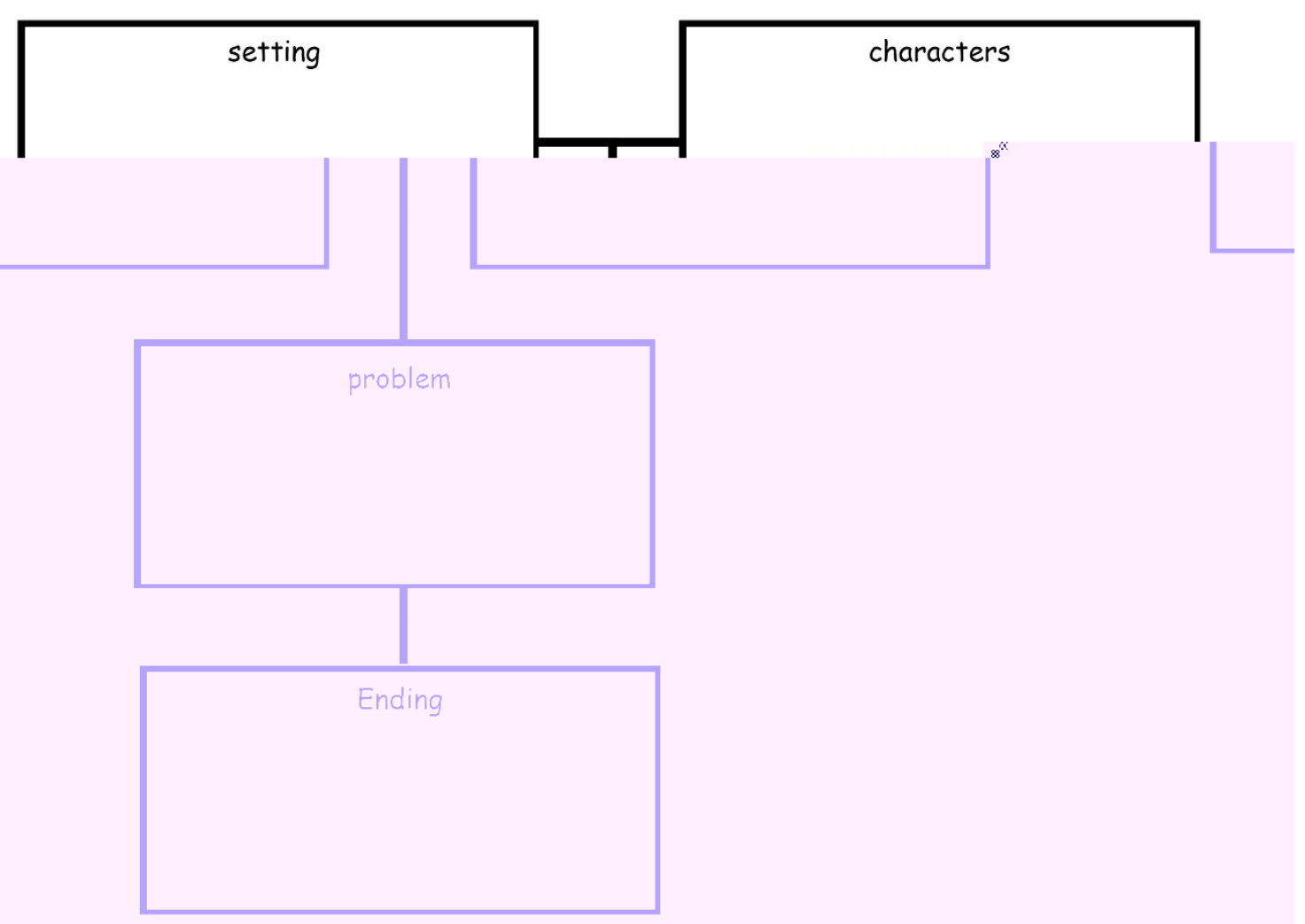




\section{Story Web Planning Template \\ (Senior)}

Adapted from Hilton Ayrey

Title:

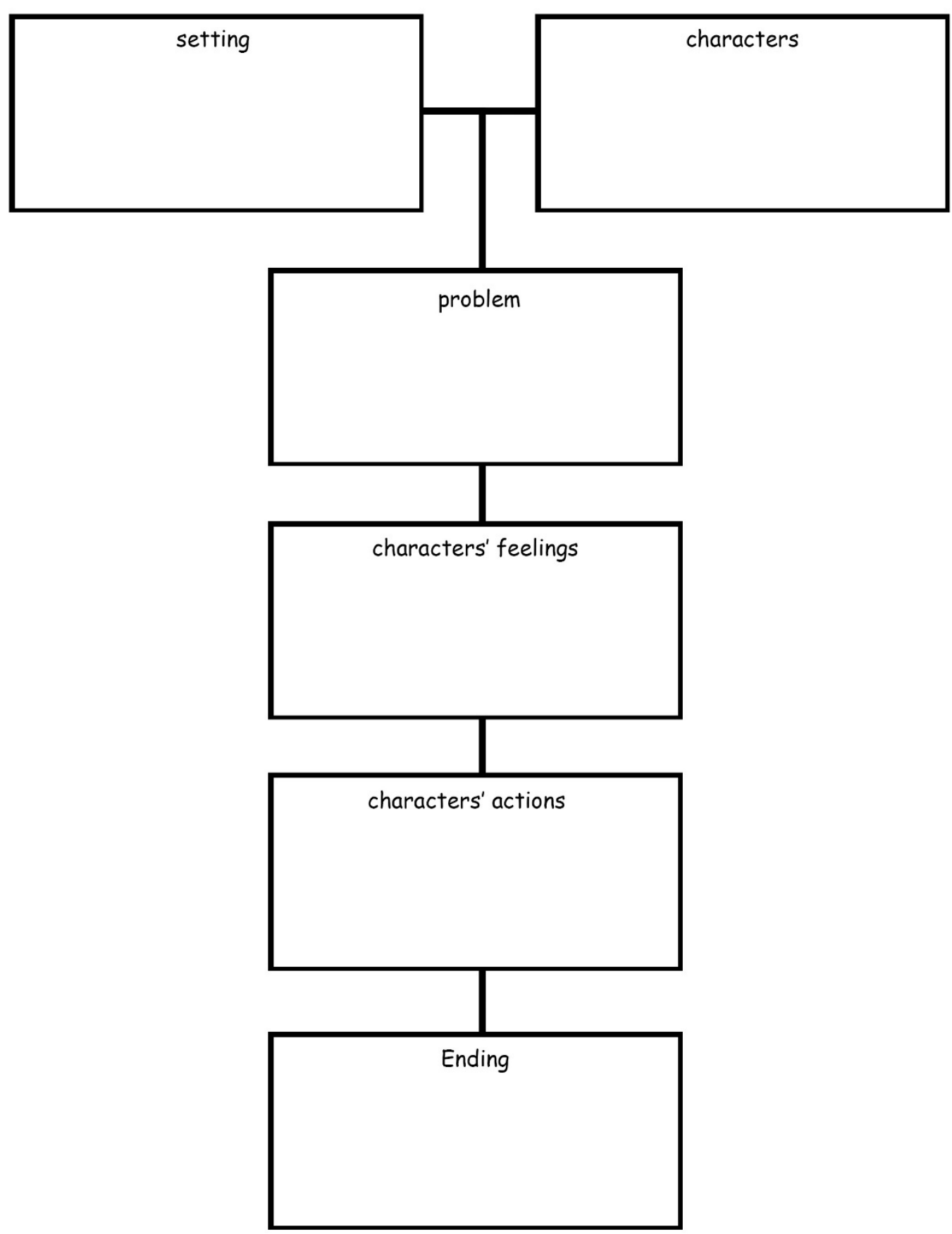




\section{Planning Template (Junior)}

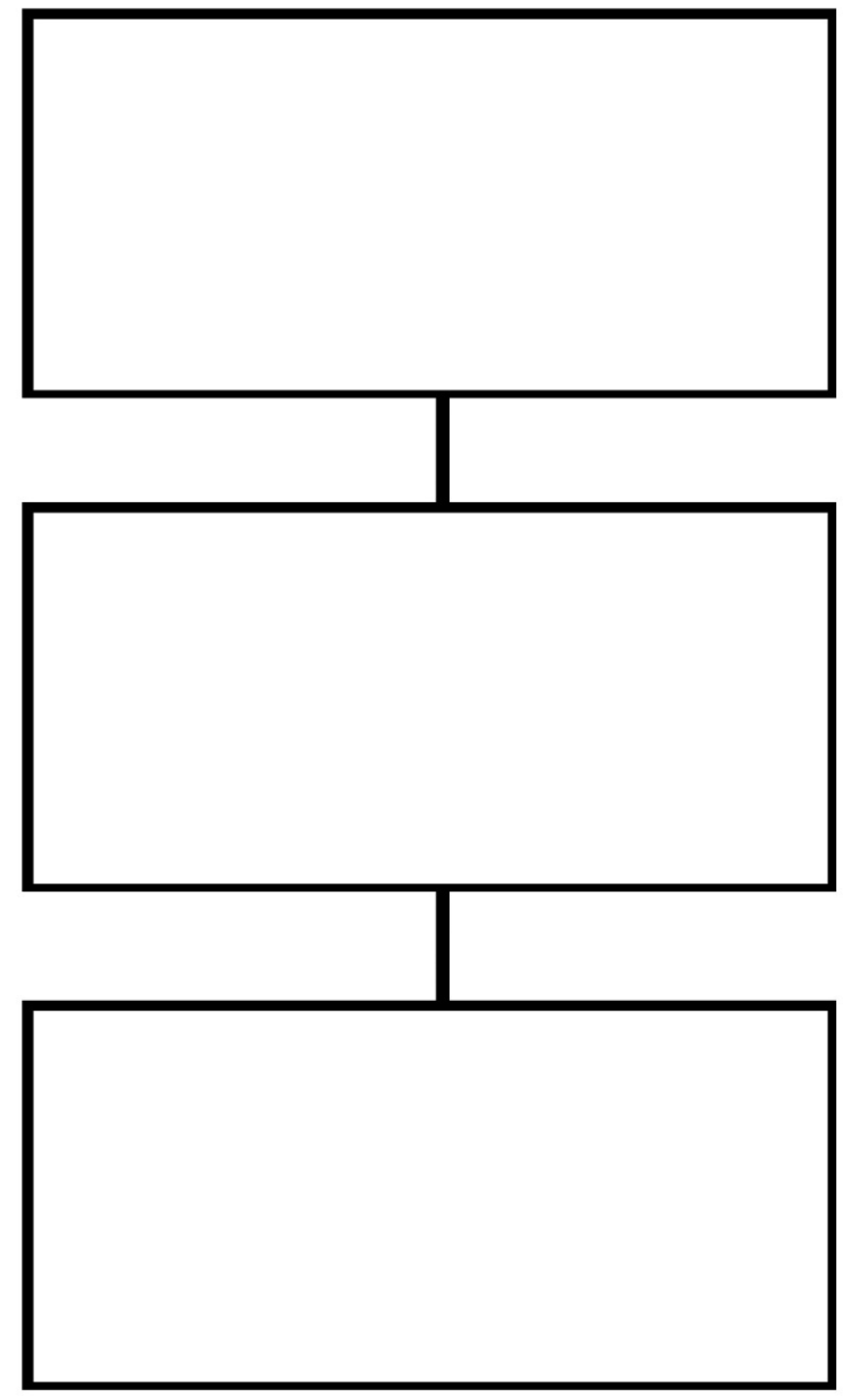


Planning Template

(Senior)

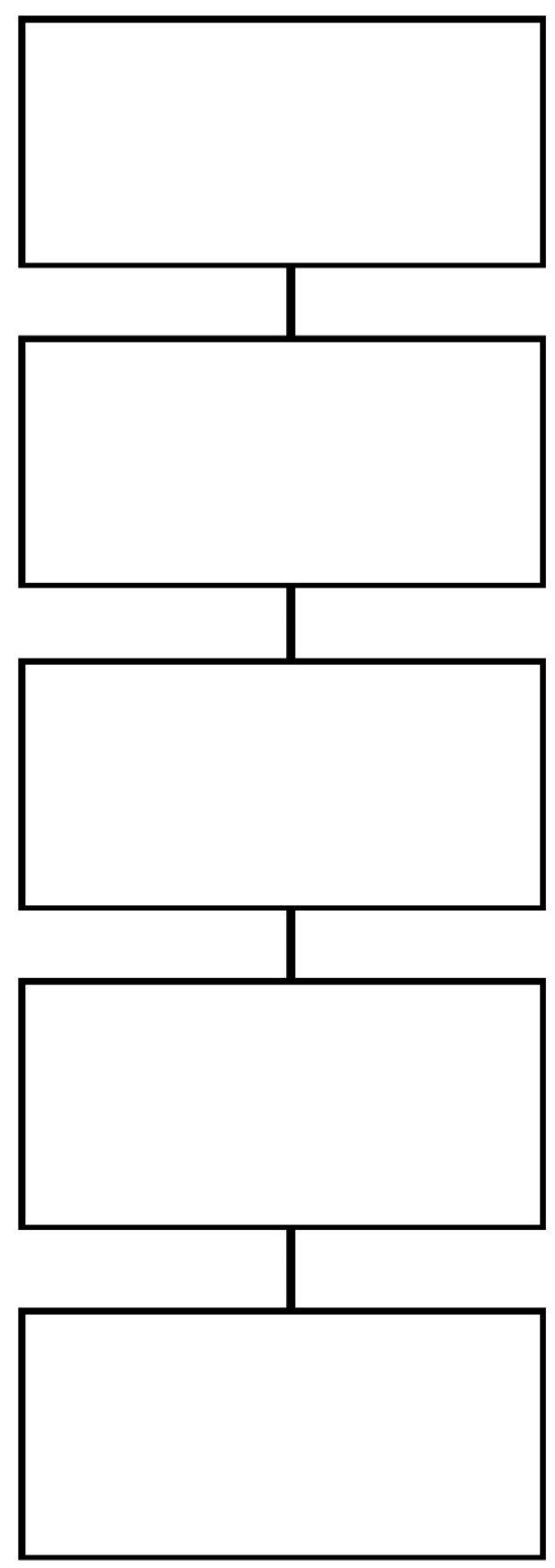


APPENDIX V: Student Survey

How helpful was Fast Feedback for your learning?

1: not helpful 2: a little helpful 3. helpful $\quad 4$. very helpful

Comments: 


\section{Teachers' Beliefs and Practices for Writing Instruction \\ INFORMATION SHEET FOR TEACHER PARTICIPANTS - SURVEY}

You are invited to take part in this research. Please read this information before deciding whether or not to take part. If you decide to participate, thank you. If you decide not to participate, thank you for considering this request.

\section{Who am I?}

My name is Helen Walls and I am a Doctoral student in the education programme at Victoria University of Wellington. This research project is work towards my thesis.

\section{What is the aim of the project?}

This project will investigate teachers' beliefs about teaching writing, and whether these beliefs impact on their classroom practice. It will also investigate whether certain beliefs and teaching practices lead improvements in student achievement.

The starting point for this research was a survey of a large number of teachers, focusing on their beliefs about teaching writing.

This research has been approved by the Victoria University of Wellington Human Ethics Committee (reference number 0000025517).

\section{How can you help?}

You have been invited to participate in a survey of New Zealand primary teachers. You have been chosen because you teach in one of the junior year levels (Years 1-4). You can withdraw from the study by contacting me at any time before the $1^{\text {st }}$ of October, 2018. If you withdraw, the information you provided will be destroyed.

\section{What will happen to the information you give?}

This research is confidential ${ }^{*}$. This means that the researcher named below will be aware of your identity but the research data will be combined and your identity will not be revealed in any reports, presentations, or public documentation. 
Only my supervisors and I will read the information you provide. It will be kept securely and destroyed on the $1^{\text {st }}$ of January 2019.

\section{What will the project produce?}

The information from my research will be used in my $\mathrm{PhD}$ dissertation and possibly for academic publications and conferences.

\section{If you accept this invitation, what are your rights as a research participant?}

You do not have to accept this invitation if you don't want to.

If you have any questions or problems, who can you contact?

If you have any questions, either now or in the future, please feel free to contact either me or one of my supervisors:

\section{Student:}

Name: Helen Walls

University email address:

Helen.walls@vuw.ac.nz

\section{Supervisor:}

Name: Dr Vivien Van Rij

Role: Lecturer, Faculty of Education

School: Education

Phone: 044721000

vivien.vanrij@vuw.ac.nz

\section{Supervisor:}

Name: Dr Michael Johnston

Role: Senior Lecturer, Faculty of Education

School: Education

Phone: 044721000

Michael.johnston@vuw.ac.nz

\section{Human Ethics Committee information}

If you have any concerns about the ethical conduct of the research you may contact the Victoria University HEC Convenor: Associate Professor Susan Corbett. Email susan.corbett@vuw.ac.nz or telephone +64-4-463 5480 . 


\title{
Teachers' Beliefs and Practices for Writing Instruction \\ INFORMATION SHEET FOR TEACHER PARTICIPANTS - INTERVIEWS
}

\begin{abstract}
You are invited to take part in this research. Please read this information before deciding whether or not to take part. If you decide to participate, thank you. If you decide not to participate, thank you for considering this request.
\end{abstract}

\section{Who am I?}

My name is Helen Walls and I am a Doctoral student in the education programme at Victoria University of Wellington. This research project is work towards my thesis.

\section{What is the aim of the project?}

This project will investigate teachers' beliefs about teaching writing, and whether these beliefs impact on their classroom practice. It will also investigate whether certain beliefs and teaching practices lead improvements in student achievement.

The starting point for this research was a survey of a large number of teachers, focusing on their beliefs about teaching writing. In this second stage of research, I hope to work in an in-depth way with some of the teachers whose survey responses were representative of a large group of respondents, in order to establish whether beliefs align with teaching practice, and whether certain beliefs are associated with better outcomes for students. In order to address these questions, I will ask teachers to self-record a writing lesson, participate in an interview about their beliefs and practices, and supply anonymous student-writing samples.

This research has been approved by the Victoria University of Wellington Human Ethics Committee (reference number 0000025517).

\section{How can you help?}

You have been invited to participate because your survey responses were representative of a large group of the teachers who responded. If you agree to take part I will interview you at your school. I will ask you questions about your teaching methods, and why you use them. The interview will take 30 minutes. I will audio record the interview with your permission and write it up later. You can choose to not answer any question or stop the interview at any time, without giving a reason. You 
can withdraw from the study by contacting me at any time before the $1^{\text {st }}$ of October, 2018 . If you withdraw, the information you provided will be destroyed or returned to you.

\section{What will happen to the information you give?}

This research is confidential ${ }^{*}$. This means that the researcher named below will be aware of your identity but the research data will be combined and your identity will not be revealed in any reports, presentations, or public documentation.

Only my supervisors and I will read the notes or transcript of the interview. The interview transcripts, summaries and any recordings will be kept securely and destroyed on the $1^{\text {st }}$ of January 2019.

\section{What will the project produce?}

The information from my research will be used in $\mathrm{my} \mathrm{PhD}$ dissertation and possibly for academic publications and conferences.

\section{If you accept this invitation, what are your rights as a research participant?}

You do not have to accept this invitation if you don't want to. If you do decide to participate, you have the right to:

- $\quad$ choose not to answer any question;

- $\quad$ ask for the recorder to be turned off at any time during the interview;

- $\quad$ withdraw from the study before the $1^{\text {st }}$ of March 2018;

- $\quad$ ask any questions about the study at any time;

- $\quad$ receive a copy of your interview recording;

- $\quad$ receive a copy of your interview transcript;

- $\quad$ be able to read any reports of this research by emailing the researcher to request a copy.

If you have any questions or problems, who can you contact?

If you have any questions, either now or in the future, please feel free to contact either me or one of my supervisors:

\footnotetext{
* Confidentiality will be preserved except where you disclose something that causes me to be concerned about a risk of harm to yourself and/or others. [include if appropriate for your research]
} 


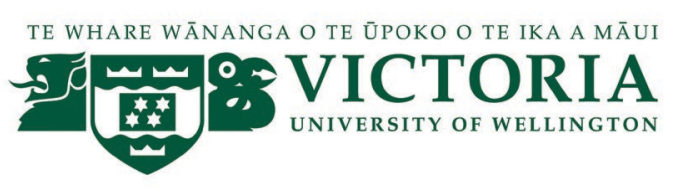

\title{
Teachers' Beliefs and Practices for Writing Instruction
}

\author{
INFORMATION SHEET FOR PRINCIPALS
}

Your teacher has been invited to take part in this research. Please read this information before deciding whether or not they may take part. If you agree to their participation, thank you. If you do not agree, thank you for considering this request.

\section{Who am I?}

My name is Helen Walls and I am a Doctoral student in the education programme at Victoria University of Wellington. This research project is work towards my thesis.

\section{What is the aim of the project?}

This project will investigate teachers' beliefs about teaching writing, and whether these beliefs impact on their classroom practice. It will also investigate whether certain beliefs and teaching practices lead to improvements in student achievement.

This research has been approved by the Victoria University of Wellington Human Ethics Committee (reference number 0000025517).

\section{How can you help?}

Your teacher has been invited to participate because their survey responses were representative of a large group of the teachers who responded. If you agree to their participation, I will ask them to video themselves teaching a writing lesson for 45 minutes. I will supply the video recording device. I will then follow up with a face to face interview. I would also request to photograph anonymous writing samples from six students in the participating teacher's class at two time points - once at the beginning of term 2, 2018, and once at the end of term 3, 2018. Parents in this class will be provided with detailed information about the study, and will be asked for consent for their child to be videoed and for their writing samples to be photographed. You can withdraw your teacher from the study by contacting me at any time before the $1^{\text {st }}$ of October, 2018. If you withdraw, the videos your teacher provided will be destroyed or returned to them.

\section{What will happen to the information you give?}


This research is confidential*. This means that the researcher named below will be aware of your teacher's identity but the research data will be combined and their identity will not be revealed in any reports, presentations, or public documentation.

Only my supervisors and I will view the recording. It will be kept securely and destroyed on the $1^{\text {st }}$ of January 2019.

\section{What will the project produce?}

The information from my research will be used in my PhD dissertation and possibly for academic publications and conferences.

\section{If you accept this invitation, what are your rights as a research participant?}

You do not have to accept this invitation if you don't want to. If you do decide to allow your teachers to participate, you have the right to:

- $\quad$ withdraw from the study before the $1^{\text {st }}$ of October 2018;

- $\quad$ ask any questions about the study at any time;

- $\quad$ be able to read any reports of this research by emailing the researcher to request a copy.

\section{If you have any questions or problems, who can you contact?}

If you have any questions, either now or in the future, please feel free to contact either me or one of my supervisors:

\section{Student:}

Name: Helen Walls

University email address:

Helen.walls@vuw.ac.nz

\section{Supervisor:}

Name: Dr Vivien Van Rij

Role: Lecturer, Faculty of Education

School: Education

Phone: 044721000

vivien.vanrij@vuw.ac.nz

\section{Supervisor:}

Name: Dr Michael Johnston

Role: Senior Lecturer, Faculty of Education

School: Education

Phone: 044721000

Michael.johnston@vuw.ac.nz 


\section{Human Ethics Committee information}

If you have any concerns about the ethical conduct of the research you may contact the Victoria University HEC Convenor: Associate Professor Susan Corbett. Email susan.corbett@vuw.ac.nz or telephone +64-4-463 5480 . 


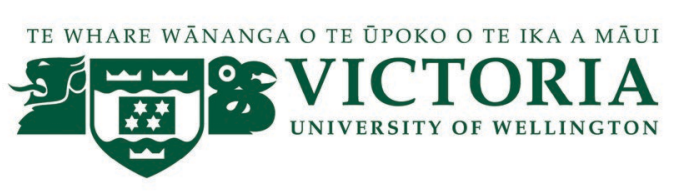

\section{Teachers' Beliefs and Practices for Writing Instruction}

\section{CONSENT TO INTERVIEW}

This consent form will be held for 2 years.

Researcher: Helen Walls, Victoria University of Wellington.

- I have read the Information Sheet and the project has been explained to me. My questions have been answered to my satisfaction. I understand that I can ask further questions at any time.

- I agree to take part in an audio recorded interview.

I understand that:

- I may withdraw from this study at any point before the $1^{\text {st }}$ of October, 2018 , and any information that I have provided will be returned to me or destroyed.

- $\quad$ The identifiable information I have provided will be destroyed on the $1^{\text {st }}$ of January 2019 .

- $\quad$ Any information I provide will be kept confidential to the researcher and the supervisors.

- I understand that the results will be used for a PhD dissertation and academic publications and/or presented to conferences.

- My name will not be used in reports, nor will any information that would identify me.

- I would like a copy of the recording of my interview:

Yes $\square \quad$ No

- I would like a copy of the transcript of my interview:

Yes $\square \quad$ No

- I would like to receive a copy of the final report and have added my email

Yes No address below.

Signature of participant:

Name of participant: 
Date:

Contact details: 


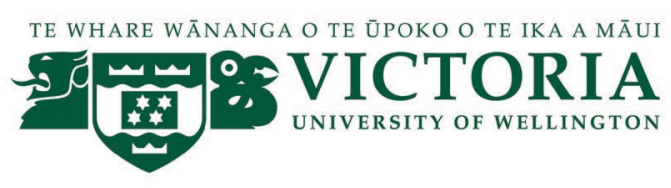

\section{Teachers' Beliefs and Practices for Writing Instruction \\ INFORMATION SHEET FOR PARTICIPANTS}

You are invited to take part in this research. Please read this information before deciding whether or not to take part. If you decide to participate, thank you. If you decide not to participate, thank you for considering this request.

\section{Who am I?}

My name is Helen Walls and I am a Doctoral student in the education programme at Victoria University of Wellington. This research project is work towards my thesis.

\section{What is the aim of the project?}

This project will investigate teachers' beliefs about teaching writing, and whether these beliefs impact on their classroom practice. It will also investigate whether certain beliefs and teaching practices lead improvements in student achievement.

This research has been approved by the Victoria University of Wellington Human Ethics Committee (reference number 0000025517).

\section{How can you help?}

You have been invited to participate because your survey responses were representative of a large group of the teachers who responded. If you agree to take part I will interview you at your school. I will ask you questions about your teaching methods, and why you use them. The interview will take 30 minutes. I will audio record the interview with your permission and write it up later. You can choose to not answer any question or stop the interview at any time, without giving a reason. You can withdraw from the study by contacting me at any time before the $1^{\text {st }}$ of October, 2018. If you withdraw, the information you provided will be destroyed or returned to you.

\section{What will happen to the information you give?}

This research is confidential* This means that the researcher named below will be aware of your identity but the research data will be combined and your identity will not be revealed in any reports, presentations, or public documentation.

\footnotetext{
* Confidentiality will be preserved except where you disclose something that causes me to be concerned about a risk of harm to yourself and/or others. [include if appropriate for your research]
} 
Only my supervisors and I will read the notes or transcript of the interview. The interview transcripts, summaries and any recordings will be kept securely and destroyed on the $1^{\text {st }}$ of January 2019.

\section{What will the project produce?}

The information from my research will be used in my $\mathrm{PhD}$ dissertation and possibly for academic publications and conferences.

\section{If you accept this invitation, what are your rights as a research participant?}

You do not have to accept this invitation if you don't want to. If you do decide to participate, you have the right to:

- $\quad$ choose not to answer any question;

- $\quad$ ask for the recorder to be turned off at any time during the interview;

- $\quad$ withdraw from the study before the $1^{\text {st }}$ of March 2018;

- $\quad$ ask any questions about the study at any time;

- $\quad$ receive a copy of your interview recording;

- $\quad$ receive a copy of your interview transcript;

- be able to read any reports of this research by emailing the researcher to request a copy.

\section{If you have any questions or problems, who can you contact?}

If you have any questions, either now or in the future, please feel free to contact either me or one of my supervisors: 


\section{APPENDIX XI: Fast Feedback Consent for Parents}

Consent to Participate in Research:

\section{The 2015 Fast Feedback Research Project}

Attached is an explanation of this research project. The researchers are available to answer further questions and you may withdraw your child, before $10^{\text {th }}$ of December 2015, without having to give reasons.

Any information about your child will be kept confidential to the researcher and the supervisors. Published results will not use the names of children or teachers.

Information from this research will not be used for any other purpose or released to others without consent.

If you would prefer for your child not to be included in this study, please record their name in the space provided and return this form to the class teacher.

I do not wish for my child to take part in the Fast Feedback project.

Student name:

Signed:

Date: 


\section{APPENDIX XII: Fast Feedback Information for Students}

\section{Information Sheet: The Fast Feedback Research Project}

Dear Students,

I am a Masters student at Victoria University of Wellington. I am studying the ways teachers talk to children about their learning.

Your teacher has offered to help with my study. Over the next 2 terms, I will be talking with your teacher about your progress with writing, and we will be thinking about ways to talk with you about your progress. I hope this will help you to learn quickly.

I will also be looking at the writing you do over the year, to see what helps you to achieve your goals. I will not show your writing to anybody except my own 2 teachers at the university.

If you do not want me to talk with your teacher about your writing, or to look at your writing, you can tell me or your teacher at any time. It is up to you and we will be happy with any decision you make.

If you have any questions please talk to your teacher and we will try to answer them clearly for you.

Regards,

Helen Walls 


\section{APPENDIX XIII: Fast Feedback Information for Parents}

\section{Information Sheet: The Fast Feedback Research Project}

Dear Parents,

I am enrolled as a Masters student at Victoria University of Wellington. I am researching teacher feedback on student writing as part of my course. This research project has received approval from the Victoria University Human Ethics Committee.

Your child's teacher has offered to help with this project. Over the next 2 terms, I will be talking with this teacher about the progress students in the class are making, and offering advice about how to give information to the students themselves about their progress. I hope that by giving clear and positive information to students they will be able to achieve learning goals quickly and easily.

In order to assess student achievement I will collect writing samples and attitude scores from the students. These samples will remain anonymous and will be kept confidential. No other person besides me and my two supervisors (Vivien Van Rij and Michael Johnston) will see the writing samples or interview notes. The thesis will be submitted for marking to the School of Education and deposited in the University Library. All data will be destroyed five years after the end of the project.

Should any participants feel the need to withdraw from the project, they may do so without question at any time, before the $10^{\text {th }}$ of December 2015. Just let me know at the time.

If you have any further questions or would like to receive further information about the project, please contact me (022 171 9682, or Helen.Walls@vuw.ac.nz); or my supervisors, Dr Michael Johnston (michael.johnston@vuw.ac.nz,463 9675) and Vivien Van Rij (vivien.vanrij@vuw.ac.nz, 463 9706), at the School of Education at Victoria University. 
Regards,

Helen Walls 


\section{APPENDIX XIV: Fast Feedback Information Control School}

\section{Information Sheet: The Fast Feedback Research Project}

I am enrolled as a Masters student in the EDUC 585 dissertation programme at Victoria University of Wellington. The Fast Feedback project will form the basis of my thesis. This research aims to investigate the use of feedback on the progress of low achieving writers in three Wellington Schools. This research project has received approval from the Victoria University Human Ethics Committee.

In order to assess student achievement I will be collecting unassisted samples from participating and control group students. I will collect these samples from the first and last writing assessments the students complete in 2015.

Thank you for offering to help with the control group samples. Early in term 2 I will email you with exact numbers of the student samples I need from the specified year levels. This could be up to 10 samples from each of the year levels.

It will not be possible for students or teachers to be identified personally in my reporting of the data. All material collected will be kept confidential. No other person besides me and my two supervisors (Vivien Van Rij and Michael Johnston) will see the writing samples or interview notes. The thesis will be submitted for marking to the School of Education and deposited in the University Library. All data will be destroyed five years after the end of the project.

Should any participants feel the need to withdraw from the project, they may do so without question at any time, before the $10^{\text {th }}$ of December 2015. Just let me know at the time.

If you have any further questions or would like to receive further information about the project, please contact me (022 171 9682, or Helen.Walls@vuw.ac.nz); or my supervisors, Dr Michael Johnston (michael.johnston@vuw.ac.nz, 463 9675) and Dr Vivien Van Rij (vivien.vanrij@vuw.ac.nz 463 9706), at the School of Education at Victoria University. 
Regards,

Helen Walls 


\section{APPENDIX XV: Fast Feedback Consent Form for Principals}

Consent to Participate in Research:

\section{The 2015 Fast Feedback Research Project}

I have been given and have understood an explanation of this research project. I have been given an opportunity to ask questions and have them answered to my satisfaction. I understood that I may withdraw myself, or any information I have provided, before $10^{\text {th }}$ of December 2015, without having to give reasons.

I understand that any information participants provide will be kept confidential to the researcher and the supervisors. I understand the published results will not use the names of participants and that no opinions will be attributed to them in any way that will identify them.

I understand that the data provided will not be used for any other purpose or released to others without consent.

I agree that (names), who are under my guardianship, may take part in this research.

Signed:

Name:

Date: 


\section{APPENDIX XVI: Fast Feedback Information for Teachers and Principals}

\section{Information Sheet: The Fast Feedback Research Project}

Dear Fast Feedback Teachers and Principals,

I am now enrolled as a Masters student in the EDUC 585 dissertation programme at Victoria University of Wellington. The Fast Feedback project will form the basis of my thesis. This research project has received approval from the Victoria University Human Ethics Committee.

As you know, participating teachers will be asked to target the lowest achieving writers in their classes, using the Fast Feedback system. Teachers could choose to work with as many or as few students as they feel comfortable with.

During the training period I will work with the teachers on the selection of individualized goals and will model in their classes, once a week, for the first 5 weeks of Term 2 . I will follow the teachers' own planning but will model the writing lesson from start to finish. I will not be observing the teachers teach the children themselves.

After this training period, I will be available to visit teachers if they want me to, perhaps to model some more, or to help select new goals as they change, or to problem-solve if a student is not progressing as fast as we want them to.

I will produce a Fast Feedback manual that teachers may choose to use if they find it helpful. This manual will include writing samples paired with appropriate goals, as well as teaching ideas for the range of goals.

In order to assess student achievement I will collect e-asttle and draft writing samples and easttle attitude scores. I will fit in with your school's assessment schedule for this data collection. If you do not use e-asttle I will collect any other unassisted writing task instead. I will mark these samples myself. 
In order to gain information about the broader impacts of this system, I will be asking teachers for an interview at the end of the project (sometime during term 4).

It will not be possible for students or teachers to be identified personally in my reporting of the data. All material collected will be kept confidential. No other person besides me and my two supervisors (Vivien Van Rij and Michael Johnston) will see the writing samples or interview notes. The thesis will be submitted for marking to the School of Education and deposited in the University Library. All data will be destroyed five years after the end of the project.

Should any participants feel the need to withdraw from the project, they may do so without question at any time, before the $10^{\text {th }}$ of December 2015. Just let me know at the time.

If you have any further questions or would like to receive further information about the project, please contact me (022 171 9682, or Helen.Walls@vuw.ac.nz); or my supervisors, Dr Michael Johnston (michael.johnston@vuw.ac.nz, 463 9675) and Dr Vivien Van Rij

(vivien.vanrij@vuw.ac.nz, 463 9706), at the School of Education at Victoria University.

Regards,

Helen Walls 


\section{REFERENCES}

Anderson, R. (1999). Foreword: Theoretical foundations for literacy acquisition. In J.S. Gaffney \& B.J. Askew (Eds.). Stirring the Waters: The Influence of Marie Clay. Portsmouth, NH: Heinemann.

Anyon, J. (1981). Social class and school knowledge. Curriculum Inquiry, 11(1), 3-42.

Applebee, A. (1984). Writing and reasoning. Review of Educational Research, 54(4), 577-596.

Atwell, N. (1982). Class-based writing research: Teachers learn from students. The English Journal, 71(1), 84-87.

Atwell, N. (1985). Everyone sits at a big desk: Discovering topics for writing. English Journal, 74(5), 35-39.

Ayrey, H. (2001). Guided Silent Reading Using Narrative Text. Christchurch: Handy Resources.

Bandura, A. (1989). Human agency in social cognitive theory. American Psychologist, 44(9), 1175-1184.

Bandura, A. (1991). Social cognitive theory of self-regulation. Organizational Behavior and Human Decision Processes, 50(2), 248-287.

Bangert-Drowns, R., Kulik, C., Kulik, J., \& Morgan, M. (1991) The Instructional Effect of Feedback in Test-Like Events. Review of Educational Research, 61(2), 213-238.

Bazerman, C. (2006). What do sociocultural studies of writing tell us about learning to write? In C. MacArthur, S. Graham, \& J. Fitzgerald. Handbook of Writing Research. New York: The Guilford Press.

Benton, R. (1986). Here today and gone tomorrow: Talking and learning in New Zealand classrooms. A paper prepared for the $21^{\text {st }}$ regional seminar "Patterns of Classroom Interaction in Southeast Asia" SEAMEO Regional Language Centre, Singapore.

Bereiter, C. \& Scardamalia, M. (1987). The Psychology of Written Composition. New Jersey: Laurence Erlbaum Associates.

Bergeron, B. (1990). What does the term whole language mean? Constructing a definition from the literature. Journal of Reading Behavior, 22(4), 301-329.

Berlin, J. (1988). Rhetoric and ideology in the writing class. College English, 50(5), 477-494.

Berninger, V. (1999). Coordinating transcription and text generation in working memory during composing: Automatic and constructive processes. Learning Disability Quarterly, 22(2), 99-112.

Berninger, V., Graham, S., Vaughan, K., Abbott, R., Begay, K., Byrd Coleman, K., Curtin, G., \& Minich Hawkins, J. (2002). Teaching spelling and composition alone and together: Implications for the simple view of writing. Journal of Educational Psychology, 94(2), 291-304. 
Bishop, R., Berryman, M., Cavanagh, T., Teddy, L. (2009). Te kotahitanga: Addressing educational disparities facing Māori students in New Zealand. Teaching and Teacher Education, 25, 734-742.

Black, P. \& Wiliam, D. (1998). Assessment and classroom learning. Assessment in Education, 5(1), 7-74. doi: 10.1080/0969595980050102.

Brann, B. (2000). The Magic Caterpillar Story: A Handwriting Programme to Reinforce Correct Letter Formation. Queensland: Merganza training and Development.

Brann, B. (2001). Working with Students with Learning Difficulties. Queensland: Merganza Training and Development.

Brindle, M., Graham, S., Harris, K., \& Herbert, M. (2016). Third and fourth grade teachers' classroom practices in writing: a national survey. Reading and Writing, 29, 929-954.

Britton, J., Burgess, T., Martin, N., McLeod, A., \& Rosen, H. (1975). The Development of Writing Abilities. Great Britain: Macmillan Education.

Bruner, J. (1990). Acts of Meaning. Cambridge: Harvard University Press.

Bruner, J., Goodnow, J., \& Austin, G. (1956). A Study of Thinking. New York: John Wiley \& Sons.

Calkins, L. (1986). The Art of Teaching Writing. Ontario, Canada: Concord Publishing.

Clay, M. (1998). By Different Paths to Common Outcomes. York, Maine: Stenhouse.

Cook, D. \& King, J. (1968). A study of the Hawthorne Effect in educational research. Research in the Teaching of English, 2(2), 93-98.

Cope, B. \& Kalantzis, M. (2009). “Multiliteracies”: New literacies, new learning. Pedagogoes: An International Journal, 4(3), 164-195.

Cresswell, J. 2013. Qualitative Inquiry \& Research Design: Choosing Among Five Approaches. 3rd Edition. California: Sage.

Delpit, L. (1986). Skills and other dilemmas of a progressive black educator. Harvard Educational Review, 56(4), 379-385.

Delpit, L. (1988). The silenced dialogue: power and pedagogy in educating other people's children. Harvard Educational Review, 58(3), 280-298.

Dewey, J. (1916). Democracy and Education. Toronto: Collier-Macmillan.

Dewey, J. (1933). How We Think. Massachusetts: D.C Heath \& Company.

Dewey, J., \& Dewey, E. (1922). Schools of Tomorrow. London: J. M. Dent \& Sons.

Dockrell, J., Marshall, C., \& Wyse, D. (2016). Teachers' reported practices for teaching writing in England. Reading and Writing, 29(3), 409-434. 
Dyson, A. (1999). Writing (Dallas) cowboys: A dialogic perspective on the 'what did I write?' question. In J. Gaffney and B. Askew (Eds.). Stirring the Waters: The Influence of Marie Clay. Portsmouth, NH: Heinemann.

Emig, J. (1971). The Composing Process of Twelfth Graders. Illinois: National Council of Teachers of English.

Fang, Z. (1996). A review of research on teacher beliefs and practices. Educational Research, $38(1), 47-65$.

Flower, L. \& Hayes, J. (1981). A cognitive process theory of writing. College Composition and Communication, 32(4), 365-387.

Fuchs, L. \& Fuchs, D. (1986). Effects of systematic formative evaluation: A meta-analysis. Exceptional Children, 53(3), 199-208.

Gadd, M. (2014). What is Critical in the Effective Teaching of Writing? A Study of Classroom Practice of some Year 5-8 Teachers in the New Zealand Context. Unpublished doctoral dissertation, University of Auckland.

Gaitas, S. \& Martins, M. (2015). Relationships between primary teachers' beliefs and their practices in relation to writing instruction. Research Papers in Education, 30(4), 492-505, doi: 10.1080/02671522.2014.908406.

Gentry, R. (1985). You Can Analyze Developmental Spelling. Retrieved from: http://www.education.uci.edu/docs/DEVELOPMENTAL SPELLING.pdf.

Gilbert, J. (2018). Untangling constructivisim, knowledge, and knowledge-building for "futureoriented" teaching. SET, 2, 18-24.

Goodman, K. (1992). I didn't found whole language. The Reading Teacher, 46(3), 188-199.

Goodman, K. (1993). I didn't found whole language: Whole language found me! The Education Digest, 59(2), 64-67.

Goodman, Y. (1989). Roots of the whole-language movement. The Elementary School Journal, 90(2), 113-127.

Gough, P, \& Tunmer, W. (1986). Decoding, reading and reading disability. Remedial and Special Education, 7(1), 6-10.

Graham. S. \& Harris, K. (1994). Implications of constructivism for teaching writing to students with special needs. The Journal of Special Education, 28(3), 275-289.

Graham, S. \& Harris, K. (1997). It can be taught, but it does not develop naturally: Myths and realities in writing instruction. School Psychology Review, 26(3), 414-424.

Graham, S., Harris, K., MacArthur, C., \& Fink, B. (2002). Primary grade teachers' theoretical orientations concerning writing instruction: Construct validation and a nationwide survey. Contemporary Educational Psychology, 27, 147-166. 
Graham, S., Harris, K., \& Santelego, T. (2015). Research-based writing practices and the common core. The Elementary School Journal, 115(4), 498-522.

Graham, S., MacArthur, C., Swartz, S., \& Page-Voth, V. (1992). Improving the compositions of students with learning disabilities using a strategy involving product and process goal setting. Exceptional Children, 58, 322-334.

Graham, S., McKeown, D., Kiuhara, S., \& Harris, K. (2012). A meta-analysis of writing instruction for students in the elementary grades. Journal of Educational Psychology. Advance online publication. doi:10.1037/a0029185.

Graham, S. \& Sandmel, K. (2011). The process writing approach: A meta-analysis. The Journal of Educational Research, 104(6), 396-407. doi: 10.1080/00220671.2010.488703.

Graves, D. (2003). Writing: Teachers and Children at Work. Portsmouth: Heinemann.

Hattie, J. (1999, August). Influences on Student Learning. Inaugural Lecture: Professor of Education, University of Auckland.

Harris, V. (1993). Evaluating children's books for whole-language learning. Illinois Digital Environment for Access to Scholarship and Learning. Retrieved from: http://hdl.handle.net/2142/642.

Harste, J., Woodward, V., \& Burke, C. (1984). Examining our assumptions: A transactional view of literacy and learning. Research in the Teaching of English, 18(1), 84-108.

Hattie, J. \& Timperley, H. (2007). The power of feedback. Review of Educational Research, 77(1), 81-112.

Hawkes, P. (2008). Vietnam protests, open admissions, peer tutor training, and the Brooklyn Institute: Tracing Kenneth Bruffee's collaborative learning. The Writing Center Journal, 28(2), 25-32.

Hillocks, G. (1984). What works in teaching composition: A meta-analysis of experimental treatment studies. American Journal of Education, 93(1), 133-170.

Hood, H. (2003). The Management of an Independent Writing Programme [video-recording]. Dunedin: Dunedin College of Education.

Ludlow, L. \& Haley, S. (1995). Rasch model logits: interpretation, use, and transformation. Educational and Psychological Measurement, 55(6), 967-975.

Huot, B. (1990). The literature of direct writing assessment: Major concerns and prevailing trends. Review of Educational Research, 60(2), 237-263.

Hull, G. A. (1981). Effects of self-management strategies on journal writing by college freshmen. Research in the Teaching of English, 15(2), 135-148.

Jesson, R. \& Cockle, V. (2016). The opportunities to build on existing expertise in writing classrooms: A study of writing lessons in New Zealand primary schools. International Journal of Primary, Elementary and Early Years Education, 44(6), 3-13. 
Jonsson, A. \& Svingby, G. (2007). The use of scoring rubrics: Reliability, validity and educational consequences. Educational Research Review, 2(2), 130-144.

Joseph, L. M. \& Konrad, M. (2009). Teaching students with intellectual or developmental disabilities to write: A review of the literature. Research in Developmental Disabilities: A Multidisciplinary Journal, 30(1), 1-19.

Kluger, A. \& DeNisi, A. (1996). The effects of feedback interventions on performance: A historical review, a meta-analysis, and a preliminary feedback intervention theory. Psychological Bulletin, 119(2), 254-284.

Lindsley, O. (1992). Precision teaching: Discoveries and effects. Journal of Applied Behavior Analysis, 25(1), 51-57.

Locke, E. \& Latham, G. (2002). Building a practically useful theory of goal setting and task motivation: A 35-year odyssey. American Psychologist, 57(9), 705-717.

Marie, D., Fergusson, D., \& Boden, J. (2008). Educational achievement in Māori: The roles of cultural identity and social disadvantage. Australian Journal of Education, 52(2), 183196.

Marks, G. (2007). Are between- and within-school differences in student performance largely due to socio-economic background? Evidence from 30 countries. Educational Research, 48(1), 21-40.

Matsuda, P. (2003). Process and post-process: A discursive history. Journal of Second Language Writing, 12, 65-83.

McCarthey, S. \& Mkhise, D. (2013). Teachers' orientations towards writing. Journal of Writing Research, 5(1), 1-33.

McCutcheon, D. (1996). A capacity theory of writing: Working memory in composition. Educational Psychology Review, 8(3), 299-325.

McDowell, S. (2010). Literacy Teaching and Learning in e-Learning Contexts: A Report to the Ministry of Education. New Zealand: Ministry of Education. Retrieved from: https://www.educationcounts.govt.nz/ data/assets/pdf file/0010/77356/950 ELiteracy2.pdf. 10/19/18.

Mckenna, M., Robinson, R., \& Miller, J. (1990). Whole language: A research agenda for the nineties. Educational Researcher, 19(8), 3-6.

McNaughton, S. (1999). Developmental diversity and beginning literacy instruction at school. In J.S. Gaffney and B.J. Askew (Eds.). Stirring the Waters: The Influence of Marie Clay. Portsmouth, NH: Heinemann.

McNeil, B., \& Kirk, C. (2013). Theoretical beliefs and instructional practices used for teaching spelling in elementary classrooms. Reading and Writing, 27, 535-554, doi: 10.1007/s11145-013-9457-0. 
Minich Hawkins, J. (2002). Teaching spelling and composition alone and together: Implications for the simple view of writing. Journal of Educational Psychology, 94(2), 291-304.

Ministry of Education. (n.d.). e-asTTle and Assessment for Learning. Retrieved from: http://easttle.tki.org.nz/About-e-asTTle/Assessment-for-Learning.

Ministry of Education. (n.d.). Teaching as Inquiry. Retrieved from: http://teaching-asinquiry.tki.org.nz.

Ministry of Education (1985). Teaching Handwriting. Wellington: Crown Publishing.

Ministry of Education. (1995). The New Zealand Curriculum. Wellington: Learning Media.

Ministry of Education (2003a). Quality Teaching for Diverse Students in Schooling: Best Evidence Synthesis. Report from the Medium Term Strategy Policy Division. Wellington: Ministry of Education.

Ministry of Education (2003b). Effective Literacy Practice in Years 1-4. Wellington: Learning Media Limited.

Ministry of Education (2007). The New Zealand Curriculum. Wellington: Learning Media.

Ministry of Education. (2013). Ka Hikitia: Accelerating Success. Retrieved from:

http://www.education.govt.nz/our-work/overall-strategies.

Ministry of Education. National standards Achievement Results. Retrieved from:

https://www.educationcounts.govt.nz/statistics/schooling/nationalstandards/National Standards.

Ministry of Education (2015). The Literacy Learning Progressions. Wellington: Learning Media Limited.

Ministry of Education (2018). Sound Sense: Supporting Reading and Writing in Years 1-3.

Wellington: Lift Education. Retrieved 10/09/18

http://literacyonline.tki.org.nz/Literacy-Online/Planning-for-my-studentsneeds/Sound-Sense.

Moffett, J. (1981). Active Voice. New Jersey: Boynton/Cook.

Montessori, M. (1912). The Montessori Method. London: William Heinemann.

Moorman, G., Blanton, W., \& Mclaughlin, T. (1994). The rhetoric of whole language. Reading Research Quarterly, 29(4), 309-329.

Murray, D. (1973). Why teach writing? - And how? The English Journal, 62(9), 1234-1237.

Myhill, D. \& Watson, A. (2014). The role of grammar in the writing curriculum: A review of the literature. Child Language Teaching and Therapy, 30(1), 41-62.

Needels, M. \& Knapp, M. (1994). Teaching writing to children who are underserved. Journal of Educational Psychology, 86(3), 339-349.

Nystrand, M. (1989). A social-interactive model of writing. Written Communication, 6(1), 66-85. 
Nystrand, M. (2006). The social and historical context for writing research. In C. MacArthur, S. Graham \& J. Fitzgerald (Eds.). Handbook of Writing Research. New York: Guilford Press.

Pajares, F. (1992). Teachers' beliefs and educational research: Cleaning up a messy construct. Review of Educational Research, 62(3), 307-332.

Palinscar, A. (1998). Social constructivist perspectives on teaching and learning. Annual Review of Psychology, 49, 345-375.

Palmer, J., Bresler, L., \& Cooper, D. E. (2001). Fifty modern thinkers on Education: from Piaget to the present. London: Routledge.

Parr, J. \& Limbrick, L. (2010). Contextualising practice: Hallmarks of effective teachers of writing. Teaching and Teacher Education, 26(3), 583-590.

Parr, J. \& Jesson, R. (2015). Mapping the landscape of writing instruction in New Zealand primary school classrooms. Reading and Writing, 29, 981-1011, doi: 10.1007/s11145015-9589-5.

Patel, S. (2010). Reading at risk: Why Effective Literacy Practice is not effective. Waikato Journal of Education, 15(3), 51-68.

Piaget, J. (1950). The Psychology of Intelligence. London: Routledge \& Kegan Paul.

Poulson, L., Avramidis, E., Fox, R., Medwell, J., \& Wray, D. (2001). The theoretical beliefs of effective teachers of literacy in primary schools: an exploratory study of orientations to reading and writing. Research Papers in Education, 16(3), 271-292.

Pressley, M., Wharton-McDonald, R., Allington, R., Collins Block, C., Morrow, L., Tracey, D., Baker, K., Brooks, G., Cronin, J., Nelson, E., \& Woo, D. (2001). A study of effective first-grade literacy instruction. Scientific Studies of Reading, 5(1), 35-58. doi: 10.1207/S1532799XSSR05012.

Pritchard, R. \& Honeycutt, R. (2006). The process approach to writing instruction: Examining its effectiveness. In C. MacArthur, S. Graham, \& J. Fitzgerald (Eds.). Handbook of Writing Research. New York: Guilford Press.

Prochnow, J., Tunmer, W., \& Greaney, K. (2015). Findings from New Zealand's participation in the Progress in International Reading Literacy Study in 2001, 2006, and 2011. In W. Tunmer \& J. Chapman (Eds.) Excellence and Equity in Literacy Education: The Case of New Zealand. Hampshire, UK: Palgrave Macmillan.

Ritchey, K., Coker, D., \& Jackson, A. (2015). The relationship between early elementary teachers' instructional practices and theoretical orientations and students' growth in writing. Reading and Writing, 28, 1333-1354.

Rogers, C. \& Skinner, B. F. (1956). Some issues concerning the control of human behavior. Science, 124(3231), 1057-1066. 
Romanish, B (1995). Authority, authoritarianism, and education. Education and Culture, 12(2), 17-25.

Rose, J. (2006). Independent review of the teaching of early reading. England: Commisioned by the Department for Education and Skills (DfES), following an investigation by the House of Commons Education Select Committee. Retrieved from: https://dera.ioe.ac.uk/5551/2/report.pdf.

Rousseau, J. (1911). Emile. London: J. M. Dent \& Sons.

Samejima, F. (1969). Estimation of latent ability pattern using a response pattern of graded scores. Pschometric Monograph 17. Retrieved from: https://www.psychometricsociety.org/sites/default/files/pdf/MN17.pdf.

Sawyer, R., Graham, S., \& Harris, K. (1992). Direct teaching, strategy instruction, and strategy instruction with explicit self-regulation: Effects on the composition skills and selfefficacy of students with learning disabilities. Journal of Educational Psychology, 84(3), 340-352.

Schunk, D. \& Swartz, C. (1993). Goals and progress feedback: Effects on self-efficacy and writing achievement. Contemporary Educational Psychology, 18(3), 337-354.

Shaughnessey, M. (1977). Errors and Expectations - A Guide for the Teacher of Basic Writing. New York: Oxford University Press.

Shuell, T. (1986). Cognitive conceptions of learning. Review of Educational Research, 56(4), 411436.

Shute, V. (2008). Focus on formative feedback. Review of Educational Research, 78(1), 153-189. Simmerman, S., Harward, S., Pierce, L., Peterson, N., Morrison, T., Billen, M., \& Shumway, J. (2012). Elementary teachers' perceptions of process writing. Literacy Research and Instruction, 51(4), 292-307, doi: 10.1080/19388071.2011.557764.

Skinner, B. (1963). Behaviorism at fifty. Science, 140(3570), 951-958.

Smith, J. \& Elley, W. (1997). How Children Learn to Write. Auckland: Longman.

Snowling, M., Hulme, C., \& Nation, K. (1997). A connectionist perspective on the development of reading skills in children. Trends in Cognitive Sciences, 1(3), 88-91.

Stanovich, K. (1986). Matthew effects in reading: Some consequences of individual differences in the acquisition of literacy. The Journal of Education, 189(1/2), 23-55.

Stotsky, S. (1995). The uses and limitations of personal or personalized writing in writing theory, research, and instruction. Reading Research Quarterly, 30(4), 758-76.

Strickland, D., Bodino, A., Buchan, K., Nelson, A., \& Rosen, M. (2001). Teaching writing in a time of reform. The Elementary School Journal, 101(4), 385-397.

Sublette, J. (1973). The Dartmouth Conference: Its reports and results. College English, 33(3), 348-357. 
Timperley, H. \& Parr, J. (2009). What is this lesson about? Instructional processes and student understandings in writing classrooms. The Curriculum Journal, 20(1), 43-60, doi: 10.1080/09585170902763999.

Troia, G., Lin, S., Cohen, S., \& Monroe, B. (2011). A year in the writing workshop linking writing instruction practices and teachers' epistomologies and beliefs about writing instruction. The Elementary School Journal, 112(1), 155-182.

Tunmer, W. \& Chapman, J. (2011). Reading Recovery: Does it work? Perspectives on Language and Literacy, 37(4), 21-24

Tunmer, W. \& Chapman, J. (2015). Excellence and Equality in Literacy Education: The Case of New Zealand. New York: Palgrave Macmillan.

Tunmer, W., Greaney, K., \& Prochnow, J. (2015). Pedagogical constructivism in New Zealand literacy education: A flawed approach to teaching reading. In W. Tunmer \& J. Chapman (Eds.) Excellence and Equity in Literacy Education: The Case of New Zealand. Hampshire, UK: Palgrave Macmillan.

Vygotsky, L. (1986). Thought and Language. Cambridge: The MIT Press.

Wyse, D. (2001). Grammar for writing? A critical review of empirical evidence. British Journal of Educational Studies, 49(4), 411-427.

Wyse. D. \& Torgerson, C. (2017). Experimental trials and "what works?" in education: The case of grammar for writing. British Educational Research Journal, 43(6), 1019-1047.

Zimmerman, B. (2013). From cognitive modeling to self-regulation: A social cognitive career path. Educational Psychologist, 48(3), 135-147. doi: 10.1080/00461520.2013.794676.

Zimmerman, B. (2015). Becoming a self-regulated learner: An overview. Theory into Practice, 41(2), 64-70. doi: 10.1207/s15430421tip4102_2.

Zimmerman, B. \& Bandura, A. (1994). Impact of self-regulatory influences on writing course attainment. American Educational Research Journal, 31(4), 845-862.

Zimmerman, B. \& Risemberg, R. (1997). Becoming a self-regulated writer: A social cognitive perspective. Contemporary Educational Psychology, 22(1), 73-101. 